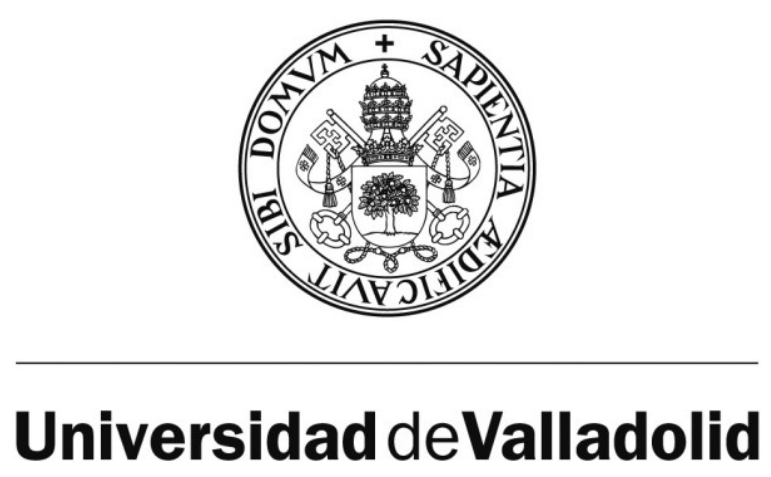

FACULTAD DE MEDICINA

DEPARTAMENTO DE MEDICINA, DERMATOLOGÍA Y TOXICOLOGÍA

TESIS DOCTORAL

\title{
ANÁLISIS DE LOS EFECTOS PONDERALES Y METABÓLICOS EN PACIENTES CON OBESIDAD MÓRBIDA TRATADOS MEDIANTE DERIVACIÓN BILIOPANCREÁTICA EN EL HOSPITAL UNIVERSITARIO RÍO HORTEGA
}

Presentada por D. Mario Rodríguez López para optar al grado de Doctor por la Universidad de Valladolid

Dirigida por

Dr. D. David Pacheco Sánchez

Dr. D. Daniel A. de Luis Román 

ANÁLISIS DE LOS EFECTOS PONDERALES Y METABÓLICOS

EN PACIENTES CON OBESIDAD MÓRBIDA TRATADOS

MEDIANTE DERIVACIÓN BILIOPANCREÁTICA EN

EL HOSPITAL UNIVERSITARIO RÍO HORTEGA

DOCTORANDO: $\quad$ Mario Rodríguez López.

DIRECTORES: $\quad$ Prof. Dr. David Pacheco Sánchez,

Prof. Dr. Daniel A. de Luis Román.

DEPARTAMENTO: Medicina, Dermatología y Toxicología.

CENTRO: $\quad$ Facultad de Medicina,

Universidad de Valladolid, España.

FINALIZACIÓN: $\quad$ Diciembre de 2015. 



\section{Universidad deValladolid}

\section{AUTORIZACIÓN DEL DIRECTOR DE TESIS}

(Art. 2.1. c de la Normativa para la presentación y defensa de la Tesis Doctoral en la UVa)

D. David Pacheco Sánchez, con D.N.I. n 07481413-I, profesor asociado del departamento de Cirugía, Oftalmología, Otorrinolaringología y Fisioterapia de la Facultad de Medicina, como Director de la Tesis Doctoral titulada “Análisis de los efectos ponderales y metabólicos en pacientes con obesidad mórbida tratados mediante derivación biliopancreática en el Hospital Universitario Río Hortega", presentada por D. Mario Rodríguez López, alumno del programa “Investigación en Ciencias de la Salud”, impartido por el departamento de Biología Celular, Histología y Farmacología, autoriza la presentación de la misma, considerando que la estructura y ejecución de este trabajo se ajusta a los objetivos propuestos inicialmente en su redacción y por ello puede ser presentada como trabajo original para la obtención del Titulo de Doctor.

En Valladolid, a 19 de enero de 2016.

El Director de la Tesis,

Fdo.: Prof. Dr. D. David Pacheco Sánchez 



\section{Universidad deValladolid}

\section{AUTORIZACIÓN DEL DIRECTOR DE TESIS}

(Art. 2.1. c de la Normativa para la presentación y defensa de la Tesis Doctoral en la UVa)

D. Daniel Antonio de Luis Román, con D.N.I. n 12378804-C, profesor titular del departamento de Medicina, Toxicología y Dermatología de la Facultad de Medicina, como Director de la Tesis Doctoral titulada “Análisis de los efectos ponderales y metabólicos en pacientes con obesidad mórbida tratados mediante derivación biliopancreática en el Hospital Universitario Río Hortega”, presentada por D. Mario Rodríguez López, alumno del programa “Investigación en Ciencias de la Salud”, impartido por el departamento de Biología Celular, Histología y Farmacología, autoriza la presentación de la misma, considerando que la estructura y ejecución de este trabajo se ajusta a los objetivos propuestos inicialmente en su redacción y por ello puede ser presentada como trabajo original para la obtención del Titulo de Doctor.

En Valladolid, a 19 de enero de 2016.

El Director de la Tesis,

Fdo.: Prof. Dr. D. Daniel Antonio de Luis Román 

Dedicada a mis padres, por todo lo que han becho por mi, y porque a ellos les debo lo que be conseguido y espero conseguir 



\section{ÍNDICE}

\section{1.- INTRODUCCIÓN}

\section{1.- DEFINICIÓN, CLASIFICACIÓN Y ETIOPATOGENLA DEL}

SOBREPESO Y LA OBESIDAD .3

1.1.1.- Clasificación: parámetros antropométricos......................................................

1.1.1.1.- Índice de masa corporal ................................................................................ 5

1.1.1.2.- Circunferencia de cintura .......................................................................... 9

1.1.2.- Histología y fisiopatología del tejido adiposo...............................................11

1.1.3.- Etiología del sobrepeso y la obesidad ............................................................. 14

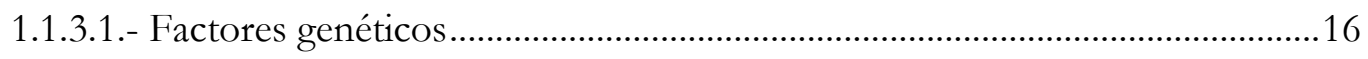

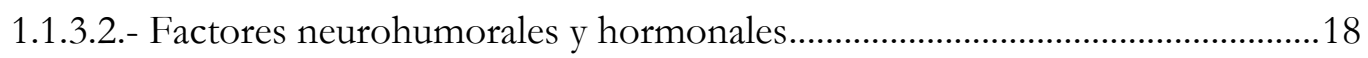

1.1.3.3.- Factores microbiológicos ......................................................................................22

1.1.3.4.- Factores reproductivos y sociodemográficos....................................................23

1.1.3.5.- Factores nutricionales y de estilo de vida .........................................................24

1.2.- EPIDEMIOLOGÍA E IMPLICACIÓN SOCIO-ECONÓMICA DE LA

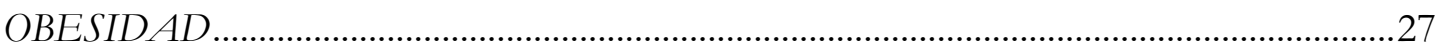

1.2.1.- Epidemiología a nivel mundial y nacional....................................................22

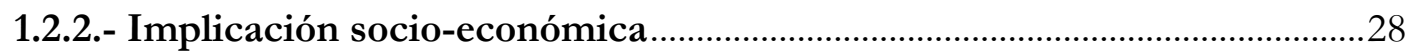

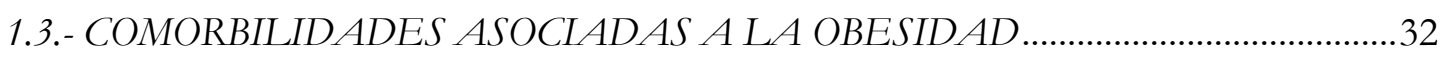

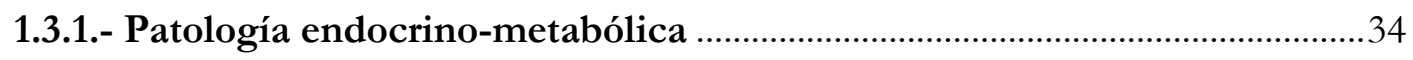

1.3.1.1.- Definición y etiopatogenia del síndrome metabólico ......................................35

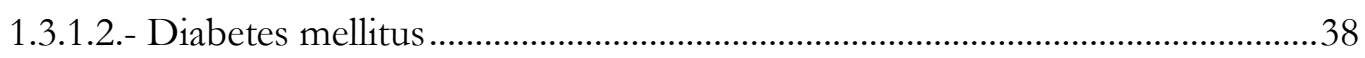

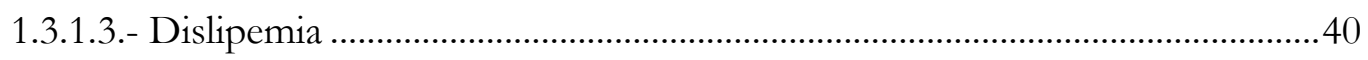

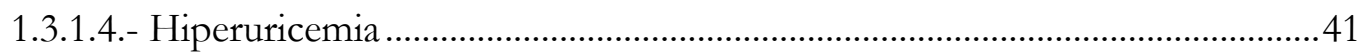




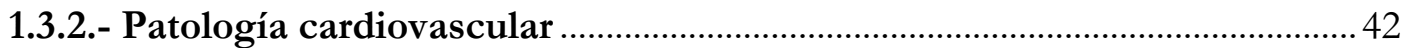

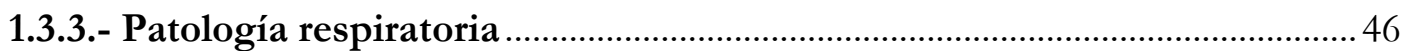

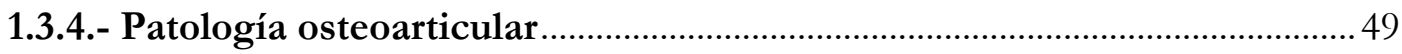

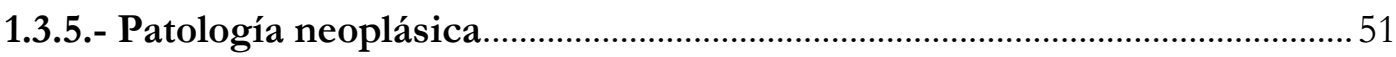

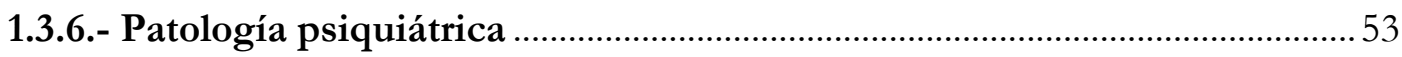

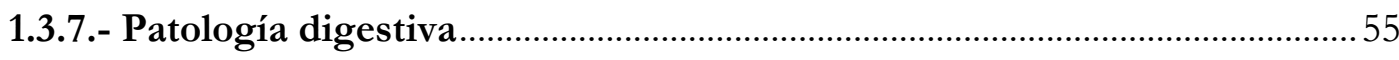

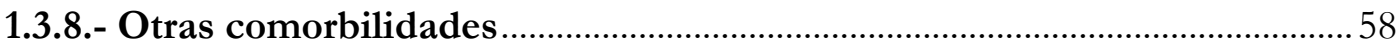

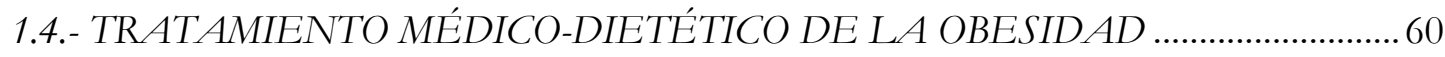

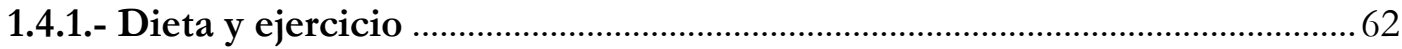

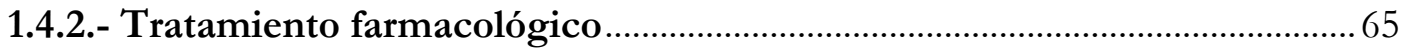

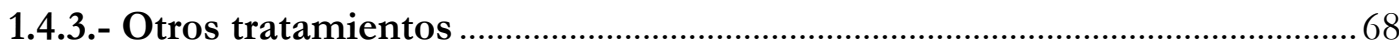

1.5.- TRATAMIENTO QUIRÚRGICO DE LA OBESID AD MÓRBID A ....................... 70

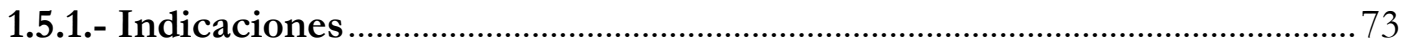

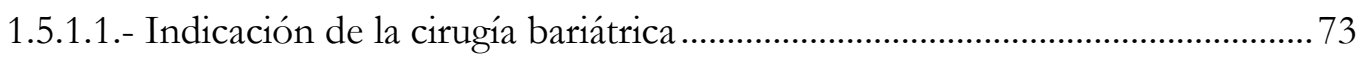

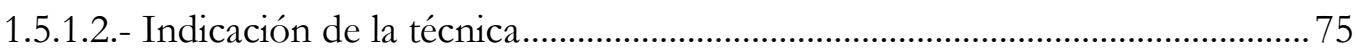

1.5.1.3.- Valoración y manejo preoperatorios.................................................................... 76

1.5.2.- Contraindicaciones ……………………………………………………. 79

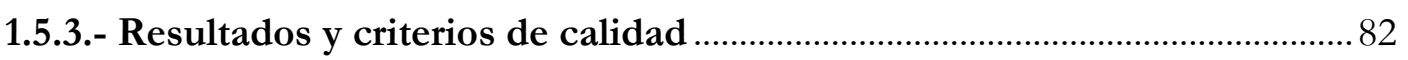

1.5.4.- Técnicas quirúrgicas y mecanismos de acción ............................................... 90

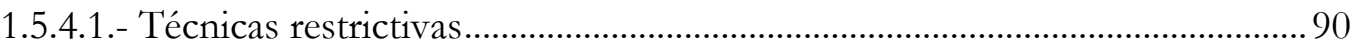

1.5.4.2.- Técnicas malabsortivas y mixtas ......................................................................... 94

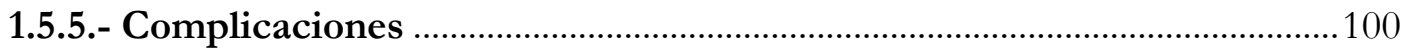

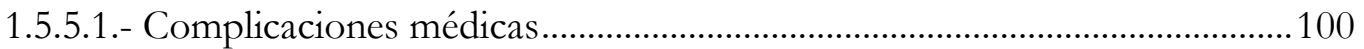

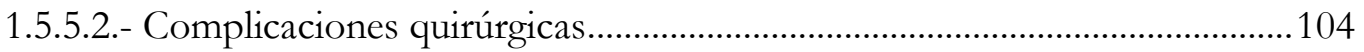

1.5.6.- La derivación biliopancreática de Scopinaro .................................................. 110

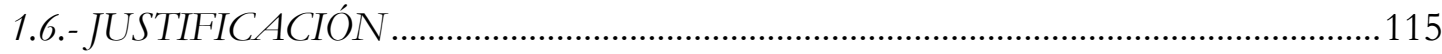

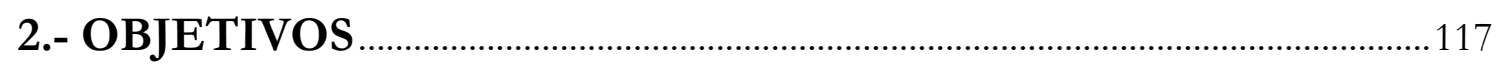

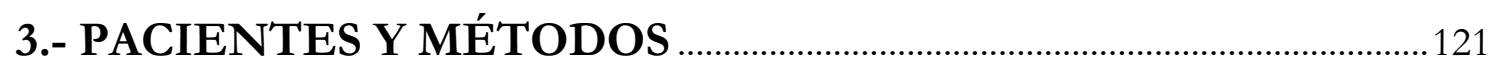

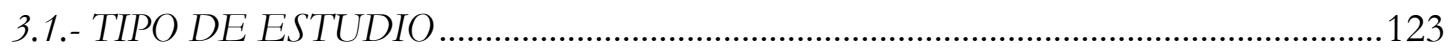




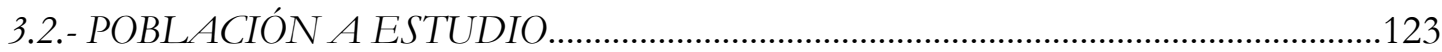

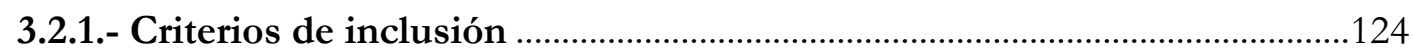

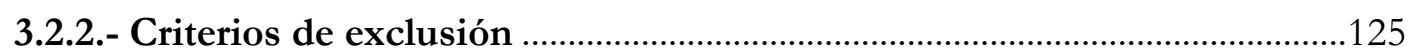

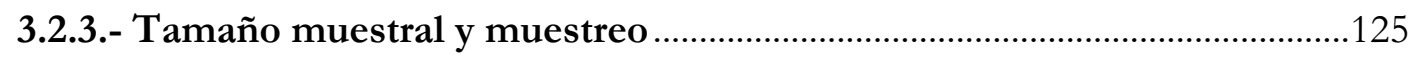

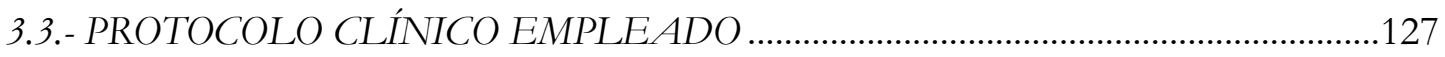

3.4.- VARIABLES DEL ESTUDIO …………………...................................................143

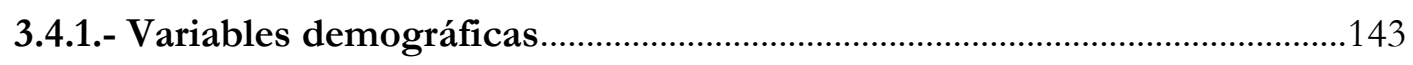

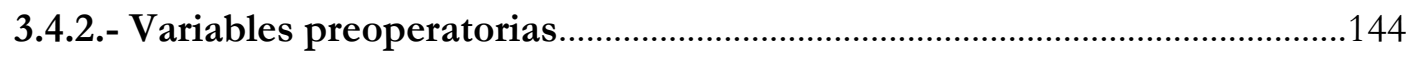

3.4.3.- Variables asociadas al ingreso hospitalario ...................................................149

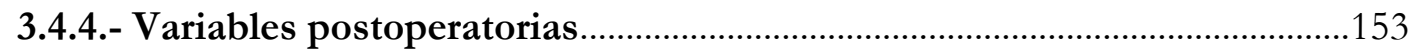

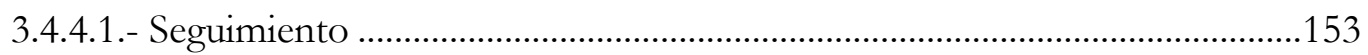

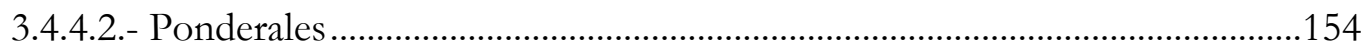

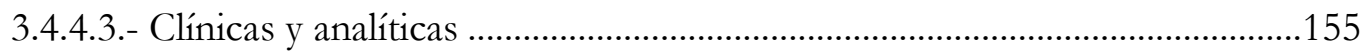

3.5.- ANÁLISIS ESTADÍSTICO .....................................................................................160

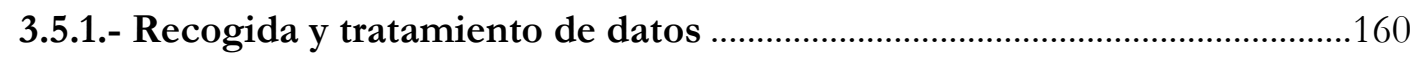

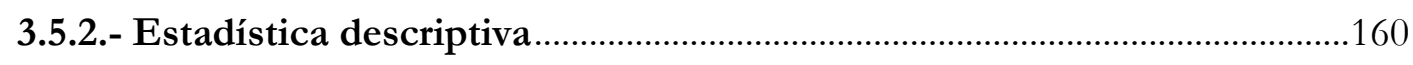

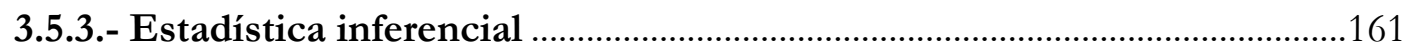

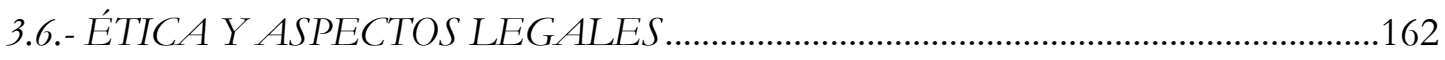

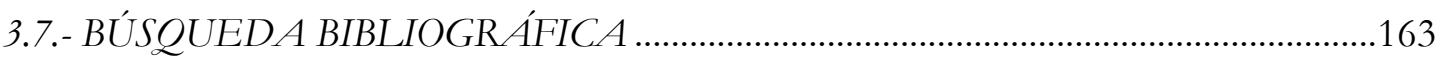

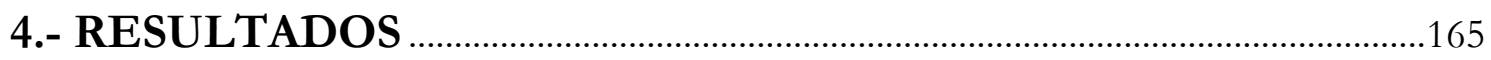

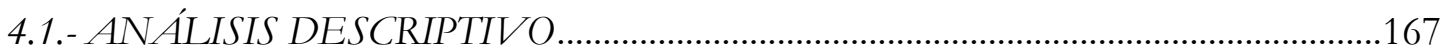

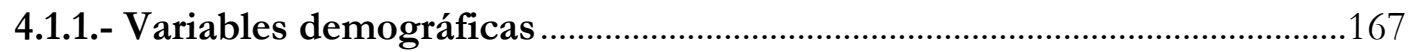

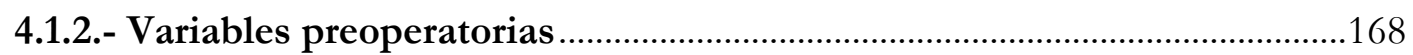

4.1.3.- Variables asociadas al ingreso hospitalario ...................................................177

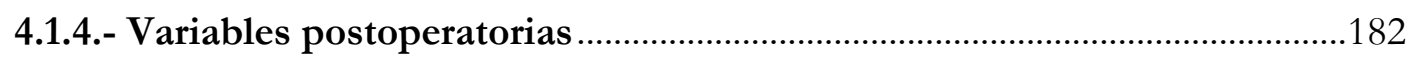

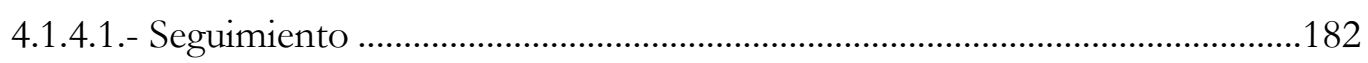

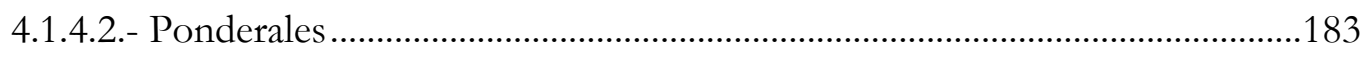

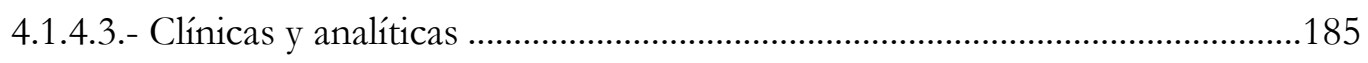

4.2.- ANÁLISIS COMPARATIVO DE LOS EFECTOS Y RESULTADOS DE

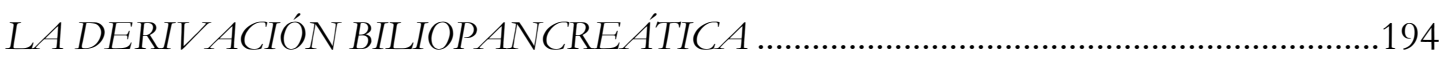

4.2.1.- Análisis comparativo de los resultados ponderales .....................................194

4.2.2.- Análisis comparativo de los efectos clínicos y analíticos ...........................197 
4.2.3.- Análisis comparativo de la modificación de los criterios de síndrome metábolico

4.3.- ANÁLISIS COMPARATIVO DE COHORTES SEGÚN EL OBESITY

SURGERY-MORTALITY RISK SCORE

4.3.1.- Análisis de morbimortalidad según el Obesity Surgery-Mortality

Risk Score

4.3.1.1.- Riesgo de morbimortalidad por factores del Obesity Surgery-Mortality

Risk Score

4.3.1.2.- Riesgo de morbimortalidad por categorías del Obesity Surgery-Mortality

Risk Score

4.3.2.- Análisis de resultados y efectos según el Obesity Surgery-Mortality

Risk Score

4.3.2.1.- Resultados ponderales según las categorías del Obesity Surgery-Mortality

Risk Score

4.3.2.2.- Efectos sobre las variables del síndrome metabólico según las categorías del Obesity Surgery-Mortality Risk Score

4.3.2.3.- Comparación de estancia hospitalaria según las categorías del Obesity

Surgery-Mortality Risk Score.

\section{5.- DISCUSIÓN}

5.1.- TAMAÑO MUESTRAL Y RESULTADOS DEMOGRÁFICOS 219

5.2.- RESULTADOS PONDERALES.....

5.2.1.- Parámetros antropométricos 222

5.2.2.- Parámetros de evaluación de resultados ponderales tras cirugía bariátrica 226

5.2.3.- Características de los pacientes con insuficiente pérdida de peso.........229

5.3.- RESULTADOS CLÍNICOS Y ANALÍTICOS .........................................................2.

5.3.1.- Modificación del metabolismo de la glucosa ................................................235

5.3.2.- Modificación del metabolismo lipídico........................................................240

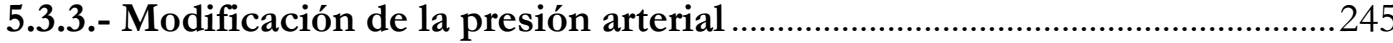

5.3.4.- Modificación de los parámetros de desnutrición ...........................................249

5.3.5.- Modificación del metabolismo del calcio ..................................................252 


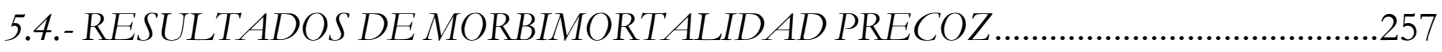

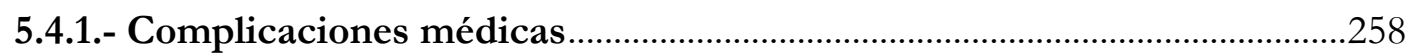

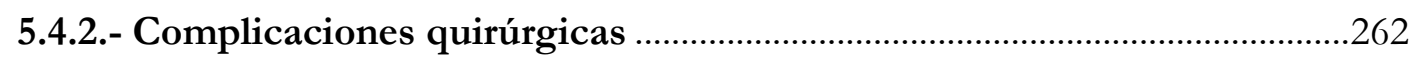

5.4.3.- Severidad de las complicaciones según la clasificación de

Dindo-Clavien

5.5.- ANÁLISIS DE RESULTADOS EMPLEANDO EL OBESITY SURGERY-

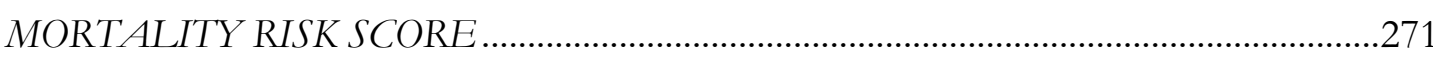

5.5.1- Morbimortalidad según el Obesity Surgery-Mortality Risk Score _...........273

5.5.1.1.- Riesgo de morbimortalidad por variables........................................................2.

5.5.1.2.- Riesgo de morbimortalidad por categorías.......................................................277

5.5.2.- Resultados ponderales y clínicos según el Obesity Surgery-Mortality

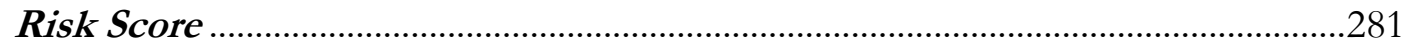

5.5.2.1.- Resultados ponderales por categorías ............................................................282

5.5.2.2.- Resultados metabólicos por categorías .........................................................283

5.5.2.3.- Resultados de estancia hospitalaria por categorías ........................................284

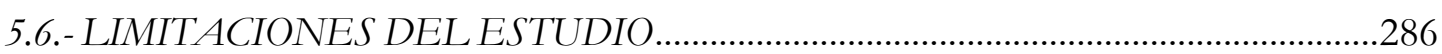

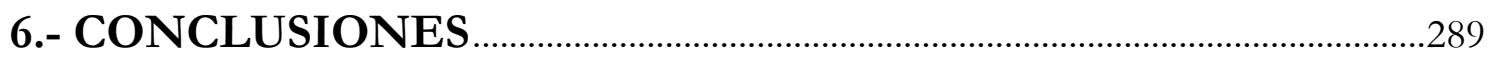

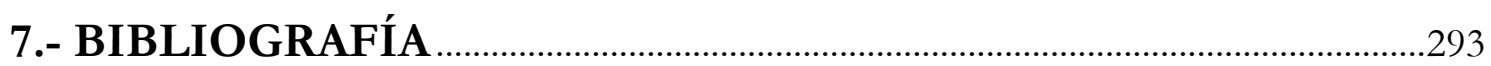





\section{ABREVIATURAS}

ACV: accidente cerebro-vascular

AGRP: agouti related protein

AHA: American Heart Association

APVP: años potenciales de vida perdidos

ASBMS: American Society of Bariatric and Metabolic Surgery

BAROS: Bariatric Analysis and Reporting Outcome System

BGA: banda gástrica ajustable

BGYR: bypass gástrico en Y de Roux

CAO: comorbilidades asociadas a la obesidad

CB: cirugía bariátrica

CC: circunferencia de cintura

CD: cruce duodenal

cm: centímetro

DBP: derivación biliopancreática

DE: desviación estándar

dl: decilitro

DM: diabetes mellitus

DNA: ácido desoxirribonucleico

DSM-5: Diagnostic and Statistic Manual of mental disorders, quinta edición

EE.UU.: Estados Unidos de América

ENS: encuesta nacional de salud

FTO: fat mass and obesity-associated protein 
g: gramo

GV: gastrectomía vertical

HbA1C: hemoglobina glicosilada

HDL: high density lipoprotein

HR: hazard ratio

HTA: hipertensión arterial

HURH: Hospital Universitario Río Hortega de Valladolid

IAM: infarto agudo de miocardio

IC: intervalo de confianza

ICA: índice de cintura-altura

ICC: índice de cintura-cadera

IGF-1: insulin growing factor 1

IMC: índice de masa corporal

Kcal: kilocalorías

Kg: kilogramo

l: litro

LDL: low density lipoprotein

m: metro

mg: miligramo

ml: mililitro

mmHg: milímetros de mercurio

n.a.: no aplicable

n.n.: no notificado

n.s.: no significativo

NAFLD: non-alcoholic fatty liver disease 
ng: nanogramo

OA: obesidad abdominal

OM: obesidad mórbida

OMS: Organización Mundial de la Salud

OR: odds ratio

OS-MRS: obesity surgery mortality risk score

PA: presión arterial

PEIMCP: porcentaje de exceso de IMC perdido

PEPP: porcentaje de exceso de peso perdido

pg: picogramo

PPTP: porcentaje de peso total perdido

PTH: parathormona

$\mathrm{RCV}$ : riesgo cardiovascular

RGE: reflujo gastro-esofágico

RI: resistencia a la insulina

RIQ: rango intercuartílico

ROS: reactive oxigen species

RR: riesgo relativo

SAOS: síndrome de apnea obstructiva del sueño

Sd.: síndrome

SEEDO: Sociedad Española para el Estudio De la Obesidad

SM: síndrome metabólico

SNC: sistema nervioso central

SNP: single nucleotide polimorphism

TAG: triacilgliceroles/triglicéridos 
TEP: tromboembolismo pulmonar

TNF $\alpha$ : tumor necrosis factor $\alpha$

TVP: trombosis venosa profunda

UI: unidades internacionales

VLDL: very low density lipoprotein

$\mu g:$ microgramo 


\section{AGRADECIMIENTOS}

A mis padres y hermana, por su apoyo incondicional, y también al resto de mi familia, incluidos aquellos que, desgraciadamente, no han podido ver esta Tesis concluida.

A mis directores de Tesis, los doctores David Pacheco y Daniel de Luis, por su supervisión, ayuda y consejos para que este trabajo vea finalmente la luz.

Al doctor Baltasar Pérez Saborido, por las sugerencias y recomendaciones que ha hecho sobre este trabajo y, también, por inculcarme su afán investigador. Asimismo, agradezco al doctor Manuel González Sagrado (Unidad de Investigación del Hospital Universitario Río Hortega de Valladolid) su colaboración para realizar los cálculos estadísticos.

A los doctores Anta y Pacheco, por iniciar y mantener la Cirugía Bariátrica en nuestro centro. Sin su buen hacer, no existirían los enfermos estudiados en esta Tesis. Igualmente, agradezco la colaboración de los endocrinólogos de nuestro hospital y del resto de centros que nos remiten sus enfermos, por llevar a cabo el seguimiento de los mismos.

A los adjuntos del servicio de Cirugía General y Digestiva del Hospital Universitario Río Hortega de Valladolid, con el doctor José Luis Marcos a la cabeza, por haberme trasmitido sus conocimientos y por su paciencia conmigo durante mi formación M.I.R., así como al resto de personal de las plantas de hospitalización de Cirugía y quirófano de nuestro hospital. 
A mis residentes mayores y pequeños, por su amistad y por los buenos momentos compartidos a lo largo de cinco años, tanto en el hospital como fuera de él.

A todos mis amigos y a algunos de mis profesores de la Facultad de Medicina de Valladolid (en especial, al doctor Pedro Gago), por su confianza en mí, desde el punto de vista personal y académico. 



\section{1.- INTRODUCCIÓN}

\section{1.- DEFINICIÓN, CLASIFICACIÓN Y ETIOPATO- GENIA DEL SOBREPESO Y LA OBESIDAD}

El sobrepeso y la obesidad han sido definidas por la Organización Mundial de la Salud (OMS) como el acúmulo excesivo de tejido adiposo que puede deteriorar la salud (1). Nos encontramos, por tanto, ante una patología crónica caracterizada por un incremento patológico en la masa adiposa corporal como consecuencia de un balance energético positivo y en la que se encuentran implicados múltiples factores etiológicos (2).

El concepto de obesidad mórbida (OM) fue introducido por J.H. Payne y L.T. DeWind en 1963 (3), con la intención de hacer una llamada de atención a las autoridades sanitarias a fin de lograr financiar con fondos públicos los gastos derivados de la cirugía bariátrica $(\mathrm{CB})$ practicada a pacientes obesos. De este modo, se podría catalogar como obeso mórbido a aquel paciente con obesidad y con las correspondientes comorbilidades asociadas a la obesidad (CAO), candidatos a tratamiento quirúrgico bariátrico.

El citado exceso de masa adiposa corporal debe ser cuantificado a fin de determinar el grado de sobrepeso y obesidad. En términos generales, se define como obeso al individuo con un porcentaje de grasa corporal superior a los valores normales: $\geq 20 \%$ en varones adultos y $\geq 30 \%$ en mujeres adultas (4). Es, por tanto, necesario conocer la composición corporal, que ha sido descrita siguiendo el conocido "modelo de cinco niveles" de Wang et al. publicado en 1972 (5): 
- Nivel atómico

- Nivel molecular

- Nivel celular

- Nivel tisular

- Nivel corporal

La descripción de los tres primeros niveles no resulta de especial interés para este trabajo. En lo referente al nivel tisular, cabe decir que existen diversos métodos para calcular la composición corporal que se basan en los distintos modelos de compartimentos corporales. Desde los años 50, cuando aparecieron las primeras descripciones de composición corporal en animales (6,7), se han desarrollado numerosas técnicas para analizarla y también modelos de complejidad creciente a medida que éstas evolucionaban. El modelo más sencillo y antiguo es el bicompartimental: masa grasa y masa libre de grasa o magra. Sin embargo, la escasa concordancia de este modelo con la composición corporal real, así como la ausencia de correlación del mismo con la variabilidad intraindividual e interindividual (sexo, edad, raza), unido al avance tecnológico, permitió llegar a desarrollar el modelo de tres y, posteriormente, de cuatro compartimentos, a saber: agua, grasa, masa ósea y masa residual (8-15). No obstante, en la actualidad ya se han desarrollado nuevos modelos multicompartimentales basados en los niveles moleculares y atómicos (16).

Por último, el nivel corporal se estudia mediante los parámetros antropométricos: peso, talla, índice de masa corporal (IMC), perímetros (también llamados circunferencias, entre ellas, la circunferencia de cintura [CC]), longitudes de las extremidades y de los segmentos corporales, superficie corporal y grosor de pliegues cutáneos. 


\subsection{1.- CLASIFICACIÓN: PARÁMETROS ANTROPOMÉTRICOS}

Para la determinación del estado nutricional, la OMS recomienda cuantificar necesariamente, como mínimo, el IMC y la CC (17), lo cual también aparece reflejado en otras publicaciones más recientes $(18,19)$. Por su amplia utilización en la práctica clínica, dada la facilidad para su medida, y por su correlación con la morbimortalidad asociada a las alteraciones nutricionales, estos dos parámetros serán ampliamente descritos.

\subsubsection{1.- Índice de masa corporal}

Fue el matemático belga A. Quetelet quien estableció, en el siglo XIX, una relación entre el peso corporal (en kilogramos $[\mathrm{Kg}]$ ) y el cuadrado de la altura (en metros [m]) del individuo (20), la cual fue posteriormente introducida en la práctica clínica habitual gracias a la publicación de Keys et al. (21), pasando a ser mundialmente empleada y conocida como IMC. Siguiendo la escala de la OMS (17,22,23), el peso, y por ende la obesidad, se clasifica en base a este parámetro antropométrico [Véase tabla 1].

Esta escala es aplicable a cualquier individuo adulto, independientemente de su sexo o edad (23), aunque se han establecido discordancias como las existentes en individuos con gran masa muscular y las debidas a las diferencias interraciales, que se describen más adelante. El IMC se correlaciona con el porcentaje de grasa corporal siguiendo un patrón curvilíneo (24), lo cual ha sido demostrado mediante el uso de ciertos métodos de estudio de la composición corporal (bioimpedancia, absorciometría dual de rayos X), obteniendo que este parámetro antropométrico tiene muy alta especificidad (97\%) pero baja sensibilidad (42\%) para definir obesidad como exceso de masa grasa en individuos con IMC $>30 \mathrm{Kg} / \mathrm{m}^{2}$. De este modo se ha definido recientemente en la comunidad científica el concepto de obeso con peso normal, para describir aquellos individuos con IMC $<25$ 
$\mathrm{Kg} / \mathrm{m}^{2}$ pero con un aumento del porcentaje de masa grasa (generalmente $>30 \%$, aunque la cifra es variable según distintos artículos) (25). A su vez, existe un subgrupo llamado obesos metabólicos en normopeso, el cual contrasta con otro concepto conocido como obeso metabólicamente sano (sin síndrome metabólico [SM]), que se desarrollará en el epígrafe 1.3.2.- Patología cardiovascular. El riesgo cardiovascular (RCV) de todos ellos se encuentra elevado (25).

Tabla 1. Clasificación internacional de la OMS del estado ponderal en adultos (23).

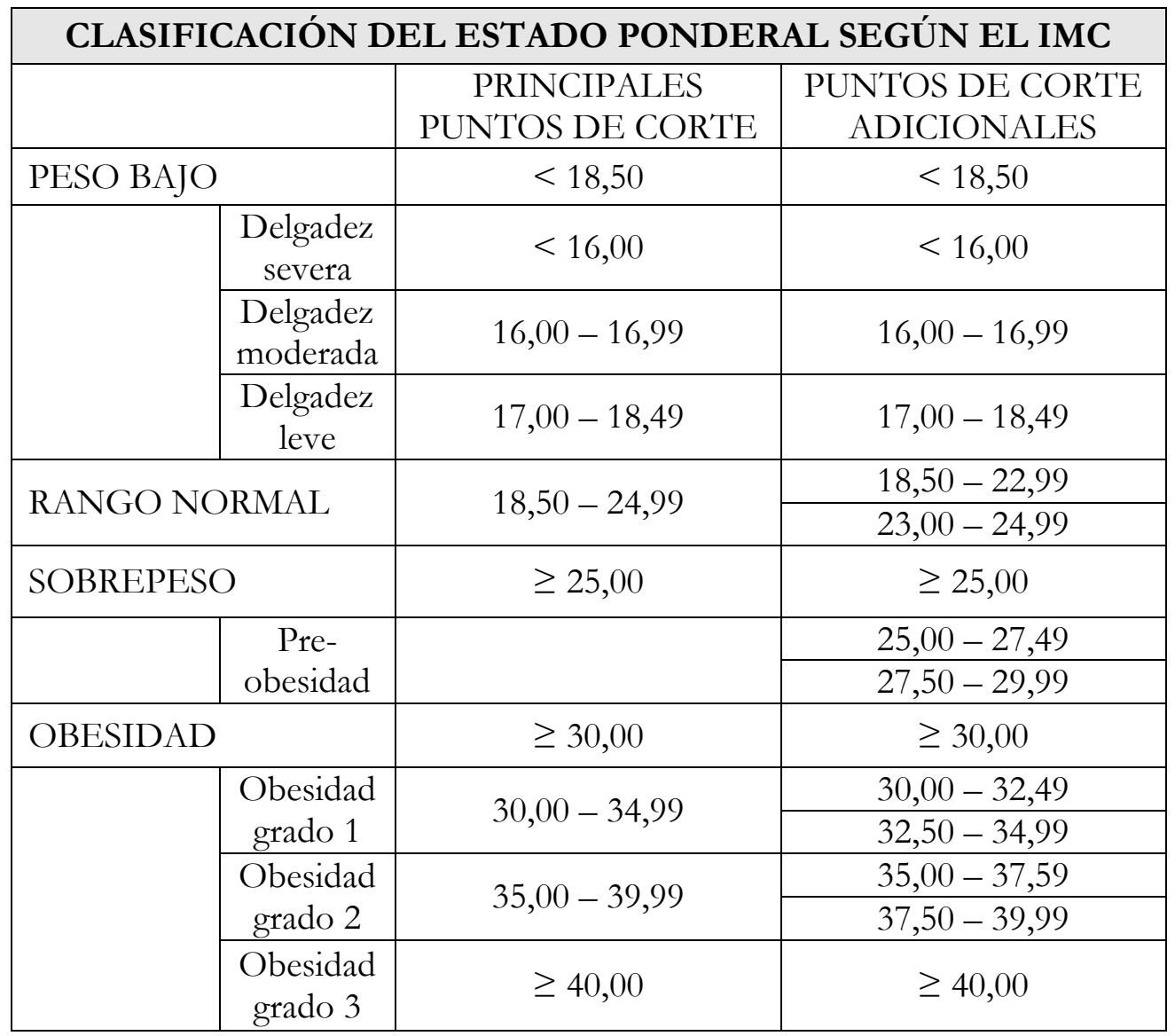

En relación a la raza, los grupos étnicos de Asia-Pacífico presentan CAO con valores de IMC inferiores a otras razas, particularmente la caucásica u occidental (26), tal y como refleja la revisión publicada por la OMS en colaboración con la International 
Association for the Study of Obesity (27). Numerosos estudios avalan la existencia de un incremento del RCV (28,29), así como de la diabetes mellitus (DM) y del SM en la población asiática (30-33). No obstante, y dada la variabilidad existente en los distintos subgrupos étnicos que la componen (34-36), no es posible establecer con claridad nuevos puntos de corte del IMC para esta población, de modo que la OMS mantiene los valores previamente establecidos, aunque añadiendo puntos adicionales como se observa en la tabla 1. En relación a otras diferencias interraciales, cabe citar la reciente guía sobre obesidad de la American Heart Association (AHA) del año 2013 (19), la cual pone de manifiesto, según la revisión de la literatura realizada, que existe un mayor RCV en mujeres blancas con obesidad respecto a las obesas afroamericanas. A pesar de todos estos datos, la escala de IMC de la OMS también ha sido validada y mantenida por la citada guía. Otros datos que constatan y confirman estas diferencias del valor de IMC respecto a la grasa corporal entre individuos caucásicos y de otras razas, aparecen claramente reflejados en el meta-análisis de Deurenberg et al. (37) y en el estudio aleatorizado de Razak et al. (38).

Es necesario mencionar la asociación entre el IMC y el riesgo de aparición de morbilidad y mortalidad. La relación entre mortalidad e IMC presenta una curva parabólica, según numerosos estudios poblacionales, correspondiendo la mínima mortalidad con los individuos de IMC en rango normal $(18,39)$. Los individuos con bajo peso presentan un discreto aumento de mortalidad, mientras que un IMC $\geq 30 \mathrm{Kg} / \mathrm{m}^{2}$ genera un riesgo de entre el 50 y el 100\% no sólo de mortalidad asociada a enfermedades cardiovasculares, sino también de mortalidad global $(40,41)$. El reciente meta-análisis con revisión sistemática de Flegal et al. publicado en el Journal of American Medical Associations (42), también notifica incrementos estadísticamente significativos de mortalidad global en pacientes con obesidad de clase 2 y 3 (hazard ratio $[\mathrm{HR}]=1$,29) [Véase tabla 2]. Sin embargo, resulta llamativo que 
un IMC en rango de sobrepeso es factor débilmente protector de mortalidad (HR $=0,94)$, dato que también demuestra dicho estudio, pero que contrasta con otros resultados publicados, en los que cualquier IMC $\geq 25 \mathrm{Kg} / \mathrm{m}^{2}$ genera incremento de la mortalidad global $(43,44)$.

Otro dato a tener en cuenta es la existencia de un posible efecto protector de la obesidad en pacientes con enfermedades crónicas de base, ya que en ellos existe menor mortalidad a mayor IMC. Este fenómeno ha sido denominado como la "paradoja de la obesidad", habiéndose descrito en insuficiencia renal crónica, enfermedad pulmonar obstructiva crónica, pero, especialmente en pacientes con patología cardiovascular: insuficiencia cardiaca y cardiopatía isquémica (45). Sin embargo, la "paradoja de la obesidad" no está avalada por completo en la literatura, y así se deduce de otros artículos recientes, tales como el meta-análisis con revisión sistemática de Kramer et al. (46), en el cual los obesos metabólicamente sanos (sin SM), al igual que todos los individuos con SM (independientemente de su IMC), tenían mayor mortalidad a más de diez años que los individuos en normopeso también metabólicamente sanos

La asociación del IMC con diversas patologías (las CAO), al igual que con la mortalidad causa-específica asociada a ellas, también ha sido evaluada, obteniendo resultados claramente desfavorables cuanto mayor es el $\operatorname{IMC}(36,44)$, los cuales serán descritos con detalle más adelante [Véase epígrafe 1.3.- Comorbilidades asociadas a la obesidad].

Por último, cabe citar que el IMC también ha sido empleado por numerosas sociedades científicas y grupos de expertos para clasificar y graduar la OM, siendo 
considerada como tal por todas ellas a partir de $40 \mathrm{Kg} / \mathrm{m}^{2}$. En la tabla 2 se muestran, como ejemplo, la nomenclatura seguida por Sociedad Española para el Estudio De la Obesidad (SEEDO) (4) y por la American Society of Bariatric and Metabolic Surgery (ASBMS) (47).

Tabla 2. Clasificación del sobrepeso y la obesidad en base al IMC por la SEEDO (4) y la ASBMS (47).

\begin{tabular}{|c|c|c|}
\hline \multicolumn{3}{|c|}{ CLASIFICACIÓN DE LA OBESIDAD SEGÚN EL IMC } \\
\hline IMC & NOMENCLATURA SEEDO & NOMENCLATURA ASBMS \\
\hline $25,0-29,9$ & Sobrepeso grados I y II & Overweight \\
\hline $30,0-34,9$ & Obesidad de tipo I & Obesity, Class I \\
\hline $35,0-39,9$ & Obesidad de tipo II & Serious Obesity, Class II \\
\hline $40,0-49,9$ & Obesidad de tipo III (mórbida) & Severe Obesity, Class III \\
\hline$\geq 50$ & Obesidad de tipo IV (extrema) & Sin denominación \\
\hline
\end{tabular}

\subsubsection{2.- Circunferencia de cintura}

La CC debe ser determinada con una cinta métrica no distensible alrededor del abdomen a nivel de las crestas iliacas con el paciente en bipedestación y al final de la espiración (48).

A diferencia del IMC, este parámetro antropométrico se correlaciona mejor con la llamada obesidad abdominal (OA) $(34,49,50)$, la cual también es conocida con los términos de obesidad central o troncular y obesidad androide, puesto que es así, precisamente, como se distribuye la masa grasa de forma preferente en los varones. Esta forma de presentación tiende a acumular la adiposidad alrededor de la vísceras, motivo por el cual, también recibe el apelativo de obesidad visceral. Por el contrario, la obesidad ginecoide tiende a acumular la masa adiposa en la periferia inferior del organismo (caderas, muslos y glúteos), 
preferentemente a nivel subcutáneo y no tanto a nivel visceral $(4,51)$ [Véase epígrafe 1.1.2.Histología y fisiopatología del tejido adiposo].

Los valores de riesgo muy elevado para este parámetro antropométrico según la SEEDO (4) son los que se muestran en la tabla 3. Estos valores coinciden con los que estableció la AHA en sus criterios para definir el SM en 2005 (52), aunque esta misma sociedad científica, en su reciente guía de manejo de la obesidad (19), indica que no hay suficiente evidencia para marcar límites precisos de la CC, sino que es una variable continua para el incremento del RCV. No obstante, un reciente estudio alemán sugiere que el límite normal actualmente establecido sobreestima el RCV, aunque sólo para mujeres (53).

Tabla 3. Valores de riesgo muy elevado para la CC según la SEEDO (4) y la AHA 2005 (52).

\begin{tabular}{|l|c|c|l|c|}
\hline \multicolumn{5}{|c|}{ VALORES DE RIESGO DE LA CC } \\
\hline \multicolumn{2}{|c|}{ SEEDO } & \multicolumn{3}{|c|}{ AHA } \\
\hline Mujeres & $>88 \mathrm{~cm}$ & Población & Mujeres & $>88 \mathrm{~cm}$ \\
\cline { 1 - 1 } & Veneral & Varones & $>102 \mathrm{~cm}$ \\
\hline \multicolumn{2}{|c|}{$\begin{array}{c}\text { Americanos } \\
\text { de origen asiático }\end{array}$} & Mujeres & $>80 \mathrm{~cm}$ \\
\cline { 5 - 5 } & & Varones & $>90 \mathrm{~cm}$ \\
\hline
\end{tabular}

Nuevamente, al igual que ocurre con el IMC, existen diferencias raciales en los valores normales de la CC, como marcador de OA, tal y como se puede ver en la tabla 3 . La población asiática presenta una mayor predisposición a la OA para un mismo valor de IMC (54). Existen también otras diferencias raciales, que aparecen reflejadas en el documento de la OMS de 2008 (55). 
En relación a la morbimortalidad asociada a la OA y, por tanto a una CC incrementada, cabe decir que este tipo de adiposidad es la que genera mayor RCV, siendo además la que se encuentra implicada en la etiopatogenia del SM, tal y como se ha demostrado en numerosas publicaciones $(19,34,49,55-57)$. Concretamente, en un estudio italiano aleatorizado con seguimiento a 148 meses, se demostró que por cada centímetro (cm) de CC mayor de los niveles normales, aumentaba la aparición de eventos cardiovasculares, la mortalidad general y la mortalidad causa-específica cardiovascular, un $4 \%, 4 \%$ y $5 \%$, respectivamente (57). También aparece reflejado en la literatura que la CC es un factor independiente del IMC para el incremento de la mortalidad $(58,59)$ y que la correlación de este parámetro con la mortalidad presenta una gráfica con curva parabólica análoga a la del IMC (18).

Finalmente, es necesario mencionar que se han descrito nuevas relaciones entre los parámetros antropométricos empleando como numerador la CC. Ellas son el índice de cintura-cadera (ICC) y el índice de cintura-altura (ICA) $(18,55,60)$. Su utilidad y difusión, así como su determinación en la práctica clínica, es variable. El informe de expertos de la OMS de 2008 (55) recomienda el empleo de la CC y del ICC y un meta-análisis publicado en 2013 (18) lo corrobora. Asimismo, otro meta-análisis (61) sugiere que el ICA también debería incluirse como parte de la valoración del paciente con sobrepeso y obesidad.

\subsection{2.- HISTOLOGÍA Y FISIOPATOLOGÍA DEL TEJIDO ADIPOSO}

El tejido adiposo deriva embriológicamente del tejido conectivo laxo y existen dos subtipos histológicos: grasa blanca (también llamada amarilla, o unilocular) y grasa parda (marrón, o multilocular). Se ha descrito un tercer tipo llamado tejido adiposo beige que son adipocitos pardos en el espesor de la grasa blanca (62). 
La grasa parda se caracteriza por presentar una gran cantidad de mitocondrias en el citoplasma de sus adipocitos y una mayor red de capilares sanguíneos y de terminaciones simpáticas entre éstos $(63,64)$. Se encuentra localizada entre las escápulas, nuca, axilas y también a nivel retroperitoneal, rodeando a los grandes vasos y a los riñones (64). La principal función de este subtipo de tejido adiposo es la termogénesis en respuesta, fundamentalmente, a un estímulo $\beta 3$-adrenérgico (65). La existencia de un desacoplamiento energético, que ocurre a nivel mitocondrial mediado por la termogenina, permite que la cadena respiratoria disipe calor en lugar de generar adenosin-trifosfato $(65,66)$. En base a esta función, la grasa parda abunda en el feto y en el recién nacido llegando a constituir el 2-5\% del peso corporal, reduciéndose progresivamente durante el crecimiento (64). No obstante, en el adulto también existe tejido adiposo marrón, especialmente en aquellos individuos sometidos prolongadamente a ambientes fríos (temperatura inferior a condiciones termoneutras) y, por el contrario, disminuye en una relación inversamente proporcional al incremento del IMC, según el estudio de Van Marken Lichtenbelt publicado en New England Journal Of Medicine (66).

La grasa blanca se diferencia de la parda, no sólo en su histología sino también en su función. En este subtipo, los adipocitos presentan una gran vacuola lipídica central con mínimo citoplasma y un núcleo rechazado hacia la periferia. La grasa blanca se clasifica por su localización en tejido adiposo subcutáneo (superficial y profundo) y en tejido adiposo interno, que a su vez se subdivide en no visceral y visceral (intratorácico e intraabdominopélvico), siguiendo la nomenclatura propuesta por Shen en 2003, basada en técnicas de imagen (67). Existen diferencias notables de acúmulo de adiposidad en estas localizaciones según la edad (64) y también con el sexo, como ya se ha expuesto anteriormente [Véase epígrafe 1.1.1.2.- Circunferencia de cintura]. Las funciones de la grasa 
blanca son variadas, pero la principal es acumular lípidos actuando como reserva energética. Para ello el adipocito sintetiza triacilgliceroles (TAG) por reesterificación de los ácidos grasos procedentes, a su vez, de los TAG de los quilomicrones y de las very low density lipoprotein (VLDL) tras la acción de la lipoproteinlipasa (68). La acumulación de TAG en los adipocitos y, por tanto, el incremento de la masa grasa, responde a dos mecanismos biológicos $(64,69)$ :

- Hiperplasia: por aumento de la celularidad del tejido adiposo, más propia de la edad infantil y con el patrón ginecoide.

- Hipertrofia: por aumento del contenido graso de los adipocitos sin incremento del número. Es la que aparece en el adulto con patrón de tendencia androide y, en consecuencia, se asocia con la presencia de CAO.

Otras funciones de la grasa blanca son la de protección mecánica frente a traumatismos, especialmente en determinadas regiones de la anatomía, y la función endocrina-paracrina, respondiendo a diversas hormonas y citocinas y secretando otras (64,70). Resulta de interés exponer, sucintamente, los efectos de algunas de estas citocinas producidas por los adipocitos blancos (denominadas con el apelativo de adipocinas), dado que sus acciones, interrelaciones y disregulación son de notable trascendencia en la comprensión del sobrepeso y la obesidad $(63,70,71)$ :

- Leptina: es una de las más potentes adipocinas y se encuentra integrada con el hipotálamo, entre otras dianas, señalizando el estado nutricional del organismo. Su efecto es anorexígeno y antidiabético, ya que estimula la sensibilidad periférica a insulina. Además ejerce una acción proinflamatoria actuando sobre las células del sistema inmune, sobre las que induce la síntesis del tumor necrosis factor $\alpha(\mathrm{TNF} \alpha)$ y otras citocinas proinflamatorias. 
- Adiponectina: posee efecto antiinflamatorio (inhibiendo la síntesis de $\mathrm{TNF} \alpha$ ), antidiabético (reduciendo la resistencia a la insulina) y cardioprotector (por la propia acción antiinflamatoria y por un mecanismo antiapoptótico del endotelio vascular).

- TNF $\alpha$ : fue la primera adipocina aislada y su síntesis principal ocurre en las células inmunitarias, siendo, por tanto, una citocina proinflamatoria. Su efecto fundamental a nivel endocrino-metabólico es inducir resistencia a la insulina (RI) a través de diversas vías de señalización bioquímica.

- Interleukina 6: es también una adipocina proinflamatoria, aunque su efecto metabólico no está completamente aclarado, con resultados contradictorios en los diversos modelos in vivo e in vitro, y también en estudios con animales y con humanos. De forma genérica se puede decir que su elevación plasmática se asocia a la obesidad y a la RI.

- Resistina: su síntesis ocurre preferentemente en los macrófagos, aunque los estudios iniciales con roedores la obtuvieron de la grasa. Tiene una acción favorecedora, como su nombre indica, de la RI. Tanto es así que varios estudios epidemiológicos han asociado unos niveles incrementados de esta adipocina con mayor riesgo de DM2, infarto agudo de miocardio (IAM) y aterosclerosis.

\subsection{3.- ETIOLOGÍA DEL SOBREPESO Y LA OBESIDAD}

Como ya se ha mencionado al inicio de esta Introducción, las causas y factores que determinan un balance energético positivo, el cual aboca a la OM, son diversas $(2,4,72)$. En general, se puede decir que la obesidad es una patología de etiología multifactorial en la que influye un trasfondo orgánico predisponente y un contexto ambiental favorecedor 
$(2,4,72,73)$. Sólo un pequeño porcentaje de obesos mórbidos, no mayor del 10\%, es el que presenta una causa única y concreta, y algunos de estos casos de OM habitualmente se diagnostican en la edad pediátrica y pueden presentar además otras malformaciones y/o retraso intelectual puesto que forman parte de síndromes congénitos claramente identificados (74). Por tanto, de forma global, se pueden distinguir dos tipos de obesidad en función de su etiología:

- Obesidad primaria, correspondiente al grupo de etiología multifactorial.

- Obesidad secundaria a causas concretas [Véase tabla 4].

Tabla 4. Algunas causas de obesidad secundaria (2,4,72-75).

\begin{tabular}{|l|l|}
\hline \multicolumn{2}{|c|}{ CAUSAS DE OBESIDAD SECUNDARIA } \\
\hline ENDOCRINOPATÍAS & $\begin{array}{l}\text { Hipercortisolismo, hipotiroidismo, Sd. Ovario } \\
\text { poliquístico, déficit de hormona de crecimiento, } \\
\text { Sd. Stein-Leventhal, etc. }\end{array}$ \\
\hline $\begin{array}{l}\text { ENFERMEDADES } \\
\text { GENÉTICAS Y } \\
\text { CROMOSOMOPATÍAS }\end{array}$ & $\begin{array}{l}\text { Acondroplasia, Osteodistrofia Hereditaria de } \\
\text { Albright, Sd. Down, Sd. Prader-Willi, Sd. Bardet- } \\
\text { Biedl, Sd. Angelman, Sd. Alström, Sd. Fanconi- } \\
\text { Bickel, Sd. Wilson Turner, Sd. Cohen, } \\
\text { Sd. Insulino-resistencia, Macrosomia adiposa } \\
\text { congénita, Lipodistrofia familiar parcial, déficit de } \\
\text { leptina o mutación de su receptor, mutación del } \\
\text { receptor de la melanocortina 4, etc. }\end{array}$ \\
\hline $\begin{array}{l}\text { PATOLOGÍA } \\
\text { HIPOTALÁMICA }\end{array}$ & $\begin{array}{l}\text { Iatrogénica, tumoral, infecciosa, traumática, etc. } \\
\alpha-\text { y } \beta \text {-bloqueantes, antidiabéticos orales e insulina, } \\
\text { hormonas esteroideas y corticosteroides, } \\
\text { anticonceptivos orales, inhibidores de la proteasa, } \\
\text { etc. }\end{array}$ \\
\hline
\end{tabular}

Una vez presentada de forma agrupada la etiología de la obesidad secundaria, se expondrán conjuntamente toda la pléyade de causas que favorecen la OM clasificadas por su patogenia. 


\subsubsection{1.- Factores genéticos}

Se han investigado una gran variedad de genes responsables de codificar para proteínas con efecto sobre la saciedad, la composición corporal o el balance energético. En la actualidad, se han determinado hasta 71 genes responsables de un incremento de adiposidad, y si a ellos sumamos alteraciones cromosómicas o mutaciones puntuales, el número asciende a más de 200 (75). Consecuentemente, numerosos estudios sugieren que la predisposición al desarrollo potencial de obesidad está establecida en el individuo desde épocas tempranas de la vida, e igualmente permite sostener, sin ninguna duda, la teoría heredo-familiar de la obesidad, aunque ello no desestima los factores dietético-nutricionales y de estilo de vida que suelen ser similares en los integrantes de una misma familia $(2,73,75,76)$. Así pues, se ha demostrado que existe un riesgo relativo $(\mathrm{RR})=7$ de aparición de $\mathrm{OM}$ en un individuo cuando alguno de sus progenitores también la presenta (75). De este modo y a pesar de la variabilidad existente en la literatura, se puede considerar que el componente hereditario de la obesidad supone del 40 al $70 \%$, según estudios epidemiológicos que han estudiado este fenómeno en hermanos gemelos y en familias de obesos (77).

De forma global, existen tres modelos que explican el componente genético de la obesidad y que se citan a continuación $(75,77)$ :

- Modelo monogénico. Consiste en la mutación en un gen concreto que codifica para una proteína implicada en los mecanismos de control energético o de la ingesta. El primero de estos genes en ser identificado, gracias a los modelos murinos ob/ob, fue el gen de la leptina. Su mutación implica la ausencia de esta molécula y en consecuencia, una insuficiente inhibición del apetito tras la ingesta. Posteriormente fueron identificadas 
mutaciones en otros genes, tales como: el gen del receptor de la leptina, el gen que codifica para la proopiomelanocortina, el gen del receptor de melanocortina 4 y el gen de la prohormona convertasa 1. La más prevalente de las mutaciones monogénicas es la del gen del receptor de la melanocortina 4, correspondiendo del 0,5-1\% de los obesos adultos.

- Modelo de obesidad sindrómica. Es la consecuencia de alteraciones génicas o cromosómicas con efecto pleiotrópico y que suelen afectar a las regiones del sistema nervioso central (SNC) implicadas en el control de la ingesta, apareciendo hiperfagia en la mayoría de los enfermos portadores, así como malformaciones o alteraciones conductuales asociadas. El más frecuente de este grupo es el síndrome (Sd.) de Prader-Willi, de carácter autosómico dominante, producido por delección del brazo corto del cromosoma 15 paterno, aunque también se describen otros mecanismos (disomía materna del cromosoma 15 o alteración en la metilación de genes de esta región cromosómica). Se manifiesta ya en la edad pediátrica con hiperfagia, obesidad, hipogonadismo, hipotonía, retraso mental, etc. También se han identificados genes cuya mutación implica alteración de los cilios celulares (Sd. Alström-Hallgren, Sd. Barbet-Biedl y Sd. Carpenter), del aparato de Golgi (Sd. Cohen) o del nucleolo (Sd. Börjeson-Forssman-Lehmann), los cuales también se asocian a obesidad.

- Modelo de los single nucleotide polimorphism (SNP). Se ha desarrollado gracias la secuenciación del genoma humano e implica mutaciones puntuales en nucleótidos. Numerosos loci de estos SNP han sido identificados, siendo tres los más representativos en la población: 
- En el intrón 1 del gen fat mass and obesity-associated protein (FTO), que es el paradigma de este modelo. La sobreexpresión del mismo induce ganancia progresiva de peso.

- En la proximidad de la secuencia del gen la proteína transmembrana 18.

- Junto al gen del receptor de la melanocortina 4.

Sin embargo, estos tres modelos no logran explicar completamente todos los casos de obesidad hereditaria. Recientes estudios han demostrado la existencia de otros mecanismos más complejos, como son las variantes del número de copias, las variantes raras de los SNP, los mecanismos de interacción de genes con el ambiente (epistasis) o la epigenética (77). En relación a estos dos últimos, cabe decir que su efecto es debido, no a alteración en la secuencia genética en sí misma, sino al mecanismo de control molecular de la expresión génica $(73,77)$, como por ejemplo, la metilación del ácido desoxirribo-nucleico (DNA) (73). El gen agouti related protein (AGRP) el caso típico de este mecanismo (77) y su efecto se expone en el siguiente epígrafe.

\subsubsection{2.- Factores neurohumorales y hormonales}

La homeostasis del peso corporal y del balance energético reside en el SNC y, fundamentalmente, en el hipotálamo, aunque se encuentra integrada con el aparato digestivo, el tejido adiposo, el sistema endocrino y las eferencias autonómicas del sistema nervioso $(4,75)$. Existen numerosos mecanismos implicados en la regulación del apetito y del gasto energético, con complejas interrelaciones entre ellos. Inicialmente, la sensación de apetito se desencadena en el hipotálamo mediada por el neuropéptido Y, la ghrelina y la AGRP $(4,75)$. Tras la ingesta, el tubo digestivo libera otras moléculas que inducen, también 
en el hipotálamo, la sensación de saciedad y cuyo objetivo es limitar un balance energético positivo $(4,75)$. También posee dicho efecto la leptina, que se sintetiza en los adipocitos blancos, como ya se ha expuesto previamente y su misión es señalizar el estado de las reservas lipídicas del organismo [Véase epígrafe 1.1.2.- Histología y fisiopatología del tejido adiposo].

Seguidamente, se presentarán estos mecanismos neurohumorales y hormonales de forma agrupada por tejidos, aparatos y sistemas para una mejor comprensión:

- SNC. Constituye tanto el punto de integración de las aferencias que regulan la ingesta, como el punto de partida de las eferencias que controlan el balance energético. Los neurotransmisores anorexígenos son la hormona melano-estimulante (ligando del receptor de melanocortina 4) y la proopiomelanocortina. Por el contrario, las principales moléculas inductoras de la ingesta son (75): el neuropéptido Y (la molécula con mayor efecto orexígeno, además de poseer acción anabólica), la AGRP (bloquea el receptor de melanocortina $4 \mathrm{y}$, consecuentemente, el efecto de saciedad de éste) y las orexinas A y B (también conocidas como hipocretinas). Por último, es necesario mencionar el efecto producido por las aferencia gustativas y olfativas generadas por los alimentos, cuyo mediador es la serotonina y que se asocia también a los estados de ánimo, al control del apetito y de la actividad física y a diversas psicopatologías (78).

- Sistema endocrino. Podemos enumerar varias hormonas implicadas en la regulación de la adiposidad corporal. En primer lugar, se ha demostrado que la insulina señaliza la sensación de saciedad, conjuntamente con la leptina aunque a diferencia de ella, posee efecto anabólico, lo que favorece 
la lipogénesis y la captación de glucosa por las células (4). Las hormonas tiroideas poseen globalmente acción catabólica y se ha demostrado que la leptina estimula la síntesis de la tirotropina (75). Por contra, la acción del cortisol, como hormona del estrés, estimula la ingesta y contrarresta el efecto de la insulina, al igual que el glucagón (4). Del mismo modo, las hormonas sexuales influyen, también, en el mantenimiento del balance energético, ya que el descenso de los niveles plasmáticos de estrógenos y andrógenos induce $\mathrm{OA}$, merced a un efecto inhibidor de la leptina (4).

- Aparato digestivo. Esta interrelación ha sido denominada eje enteroencefálico. Los péptidos intestinales con acción anorexígena son la colecistoquinina; la enterostatina, sintetizada por el páncreas; el péptido similar al glucagón 1, sintetizado en la células L del íleon en respuesta a comidas altamente calóricas, y el péptido liberador de gastrina. Otras moléculas que también favorecen la sensación de saciedad son la bombesina y el polipéptido insulinotrópico dependiente de glucosa, el cual estimula la síntesis de insulina ante estados de hiperglucemia. La ghrelina, por el contrario, fue el primer péptido aislado con efecto inductor del apetito y se libera a nivel gástrico y duodenal, actuando en el hipotálamo (75).

- Sistema nervioso vegetativo. Por una parte, la leptina favorece un efecto simpático que, por estímulo $\alpha 1$ y $\beta 3$-adrenérgico, minimiza la ingesta, induce termogénesis y favorece el gasto energético. Por otra, el sistema parasimpático favorece el vaciamiento gástrico y a nivel hepático incrementa la síntesis de insulina (75).

- Tejido adiposo. Las diversas adipocinas sintetizadas por la grasa blanca ejercen numerosos efectos paracrinos y endocrinos, como ya se ha expuesto 
[Véase epígrafe 1.1.2.- Histología y fisiopatología del tejido adiposo]. Es necesario reseñar que el tejido adiposo visceral es más activo desde el punto de vista metabólico que la grasa subcutánea, al tiempo que responde a las modificaciones de los niveles plasmáticos de glucosa, insulina o lípidos con mayor síntesis de adipocinas (75).

Diversas alteraciones en todo este complejo entramado de regulación bioquímica y molecular han sido descritas como causa de sobrepeso y obesidad. Además, muchas de ellas se integran formando parte, a su vez, de los mecanismos que dan lugar a las CAO. En general, los individuos obesos presentan un estado de hiperleptinemia en el contexto de una resistencia periférica y central a la leptina, así como un déficit de adiponectina. El exceso de adiposidad, especialmente la OA, desencadena también un estado de RI con hiperinsulinemia secundaria que es el pilar fundamental para que se establezca el SM [Véase epígrafe 1.3.1.1.- Etiopatogenia del síndrome metabólico]. Las consecuencias globales de todo ello son, entre otras (79-81):

- Predominio de la sensación de hambre.

- Hipertonía del sistema nervioso simpático.

- Inducción de la síntesis de citocinas proinflamatorias, estableciéndose un estado de inflamación leve crónica, por estímulo de la principal ruta de señalización intracelular de la inflamación: el factor nuclear kB. Ello se ve favorecido por la disregulación inmunitaria en el tejido adiposo del obeso, secundaria a la presencia de una ratio macrófago:adipocito incrementada en el contexto de una hipoxia relativa del tejido graso con necrosis adipocitaria. 
- Incremento del estrés oxidativo, secundario al descenso de agentes antioxidantes y al incremento de los llamados radicales libres (reactive oxigen species [ROS]): peróxido de hidrógeno, radical superóxido y radical hidroxilo.

Por último, es necesario reseñar el efecto que poseen, a nivel endocrino, ciertos agentes químicos presentes en nuestro entorno y que reciben el nombre de disruptores endocrinológicos (73). Productos tales como los metabolitos del pesticida DDT u otros empleados en la industria (bifenoles, ftalatos, etc.) se han relacionado en algunos estudios observacionales epidemiológicos con alteración del metabolismo de las hormonas sexuales y tiroideas y con efectos adipogénicos, aunque aún no están clarificados ni el tiempo de exposición ni la dosis necesaria (73).

\subsubsection{3.- Factores microbiológicos}

Recientemente se ha postulado el papel de los microorganismos presentes en el tubo digestivo como nuevo factor relacionado con la aparición de obesidad. Los mecanismos no están aún bien establecidos, aunque se proponen los siguientes $(2,73)$ : modificación química de los nutrientes trasformando la fibra alimentaria en ácidos grasos, alteración en la regulación de los péptidos intestinales con acción hormonal, inducción de un estado de inflamación leve crónica mediada por lipopolisacáridos bacterianos y por endotoxemia.

La alteración de la microbiota intestinal se ha demostrado en algunos estudios que modifica el estado de resistencia a la insulina y los niveles de leptina (75). La bacteria Methanobrevibacter smithii o una mayor proporción de Firmicutes sobre Bacteriodetes en el tubo digestivo es un ejemplo de asociación de factores microbiológicos con la obesidad (73). No 
sólo las bacterias intestinales se han relacionado con incremento de la adiposidad del individuo, sino también agentes patógenos tales como la Chlamidya pneumoniae y el Adenovirus Ad-36 (73).

\subsubsection{4.- Factores reproductivos y sociodemográficos}

Desde la etapa fetal se describen factores que influyen en el desarrollo de un exceso de adiposidad. Como ya se ha expuesto anteriormente, está demostrada una mayor frecuencia de obesidad en niños cuyos progenitores también son obesos. Por este motivo se considera que la etapa prenatal es el primero de los tres períodos críticos (2) para el desarrollo de obesidad. Los dos siguientes son el período de los 5 a los 7 años (conocido con el término inglés de adiposity rebound) y la pubertad, especialmente en el sexo femenino. En el primer período de riesgo, cabe citar diversas variables que actúan en el feto y en el recién nacido favoreciendo un potencial desarrollo de sobrepeso y obesidad (2):

- Hábito tabáquico o la presencia de DM gestacional en la madre, así como los estados de hipo o hipernutrición durante el embarazo.

- Neonatos de peso elevado y también aquellos de bajo peso pero con una rápida ganancia ponderal en el primer año, y la ausencia de lactancia materna.

Existen, también, otros factores reproductivos que afectan, precisamente, a la mujer con descendencia. El estudio DORICA demostró una mayor prevalencia de obesidad en aquellas mujeres con mayor número de hijos, alcanzando una media de incremento de peso corporal tras cada embarazo de $2 \mathrm{Kg}$ en comparición con nulíparas de igual edad (76). Asimismo, la edad materna incrementada se ha relacionado con mayor prevalencia de sobrepeso y obesidad en su descendencia, cuyo mecanismo parece ser doble (73): 
- Riesgo elevado de sufrir patologías gestacionales (DM gestacional o preeclampsia) o bien de quedar embarazada siendo ya diabética u obesa, puesto que son situaciones que favorecen la obesidad de la descendencia, como ya se ha explicado.

- Mayor incidencia de hijos con pesos bajos y elevados al nacimiento en las madres añosas.

Finalmente, también está establecida la tendencia al incremento del peso corporal a medida que el individuo aumenta la edad, siendo los 60 años el periodo etario de mayor prevalencia de obesidad en la población española (76). De igual modo, existen factores culturales, sociales y económicos que favorecen la obesidad y que se exponen más adelante [Véase epígrafe 1.2.- Epidemiología e implicación socio-económica de la obesidad].

\subsubsection{5.- Factores nutricionales y de estilo de vida}

Este último grupo de factores son de gran importancia a lo largo de la vida del individuo, pero alcanzan especial relevancia en el segundo y tercer períodos críticos (2).

En primer lugar, los hábitos nutricionales del mundo occidental son responsables en gran medida de la epidemia de obesidad actual. En este sentido, el acceso rápido y fácil a productos altamente calóricos (tales como: bollería industrial, bebidas carbonatadas, alimentos precocinados, la comida rápida, etc.), las comidas fuera de casa de manera habitual o los alimentos grasos y de origen animal juegan un papel fundamental en estos dos períodos $(2,75,82)$. De igual modo, el consumo excesivo de alcohol, aunque con resultados controvertidos según algunos estudios (82), o la menor ingesta de fibra alimentaria, de pan integral y de productos vegetales y frutas son favorecedores de OM 
$(2,76,82)$ [Véase tabla 5]. El patrón horario de alimentación a lo largo del día también se ha postulado como factor influyente en el desarrollo de obesidad: el llamado síndrome de ingesta nocturna, en el cual más del 25\% de las calorías diarias se ingieren entre la cena y el desayuno (83), así como una escasa ingesta alimentaria durante el desayuno y el almuerzo respecto a la cena se asocian a un exceso de adiposidad (82).

En segundo lugar, el hábito de vida sedentario y la ausencia de actividad física es otro factor clave $(2,75)$, como se puede apreciar en la tabla 5. Muchas de las actividades de ocio actuales (televisión, ordenador, videoconsolas, etc.) no sólo suponen un bajo consumo energético, sino que además van ligadas, en muchos individuos, a la ingesta de productos altamente calóricos mientras se realizan (2). Por otra parte, se conoce desde los años 50, tras la publicación de Meyer et al. en el American Journal of Clinical Nutrition (2), que la mejor correlación entre gasto e ingesta energética se obtiene cuando el organismo es sometido a cierta actividad física, aunque no exagerada, y, por el contrario, en aquellos individuos físicamente inactivos es necesario una limitación de la ingesta calórica mucho mayor para mantener el IMC en rango normal.

Tabla 5. Riesgo de obesidad según ciertos hábitos nutricionales y de estilo de vida. Tomado de Aranceta-Bartrina et al. (76).

\begin{tabular}{|c|c|}
\hline \multicolumn{2}{|c|}{$\begin{array}{l}\text { HÁBITOS NUTRICIONALES Y ESTILO DE VIDA } \\
\text { ASOCIADOS CON RIESGO DE OBESIDAD }\end{array}$} \\
\hline Número de comidas diarias (1-2 al día) & $\mathrm{OR}=1,35(\mathrm{IC} 95 \%, 1,34-1,36)$ \\
\hline $\begin{array}{l}\text { Actividad sedentaria } \\
(>3 \text { horas de televisión/día) }\end{array}$ & $\mathrm{OR}=1,48(\mathrm{IC} 95 \%, 1,47-1,49)$ \\
\hline $\begin{array}{l}\text { Consumo de frutas y verduras } \\
(<4 \text { raciones/día) }\end{array}$ & $\mathrm{OR}=1,22(\mathrm{IC} 95 \%, 1,20-1,24)$ \\
\hline Ausencia de práctica deportiva habitual & $\mathrm{OR}=1,23(\mathrm{IC} 95 \%, 1,22-1,24)$ \\
\hline Ingesta grasa habitual > 38\% & $\mathrm{OR}=1,21(\mathrm{IC} 95 \%, 1,19-1,23)$ \\
\hline $\begin{array}{l}\text { Consumo habitual de bollería, refrescos, } \\
\text { embutidos }\end{array}$ & $\mathrm{OR}=1,19(\mathrm{IC} 95 \%, 1,17-1,21)$ \\
\hline
\end{tabular}


Por último, otros datos correspondientes al estilo de vida y asociados a incremento ponderal son:

- El abandono del hábito tabáquico, cuyo mecanismo parece estar en relación a la deprivación de nicotina, que es un agente termogénico (motivo por el cual los fumadores suelen presentar IMC menores) y a la hiperingesta secundaria a la misma como compensación $(73,76)$.

- El déficit de horas de sueño, habiéndose demostrado niveles menores de leptina y mayores de ghrelina con sensación incrementada de hambre y de apetencia por alimentos altamente calóricos, al igual que un descenso en la actividad física por cansancio, según concluyen series poblacionales largas e incluso meta-análisis (73). 


\section{2.- EPIDEMIOLOGÍA E IMPLICACIÓN SOCIO- ECONÓMICA DE LA OBESIDAD}

Actualmente el sobrepeso y la obesidad presentan unas cifras de incidencia y prevalencia que llevaron a la OMS a catalogarla como epidemia global en su informe de 2000 (22), lo cual deriva, como es lógico, en una elevada repercusión socio-económica.

\subsection{1.- EPIDEMIOLOGÍA A NIVEL MUNDIAL Y NACIONAL}

A nivel mundial, según cifras publicadas por la OMS, más de 1400 millones de personas mayores de 20 años ( $35 \%$ de la población mundial) presentaban IMC $>25 \mathrm{Kg} / \mathrm{m}^{2}$ y, de ellos, 500 millones alcanzaban el rango de obesidad (11\%) en el año 2008. Aunque este trabajo no se ocupa de la población pediátrica, los datos de prevalencia mundial de sobrepeso y obesidad infantil son igualmente alarmantes: 44 millones de niños menores de 5 años en 2012 (1).

Resulta de interés remarcar la variabilidad de prevalencia existente entre países y continentes. Basándonos en datos de la OMS, la máxima frecuencia poblacional la encontramos en el continente americano, con un $62 \%$ de sobrepeso y un $26 \%$ de obesidad, y la menor prevalencia corresponde al sudeste asiático (14\% y 3\%, respectivamente) (1). En nuestro país, la SEEDO presentó en 2005 un trabajo con los datos de los estudios DORICA y EnKid (76). En aquella fecha, el 54,7\% de la población española entre 25 y 64 años tenía IMC $>25 \mathrm{Kg} / \mathrm{m}^{2}$, con mayor prevalencia entre los varones. Para IMC en rango de obesidad, las cifras en ese mismo grupo etario alcanzaron un 15,5\%, siendo más frecuente en el sexo femenino. El pico de edad con presencia de mayor adiposidad corresponde con los 60 años, según este mismo artículo. 
Los datos globales más recientes en España se encuentran en la encuesta nacional de salud (ENS) de 2011-2012 (84), estando reflejados en la tabla 6. La tendencia es claramente al alza desde la primera ENS llevada a cabo en 1987, cuando la prevalencia global de obesidad en adultos era del 7,4\%. Las diferencias entre sexos para IMC en rango de obesidad son poco llamativas: 18\% entre los varones y 16\% en mujeres, no así para el rango de sobrepeso. La edad también es un dato que ha variado respecto a la revisión de la SEEDO, ya que, actualmente, los valores de IMC son crecientes hasta el grupo de 74 años.

Tabla 6. Estado ponderal en adultos españoles según el sexo. Fuente: ENS 2011-2012: Determinantes de la salud (cifras relativas en la población de 18 y más años) (84).

\begin{tabular}{|c|c|c|}
\hline \multicolumn{3}{|c|}{ IMC POR SEXO. ENS 2011-2012 } \\
\hline & SOBREPESO & OBESIDAD \\
\hline $\begin{array}{c}\text { Total en ambos } \\
\text { sexos }\end{array}$ & $36,65 \%$ & $17,03 \%$ \\
\hline Varones & $45,14 \%$ & $18,01 \%$ \\
\hline Mujeres & $28,14 \%$ & $16,04 \%$ \\
\hline
\end{tabular}

Las diferencias también son notables entre las Comunidades Autónomas, dato objetivado tanto en el artículo de la SEEDO (76) como en la última ENS (84): existe mayor prevalencia de obesidad en las regiones del sur de España (Ceuta, Andalucía, Extremadura, Murcia), con valores por encima del $20 \%$ de la población. No obstante, este dato contrasta con el hecho de que Cantabria sea la Comunidad Autónoma con mayor prevalencia de individuos con IMC en rango de sobrepeso (42,35\%) y no así de obesidad (11,12\%) (84).

\subsection{2.- IMPLICACIÓN SOCIO-ECONÓMICA}

En primer lugar, es necesario hacer referencia al nivel socio-económico-cultural y su relación con el sobrepeso y la obesidad. De forma general se puede decir que existe una 
relación inversa entre el nivel cultural del individuo y la prevalencia de obesidad, mientras que la influencia del nivel económico es diferente según el grado de desarrollo del país: para los países del tercer mundo hay mayor frecuencia de sobrepeso en los grupos sociales más acomodados, ocurriendo el fenómeno contrario en los países desarrollados (76). En España, la ENS del 2011-2012 (84) también muestra diferencias del IMC según el nivel del estudios con una tendencia inversamente proporcional: las diferencias son claras en mujeres y en varones con IMC en rango de obesidad. Sin embargo, éstas son poco llamativas para varones con sobrepeso: prevalencia nacional del 48,17\% en aquellos con mínimo nivel cultural frente a un 45,24\% para aquellos con estudios universitarios (84).

En segundo lugar, las consecuencias sociales y económicas derivadas del sobrepeso y la obesidad se relacionan principalmente con un aumento de la discapacidad y la mortalidad prematura secundarias a las $\mathrm{CAO}$, con los gastos sanitarios que ello genera. En 2008, la OMS estimó una mortalidad anual derivada de las CAO de al menos 2,8 millones de individuos, así como 35,8 millones (2,3\%) de "años de vida ajustados por discapacidad" causados por la obesidad (1). En cuanto a los años potenciales de vida perdidos (APVP), el estudio de Finkelstein et al. (85) concluyó que, para individuos adultos con IMC $>40$ $\mathrm{Kg} / \mathrm{m}^{2}$, la cifra va desde 5 para mujeres negras no fumadoras hasta 12 años para varones blancos fumadores. Asimismo, el artículo de Whitlock et al. publicado en The Lancet en 2009 (44), obtuvo los siguientes resultados: para IMC entre $30-35 \mathrm{Kg} / \mathrm{m}^{2}$, la supervivencia mediana se reduce 2 a 4 años, y de 8 a 10 años con valores entre 40 y $45 \mathrm{Kg} / \mathrm{m}^{2}$.

En nuestro país, según datos del 2012 y disponibles en la página web del Instituto Nacional de Estadística (86), se puede extrapolar la mortalidad y los APVP derivados de las CAO en función de los valores correspondientes a las enfermedades endocrino- 
nutricionales y a las enfermedades cardiovasculares, puesto que la página web no da opción a realizar un filtro específico por obesidad [Véanse tablas 7 y 8]. Oliva et al. (87) cifraron en 28000 muertes anuales atribuibles al sobrepeso y la obesidad (un 8,5\% del total) en España.

Tabla 7. Defunciones por 100.000 habitantes, para todas las edades y en ambos sexos, España, año 2012. Fuente: Instituto Nacional de Estadística (86).

\begin{tabular}{|c|c|}
\hline \multicolumn{2}{|c|}{ DEFUNCIONES POR 100.000 HABITANTES } \\
\hline $\begin{array}{c}\text { Enfermedades nutricionales, endocrinas y } \\
\text { metabólicas }\end{array}$ & 27,42 \\
\hline Infarto Agudo de Miocardio & 37,73 \\
\hline Aterosclerosis & 3,83 \\
\hline
\end{tabular}

Tabla 8. Media de APVP por etiología y sexo, para todas las edades, España, año 2012. Fuente: Instituto Nacional de Estadística (86).

\begin{tabular}{|c|c|c|}
\hline \multicolumn{3}{|c|}{ MEDIA DE APVP EN ESPAÑA } \\
\hline ETIOLOGÍA & VARONES & MUJERES \\
\hline $\begin{array}{c}\text { Enfermedades endocrinas, nutricionales y } \\
\text { metabólicas }\end{array}$ & 12,3 & 9,1 \\
\hline Enfermedades del sistema circulatorio & 12,1 & 9,7 \\
\hline
\end{tabular}

Por último, la estimación del coste sanitario de la obesidad en nuestro país fue de un 7\% del gasto sanitario en 2004 (87). Previamente, en el año 2002, se publicaron los resultados actualizados del estudio Delphi sobre "Costes sociales y económicos de la obesidad y sus patologías asociadas" (88), que se pueden ver en la tabla 9. 
Tabla 9. Costes directos e indirectos de la obesidad y enfermedades asociadas en España (en millones de euros), según el estudio Delphi del año 2002 (88).

\begin{tabular}{|c|c|c|c|c|}
\hline \multicolumn{6}{|c|}{ ESTUDIO DELPHI. COSTES DE LA OBESIDAD EN ESPAÑ. 2002 } \\
\hline ENFERMEDAD & $\begin{array}{c}\text { COSTES } \\
\text { DIRECTOS }\end{array}$ & $\begin{array}{c}\text { COSTES } \\
\text { INDIRECTOS }\end{array}$ & $\begin{array}{c}\text { COSTE } \\
\text { TOTAL }\end{array}$ & $\%$ \\
\hline Cardiovascular & 344,97 & 221,48 & 566,45 & 22,6 \\
\hline Musculoesquelética & 3,03 & 22,02 & 25,06 & 1 \\
\hline DM & 184,15 & 41,37 & 225,52 & 9 \\
\hline DL & 59,89 & 0 & 59,89 & 2,4 \\
\hline Obesidad per se & 28,30 & 1606,04 & 1634,34 & 65 \\
\hline TOTAL & 620 & 1890,92 & 2507,60 & 100 \\
\hline
\end{tabular}




\section{3.- COMORBILIDADES ASOCIADAS A LA OBESIDAD}

Tal y como se ha citado anteriormente, el sobrepeso y la obesidad se asocian a una amplia serie de entidades clínicas, las cuales se desarrollan como consecuencia del exceso de adiposidad, aunque su patogenia está mediada por otros tantos mecanismos que se encuentran alterados en los obesos. A mayor adiposidad, mayor es el riesgo de sufrir estas CAO (48), debiéndose tener en cuenta el efecto deletéreo de la OA como factor favorecedor de muchas de ellas, aún con IMC en rango normal [Véanse tablas 10 y 11].

Tabla 10. Estratificación del riesgo de aparición de CAO según el IMC correlacionado con la CC. Tomado del documento de consenso de 2007 de la SEEDO (4).

\begin{tabular}{|c|c|c|}
\hline \multicolumn{2}{|c|}{ RIEGO DE APARICIÓN DE CAO SEGÚN IMC Y CC } \\
\hline \multirow{2}{*}{$\begin{array}{c}\text { IMC } \\
\left(\mathrm{Kg} / \mathrm{m}^{2}\right)\end{array}$} & $\begin{array}{c}\text { HOMBRES }<102 \mathrm{~cm} \\
\text { MUJERES }<88 \mathrm{~cm}\end{array}$ & $\begin{array}{c}\text { HOMBRES }>102 \mathrm{~cm} \\
\text { MUJERES }>88 \mathrm{~cm}\end{array}$ \\
\cline { 2 - 3 } & Ninguno & Ligeramente aumentado \\
\hline $18,5-24,9$ & Aumentado & Aumentado \\
\hline $35,0-29,9$ & Ligeramente aumentado & Alto \\
\hline $35,0-39,9$ & Alto & Muy alto \\
\hline$>40$ & Muy alto & Muy alto \\
\hline
\end{tabular}


Tabla 11. RR (con IC 95\%) de aparición de algunas CAO, según el IMC y el sexo. Tomado de Guh et al. (89). [n.a.: no aplicable].

\begin{tabular}{|c|c|c|c|c|}
\hline \multicolumn{5}{|c|}{ RIESGO RELATIVO DE CAO SEGÚN EL IMC Y SEXO } \\
\hline \multirow{2}{*}{$\mathrm{CAO}$} & \multicolumn{2}{|c|}{ SOBREPESO } & \multicolumn{2}{|c|}{ OBESIDAD } \\
\hline & VARONES & MUJERES & VARONES & MUJERES \\
\hline DM2 & $\begin{array}{c}2,40 \\
(2,12-2,72)\end{array}$ & $\begin{array}{c}3,92 \\
(3,10-4,97)\end{array}$ & $\begin{array}{c}6,74 \\
(5,55-8,19)\end{array}$ & $\begin{array}{c}12,41 \\
(9,03-17,06)\end{array}$ \\
\hline $\begin{array}{c}\text { Cáncer de } \\
\text { mama }\end{array}$ & n.a. & $\begin{array}{c}1,08 \\
(1,03-1,14)\end{array}$ & n.a. & $\begin{array}{c}1,13 \\
(1,05-1,22)\end{array}$ \\
\hline $\begin{array}{c}\text { Cáncer } \\
\text { colorrectal }\end{array}$ & $\begin{array}{c}1,51 \\
(1,37-1,67)\end{array}$ & $\begin{array}{c}1,45 \\
(1,30-1,62)\end{array}$ & $\begin{array}{c}1,95 \\
(1,59-2,39)\end{array}$ & $\begin{array}{c}1.66 \\
(1,52-1,81)\end{array}$ \\
\hline $\begin{array}{l}\text { Cáncer de } \\
\text { endometrio }\end{array}$ & n.a. & $\begin{array}{c}1,53 \\
(1,45-1,61)\end{array}$ & n.a. & $\begin{array}{c}3,22 \\
(2,91-3,56)\end{array}$ \\
\hline $\begin{array}{l}\text { Cáncer de } \\
\text { esófago }\end{array}$ & $\begin{array}{c}1,13 \\
(1,02-1,26) \\
\end{array}$ & $\begin{array}{c}1,15 \\
(0,97-1,36) \\
\end{array}$ & $\begin{array}{c}1,21 \\
(0,97-1,52) \\
\end{array}$ & $\begin{array}{c}1,20 \\
(0,95-1,53)\end{array}$ \\
\hline $\begin{array}{l}\text { Cáncer de } \\
\text { riñón }\end{array}$ & $\begin{array}{c}1,40 \\
(1,31-1,49)\end{array}$ & $\begin{array}{c}1,82 \\
(1,68-1,98)\end{array}$ & $\begin{array}{c}1,82 \\
(1,61-2,05)\end{array}$ & $\begin{array}{c}2,64 \\
(2,39-2,90)\end{array}$ \\
\hline $\begin{array}{c}\text { Cáncer de } \\
\text { ovario }\end{array}$ & n.a. & $\begin{array}{c}1,18 \\
(1,12-1,23) \\
\end{array}$ & n.a. & $\begin{array}{c}1,28 \\
(1,20-1,36)\end{array}$ \\
\hline $\begin{array}{l}\text { Cáncer de } \\
\text { páncreas }\end{array}$ & $\begin{array}{c}1,28 \\
(0,94-1,75)\end{array}$ & $\begin{array}{c}1,24 \\
(0,98-1,56)\end{array}$ & $\begin{array}{c}2,29 \\
(1,65-3,19)\end{array}$ & $\begin{array}{c}1,60 \\
(1,17-2,20)\end{array}$ \\
\hline $\begin{array}{l}\text { Cáncer de } \\
\text { próstata }\end{array}$ & $\begin{array}{c}1,14 \\
(1,00-1,31)\end{array}$ & n.a. & $\begin{array}{c}1,05 \\
(0,85-1,30)\end{array}$ & n.a. \\
\hline HTA & $\begin{array}{c}1,28 \\
(1,10-1,50) \\
\end{array}$ & $\begin{array}{c}1,65 \\
(1,24-2,19) \\
\end{array}$ & $\begin{array}{c}1,84 \\
(1,51-2,24) \\
\end{array}$ & $\begin{array}{c}2,42 \\
(1,59-3,67) \\
\end{array}$ \\
\hline $\begin{array}{c}\text { Enfermedad } \\
\text { coronaria }\end{array}$ & $\begin{array}{c}1,29 \\
(1,18-1,41) \\
\end{array}$ & $\begin{array}{c}1,80 \\
(1,64-1,98) \\
\end{array}$ & $\begin{array}{c}1,72 \\
(1,51-1,96) \\
\end{array}$ & $\begin{array}{c}3,10 \\
(2,81-3,43)\end{array}$ \\
\hline $\begin{array}{c}\text { Insuficiencia } \\
\text { cardiaca }\end{array}$ & $\begin{array}{c}1,31 \\
(0,96-1,79)\end{array}$ & $\begin{array}{c}1,27 \\
(0,68-2,37)\end{array}$ & $\begin{array}{c}1,79 \\
(1,24-2,59)\end{array}$ & $\begin{array}{c}1,78 \\
(1,07-2,95)\end{array}$ \\
\hline $\begin{array}{l}\text { Tromboem- } \\
\text { bolismo }\end{array}$ & $\begin{array}{c}1,91 \\
(1,39-2,64)\end{array}$ & $\begin{array}{c}1,91 \\
(1,39-2,64)\end{array}$ & $\begin{array}{c}3,51 \\
(2,61-4,73)\end{array}$ & $\begin{array}{c}3,51 \\
(2,61-4,73)\end{array}$ \\
\hline ACV & $\begin{array}{c}1,23 \\
(1,13-1,34)\end{array}$ & $\begin{array}{c}1,15 \\
(1,00-1,32)\end{array}$ & $\begin{array}{c}1,51 \\
(1,33-1,72)\end{array}$ & $\begin{array}{c}1,49 \\
(1,27-1,74)\end{array}$ \\
\hline Asma & $\begin{array}{c}1,20 \\
(1,08-1,33)\end{array}$ & $\begin{array}{c}1,25 \\
(1,05-1,49)\end{array}$ & $\begin{array}{c}1,43 \\
(1,14-1,79)\end{array}$ & $\begin{array}{c}1,78 \\
(1,36-2,32)\end{array}$ \\
\hline Colelitiasis & $\begin{array}{c}1,09 \\
(0,87-1,37)\end{array}$ & $\begin{array}{c}1,44 \\
(1,05-1,98)\end{array}$ & $\begin{array}{c}1,43 \\
(1,04-1,96)\end{array}$ & $\begin{array}{c}2,32 \\
(1,17-4,57)\end{array}$ \\
\hline Osteoartritis & $\begin{array}{c}2,76 \\
(2,05-3,70)\end{array}$ & $\begin{array}{c}1,80 \\
(1,75-1,85)\end{array}$ & $\begin{array}{c}4,20 \\
(2,76-6,41)\end{array}$ & $\begin{array}{c}1,96 \\
(1,88-2,04)\end{array}$ \\
\hline $\begin{array}{c}\text { Dolor crónico } \\
\text { de espalda }\end{array}$ & $\begin{array}{c}1,59 \\
(1,34-1,89)\end{array}$ & $\begin{array}{c}1,59 \\
(1,34-1,89)\end{array}$ & $\begin{array}{c}2,81 \\
(2,27-3,48)\end{array}$ & $\begin{array}{c}2,81 \\
(2,27-3,48)\end{array}$ \\
\hline
\end{tabular}




\subsection{1.- PATOLOGÍA ENDOCRINO-METABÓLICA}

Es imprescindible tener presente, al desarrollar la patología endocrino-metabólica en el obeso, la estrecha relación entre ambas, ya sea como causa o como consecuencia. Muchos de los ejes y componentes del sistema endocrino pueden encontrarse alterados en el contexto de la OM [Véase tabla 12]. Sin embargo, tres son las CAO de este grupo que deben ser consideradas de forma especial: la DM, la dislipemia y la hiperuricemia. Las dos primeras están englobadas en el SM, motivo por el cual es necesario exponer su base etiológica como punto de partida.

Tabla 12. Principales endocrinopatías y metabolopatías asociadas a la obesidad. Modificado de Álvarez-Castro et al. (90) y de Forga et al. (91).

\begin{tabular}{|c|l|}
\hline \multicolumn{2}{|c|}{ PRINCIPALES CAO ENDOCRINO-METABÓLICAS } \\
\hline $\begin{array}{c}\text { EJE O GLÁNDULA } \\
\text { AFECTA }\end{array}$ & \multicolumn{1}{c|}{ ALTERACIÓN } \\
\hline $\begin{array}{c}\text { Hipotálamo- } \\
\text { hipfisario-suprarrenal }\end{array}$ & $\begin{array}{l}\text { Aumento de cortisol libre urinario y cortisol } \\
\text { plasmático normal. }\end{array}$ \\
\hline $\begin{array}{c}\text { Hipotálamo- } \\
\text { hipofisario-gonadal }\end{array}$ & $\begin{array}{l}\text { Descenso de proteínas trasportadoras, mayor } \\
\text { aromatización de andrógenos en tejido adiposo } \\
\text { Mujer: aumento de estradiol libre y testosterona } \\
\text { libre } \\
\text { Hombre: descenso de testosterona total y libre, } \\
\text { aumento de estrógenos }\end{array}$ \\
\hline $\begin{array}{c}\text { Otras hormonas } \\
\text { hipofisarias }\end{array}$ & $\begin{array}{l}\text { Vasopresina: basal normal, que no se inhibe tras } \\
\text { sobrecarga hídrica. } \\
\text { Prolactina: menor respuesta a los inductores de su } \\
\text { síntesis } \\
\text { Hormona del crecimiento: disminución de basal y } \\
\text { tras estímulo, insulin growing factor 1 (IGF-1) total } \\
\text { menor, IGF-1 libre mayor }\end{array}$ \\
\hline Páncreas endocrino & $\begin{array}{l}\text { Hiperinsulinemia con RI y pulsatilidad alterada en } \\
\text { la células } \beta\end{array}$ \\
\hline Tiroides & Aumento de TSH y T3 libre \\
\hline Paratiroides & Aumento de parathormona (PTH) \\
\hline Metabolismo & Dislipemia, hiperuricemia \\
\hline
\end{tabular}




\subsubsection{1.- Definición y etiopatogenia del síndrome metabólico}

La asociación entre obesidad, hipertensión arterial (HTA), e hiperglucemia ya se postulaba desde los años 20 del siglo pasado (92), pero no fue hasta el año 1988 cuando G. Reaven estableció la asociación de diversos factores de riesgo cardiovascular (RCV) con la RI y acuñó el término de síndrome X (93), el cual es conocido actualmente y a nivel global como SM. Su epidemiología es variable según los numerosos estudios publicados, aunque hasta un cuarto de la población adulta mundial lo presenta (92).

Una cierta predisposición genética, unida a factores ambientales desencadenantes, son los mecanismos etiopatogénicos que dan lugar a la RI, núcleo central en torno al cual se desarrollan los cuatro componentes del SM (OA, HTA, alteración del metabolismo hidrocarbonado y dislipemia) (92):

- Factores genéticos. No está demostrado que existan genes implicados per se en el desarrollo directo del SM, sino que cada uno de los componentes del mismo tiene su trasfondo genético susceptible de sufrir mutaciones [Véase epígrafe 1.1.3.1.- Factores genéticos].

- Dieta hipercalórica y acúmulo graso. Esta situación induce un exceso plasmático de ácido grasos libres, los cuales alteran la función de la célula $\beta$ del islote pancreático, así como la captación periférica de glucosa.

- Alteración de las adipocinas. Sus consecuencias bioquímico-metabólicas ya han sido analizadas con anterioridad.

- Estado inflamatorio leve crónico y de estrés oxidativo. Ello es debido al incremento de las citocinas proinflamatorias y los ROS, puesto que alteran la sensibilidad del receptor de insulina o la cascada de señalización 
intracelular posterior [Véase epígrafe 1.1.3.1.- Factores neurohumorales y hormonales].

Las consecuencias bioquímicas de la RI en el organismo son, a su vez, factores que cierran el círculo vicioso del SM. Se define como RI al estado metabólico en el cual la concentración normal de insulina no induce una respuesta suficiente en los órganos diana, encargados de captar la glucosa plasmática, ya sea para la glucogenogénesis (en el músculo e hígado) o para la lipogénesis (en el tejido adiposo). Este estado estimula una mayor síntesis y liberación de insulina por parte de la célula $\beta$ del páncreas (hiperinsulinemia), a fin de mantener la normoglucemia. Si este estado se mantiene en el tiempo, da lugar al agotamiento funcional del islote pancreático y al desarrollo subsiguiente de DM2 (92). Asimismo, la trascendencia clínica del SM y la RI es notable y está reflejada en la tabla 13.

Tabla 13. Entidades clínicas asociadas al SM y a la RI. Modificado de Kaur et al. (92).

\begin{tabular}{|c|c|}
\hline \multicolumn{2}{|c|}{ ENTIDADES CLÍNICAS ASOCIADAS AL SM Y RI } \\
\hline $\begin{array}{l}\text { ÓRGANO O } \\
\text { SISTEMA }\end{array}$ & ALTERACIÓN \\
\hline Renal & $\begin{array}{l}\text { Microalbuminuria, glomeruloesclerosis focal y } \\
\text { segmentaria, enfermedad renal crónica }\end{array}$ \\
\hline Hepática & Elevación de transaminasas, NAFLD \\
\hline Piel & $\begin{array}{l}\text { Acantosis nigricans, liquen plano, lupus } \\
\text { eritematoso sistémico, psoriasis, alopecia } \\
\text { androgenética, estrías, acné inversa }\end{array}$ \\
\hline Oftálmico & $\begin{array}{l}\text { Retinopatía ocular no diabética, cataratas } \\
\text { relacionadas con la edad y subcapsulares } \\
\text { posteriores, oclusión de arteria central de la } \\
\text { retina, glaucoma primario de ángulo abierto, } \\
\text { parálisis del nervio motor ocular común, } \\
\text { entropion inferior }\end{array}$ \\
\hline Genito-urinario & $\begin{array}{l}\text { Hipogonadismo, síndrome de ovario } \\
\text { poliquístico, disfunción eréctil }\end{array}$ \\
\hline Cardiorrespiratorio & SAOS, cardiopatía isquémica, ACV \\
\hline Neoplasias & Mama, páncreas, próstata \\
\hline
\end{tabular}


En términos de mortalidad, la conjunción de los factores de RCV de esta entidad parece conferir una mayor predisposición para sufrir eventos fatales que cada uno de ellos individualmente.

Finalmente, en relación a los criterios diagnósticos del SM, debemos saber que éstos varían según las guías de las distintas sociedades científicas, siendo las más relevantes:

- National Cholesterol Education Program-Adult Treatment Panel (ATP-III), 2001 (94). $\mathrm{Al}$ menos tres de los siguientes:

- $\quad \mathrm{CC}>102 \mathrm{~cm}$ en hombres y $>88 \mathrm{~cm}$ en mujeres.

- Triacilgliceroles/triglicéridos (TAG) séricos $\geq 150$ miligramos $(\mathrm{mg}) /$ decilitro (dl).

- Colesterol high density lipoprotein (HDL) $<40 \mathrm{mg} / \mathrm{dl}$ en hombres y $<50 \mathrm{mg} / \mathrm{dl}$ en mujeres.

- Presión arterial (PA) $\geq 130 / 85$ milímetros de mercurio (mmHg).

- Glucosa en ayunas $>110 \mathrm{mg} / \mathrm{dl}$.

- International Diabetes Federation, 2005 (95). OA, definida como CC $\geq 94 \mathrm{~cm}$ para hombres y $\geq 80 \mathrm{~cm}$ para mujeres de raza caucásica (con distintos valores para otras razas) y al menos dos de los siguientes:

- $\mathrm{TAG} \geq 150 \mathrm{mg} / \mathrm{dl}$ o en tratamiento hipolipemiante.

- HDL $<40 \mathrm{mg} / \mathrm{dl}$ en hombres y $<50 \mathrm{mg} / \mathrm{dl}$ en mujeres, o en tratamiento hipolipemiante.

- $\mathrm{PA} \geq 135 / 85 \mathrm{mmHg}$ o tratamiento antihipertensivo.

- Glucosa en ayunas $\geq 100 \mathrm{mg} / \mathrm{dl}$ (recomendando realizar test de tolerancia oral) o DM2 previamente diagnosticada. 
- Consenso mundial del año 2009 publicado en la revista Circulation por Alberti et al. (96). Presencia de 3 de los siguientes:

- Incremento de la CC por encima de los valores establecidos según la raza.

- $\mathrm{TAG} \geq 150 \mathrm{mg} / \mathrm{dL}$ o toma de medicación.

- HDL $<40 \mathrm{mg} / \mathrm{dl}$ en varones o $<50 \mathrm{mg} / \mathrm{dl}$ en mujeres o toma de medicación.

- PA sistólica $\geq 130 \mathrm{mmgHg}$ y/o PA diastólica $\geq 85 \mathrm{mmHg}$ o toma de medicación.

- Glucemia en ayunas $\geq 100 \mathrm{mg} / \mathrm{dl}$ o toma de medicación.

\subsubsection{2.- Diabetes mellitus}

Se considera DM a la entidad clínica en la que existe una alteración del metabolismo de la glucosa con aparición de hiperglucemia y en última medida de glucosuria, cuya causa radica en dos mecanismos diferentes según el tipo de DM:

- DM1. Ausencia de insulina secundaria a la destrucción de las células $\beta$ pancreáticas (de origen autoinmune en la mayoría de los casos).

- DM2. Mediado por RI, como se acaba de exponer en el epígrafe anterior.

El diagnóstico, sea cual sea su tipo, viene dado por los criterios de la American Diabetes Association (97), de modo que si se demuestra la existencia de cualquiera de ellos, y se confirma tras repetir el mismo test, el paciente debe ser diagnosticado de DM. Estos criterios son:

- Glucemia en ayunas $\geq 126 \mathrm{mg} / \mathrm{dl}$.

- Hemoglobina glicosilada (HbA1C) $\geq 6,5 \%$. 
- Glucemia a las 2 horas $\geq 200 \mathrm{mg} / \mathrm{dl}$ en el test de tolerancia oral, con una carga de 75 gr de glucosa.

- Hallazgo casual de glucemia plasmática $\geq 200 \mathrm{mg} / \mathrm{dl}$, en presencia de síntomas.

La DM2 supone el 90\% de todos los casos de DM y tiene una prevalencia global en la población adulta mundial del $9,8 \%$ en varones y 9,2\% en mujeres (con amplias diferencias entre países), según el artículo publicado en The Lancet en 2011 (98). La DM2 posee relación con un gran número de situaciones clínicas, así como con factores modificables y no modificables (99): sexo, edad, componente genético-hereditario y racial y componente pre y neonatal. No obstante, de todos los mecanismos causales de esta patología, se considera que el exceso de adiposidad corporal, especialmente la $\mathrm{OA}$, es el principal factor etiológico de la misma. Numerosos estudios confirman esta asociación, como por ejemplo el reciente estudio OBEDIA llevado a cabo en nuestro país (100): el $23,6 \%$ de los individuos con IMC $>25 \mathrm{Kg} / \mathrm{m}^{2}$ presentaba DM2, al tiempo que en el 17,8\% y $34,8 \%$ de los diabéticos tipo 2 , su IMC se encontraba en rango de sobrepeso y obesidad, respectivamente. Tras ajustar por IMC, la dislipidemia fue el factor de riesgo más frecuente (92,6\%), seguido de HTA $(73,7 \%)$ y la escasa actividad física $(62,5 \%)$.

Las consecuencias de la DM2 y la obesidad en términos de mortalidad global y específica cardiovascular no han sido totalmente aclaradas. Varios artículos sostienen la existencia de la "paradoja de la obesidad" en referencia a la asociación de estas dos entidades, de tal modo que en pacientes con DM2 habría menor mortalidad a mayor IMC. Un reciente meta-análisis del European Journal of Epidemiology publicado en 2014 (101) habla a favor de ello, al obtener un $\mathrm{RR}=0,72$ para mortalidad por cualquier causa en individuos 
con DM2 e IMC $>30 \mathrm{Kg} / \mathrm{m}^{2}$ frente al grupo de IMC en rango normal, concluyendo que el incremento de adiposidad se comporta como factor protector en los diabéticos tipo 2, con una reducción del riesgo de mortalidad global en un $5 \%$ por cada $5 \mathrm{Kg} / \mathrm{m}^{2}$ que se gana. Contrastando con este trabajo, en un artículo del mismo año publicado en New England Journal of Medicine y que empleó datos de la cohorte del Nurses' Health Study (102), no se obtuvieron diferencias de mortalidad entre las diabéticas en normopeso respecto a aquellas con IMC elevado.

\subsubsection{3.- Dislipemia}

La alteración del perfil lipídico concurre frecuentemente con la existencia de sobrepeso y obesidad y se caracteriza por el incremento plasmático de TAG, la disminución de HDL y un aumento de low density lipoprotein (LDL) (103,104).

Todas estas alteraciones lipídicas están consideradas como factores de RCV (la llamada "triada lipídica aterogénica"), pero se ha demostrado claramente que el mayor potencial corresponde al descenso de HDL, aún incluso en pacientes con LDL baja, puesto que aquella es la lipoproteína encargada del trasporte reverso de colesterol, desde tejidos periféricos al hígado para su metabolismo y eliminación, con lo que ejerce una función cardioprotectora $(103,104)$. Parece ser que las HDL de los obesos y de los individuos con SM pierden parcialmente esta capacidad (104).

El fenotipo lipídico en plasma del obeso es superponible al que acontece en el SM, de tal modo que existe un nexo común en el mecanismo y que no es otro que la RI (104). El estado de hiperinsulinemia y RI implica una disregulación de dos enzimas clave en el metabolismo de las grasas, la lipasa sensible a hormonas y la lipoproteinlipasa, y cuyos 
efectos son la hipertrigliceridemia y la ausencia de inhibición de la lipólisis, con lo que se eleva la concentración sérica de ácidos grasos libres. Esta situación se ve igualmente favorecida por la adiposidad incrementada, especialmente la OA, ya que la grasa visceral, al contrario que la grasa subcutánea, es más lipolítica y menos reactiva a la acción lipogénica de la insulina (105). Todo ello genera una estimulación de la síntesis de VLDL y un decremento de HDL, este último causado por el exceso circulante de TAG, el menor aclaramiento de VLDL, la hipertrigliceridemia y la estimulación de la transferasa de ésteres de colesterol desde las HDL a las lipoproteínas ricas en TAG (quilomicrones y VLDL).

\subsubsection{4.- Hiperuricemia}

El metabolismo del ácido úrico tiene origen en la degradación de las purinas, siendo endógeno dos tercios del mismo, frente al tercio restante que procede de la dieta, especialmente de las carnes rojas, pescados, mariscos, alcohol (preferentemente la cerveza) y las bebidas azucaradas (en concreto de aquellas con fructosa) $(106,107)$. La hiperuricemia es el sustrato fisiopatológico que origina la gota por depósito de los cristales de urato, y ambas situaciones clínicas se correlacionan con otras enfermedades, como la litiasis renal, la insuficiencia renal crónica y también con la obesidad y el SM. En el caso de la obesidad, se ha demostrado su asociación con la hiperuricemia mediada por exceso de síntesis y por menor eliminación renal, mientras que para el SM, el exceso plasmático de uratos es inductor de RI, al desencadenar estrés oxidativo a nivel de las células $\beta$ pancreáticas, de los adipocitos blancos y de los hepatocitos e inhibición de la síntesis de adiponectina (107). La hiperinsulinemia, a su vez, parece bloquear la excreción renal de uratos.

Así pues, y según diversos estudios, la hiperuricemia es un predictor independiente de la DM, de non-alcoholic fatty liver disease (NAFLD), de obesidad y de HTA (107). Aunque la 
prevalencia es variable según las series, el SM está presente hasta en el $76 \%$ de los individuos con hiperuricemia (108). Asimismo, existe una asociación de algunos de los componentes del SM con la hiperuricemia y la gota. Según datos del estudio THIN del Reino Unido (109), el IMC $>30 \mathrm{Kg} / \mathrm{m}^{2}$ y la HTA implican una odds ratio (OR) de sufrir gota del 2,34 y 1,18, respectivamente, mientras que la DM constituye un factor protector de gota que parece estar mediado por el efecto de diuresis osmótica inducido por la glucosuria.

\subsection{2.- PATOLOGÍA CARDIOVASCULAR}

La enfermedad cardiovascular en la OM tiene una gran trascendencia y un amplio espectro que incluye desde la HTA hasta la enfermedad coronaria y otras patologías cardiacas, sin olvidar el accidente cerebro-vascular (ACV). Es importante reseñar que el exceso de peso es, precisamente, el factor de riesgo más prevalente implicado en el desarrollo de enfermedad cardiovascular (110) y que ésta es la primera causa de muerte en los países desarrollados (72). Sin embargo, y en relación con el riesgo de mortalidad secundario a la enfermedad cardiovascular en la OM, es necesario retomar, nuevamente, el fenómeno de la "paradoja de la obesidad", aunque no esté completamente aclarado [Véase epígrafe 1.1.1.1.- Índice de masa corporal]. Según el meta-análisis de Niedziela et al. publicado en 2014 (45), en obesos con enfermedad coronaria, la mortalidad presenta un $\mathrm{RR}=0,6$ para IMC en rangos superiores al normopeso.

La patogenia del incremento de RCV es diversa y compleja, englobando e interrelacionando este grupo de $\mathrm{CAO}$ con otras que se explicarán en los siguientes epígrafes. De forma sucinta, se presentan a continuación estos mecanismos patogénicos $(91,111-113):$ 
- Lesión vascular directa y aterogénesis. La alteración de los valores plasmáticos de adipocinas en los obesos, unida a la dislipemia, favorece el depósito lipídico y cálcico en la capa media de las arterias, estableciéndose así la aterosclerosis. De igual modo, el estado protrombótico e hipofibrinolítico mediado por el incremento de proteína $\mathrm{C}$ reactiva, del inhibidor del activador del plasminógeno, de fibrinógeno y de los tromboxanos pueden desencadenar trombosis sobre una placa de ateroma, dando lugar a un evento vascular agudo, ya sea en el territorio cerebral (ACV) o en las arterias coronarias (IAM).

- Predominio de la vasoconstricción. El incremento del tono simpático y la activación del sistema renina-angiotensina-aldosterona típicos de los obesos, ejerce un efecto vasocontrictor. Asimismo, se produce una disfunción de la vasodilatación mediada por óxido nítrico: reducción de la actividad de la óxido nítrico sintetasa endotelial e inactivación de esta molécula por el exceso de ROS existente en la obesidad.

- Alteración estructural y de la dinámica y excitabilidad cardiaca. Las modificaciones bioquímicas presentes en la obesidad, unido al propio depósito adiposo intra-cardiaco y pericárdico-epicárdico (adipositas cordis) induce modificaciones, no sólo de tipo mecánico, sino también de tipo eléctrico. Por otra parte, el estado de vasoconstricción induce un aumento de la postcarga, lo que, a su vez, favorece una hipertrofia ventricular izquierda. Estas situaciones dan lugar a largo plazo (más de 15 años) a una alteración estructural de este órgano con riesgo potencial de establecerse, finalmente, una insuficiencia cardiaca. 
Por todo lo expuesto, se detallan a continuación las CAO cardiovasculares de mayor relevancia:

- HTA. Se considera HTA a la presencia de cifras de PA sistólica >140 mmHg y/o diastólicas $>90 \mathrm{mmHg}$, según el Joint National Committee on Prevention, Detection, Evaluation, and Treatment of High Blood Pressure. Según este panel de expertos, la HTA repercute a largo plazo sobre los llamados órganos diana: corazón, SNC, riñón, sistema vascular. En cuanto a la relación con la obesidad, diversos estudios poblacionales ponen de manifiesto que ella es el factor de riesgo más importante para la aparición de cifras elevadas de PA. Así pues y según el estudio Framingham (114), el RR ajustado por edad para IMC $>25 \mathrm{Kg} / \mathrm{m}^{2}$ es 1,46 para varones y de 1,75 para mujeres, lo que se corresponde con un $34 \%$ y $62 \%$ de casos de HTA atribuibles al sobrepeso y la obesidad, respectivamente en cada sexo.

- Cardiopatía isquémica. Aunque el máximo riesgo atribuible para el desarrollo de IAM en la población corresponde a la dislipemia y al tabaco (49,2\% y $35,7 \%$, respectivamente), la obesidad contribuye al mismo con un 20,1\%, según los resultados que arrojó el estudio INTERHEART publicado en The Lancet en 2004 (115). Sin embargo, en el reciente análisis combinado de 1,8 millones de individuos publicado por la Global Burden of Metabolic Risk Factors for Chronic Diseases Collaboration en 2014 (116), apunta que es la HTA (seguido de la hiperglucemia) el principal mediador del efecto de la obesidad sobre la cardiopatía isquémica y la enfermedad cerebrovascular.

- Insuficiencia cardiaca. Este síndrome puede establecerse como consecuencia de los mecanismos previamente enumerados, aunque también por la propia cardiopatía isquémica. Según otros resultados procedentes 
también de la cohorte de Framingham (117), los obesos tienen un riesgo dos veces mayor de fallo cardiaco que los no obesos. A la inversa, se cumple que el $32-49 \%$ de los pacientes con insuficiencia cardiaca tienen IMC $\geq 30$ $\mathrm{Kg} / \mathrm{m}^{2}$ (118). Por último, existe una importante interrelación entre el síndrome de apnea obstructiva del sueño (SAOS), muy frecuente en obesos, y la génesis de la insuficiencia cardiaca, ya que la hipoxemia y la vasoconstricción del territorio vascular pulmonar favorece el fallo ventricular derecho [Véase epígrafe 1.3.2.- Patología respiratoria].

- Arritmias. Diversas alteraciones del trazado electrocardiográfico han sido descritas en individuos obesos, ya sean como manifestación de las anomalías estructurales cardiacas explicadas, ya como consecuencia del estado arritmogénico por la hipertonía simpática, la hiperglucemia y el exceso de ácidos grasos libres circulantes (119). La arritmia más característica del obeso es la fibrilación auricular, y según el estudio de Wang et al. (120), existe una HR de 1,52 y 1,46 en varones y mujeres, respectivamente. La aparición de esta arritmia en obesos va ligada a la presencia de la citada alteración estructural cardiaca, concretamente de dilatación auricular izquierda (120).

- Enfermedad cerebrovascular. Diversos estudios ponen de manifiesto el riesgo incrementado de ACV en obesos, como por ejemplo el Nurses' Health Study, con un resultado de $\mathrm{RR}=2,37$ para $\mathrm{IMC}>32 \mathrm{Kg} / \mathrm{m}^{2}$. Además, el ACV de los obesos acontece a edades más tempranas (121). Sin embargo, la relación de la obesidad con la aparición de $\mathrm{ACV}$, no parece ser directa a la luz del reciente artículo de la Global Burden of Metabolic Risk Factors for Chronic Diseases Collaboration (116), ya citado anteriormente. La HTA, junto con la 
DM y la dislipemia, el nexo que une obesidad con enfermedad cerebrovascular, obteniendo un $76 \%$ el exceso de riesgo de ACV por obesidad debido a estos tres factores. En la misma línea, en el estudio de cohortes español EPIC publicado en 2014 por Abete et al. (122), no encontró asociación del IMC con mayor incidencia de ACV, mientras que la CC y el ICC sí se asocian con esta entidad clínica pero sólo en varones.

- Enfermedad tromboembólica. El estado protrombótico ya citado junto con los mecanismos puramente mecánicos del obeso (la insuficiencia y estasis venosas secundarias a la OA, escasa movilidad del obeso por CAO de tipo osteoarticular, etc.) favorecen esta entidad (113). El reciente estudio poblacional danés de Klovaite et al. (123) concluyó que la HR de trombosis venosa profunda (TVP) y de TVP complicada con tromboembolismo pulmonar (TEP) para individuos con OM fue de 3,4 y de 5,1, respectivamente. Por su parte, la fibrilación auricular induce la génesis de trombos en la aurícula, los cuales pueden desprenderse y desencadenar un evento agudo de tipo cardioembólico (119).

\subsection{3.- PATOLOGÍA RESPIRATORIA}

En los obesos se producen una serie de anomalías de la mecánica ventilatoria, así como a nivel alveolar, que desencadenan las $\mathrm{CAO}$ del aparato respiratorio. Es necesario apuntar que la existencia de OA parece tener una relación más directa con la patología respiratoria que el IMC elevado, estando publicado que el incremento del ICC y de ICA son factores favorecedores para la aparición de este subgrupo de CAO (124). Aunque cada una de ellas presenta unos mecanismos patogénicos particulares, en términos generales se establecen los siguientes $(124,125)$ : 
- La limitación de las excursiones ventilatorias de la caja torácica parece ser el sustrato fisiopatológico fundamental, como consecuencia de la infiltración grasa de la musculatura respiratoria, del exceso de panículo adiposo de ésta y de la OA, que impide un completo descenso del diafragma. Existe, además, menor compliance pulmonar y un estado crónico de broncoespasmo. Por todo lo expuesto, se genera una situación de restricción que induce descensos del volumen tidal, de la capacidad residual funcional y de la reserva espiratoria, que son objetivables en la espirometría.

- La ventilación alveolar en obesos se encuentra minimizada en los campos pulmonares inferiores debido a microatelectasias, lo cual contrasta con la mejor vascularización de los mismos. Esta situación da lugar a una alteración del cociente ventilación-perfusión y genera un descenso del gradiente alveolo-arterial de $\mathrm{O}_{2}$ y cierto grado de hipoxemia, desencadenando taquipnea compensatoria.

De forma concreta, las patologías relacionadas con el aparato respiratorio y asociadas a la $\mathrm{OM}$ se analizan seguidamente:

- Asma $(125,126)$. La obesidad es factor de riesgo para el desarrollo de asma, al tiempo que los obesos asmáticos presentan mayor sintomatología y peor respuesta al tratamiento broncodilatador. El descenso de calibre de la vía aérea por infiltración grasa y la inflamación local persistente por citocinas proinflamatorias, con el broncoespasmo secundario, son la base patogénica del asma en los obesos, aunque en ellos existe una respuesta neutrofílica, a diferencia del asma alérgico de la población general, en el cual son los eosinófilos las células desencadenantes. 
- Sd. Pickwick (127). También conocido como síndrome de hipoventilaciónobesidad, es una entidad distinta del SAOS, aunque ambas suelen presentarse conjuntamente en el $90 \%$ de obesos. La prevalencia global de esta entidad clínica es 11-20\% en los Estados Unidos de América (EE.UU). Se define como la existencia de hipercapnia en vigilia (presión parcial arterial de $\mathrm{CO}_{2} \geq 45 \mathrm{mmHg}$ ) e hipoxemia (presión parcial arterial de $\mathrm{O}_{2}$ $\geq 70 \mathrm{mmHg}$ ) en ausencia de otras causas que lo justifiquen. Las consecuencias del Sd. Pickwick son: mayor obstrucción de la vía aérea superior, alteración de la mecánica respiratoria e hipertensión pulmonar, todo lo cual aboca a un incremento de mortalidad en los enfermos sin tratamiento que se ha cifrado hasta en un $46 \%$ a 50 meses.

- SAOS (81,127-130). La asociación entre el colapso intermitente de la vía aérea superior durante el sueño y el exceso de IMC ha sido analizado en numerosas publicaciones. Se calcula que hasta un $60 \%$ de obesos sufren SAOS y se ha encontrado un RR de 5 en varones y 2,5 en mujeres para presentar índices de apnea-hipopnea mayores de 15 cuando el individuo incrementa su peso en más de $10 \mathrm{Kg}$. En lo referente a los mecanismos que inducen SAOS en obesos, además del puro efecto mecánico de estrechamiento de la vía aérea superior por depósito adiposo, cabe citar la relación observada de la hipoxia intermitente secundaria a esta enfermedad con la hiperproducción de ROS y la estimulación de las cascadas bioquímicas de la inflamación. Ello favorece el desarrollo de RI, estableciéndose un círculo vicioso en el cual el incremento progresivo de la adiposidad del individuo provoca mayor severidad del SAOS y éste, a su vez, condicionaría empeoramiento del SM y elevación del IMC. Este 
fenómeno de coexistencia de SAOS y SM ha sido denominado por algunos autores como síndrome Z. Las consecuencias clínicas del SAOS son múltiples y afectan a diversos órganos y sistemas. Describir todas ellas escapa del objetivo de este trabajo, por lo que sólo se enumeran las más relevantes desde el punto de vista cardiovascular, por la relación con la obesidad: remodelado cardiaco con riesgo arritmogénico potencial, HTA con disfunción endotelial y aterogénesis.

\subsection{4.- PATOLOGÍA OSTEOARTICULAR}

Las enfermedades del aparato locomotor son también un grupo de relevancia dentro de las CAO, y con consecuencias importantes para la calidad de vida de los obesos. En primer lugar es necesario mencionar la asociación de la obesidad con la osteoartritis o artrosis en articulaciones de carga, entidad clínica en la cual se produce una inflamación y degeneración del cartílago articular, provocando dolor y limitación funcional. Dicha relación se debe, entre otros mecanismos, al exceso de peso corporal soportado, y ha sido claramente demostrada en estudios poblacionales como el de Grotle et al. (131), estableciendo un $\mathrm{RR}=2,81$ de osteoartritis para $\mathrm{IMC}>30 \mathrm{Kg} / \mathrm{m}^{2}$ en la articulación de la rodilla. No obstante, el RR incrementado para la articulación de la cadera no fue estadísticamente significativo en este estudio. La osteoartritis, bajo ciertas condiciones, es indicación de sustitución protésica de la articulación afecta, habiéndose determinado un RR de artroplastia total de rodilla del 8,5 y del 32,7 en pacientes con IMC $>30 \mathrm{Kg} / \mathrm{m}^{2}$ y $>40$ $\mathrm{Kg} / \mathrm{m}^{2}$, respectivamente. (132).

Por otro lado, un punto de controversia ha sido la asociación entre obesidad y osteoporosis. Históricamente se preconizaba un efecto protector en relación a una 
densidad mineral ósea incrementada (133). Sin embargo, actualmente parece existir evidencia en sentido contrario, por ser un hueso de baja calidad merced a las adipocinas proinflamatorias y a la RI con DM2 y neuropatía secundaria; por lo que el riesgo de fracturas patológicas está incrementado en la población obesa (133).

La obesidad también es factor predisponente para sufrir traumatismos músculoesqueléticos (132). A pesar de que el exceso de tejido adiposo pudiera conferir una protección para las lesiones viscerales en el contexto de un politraumatismo grave, existe riesgo aumentado de mortalidad en los obesos politraumatizados. En este mismo sentido, otras entidades traumatológicas del aparato locomotor relacionadas con la obesidad son $(132,134)$ :

- En la extremidad superior: la tendinitis del manguito de los rotadores o el Sd. de túnel carpiano.

- En la extremidad inferior: la luxación de rodilla, la patología de menisco y la tendinitis del tendón de Aquiles, así como las deformidades óseas (genu valgum y genu recurvatum, especialmente en obesidad infantil).

- En la columna vertebral: incremento de patología discal, de estenosis de canal lumbar y de percepción de dolor de espalda, aunque no está completamente aclarado en la literatura.

Finalmente, resulta de interés exponer la relación de la obesidad con enfermedades reumáticas autoinmunes (artritis reumatoide, lupus sistémico, artritis psoriásica o espondilitis anquilosante), puesto que el estado proinflamatorio parece influir en ellas (80). 


\subsection{5.- PATOLOGÍA NEOPLÁSICA}

Se ha objetivado un incremento del riesgo de aparición de diversos cánceres en obesos de ambos sexos, y no sólo tumores sólidos, sino también neoplasias de los progenitores hematopoyéticos (135,136): cáncer de endometrio, cáncer colorrectal, adenocarcinoma esofágico y de la unión esófago-gástrica, de vesícula biliar, adenocarcinoma de páncreas, hepatocarcinoma, carcinoma de riñón y próstata, de ovario, de mama en mujeres postmenopaúsicas, papilar de tiroides, linfoma no Hodgkin, mieloma múltiple y otros que aún se encuentran en estudio. De todos ellos, el mayor número de publicaciones existentes conciernen al cáncer colorrectal y al de mama (135). En la tabla 14 se puede observar el riesgo de aparición de algunos de los citados tumores, según publicó un meta-análisis de 2008 en el que se analizaron más de 280.000 pacientes (137).

Tabla 14. RR de aparición de algunos tumores, según el sexo, asociado a un incremento en $5 \mathrm{Kg} / \mathrm{m}^{2}$ de IMC (137).

\begin{tabular}{|c|c|c|c|}
\hline \multicolumn{3}{|c|}{ RR DE CÁNCER POR INCREMENTO DE IMC EN $\mathbf{5 ~ K g} / \mathbf{m}^{2}$} \\
\hline \multicolumn{2}{|c|}{ VARONES } & NEOPLASIA & $\mathrm{RR}$ \\
\hline NEOPLASIA & $\mathrm{RR}$ & Endometrio & $1,59, \mathrm{p}<0,0001$ \\
\hline $\begin{array}{c}\text { Adenocarcinoma } \\
\text { de esófago }\end{array}$ & $1,52, \mathrm{p}<0,0001$ & Vesícula biliar & $1,59, \mathrm{p}=0,04$ \\
\hline Tiroides & $1,33, \mathrm{p}=0,02$ & $\begin{array}{c}\text { Adenocarcinoma } \\
\text { de esófago }\end{array}$ & $1,51, \mathrm{p}<0,0001$ \\
\hline Colon & $1,24, \mathrm{p}<0,0001$ & Renal & $1,34, \mathrm{p}<0,0001$ \\
\hline Renal & $1,24, \mathrm{p}<0,0001$ & & \\
\hline
\end{tabular}

Los mecanismos que generan esta asociación del sobrepeso y la obesidad con la aparición de neoplasias son complejos y se presentan, sucintamente, a continuación $(135,136)$ : 
- Situación de estrés oxidativo y de inflamación crónica. Su acción cancerígena está mediada por el daño directo de los ROS al DNA y la activación de oncogenes, tales como Ras.

- Incremento de factores de crecimiento como el IGF-1, en el contexto de la DM2, el hiperinsulinismo y la RI. El IGF-1 actúa sobre receptores de superficie de las vías del fosfatidil inositol y del mTOR, entre otras, favoreciendo la acción mitótica de genes reguladores del ciclo celular.

- Factores dietéticos, puesto que los ácidos grasos, especialmente los saturados, se asocian a un estado proinflamatorio y carcinogénico en el tubo digestivo y el hígado. El déficit de vitamina $\mathrm{D}$ es otro factor relacionado parcialmente con la dieta y frecuente en obesos, que se ha postulado como responsable de hasta el 20\% de los tumores en el contexto de la OM.

- Elevación plasmática de estrógenos y leptina con descenso de adiponectina. Los tumores hormono-sensibles, como el cáncer de mama en mujeres postmenopaúsicas o el carcinoma de endometrio, están relacionados con el exceso de estradiol circulante en mujeres obesas. La leptina, por su parte, posee capacidad para activar varias rutas de señalización, incluidas las citadas previamente para el IGF-1, además de poseer un efecto antiapoptótico. Por último, el decremento de adiponectina en obesos minimiza su acción antitumoral, antiinflamatoria y antiangiogénica, inductora de la apoptosis y de bloqueo de la cascada de la $M A P K$.

- Alteración de la microbiota intestinal en obesos. Este desequilibrio induce un exceso de fermentación de carbohidratos dando lugar a ácidos grasos con efecto proinflamatorio, al tiempo que metabolizan ácidos biliares, como 
el desoxicólico, que posee acción mutagénica demostrada sobre el colonocito.

La repercusión desde el punto de vista epidemiológico es notable, puesto que se ha establecido que, en EE.UU., hasta el 14\% y el 20\% de las muertes por cáncer en varones y mujeres, respectivamente, son debidas a la obesidad $(135,136)$. También es necesario añadir que la OM, además de asociarse a la aparición de tumores, es una situación clínica que dificulta su tratamiento, no sólo quirúrgico sino también oncológico. Tanto es así, que se ha demostrado la relación entre algunos de los mecanismos previamente expuestos y la génesis de resistencia a fármacos citostáticos empleados para quimioterapia (138).

\subsection{6.- PATOLOGÍA PSIQUIÁTRICA}

Las enfermedades mentales guardan relación con el sobrepeso y la obesidad, de tal modo que pueden encontrarse implicadas tanto en su etiología, como aparecer de forma secundaria al exceso de adiposidad, al tiempo que constituyen un factor clave para un potencial fracaso terapéutico, no sólo del tratamiento médico-dietético, sino también de la CB. No obstante, en la actualidad, la obesidad per se no está incluida como patología psiquiátrica en el Diagnostic and Statistic Manual 5th edition (DSM-5) (139).

Existen diversos mecanismos patogénicos que asocian la patología psiquiátrica con la obesidad y el SM, entre ellos las mutaciones tipo SNP en el gen del factor neurotrófico derivado del cerebro o el exceso de citocinas proinflamatorias, apareciendo una elevación de niveles de IL-6 en el trastorno depresivo y de TNF $\alpha$ en la esquizofrenia, como ejemplos más característicos (140). También es necesario recordar que algunos psicofármacos son inductores de obesidad secundaria [Véase epígrafe 1.1.3.- Etiología del sobrepeso y la 
obesidad]. Igualmente, está implicada la alteración de ciertos neurotransmisores y hormonas, a saber (140):

- Sistema serotoninérgico y dopaminérgico.

- Otros neurotransmisores hipotalámicos como el neuropéptido Y, cuyo déficit se relaciona también con la ansiedad, la esquizofrenia o el trastorno bipolar.

- Alteraciones en el eje hipotálamo-hipofisario-adrenal, estando demostrado un mayor nivel plasmático de cortisol en individuos con depresión mayor, al tiempo que la obesidad y el SM son estados que cursan con hipercortisolismo.

En primer lugar, el trastorno por atracones junto con el trastorno de abuso de sustancias (por analogía de los obesos que sufren sensación de adicción y búsqueda de comida con los individuos drogodependientes), se han postulado como los dos fenotipos conductuales psicológicos asociados etiológicamente con la obesidad (140,141). En el capítulo de los trastornos de la conducta alimentaria del DSM-5, se ha incluido el citado trastorno por atracones (en inglés, binge eating disorder) como categoría independiente de la bulimia (139).

En segundo lugar, la aparición de patología psiquiátrica como consecuencia de la obesidad está demostrada en numerosas publicaciones, especialmente para los trastornos afectivos. A medida que se incrementa la adiposidad corporal, pueden establecerse estos trastornos, en los que influyen la pérdida de autoestima, la dificultad para las relaciones sociales y hasta el rechazo colectivo hacia los obesos, abocando todo ello al desarrollo de depresión mayor, ansiedad, desorden borderline de la personalidad, estrés post-traumático, 
déficit de atención e hiperactividad, etc. Aunque las cifras varían según las series, se ha cuantificado que más de la mitad de los obesos candidatos a CB han sido diagnosticados de patología psiquiátrica en algún momento a lo largo de la vida $(140,141)$.

La asociación inversa también ha sido descrita, de modo que los enfermos mentales tienden a presentar valores de IMC en rango más elevado que la población general, estimándose esta cifra en el 45\%. De forma concreta, el trastorno bipolar y la esquizofrenia son las enfermedades mentales más relacionadas con la obesidad y el SM, aunque a ello contribuyen, en parte, los fármacos antipsicóticos y antidepresivos $(140,141)$.

\subsection{7.- PATOLOGÍA DIGESTIVA}

Como se ha explicado anteriormente, existe una clara asociación entre el aparato digestivo y la obesidad en lo referente a la etiopatogenia, influyendo el primero en los mecanismos de regulación del apetito y la saciedad y siendo el reservorio de aquellos microorganismos que recientemente se han implicado en la génesis de la misma [Véanse epígrafes 1.1.3.2.- Factores neurohumorales y hormonales y 1.1.3.3.- Factores microbiológicos]. Pero además, es necesario tener en cuenta la relación bidireccional existente, puesto que el exceso de adiposidad corporal induce, a su vez, la aparición de patología gastrointestinal y de las glándulas anejas (hígado, vía biliar y páncreas). Algunas de las patologías digestivas más frecuentes en el contexto de un paciente obeso son (142): el reflujo gastro-esofágico (RGE) con desarrollo a largo plazo de esófago de Barret (OR= 1,94 y 4,0, respectivamente), el hígado graso no alcohólico [más conocido por su denominación en inglés, non-alcoholic fatty liver disease (NAFLD)] con evolución potencial a cirrosis hepática $(R R=4,6$ y 4,1, respectivamente) y la enfermedad litiásica biliar $(R R=2,51$ y 2,32 en varones y mujeres, respectivamente); las cuales se desarrollarán seguidamente: 
- RGE. El estudio de 1999 de Locke et al. (143) obtuvo el siguiente resultado: un $30 \%$ de los individuos con IMC $>30 \mathrm{Kg} / \mathrm{m}^{2}$ presentan clínica semanal de RGE. La hiperpresión intraabdominal por el exceso de grasa visceral y OA (más que el propio IMC elevado) unida a una longitud acortada del segmento abdominal del esófago y a la frecuente existencia de hernia de hiato y/o trastornos motores esofágicos, son los mecanismos que inducen la aparición de esta entidad clínica, existiendo además en los obesos una hipersecrección ácida (142,144). El RGE y la exposición de la mucosa esofágica al ácido clorhídrico es 5 veces mayor en obesos (144), lo cual favorece la esofagitis erosiva, seguida de la metaplasia del epitelio (esófago de Barret), la displasia y finalmente, el adenocarcinoma (secuencia del profesor Correa). Otros artículos concluyen también que existe una mayor incidencia de RGE de tipo no ácido, motivo por el cual se justifica que los obesos con esta CAO son más refractarios al tratamiento con inhibidores de la bomba de protones (144).

- NAFLD. Esta enfermedad hepática, que cursa con acumúlo lipídico en el citoplasma hepatocitario, ha alcanzado la primera posición en frecuencia mundial, con más del 30\% de prevalencia en países desarrollados (145). La obesidad, en conjunción con la RI, el SM y la DM2 favorece el depósito graso en el hígado y, según ciertas series, hasta el 95\% de los obesos la presentan (142). A nivel bioquímico, el exceso de ácido grasos libres circulantes, las endotoxinas bacterianas procedentes del intestino por vía portal, la dislipemia y la lipogénesis incrementada, el estrés oxidativo y el estado inflamatorio crónico del obeso se han determinado como los mecanismos patogénicos, aunque la propia NAFLD se ha postulado como 
inductora per se de RI y aterogénesis, de tal modo que se establece un círculo vicioso (145). Hasta el 20-30\% de los casos de esteatosis evolucionan a esteatohepatitis, en la cual ya se demuestra la existencia de infiltrados inflamatorios de neutrófilos y linfocitos a nivel lobulillar y periportal en el estudio histopatológico $(91,142,145)$. A su vez, el 20-40\% de los enfermos con esteatohepatitis progresan hacia cirrosis, que es causa conocida de hepatocarcinoma; de modo que se ha cifrado en un tercio los casos de hepatocarcinoma en EE.UU. secundarios a NAFLD $(142,145)$.

- Enfermedad litiásica biliar. Por cada Kg de tejido adiposo que se gana, aumenta en $20 \mathrm{mg}$ la excreción biliar diaria de colesterol, siendo la bilis sobresaturada de esta molécula, la situación litogénica por antonomasia. Aquellos individuos con un peso superior al 50\% del ideal tienen 6 veces más de riesgo de colelitiasis $(91,146)$. Es importante remarcar también el potencial litogénico de una pérdida de peso demasiado rápida (mayor de 1,5 $\mathrm{Kg} / \mathrm{semana}$ ) como puede acontecer con dietas de muy bajas calorías y tras la CB (especialmente las técnicas malabsortivas y mixtas) (146), situaciones en las que se recomienda la administración de ácido ursodesoxicólico con el fin de minimizar la litogénesis, tal y como avala el meta-análisis de Uy et al. publicado en 2008 (147). A pesar de este dato, la colecistectomía profiláctica simultánea con la $\mathrm{CB}$ no está actualmente indicada, salvo colelitiasis sintomática previa o hallazgos anómalos en vesícula durante la cirugía (146).

También se han descrito otras entidades clínicas del tracto gastrointestinal que son favorecidas por la obesidad, entre ellas (142): gastritis erosiva con riesgo potencial de establecerse ulcus péptico (se ha postulado el déficit de adiponectina existente en los 
obesos como factor independiente de la misma); diarrea por tránsito acelerado y por alteración del metabolismo de las sales biliares, provocando cierto grado de malabsorción de lípidos con esteatorrea subsiguiente; celiaquía y enfermedad inflamatoria intestinal (resultados controvertidos en la literatura); enfermedad diverticular del colon con riesgo incrementado de diverticulitis de repetición y de hemorragia diverticular y, por último, la pancreatitis aguda con mayor incidencia en obesos de complicaciones locales y sistémicas, así como de mortalidad hospitalaria en el contexto de aquella. Finalmente, no se debe olvidar la patología digestiva maligna relacionada con la obesidad y que ya ha sido expuesta [Véase epígrafe 1.3.5.- Patología neoplásica].

\subsection{8.- OTRAS COMORBILIDADES}

Existe una pléyade de patologías asociadas a la obesidad que no han sido incluidas en los epígrafes anteriores, aunque no por ello revisten menor importancia. A continuación, se enumeran simplificadamente muchas de las restantes CAO $(91,128,132,148)$ :

- Genitourinarias: nefrolitiasis, incontinencia urinaria y ciertas glomerulonefritis, así como otras más propias de mujeres obesas: infertilidad, Sd. ovario poliquístico, alteración de la síntesis de gonadotropinas, patología obstétrica (diabetes gestacional, embarazos múltiples, preeclampsia, etc.).

- Neurológicas: psendotumor cerebri o demencia tipo Alzheimer y, también, la demencia vascular, como consecuencia de la aterosclerosis a nivel cerebral.

- Piel y anejos: estrías, acantosis nigricans, intertrigo e hirsutismo.

Finalmente, es necesario hacer mención del riesgo quirúrgico-anestésico incrementado de los obesos mórbidos debido, en gran medida, a muchas de las CAO ya citadas en los epígrafes anteriores. En los obesos existe mayor dificultad para la 
administración de anestesia locorregional y para la intubación oro-traqueal, así como para el propio manejo respiratorio durante la anestesia general, con posibilidad de requerir conexión prolongada a ventilación mecánica en el postoperatorio. Dentro de quirófano, se añaden numerosos inconvenientes en estos individuos: dificultad de posicionamiento del enfermo en la mesa de quirófano, imposibilidad de palpar las referencias óseas, inexactitud de medidas por magnificación en las pantallas de fluoroscopia, además de ser necesaria mayor dosis de radiación. Asimismo, existe un incremento de las complicaciones postquirúrgicas, en especial, TVP, TEP y retraso de la cicatrización con riesgo de infección del sitio quirúrgico. Respecto a esta última, cabe decir que, en general, los individuos con exceso de adiposidad presentan riesgo incrementado para sufrir infecciones en multitud de focalidades (respiratoria, urinaria, cutánea, abdominal, etc.) causadas por diversos agentes patógenos. El estado proinflamatorio crónico, la disregulación inmunitaria y el excesivo panículo adiposo son factores favorecedores $(91,148)$. 


\section{4.- TRATAMIENTO MÉDICO-DIETÉTICO DE LA}

\section{OBESIDAD}

El primer escalón terapéutico del sobrepeso y la obesidad lo integran un grupo de medidas conservadoras, que van desde el fomento de hábitos de vida saludables (evitando los factores nutricionales y de estilo de vida mencionados en el epígrafe homónimo) y la indicación de dietas hipocalóricas, hasta la administración de fármacos, los cuales inducen una reducción del peso corporal merced a distintos mecanismos de acción. En muchos de estos enfermos, sin embargo, el objetivo de tratamiento no es alcanzar el normopeso (especialmente aquellos con grados avanzados de obesidad), sino lograr un descenso de la adiposidad corporal que reduzca la incidencia de CAO y la morbimortalidad asociada. Ello se logra, generalmente, con una pérdida de peso de 3-5\% mantenida en el tiempo, la cual aporta reducción clínicamente significativa para algunos factores de RCV, aunque pérdidas más importantes alcanzan un mayor beneficio, tal y como expone la AHA en su guía de 2013 sobre el manejo del sobrepeso y la obesidad (19).

La SEEDO publicó en 2007 su documento de consenso (4), en el cual se establece un completo protocolo clínico para llevar a cabo la evaluación del paciente obeso y las medidas terapéuticas aplicables en cada individuo según su IMC. A continuación se expone, resumidamente, el manejo propuesto por esta sociedad científica:

- Para IMC en rango normal, no está justificada ninguna actitud terapéutica de forma global, aunque se debe insistir en tener hábitos de vida saludables.

- Para IMC 25-26.9 Kg/m², está justificada en presencia de factores de RCV u OA, estando indicado reforzar los consejos dietéticos e insistir en la práctica de actividad física. 
- Para IMC 27-29,9 Kg/m², el objetivo debe ser una pérdida de peso del 5$10 \%$, por lo que es necesario pautar una dieta hipocalórica y actividad física, con control periódico del enfermo. Si no se logra el objetivo en 6 meses, se plantearía la asociación de fármacos.

- Para IMC 30-34,9 Kg/m², el paciente debe perder el $10 \%$ de su peso, mediante las mismas medidas que en el grupo anterior y con vigilancia en una unidad de obesidad si existen CAO. Se evaluará también la asociación de fármacos si no hay resultados tras 6 meses.

- Para IMC 35-39,9 Kg/m², el objetivo de pérdida de peso debe ser mayor del 10\% con idénticas medidas terapéuticas, control periódico en unidad de obesidad y, en caso de no lograr el objetivo en 6 meses, se puede optar por pautar una dieta de muy bajas calorías y/o CB.

- Para IMC $>40 \mathrm{Kg} / \mathrm{m}^{2}$, la pérdida de peso debe ser mayor del $20 \%$ aplicando las mismas directrices que en el grupo anterior.

Más recientemente, la citada guía de la AHA (19) propone también un algoritmo de manejo global de estos pacientes. El objetivo de pérdida de peso propugnado por esta sociedad científica es del 5-10\% a alcanzar en 6 meses y ha de basarse en una triple intervención, incluyendo además el control de los factores de RCV en los casos pertinentes (fármacos antihipertensivos y antidiabéticos orales):

- Dieta hipocalórica (1200-1500 kilocalorías [Kcal] para mujeres y 1500-1800 Kcal para varones), con el objetivo de lograr un balance energético negativo de 500-750 Kcal/día, o lo equivalente al 30\% de la ingesta energética diaria.

- Ejercicio físico aeróbico de intensidad moderada, superior a 150 minutos semanales ( $\geq 30$ minutos/día la mayoría de los días de la semana). 
- Terapia conductual, tanto en la fase de pérdida de peso, como en la de mantenimiento [Véase epígrafe 1.4.3.- Otros tratamientos].

La citada guía sostiene que, una vez alcanzado el objetivo ponderal, es necesario llevar a cabo un programa de mantenimiento del peso, cuyas características difieren de los programas de pérdida de peso: dieta hipocalórica, niveles más altos de actividad física (200300 minutos/semana), seguimiento mensual, medida del peso corporal semanal, etc. Si estas medidas son infructuosas y el paciente persiste con IMC elevado $\left(>30 \mathrm{Kg} / \mathrm{m}^{2}\right.$, o $>27$ en presencia de $\mathrm{CAO}$ ), la AHA preconiza la asociación de terapia farmacológica. En el caso de IMC en categoría de OM o $>35 \mathrm{Kg} / \mathrm{m}^{2}$ en presencia de CAO, tras una terapia médicodietética sin resultado, el enfermo debe ser remitido para valorar CB.

Los resultados globales del tratamiento conservador son poco alentadores a largo plazo, y menos aún en pacientes con obesidad de grado elevado y OM, como se expondrá más adelante [Véase epígrafe 1.5.- Tratamiento quirúrgico de la obesidad mórbida]. El meta-análisis de Franz et al. (149) lo corrobora, ya que concluyó que la pérdida media de peso durante los primeros 6 meses para el tratamiento médico-dietético era de 5 a 8,5 $\mathrm{Kg}$ ( $5 \%$ a $9 \%$ de pérdida de peso corporal total). Sin embargo, los estudios con mayor tiempo de seguimiento analizados en este mismo trabajo, obtuvieron que a 48 meses, sólo se mantenía una pérdida de 3 a $6 \mathrm{Kg}$ respecto del peso inicial, sin reganancia posterior.

\subsection{1.- DIETA Y EJERCICIO}

La dieta y el ejercicio físico son los dos pilares fundamentales de las medidas conservadoras, y su misión es lograr un balance energético negativo en el individuo, bien limitando las entradas, bien incrementando el gasto (4). Existen numerosos tipos de dietas, 
como las enumeradas en la guía de la AHA (19) o en el documento de consenso de la SEEDO de 2011 sobre "Recomendaciones nutricionales basadas en la evidencia para la prevención y el tratamiento del sobrepeso y la obesidad en adultos" (150), las cuales poseen nivel de evidencia y grados de recomendación variables para lograr el objetivo ponderal. En la tabla 15 se exponen algunas de las dietas empleadas en el manejo de la obesidad, aunque la revisión detallada de ellas excede el alcance de este trabajo.

Tabla 15. Clasificación y características de los principales tipos de dieta $(150,151)$.

\begin{tabular}{|c|c|c|c|}
\hline \multicolumn{3}{|c|}{ TIPOS Y CARACTERÍSTICAS DE ALGUNAS DIETAS } \\
\hline DIETA & $\begin{array}{c}\text { APORTE } \\
\text { ENERGÉTICO }\end{array}$ & COMPOSICIÓN & CARACTERÍSTICAS \\
\hline $\begin{array}{c}\text { Hipocalórica } \\
\text { equilibrada }\end{array}$ & $800-1500 \mathrm{Kcal}$ & $\begin{array}{c}50 \% \\
\text { carbohidratos, } \\
30 \% \text { lípidos, } \\
20 \% \text { proteínas }\end{array}$ & $\begin{array}{c}\text { Pérdida 10\% en 3-12 } \\
\text { meses, con mejoría de } \\
\text { HTA, LDL, TAG y } \\
\text { glucemia }\end{array}$ \\
\hline Hipograsa & $1000-1500 \mathrm{Kcal}$ & $20-25 \%$ lípidos & $\begin{array}{c}\text { Pérdida 5\% en 2-12 } \\
\text { meses. Poco agradable } \\
\text { y eleva TAG }\end{array}$ \\
\hline Hiperglucémica & $1000-1500 \mathrm{Kcal}$ & $\begin{array}{c}60-150 \text { g diarios } \\
\text { de carbohidratos }\end{array}$ & $\begin{array}{c}\text { Pérdida 5\% en 2-12 } \\
\text { meses. Riesgo } \\
\text { potencial de cetosis }\end{array}$ \\
\hline $\begin{array}{c}\text { Dieta de muy } \\
\text { bajas calorías } \\
\text { (bajo control } \\
\text { médico) }\end{array}$ & $200-800 \mathrm{Kcal}$ & $\begin{array}{c}55-60 \% \\
\text { carbohidratos } \\
<30 \% \text { lípidos }\end{array}$ & $\begin{array}{c}\text { Pérdida }>10 \% \text { en 2-8 } \\
\text { semanas. Riesgo de } \\
\text { disionias, colelitiasis } \\
\text { e hipotensión. }\end{array}$ \\
\hline
\end{tabular}

La dieta debe ser individualizada para cada paciente e indicada y supervisada por profesionales (endocrinólogo, nutricionista). Es obligatorio que sea una dieta equilibrada, con una distribución de los principios inmediatos acorde a las necesidades del obeso, aunque suele existir cierta preponderancia de la fracción proteica en la dieta hipocalórica convencional (4). De igual modo, es conveniente una ingesta abundante de fibra (20-40 gr/día), por su capacidad de producir repleción gástrica y saciedad, al tiempo que es 
necesario la toma de las cantidades correspondientes de oligoelementos (vitaminas y minerales) (4). Se recomienda, también, adaptar el tipo de dieta según las preferencias alimentarias y culinarias del paciente, con una distribución de los macronutrientes acorde a ello, puesto que está demostrado que no influye en el resultado ponderal a largo plazo, según el ensayo clínico de Sacks et al. publicado en New England Journal Of Medicine (152), mientras que sí favorece la adherencia del obeso a la dieta $(4,151)$.

En lo referente al balance energético negativo de la dieta, la SEEDO propone unos valores discretamente diferentes a la AHA, siendo éstos de entre 500 y $1000 \mathrm{Kcal} /$ día y pautando, para ello, dietas algo más estrictas que la sociedad científica americana: 10001200 Kcal para mujeres y 1200-1600 Kcal para varones, con lo que se obtendría una pérdida ponderal de $0.5-1 \mathrm{Kg} / \mathrm{semana}$ y del $8 \%$ a los 6 meses. No obstante, esta pérdida no es lineal a lo largo del tiempo, de tal modo que alcanza su máximo valor a los 6 meses de media (4-12 Kg) con una reganancia de peso posteriormente: tras el primer año, la pérdida ponderal se mantiene en 4-10 Kg respecto al peso inicial (4) y a los dos años, según el ya mencionado meta-análisis de Franz et al. (149), es sólo de 3-6 Kg.

En cuanto al ejercicio físico, es necesario puntualizar en primer lugar, que debe ir asociado a la dieta para obtener beneficio, puesto que su realización exclusiva no alcanza una pérdida ponderal significativa a largo plazo, según la reciente revisión sistemática de Washburn et al. (153). A la hora de indicar actividad física, la pauta debe ser tal que permita un incremento paulatino a medida que el individuo pierde peso, aumenta su capacidad funcional y mejoran las CAO (cardiovascular, respiratoria y osteoarticular) (4). El objetivo es realizar, en la fase de pérdida de peso, un ejercicio aeróbico de intensidad moderada (3 a 6 equivalentes metabólicos, correspondiente con 3.5 a $7 \mathrm{Kcal} /$ minuto) o intensa (>6 
equivalentes metabólicos) (4), empleando preferentemente los grandes grupos musculares del tren inferior (caminar a paso ligero, correr, bicicleta), ya que son los que más glucógeno y TAG consumen durante la contracción (79), aunque es necesario individualizar esta pauta según la edad, capacidad basal, lesiones previas, etc. (4). La duración del ejercicio en esta fase, según la AHA (19) y el American College of Sports Medicine (151), debe ser superior a 150 minutos/semana. Finalmente, en la fase de mantenimiento de la pérdida de peso, la International Association for the Study of Obesity recomienda actividad física de intensidad moderada de 420-630 minutos/semana.

\subsection{2.- TRATAMIENTO FARMACOLÓGICO}

Numerosos fármacos con distintos mecanismos de acción se han empleado para el tratamiento de la obesidad, algunos de los cuales se encuentran contraindicados actualmente por presentar un perfil de toxicidad inaceptable. La indicación de los mismos debe ser bajo estricto control facultativo y siguiendo las recomendaciones de las sociedades científicas: pacientes con IMC $>30 \mathrm{Kg} / \mathrm{m}^{2}$, o $>27$ en presencia de $\mathrm{CAO}$, que no respondan a las medidas conservadoras previamente expuestas, asociadas inexcusablemente a la terapia dietética y de ejercicio físico $(4,19)$.

A modo de breve reseña histórica (154), los primeros fármacos empleados en el tratamiento de la obesidad fueron los laxantes catárticos y los eméticos en los siglos XVIII y XIX, seguidos de la hormona tiroidea, el dinitrofenol y la anfetamina desde finales del siglo XIX hasta la Segunda Guerra Mundial. Posteriormente y hasta el último tercio del siglo XX, se sintetizaron otros principios activos tales como la desfenfluramina, la efedrina o la fenilpropanolamina. Los fármacos empleados en los últimos años son los que se exponen seguidamente, clasificados por su mecanismo de acción $(4,79,154)$ : 
- Fármacos termogénicos. Las hormonas tiroideas y la efedrina o la fentermina poseen efecto adrenérgico periférico (por acción $\beta 3$ inducen lipólisis y termogénesis) y además actúan a nivel central con efecto anorexígeno.

- Fármacos con acción sobre el SNC. Con el progreso en la investigación de los mecanismos de control del apetito y la saciedad se fueron desarrollando distintos agentes químicos cuyo mecanismo de acción es inducir anorexia. La anfetamina, la metanfetamina y el mazindol poseen efecto simpaticomimético y noradrenérgico central, al igual que la efedrina y la fentermina. El siguiente grupo tiene efecto serotoninérgico y lo integran la fenfluramina, su isómero la desfenfluramina y la lorcaserina, así como los fármacos inhibidores selectivos de la recaptación de serotonina, concretamente la fluoxetina. La inhibición de la vía dopaminérgica también induce un efecto anorexígeno, aunque los fármacos con este mecanismo de acción, como el ecopipam, desencadenan depresión. Existen, también, fármacos con efecto sobre dos o más vías: bupropion (inhibidor de recaptación dopaminérgico y noradrenérgico) y sibutramina y tesofensina (inhibidores de recaptación serotoninérgico, noradrenérgico y mínimo dopaminérgico). Dos fármacos anorexígenos con acción sobre otros receptores son el rimonabant (antagonista de los receptores de cannabinoides tipo 1) y la naltrexona (antagonista del receptor de opiodes que bloquea de la liberación de endorfinas provocada por el bupropion, las cuales tienen efecto orexígeno, y por este motivo ambos fármacos van asociados en su presentación comercial). Finalmente, algunos agentes antiepilépticos como el topiramato o la zonisamida también se han asociado 
a pérdida de peso, y existen diversos trabajos publicados empleando leptina, colecistoquinina o antagonistas del neuropéptido Y.

- Fármacos con acción a nivel digestivo. El orlistat es un inhibidor de la lipasa gástrica y pancreática, por lo que su acción se basa en evitar la absorción de lípidos. Sus efectos adversos van ligados a su mecanismo de acción: esteatorrea y déficit de vitaminas liposolubles. El cetilistat es un fármaco con el mismo mecanismo de acción y, aparentemente, mejor perfil de seguridad que el orlistat, aunque aún no ha sido aprobada su comercialización en EE.UU. ni en España.

- Fármacos antidiabéticos. Los principios activos empleados para el tratamiento por vía oral de la DM2 que favorecen la pérdida de peso, son: la metformina, la pramlintida y los análogos de las incretinas (exenatida y liraglutida). Sin embargo, otros grupos de antidiabéticos orales poseen el efecto opuesto: las sulfonilureas, las glitinidas y las tiazolidindionas.

Una mención especial merecen la sibutramina y el rimonabant, con notable capacidad de pérdida ponderal avalada por estudios como el STORM para el primer fármaco y el RIO para el segundo. No obstante, ambos fármacos tuvieron que ser retirados del mercado por su perfil de reacciones adversas: el primero por inducir HTA, taquicardia y eventos agudos cardiovasculares; y el segundo, por trastornos psiquiátricos graves. En este momento, la Food and Drug Administration de los EE.UU. tiene autorizados en dicho país los siguientes cinco compuestos, de los cuales dos son asociación de principios activos (155): Xenical $^{\circledR}$ (orlistat), Contrave ${ }^{\circledR}$ (bupropion y naltrexona), Qsymia/Quexa ${ }^{\circledR}$ (fentermina y topiramato), Saxenda ${ }^{\circledR}$ (liraglutida) y Belviq ${ }^{\circledR}$ (lorcaserina). En nuestro entorno, la Agencia Europea del Medicamento (156) sólo permite la comercialización del Xenical ${ }^{\circledR}$ (orlistat), 
aunque están a la espera de aprobación la liraglutida y la combinación de bupropion con naltrexona.

\subsection{3.- OTROS TRATAMIENTOS}

En este grupo se incluye la psicoterapia conductual o el trasplante fecal, así como recientes técnicas y dispositivos endoscópicos. La liposucción no puede considerarse un tratamiento de la obesidad, puesto que no logra beneficios significativos sobre la RI, los factores de RCV o las citocinas proinflamatorias, tal y como demostró el trabajo de Klein et al. publicado en New England Journal of Medicine (157).

Los programas de terapia cognitivo-conductual suelen desarrollarse conjuntamente con las medidas dietéticas y de ejercicio. Se fundamentan en la corrección de aquellos hábitos negativos arraigados en la psique del individuo, intentando establecer nuevos patrones adecuados de comportamiento alimentario y de estilo de vida (158). El reciente meta-análisis de Johns et al. (159) concluye que a los 12 meses, los programas de terapia cognitivo-conductual (incluyendo dieta y ejercicio) lograban pérdida ponderal significativamente mayor $(1,72 \mathrm{Kg})$ que la dieta o el ejercicio solos.

La siguiente opción terapéutica es el trasplante fecal, que se ha empleado en el tratamiento de patologías digestivas como la infección por Clostridium difficile recurrente, la enfermedad inflamatoria intestinal y el intestino irritable, además de otras enfermedades no digestivas (160). La utilidad potencial de esta terapia se ha postulado tras la aparición de los distintos trabajos que implican a la flora bacteriana como mecanismo etiológico de la obesidad. Sólo están publicados dos artículos obteniendo resultados favorables (79): uno identificó un aumento significativo de la sensibilidad a la insulina y el otro obtuvo 
reducción de los niveles basales de TAG y, también, mayor sensibilidad a la insulina periférica en los pacientes obesos trasplantados con heces de individuos sanos.

Por último, se están desarrollando e implementando técnicas no quirúrgicas mínimamente invasivas para el tratamiento de la obesidad consistentes en procedimientos endoscópicos: el bypass duodeno-yeyunal mediante el dispositivo Endobarrier ${ }^{\circledR}$ y la plicatura endoscópica gástrica. El primero simula un procedimiento malabsortivo puro [Véase epígrafe 1.5.3.2.- Técnicas malabsortivas y mixtas] mediante la colocación endoscópica de una cubierta plástica luminal de $60 \mathrm{~cm}$ de longitud anclada en la primera porción duodenal, la cual impide el contacto de los nutrientes con las vellosidades intestinales. Las publicaciones sobre sus resultados son aún muy escasas y con seguimiento a corto plazo, aunque éstos parecen favorables inicialmente. El reciente ensayo clínico de Koehestanie et al. (161) obtuvo un porcentaje de exceso de peso perdido (PEPP) [Véase epígrafe 1.5.3.- Resultados y criterios de calidad] a los 12 meses del 19,8\% en obesos con Endobarrier $^{\circledR}$ más dieta frente al $11,7 \%$ en los controles sólo con dieta, aunque otras variables, como la HbA1C, no alcanzaron significación estadística. La segunda técnica endoscópica a la que se ha hecho alusión consiste en la plicatura interna de la luz gástrica mediante endoscopia, aunque también se realiza por vía laparoscópica mediante plicatura externa. Es, por tanto, un procedimiento restrictivo puro [Véase epígrafe 1.5.3.1.- Técnicas restrictivas] con unos resultados al primer año de PEPP $=34,9 \%$, según uno de los artículos más recientemente publicados sobre esta técnica (162). 


\section{5.- TRATAMIENTO QUIRÚRGICO DE LA OBESIDAD MÓRBIDA}

El último escalón terapéutico de la obesidad es la $\mathrm{CB}$, término que deriva etimológicamente del griego barys (peso, presión) e iatrikos (tratamiento), y que está integrada por numerosas técnicas, cuyos resultados y complicaciones varían de unas a otras. La evolución de estos procedimientos ocupa, aproximadamente, los últimos 60 años de la historia de la Cirugía, de modo que algunos de ellos han dejado de estar indicados en estos momentos. Al mismo tiempo, la vía de abordaje se ha modificado en conjunción con el desarrollo tecnológico: cirugía abierta en los inicios, aunque se mantiene en la actualidad, y más recientemente, las técnicas mini-invasivas de laparoscopia convencional, robótica o monopuerto, las cuales, según las guías de sociedades científicas como la Society of American Gastrointestinal and Endoscopic Surgeons (163), deben ser de elección frente a la vía abierta.

Tal y como se expuso en el epígrafe anterior, los individuos con IMC $>40 \mathrm{Kg} / \mathrm{m}^{2}$ han de perder al menos un $20 \%$ de su peso de forma mantenida en el tiempo, a fin de favorecer una reducción de la mortalidad y una mejoría o resolución de las CAO (4). Dado que el tratamiento conservador tiene un efecto limitado en los grandes obesos, tanto para la cuantía de la pérdida ponderal, como para el mantenimiento de la misma a largo plazo, la $\mathrm{CB}$ es actualmente el tratamiento de elección de la OM con un nivel de evidencia I y un grado de recomendación A (164), según la nomenclatura de la Medicina Basada en la Evidencia. Los recientes meta-análisis con revisión sistemática de Gloy et al. publicado en el British Medical Journal (165), de Chang et al. publicado en JAMA-Surgery (166) y de Ribaric et al. publicado en Obesity Surgery (167), sostienen que la CB obtiene mayor beneficio tanto ponderal, como de mejora de muchas de las CAO. Por su parte, la Cochrane Collaboration 
también ha publicado en 2014 el trabajo de actualización de resultados sobre este tema, concluyendo que la $\mathrm{CB}$ ofrece superioridad en cuanto a los resultados de pérdida de peso y de CAO en comparación con el tratamiento médico-dietético, independientemente del tipo de técnica empleada (168).

La $\mathrm{CB}$ se ha convertido en una rama quirúrgica de elevada trascendencia e importancia, a la luz de los datos publicados sobre el número de procedimientos realizados a nivel mundial: 468.609 intervenciones en el año 2013, según el reciente trabajo de Angrisani et al. basado en encuestas (169), siendo el bypass gástrico en Y de Roux (BGYR) el procedimiento más frecuentemente realizado en ese momento (45\%), aunque en franco retroceso desde el año 2003 (65,1\%), al igual que la derivación biliopancreática (DBP) y el cruce duodenal (CD). Esto contrasta con el ascenso vertiginoso en la indicación de la gastrectomía vertical (GV), que en 2013 ya suponía el 37\% de todos los procedimientos.

Mención aparte merece la llamada cirugía metabólica, que se ha preconizado como el tratamiento quirúrgico de la DM2 en pacientes no obesos mórbidos (170). Desde los años 50 del siglo pasado, se han publicado numerosos trabajos al respecto, tales como el clásico estudio de Pories et al. en Annals of Surgery (171), en el cual, tras 14 años de seguimiento, el 83\% de los obesos mórbidos sometidos a BGYR alcanzaban resolución de la DM2. La cirugía metabólica, según la definieron H. Buchwald y R. Varco, consiste en realizar modificaciones quirúrgicas en un órgano sano a fin de conseguir cambios biológicos beneficiosos, incluidas aquellas sobre el tubo digestivo que generen mejoría metabólica. Así pues, existe suficiente evidencia como para proponer tratamiento quirúrgico a los pacientes con IMC a partir de $35 \mathrm{Kg} / \mathrm{m}^{2}$ y DM2 con mal control médico, constituyendo una indicación clara de CB [Véanse epígrafes 1.5.1.- Indicaciones y 1.5.4.- 
Resultados y criterios de calidad], tal como aparece reflejado en el documento de 2012 sobre la cirugía metabólica de la SEEDO en colaboración con otras sociedades científicas españolas (170). Por otro lado, los obesos no mórbidos (IMC entre 30 y $35 \mathrm{Kg} / \mathrm{m}^{2}$ ), con DM2 y con factores de RCV pueden ser sometidos a procedimientos bariátricos, especialmente de tipo mixto, con el fin lograr remisión parcial o completa de dichas entidades, sólo bajo ciertas condiciones citadas en el mencionado documento:

- Descartados otros tipos de DM (DM1, LADA, MODY, etc.), tras exhaustiva valoración endocrinológica.

- DM2 con mal control glucémico (HbA1C $>7,5 \%)$ a pesar del tratamiento médico correcto y, especialmente, en el contexto de otras CAO también mal controladas.

En el ya mencionado meta-análisis de Ribaric et al. (167), la OR de remisión de DM2 en pacientes con IMC $\geq 35 \mathrm{Kg} / \mathrm{m}^{2}$ frente a los de IMC $<35 \mathrm{Kg} / \mathrm{m}^{2}$ fue de 15,2 y 17,1, respectivamente. Los mecanismos fisiopatológicos, merced a los cuales se obtiene la mejoría de la DM2, se expondrán conjuntamente con las técnicas bariátricas /Véase epígrafe 1.5.4.- Técnicas quirúrgicas y mecanismos de acción]. La indicación de cirugía metabólica en individuos con IMC entre 30 y $35 \mathrm{Kg} / \mathrm{m}^{2}$, a fin de obtener mejoría de los marcadores bioquímicos de RCV o mejoría del control glucémico, posee nivel de recomendación B y C, respectivamente, según la ASBMS (172), mientras que las guías europeas sostienen que puede existir beneficio, aunque no hay suficiente evidencia científica aún (175). La SEEDO, por su parte, avala el empleo de la cirugía metabólica aunque con reservas, siempre que se cumplan los dos criterios anteriormente mencionados (170). 
Por último, la $\mathrm{CB}$ ha demostrado ser coste-efectiva frente al tratamiento conservador de la OM, estando avalado desde hace años por diversos artículos, entre ellos la exhaustiva revisión sistemática de Picot et al. (173), publicada en 2009. Con tratamiento médico-dietético, resulta desfavorable no sólo el gasto sanitario derivado de la administración de fármacos, asistencia sanitaria, etc. para controlar las $\mathrm{CAO}$, sino también las pérdidas económicas relacionadas con el absentismo laboral de los obesos (174).

\subsection{1.- INDICACIONES}

En CB, se debe sentar la indicación general del tratamiento quirúrgico como tal, para, a continuación, establecer la indicación de la técnica más apropiada según diversos factores y variables, así como unas directrices de valoración y manejo preoperatorios.

\subsubsection{1.- Indicación de la cirugía bariátrica}

De forma genérica, el criterio antropométrico basado en el IMC es el determinante de la indicación de $\mathrm{CB}$, junto con la presencia de CAO. Así pues, y según las más recientes actualizaciones de las guías europeas en el año 2014 (175) y las americanas en 2013 (172), son candidatos a $\mathrm{CB}$ los individuos con IMC $\geq 40 \mathrm{Kg} / \mathrm{m}^{2}$ (punto de corte a partir del cual se considera OM, como ya se ha expuesto anteriormente) en ausencia de CAO, y aquellos con IMC $\geq 35 \mathrm{Kg} / \mathrm{m}^{2}$ en presencia de una o más CAO. Según las guías americanas, las CAO incluidas son: DM2, HTA, dislipemia, SAOS, Sd. Pickwick, NAFLD, psendotumor cerebri, RGE, asma, enfermedad varicosa, incontinencia urinaria severa, artritis debilitante o calidad de vida notablemente disminuida.

En el caso de las guías asiáticas publicadas tras la reunión de consenso celebrada en la India en 2008 (176), la indicación de CB en estos grupos étnicos difiere de la población 
occidental, merced a las diferencias raciales que se mencionaron en el epígrafe 1.1.1.1.Índice de masa corporal:

- $\quad$ IMC $\geq 35 \mathrm{Kg} / \mathrm{m}^{2}$ en ausencia de CAO.

- $\quad$ IMC $\geq 32 \mathrm{Kg} / \mathrm{m}^{2}$ con una o más CAO.

- $\quad$ IMC $\geq 30 \mathrm{Kg} / \mathrm{m}^{2}$ en el contexto de OA (CC $>80 \mathrm{~cm}$ en mujeres y $>90 \mathrm{~cm}$ en varones) con presencia de, al menos, otros 2 criterios de SM.

Además de esta indicación genérica, el enfermo debe cumplir una serie de indicaciones adyuvantes, que se presentan a continuación, tal y como señala la Asociación Española de Cirujanos en su guía clínica de Cirugía de la OM (177):

- OM de 5 años de evolución sin respuesta a tratamiento médico-dietético, o con reganancia de peso tras una pérdida ponderal inicial.

- Edad entre 18 y 60-65 años.

- Obesidad de etiología primaria, habiendo descartado de forma específica obesidad secundaria a endocrinopatías.

- Ausencia de patología psiquiátrica grave, drogodependencia o alcoholismo que desestime el procedimiento.

- Aceptación y compromiso por parte del enfermo de llevar a cabo las normas postquirúrgicas que se pauten, así como comprensión de los riesgos, firmando un consentimiento informado.

En relación a los límites de edad para indicar $\mathrm{CB}$, se deben tener en cuenta unas consideraciones especiales. En el caso de los menores de 18 años, la indicación de CB varía según las guías (177), siendo algunas muy laxas, con idénticos criterios que en el adulto, mientras que otras son más restrictivas y limitan estos procedimientos a los adolescentes 
con IMC $\geq 50 \mathrm{Kg} / \mathrm{m} 2$ sin $\mathrm{CAO}$ o IMC $\geq 40 \mathrm{Kg} / \mathrm{m} 2$ con CAO. En cualquier caso, el candidato debe haber alcanzado un desarrollo puberal suficiente (grado 4 o 5 de Tanner), una estatura del 95\% según la edad ósea y adecuada madurez psíquica, además de haber fracasado el tratamiento conservador tras 6 meses $(175,177)$.

En cuanto a los obesos mórbidos mayores de 65 años, existe en ellos mayor tasa de morbimortalidad postquirúrgica así como de una menor pérdida ponderal tras la $\mathrm{CB}$ que los individuos jóvenes. Sin embargo, no hay diferencias en la mejora o resolución de las CAO, aunque sí favorece una menor necesidad de medicación para controlarlas (la HTA y la patología osteoarticular son las que obtienen menor remisión). Por tanto, la indicación debe hacerse de forma individualizada en este grupo etario, valorando el balance riesgobeneficio, con una tendencia actual a no restringir la CB simplemente por edad avanzada $(175,177)$. El artículo del New England Journal of Medicine con los resultados del Longitudinal Assessment of Bariatric Surgery Consortium (178) notifica que la edad no presentaba incremento estadísticamente significativo del riesgo. Esto contrasta con los datos aportados por otros scores, en los que la edad sí se incluye como factor de riesgo en CB [Véase epígrafe 1.5.2.Contraindicaciones].

\subsubsection{2.- Indicación de la técnica}

Existen diversos tipos de procedimientos bariátricos y cada uno de ellos posee diferente perfil en cuanto a pérdida ponderal, mejora de CAO y riesgo de complicaciones postquirúrgicas [Véase epígrafe 1.5.3.- Técnicas quirúrgicas y mecanismos de acción]. Por este motivo, es fundamental una selección adecuada de la técnica según ciertos factores, características y patologías concomitantes de los candidatos, aunque no existe suficiente 
evidencia sobre cómo realizar esta asignación, según las guías europeas (175). Entre los factores a tener en cuenta se incluyen (177):

- IMC y presencia de CAO. Existe un aforismo clásico entre los cirujanos bariátricos que aboga por una técnica tanto más agresiva, en lo referente a pérdida ponderal, cuanto mayor sea el grado de OM y CAO. En este sentido, Buchwald publicó en 2002 un algoritmo para la selección de la técnica más adecuada (179). Dicho aforismo ha perdido validez tras la descripción de la GV como técnica puente por M. Gagner (180) [Véase epígrafe 1.5.3.1.- Técnicas restrictivas].

- Hábito alimentario del obeso. Los pacientes llamados "picadores de dulce o salado" suelen beneficiarse de procedimientos malabsortivos/mixtos, a excepción del BGYR que genera hipoglucemias en los picadores de dulces. Por el contrario, en los pacientes comedores de volumen se ha de plantear una técnica restrictiva, y en aquellos con un patrón compulsivo o por atracones, es preferible de nuevo $\mathrm{CB}$ malabsortiva/mixta.

- Patología concomitante. Numerosas entidades clínicas presentes en el obeso pueden influir a la hora de decidir la técnica bariátrica. Ejemplos de ello son: ante la existencia de hernia de hiato y RGE sintomático no se recomienda la banda gástrica ajustable (BGA) ni la GV, o bien, en presencia de enfermedad de Cröhn o de nefrolitiasis (especialmente de oxalato) se desaconseja la realización de técnicas malabsortivas.

\subsubsection{3.- Valoración y manejo preoperatorios}

Es necesaria una estricta valoración del obeso candidato a CB antes de someterse al procedimiento. Ella incluye un completo estudio llevado a cabo por un equipo 
multidisciplinar con experiencia, formado por endocrinólogos, cirujanos, anestesiológos, nutricionistas, psicólogos y psiquiatras $(172,175,177)$ :

- Historia clínica detallada y exploración física exhaustiva, así como una valoración de patologías cardiológicas y respiratorias a fin de detectar CAO de estos subgrupos (con realización de las correspondientes pruebas complementarias en los casos pertinentes: ecocardiograma, espirometría, estudio del sueño), estimándose de este modo el riesgo quirúrgicoanestésico. La consulta de preanestesia es fundamental, ya que muchos obesos han de ser incluidos en protocolos de vía aérea difícil. Se debe realizar también un despistaje de tumores.

- Pruebas de laboratorio que incluyan perfil renal, hepático y lipídico, así como estudio analítico del metabolismo de la glucosa y determinación de niveles plasmáticos de diversos micronutrientes y vitaminas.

- Evaluación endocrinológica y nutricional, descartando causas secundarias de OM (actualmente el screening sistemático de hipotiroidismo posee un grado de recomendación D) y evaluando el patrón alimentario del obeso, al tiempo que se deben establecer y explicar las normas dietéticas que el enfermo ha de seguir de por vida en el postoperatorio.

- Evaluación gastrointestinal, con screening de Helicobacter pylori en zonas de alta prevalencia y ecografía abdominal focalizando en el árbol biliar si estuviera indicado clínicamente y/o endoscopia digestiva alta en casos de técnicas con exclusión gástrica.

- Evaluación psicosocial, a fin de detectar no sólo posibles contraindicaciones para el procedimiento, sino también la existencia de soporte familiar y social adecuado. 
- Firma del consentimiento informado, habiendo comprendido y aceptado los riesgos derivados de la intervención y manifestando el compromiso de seguimiento médico a largo plazo.

En segundo lugar, el enfermo debe someterse a una optimización previa a la $\mathrm{CB}$, cuyo objetivo es facilitar la intervención, mejorar la posible limitación funcional secundaria a las CAO y, en última instancia, minimizar el riesgo de morbimortalidad postquirúrgica. Estas medidas incluyen, entre otras, las que se exponen a continuación:

- Estabilización de las CAO y ajuste de medicación (172,175,177). Es necesario suspender los anticonceptivos orales para reducir el riesgo de TVP y TEP. En caso de TVP previa o cor pulmonale, la colocación profiláctica de un filtro de vena cava aporta mayor riesgo que beneficio según los datos publicados (nivel de evidencia III). Los antihipertensivos que actúan sobre el sistema renina-angiotensina han de ser suspendidos porque generan hipotensiones refractarias intraoperatorias. Las estatinas deben mantenerse y reintroducirse cuanto antes tras la intervención. De igual modo, es beneficioso intentar la normalización glucémica y de HbA1C, mediante dieta, actividad física y farmacoterapia (la metformina, en concreto, ha de ser suspendida 48 horas antes). Se debe instaurar tratamiento con ventilación no invasiva nocturna (CPAP) en los casos de SAOS diagnosticado durante la evaluación preoperatoria, enseñando también el uso del inspirómetro incentivado, aún en ausencia de SAOS. Igualmente, es recomendable mantener los broncodilatadores en aquellos obesos asmáticos, así como dejar de fumar al menos 6-8 semanas antes del procedimiento. 
- Pérdida de peso preoperatoria $(177,181)$. Una pérdida de peso en torno al 5$10 \%$ del peso corporal en $4-6$ semanas previas a la $\mathrm{CB}$ obtiene notables beneficios, tales como disminución del volumen hepático, acortamiento del tiempo quirúrgico y reducción de estancia hospitalaria. Asimismo, el propio descenso ponderal contribuye a mejorar las CAO y se asocia a menor morbimortalidad postoperatoria. Las opciones para lograr la citada pérdida son: dietas hipocalóricas, dietas de muy bajas calorías (se postulan como las más recomendables), balón intragástrico o dispositivos endoscópicos como el Endobarrier ${ }^{\circledR}$. Además, es necesario apuntar que muchos equipos de $\mathrm{CB}$ emplean estos medios como prueba de la adherencia postquirúrgica al tratamiento, llegando incluso a desestimar al obeso candidato si no logra el citado objetivo ponderal antes de la intervención.

Por último, en el momento previo a la intervención, al igual que en cualquier otra cirugía mayor abdominal, es necesario pautar la correspondiente profilaxis infecciosa y antitrombótica, asociando el uso de medias de compresión. En relación a esta última, se debe mantener la pauta de heparina de bajo peso molecular tras el alta durante, al menos, el primer mes de postoperatorio. En presencia de RGE y/o hernia de hiato, la administración de ranitidina una hora antes de la cirugía está recomendada (177).

\subsection{2.- CONTRAINDICACIONES}

En primer lugar y de forma general, como ocurre en cualquier intervención quirúrgica, la existencia de un balance riesgo-beneficio desfavorable ha de constituir contraindicación para la misma. En este sentido, la publicación del Obesity Surgery Mortality Risk Score (OS-MRS) por DeMaria et al. en 2007 (182,183) es de gran importancia y 
utilidad, validada posteriormente por la revisión sistemática de Thomas et al. de 2012 (184). Son factores de riesgo de mortalidad en CB: IMC $>50 \mathrm{Kg} / \mathrm{m}^{2}$, sexo masculino, HTA (definida como PA sistólica $>150 \mathrm{mmHg}$ y/o PA diastólica $>90 \mathrm{mmHg}$ y/o tratamiento antihipertensivo), riesgo de TEP (incluyendo TEP previo, TVP previa, úlcera por estasis venoso en extremidades inferiores, filtro de vena cava, presencia de fallo cardíaco derecho, hipertensión pulmonar o SAOS) y edad $>45$ años. De este modo, la coexistencia de 4 o los 5 factores (clase C) eleva el RR de muerte hasta 15 veces frente a los individuos con uno o ninguno de ellos, motivo por el cual debería contraindicarse la CB.

De forma concreta, según las guías europeas de 2014 (175), son contraindicaciones para CB las que se enumeran a continuación:

- Ausencia de un período de adecuado tratamiento conservador.

- Imposibilidad por parte del enfermo de someterse al seguimiento médico postoperatorio.

- Patología psiquiátrica no estabilizada y ausencia de apoyo socio-familiar en aquellos obesos incapaces de cuidar de sí mismos.

- Coexistencia de enfermedades graves con riesgo de muerte a corto plazo.

- En el caso de cirugía metabólica para la DM2, son criterios de exclusión específicos: DM secundaria y DM con anticuerpos positivos o péptido C $<1$ nanogramo (ng)/mililitro (ml).

Por último, la concomitancia de determinadas patologías, sean o no CAO, pueden limitar el tipo de técnica o, incluso, llegar a constituir también una verdadera contraindicación $(172,175,177,185)$. Como se acaba de exponer, la presencia de trastornos psicóticos, depresión mayor o trastornos de conducta alimentaria, como la bulimia nerviosa 
o el trastorno por atracones, trastornos de la personalidad, etc., que no estén estabilizados son contraindicación, a menos que sea aconsejado específicamente por un psiquiatra con experiencia en OM. En el caso de patología orgánica, es necesario estratificar el riesgo quirúrgico en pacientes obesos mórbidos con fallo terminal de un órgano con potencial indicación para trasplante (hepático, cardíaco, renal). Es sabido que la obesidad genera:

- Incremento de complicaciones post-trasplante.

- Menor supervivencia del injerto y, también, del receptor.

- Potenciación del efecto deletéreo de las drogas inmunosupresoras a nivel endocrino-metabólico y de RCV, en lo que se ha denominado el SM posttrasplante.

Por todo ello, la CB se ha demostrado útil en los candidatos a trasplante de órgano sólido con OM, permitiendo que desaparezca la contraindicación del mismo que determina el exceso de adiposidad. Según las publicaciones existentes, el procedimiento bariátrico no parece alterar la farmacocinética de las drogas inmunosupresoras, siendo la GV la técnica empleada con mayor frecuencia, tanto en período pre-trasplante como en aquellos trasplantados que han de someterse posteriormente a CB (185).

Un comentario especial merece el paciente obeso mórbido con fallo hepático terminal y cirrosis, en los cuales la hipertensión portal supone un elevado riesgo de hemorragia operatoria, de complicaciones y de descompensación postquirúrgicas. La indicación de $\mathrm{CB}$ puede sentarse en el periodo pretrasplante, durante el propio implante hepático o tras la realización del mismo. De forma genérica, la técnica recomendada es la GV, pero también se pueden realizar otras (clásicamente las técnicas malabsortivas estaban contraindicadas en el obeso cirrótico), al tiempo que un estadio B en la clasificación de 
Child-Pough desaconseja la CB, aunque algunos equipos bariátricos sí la han llevado a cabo en pacientes con este estadio (185). Los resultados en este grupo de enfermos han sido recientemente publicados en la revisión sistemática de Lazzati et al. (186). Globalmente, la mortalidad es nula en los 30 primeros días, aunque asciende al primer año hasta el 5.3\%. La tasa de reoperación es del 12,2\% y la PEPP al año de 53,9\%, siendo la GV el procedimiento más frecuentemente realizado.

\subsection{3.- RESULTADOS Y CRITERIOS DE CALIDAD}

Todos los pacientes sometidos a CB deben contar con un estrecho seguimiento postoperatorio por parte de un equipo multidisciplinar, especialmente a cargo de endocrinólogos y cirujanos, con la doble intención de detectar la aparición de complicaciones y, también, de evaluar y controlar la respuesta al tratamiento quirúrgico en lo que respecta a la pérdida de peso y a la resolución o mejoría de las CAO. El período mínimo de seguimiento que se recomienda en la literatura a la hora de presentar y publicar estos resultados es de 5 años (187) y la tasa de pérdida de enfermos intervenidos durante el seguimiento no debe superar el 40\%, según el Registro Internacional de Cirugía Bariátrica y el Comité de Estándares.

En referencia a la pérdida ponderal, es necesario citar los distintos parámetros empleados para cuantificarla: el porcentaje de exceso de peso (sobrepeso) perdido (PEPP), el porcentaje de exceso de IMC perdido (PEIMCP) y el porcentaje de peso total perdido (PPTP). Las fórmulas empleadas para su cálculo son las siguientes $(187,188)$ :

$$
\begin{aligned}
& \text { PEPP }=[(\text { peso inicial }- \text { peso actual }) /(\text { peso inicial }- \text { peso ideal })] \times 100 \\
& \text { PEIMCP }=[(\text { IMC inicial }- \text { IMC actual }) /(\text { IMC inicial }-25)] \times 100 \\
& \text { PTPP }=[(\text { peso inicial }- \text { peso actual }) / \text { peso inicial }] \times 100
\end{aligned}
$$


Los dos primeros parámetros son los que han sido utilizados clásicamente para expresar resultados de pérdida de peso en CB (187). Sin embargo, y según los trabajos publicados para la técnica de BGYR por el Bariatric Outcomes Longitudinal Database $(188,189)$, el PTPP estima mejor la pérdida ponderal y no se ve influenciado por el peso ni el IMC iniciales, como ocurre con el PEPP y el PEIMCP, de tal modo que sugiere abandonar el cálculo de estos dos. En cualquier caso, tal y como publicaron Larrad et al. (187), el indicador de calidad está claramente establecido: la $\mathrm{CB}$, independientemente de la técnica, ha de alcanzar un PEPP $>50 \%$ en más del $75 \%$ de los pacientes a los 5 años. Según este mismo autor, los resultados ponderales se pueden clasificar según el PEIMCP en excelentes (PEIMCP > 65\%), buenos (PEIMCP entre el 50 y el 65\%) y en fracaso (PEIMCP < 50\%).

Los resultados ponderales publicados en los tres meta-análisis citados al inicio del epígrafe son los siguientes: según Gloy et al. (165), los individuos sometidos a CB pierden, de media, $26 \mathrm{Kg}$ más que con tratamiento conservador; Ribaric et al. (167) obtuvieron un descenso del IMC de $11,4 \mathrm{Kg} / \mathrm{m}^{2}$ tras el tratamiento en el grupo de CB frente a 1,6 Kg/m² en el grupo de terapia médico-dietética; y en el trabajo de Chang et al. (166), los resultados de PEPP para el grupo de CB (exclusivamente para los artículos del meta-análisis que describen ensayos clínicos aleatorizados) fueron de $59,82 \%$ y de $41,60 \%$, al primer y quinto año respectivamente, mientras que para el grupo de tratamiento conservador (sólo analizados estudios observacionales), el PEPP al primer año fue de $20 \%$, sin datos existentes más allá de este período. Estos valores son diferentes en función del tipo de procedimiento empleado, aunque es bien sabido que los procedimientos malabasortivos y mixtos alcanzan mejores resultados ponderales que los restrictivos, lo cual está corroborado por los meta-análisis de Chang et al. (166) y Gloy et al. (165). 
En segundo lugar, la resolución o mejoría de las CAO también debe ser evaluada tras la realización de CB. Se citan a continuación los estándares de calidad que aparecen reflejados actualmente en la literatura para las entidades más frecuentes:

- Patología endocrino-metabólica. Según la guía de 2009 de la American Diabetes Association (190), existen criterios de remisión total de la DM2 y de remisión parcial, que se especifican en la tabla 16. En lo referente a la dislipemia asociada a la OM, el consenso de la SEEDO de 2012 (170) fija los siguientes valores de corte para considerar resolución: LDL $<100 \mathrm{mg} / \mathrm{dl}$, TAG $<150 \mathrm{mg} / \mathrm{dl}$, HDL $>40 \mathrm{mg} / \mathrm{dl}$ (varones) y $>50 \mathrm{mg} / \mathrm{dl}$ (mujeres). De forma global, la International Diabetes Federation estableció también unos criterios de optimización del estado metabólico (HbA1c $<6 \%$, en ausencia de hipoglucemias, colesterol total $<4$ milimol/1, LDL $<2$ milimol/1, TAG $<2,2$ milimol/1, PA $<135 / 85$ mmHg, pérdida de peso del 15\% y suspensión o reducción de medicación respecto al momento previa a la $\mathrm{CB}$ ), así como criterios de mejora sustancial del SM (reducción de $\mathrm{HbA1c} \geq 20 \%$, LDL $<2,3$ milimol/1, PA <135/85 mmHg, con reducción de medicación respecto al momento previa a la CB) (191). De este modo, se ha establecido como criterio de calidad que $>70 \%$ de los pacientes sometidos a $\mathrm{CB}$, independientemente de la técnica, deben alcanzar resolución de la dislipemia a los 2 años de seguimiento (177). Por último, cabe decir que no existe un criterio claro para considerar la curación de la hiperuricemia, salvo, el de descenso de los niveles plasmáticos de ácido úrico a valores en rango de normalidad.

- Patología cardiovascular. Se considera resolución de la HTA tras CB, según el consenso de la SEEDO, a alcanzar valores de PA sistólica $<140 \mathrm{mmHg}$ y de PA siastólica $<80 \mathrm{mmHg}$ (170), aunque estas cifras cambian discretamente 
según la International Diabetes Federation, tal y como se acaba de mencionar (191). Así pues, la recomendación es que se alcance el criterio de resolución de la HTA en, al menos, un $70 \%$ a los 2 años de seguimiento para cualquier procedimiento bariátrico (177).

- Patología respiratoria. El criterio polisomnográfico de resolución del SAOS, según la American Academy of Sleep Medicine, es la presencia de <5 episodios de apnea o hipopnea por hora (192). El criterio de calidad establecido es de resolución del SAOS en $>25 \%$ de los obesos con SAOS sometidos a $\mathrm{CB}$, al alcanzar la estabilidad ponderal (177).

Tabla 16. Criterios de remisión total y parcial de la DM2 tras CB según la American Diabetes Association, publicados por Buse et al. en 2009 (190).

\begin{tabular}{|c|c|c|}
\hline \multicolumn{3}{|c|}{ CRITERIOS DE LA AMERICAN DIABETES } \\
ASSOCIATION PARA LA REMISIÓN DE LA DM2 \\
\hline & $\begin{array}{c}\text { REMISIÓN } \\
\text { TOTAL }\end{array}$ & $\begin{array}{c}\text { REMISIÓN } \\
\text { PARCIAL }\end{array}$ \\
\hline HbA1C & $<6 \%$ & $<6,5 \%$ \\
\hline $\begin{array}{c}\text { Glucemia en } \\
\text { ayunas }\end{array}$ & $<100 \mathrm{mg} / \mathrm{dl}$ & $100-125 \mathrm{mg} / \mathrm{dl}$ \\
\hline $\begin{array}{c}\text { Ausencia de } \\
\text { medicación }\end{array}$ & $\begin{array}{c}\text { Durante } 1 \text { año, } \\
\text { mínimo }\end{array}$ & $\begin{array}{c}\text { Durante } 1 \mathrm{año}, \\
\text { mínimo }\end{array}$ \\
\hline
\end{tabular}

En la tabla 17 se exponen los resultados de la $\mathrm{CB}$ en lo referente a la mejora o resolución de las $\mathrm{CAO}$, según los conceptos que se acaban de enumerar. Existen diferencias notables según el tipo de técnica bariátrica empleada que se pueden resumir en que los procedimientos restrictivos puros obtienen resultados más limitados que las malabsortivas y mixtas de forma global $(165,166)$. Sin embargo, la exposición detallada del efecto que genera cada una de las técnicas bariátricas sobre las CAO, supera el objetivo de 
esta Introducción. En relación a los resultados para otras CAO no incluidas en la tabla 17, es necesario citar uno de los estudios de mayor impacto acerca de los resultados en OM y CB: el Swedish Obese Subjects. Según datos publicados en 2013 con seguimiento a 16 años para un tercio de los individuos reclutados en este estudio, la mortalidad ajustada se reduce en un 30\% para ese periodo de seguimiento $(\mathrm{HR}=0,71)$ en el grupo de obesos con $\mathrm{CB}$ frente a la cohorte de obesos sin CB (193). En este mismo artículo, la CB resultó ser factor protector de eventos cardiovasculares frente a los obesos no sometidos a tratamiento quirúrgico de la OM (HR ajustadas para eventos totales y eventos letales de 0,47 y 0,67, respectivamente), así como para el desarrollo de nuevos tumores, aunque con resultados significativos exclusivamente en mujeres (HR ajustada $=0,58)$. La patología osteoarticular también resulta favorecida por el tratamiento quirúrgico de la OM según el Swedish Obese Subjects, con una OR que oscila entre 1,4 y 4,8 para la mejora de los síntomas iniciales en las articulaciones de la rodilla y tobillo para varones, así como en cadera, rodilla y tobillo para mujeres.

Tabla 17. Resultados para algunas $\mathrm{CAO}$, expresadas en porcentaje del grupo de tratamiento conservador frente al grupo de CB. Tomado de Chang et al. (166). [n.n.: no notificado].

\begin{tabular}{|c|c|c|}
\hline \multirow{2}{*}{ RESULTADOS DE RESOLUCIÓN DE CAO EN CB } \\
\hline \multirow{2}{*}{ CAO } & \multicolumn{2}{|c|}{ TIPO DE ESTUDIO } \\
\cline { 2 - 3 } & $\begin{array}{c}\text { ENSAYOS } \\
\text { CLÍNICOS }\end{array}$ & $\begin{array}{c}\text { ESTUDIOS } \\
\text { OBSERVACIONALES }\end{array}$ \\
\hline $\begin{array}{c}\text { Remisión de } \\
\text { DM }\end{array}$ & $17,64 \%$ versus $91,99 \%$ & n.n. versus $86,05 \%$ \\
\hline $\begin{array}{c}\text { Remisión de } \\
\text { HTA }\end{array}$ & $49,00 \%$ versus $75,18 \%$ & $15,00 \%$ versus $74,36 \%$ \\
\hline $\begin{array}{c}\text { Remisión de } \\
\text { dislipemia }\end{array}$ & n.n versus $75,77 \%$ & $5,42 \%$ versus $67,93 \%$ \\
\hline $\begin{array}{c}\text { Remisión de } \\
\text { SAOS }\end{array}$ & n.n. versus $96,16 \%$ & n.n. versus $89,53 \%$ \\
\hline \multicolumn{2}{|c|}{} \\
\hline
\end{tabular}


Acerca de las CAO del aparato digestivo, cabe mencionar el efecto de la CB sobre la NAFLD, dada su gran trascendencia [Véase epígrafe 1.3.7.- Patología digestiva]. En la última revisión sistemática publicada en 2015 (194), se concluye que los procedimientos bariátricos mejoran significativamente los datos histopatológicos (por ejemplo, descenso de la esteatosis en un 50,2\%) y reducen los parámetros analíticos asociados a la NAFLD, entre ellos, la $\gamma$-glutamil-transferasa en 18,39 unidades internacionales (UI)/litro (l). El efecto de la $\mathrm{CB}$ sobre el RGE no está claramente dilucidado en la literatura. El reciente artículo de revisión del Surgical Clinics of North America sobre este tema (195) concluye que el BGYR se asocia a disminución de la incidencia del RGE, siendo la técnica de elección para los obesos con RGE que vayan a someterse a $\mathrm{CB}$, con resultados contradictorios para la GV y la BGA, sugiriendo que se eviten ambos procedimientos en enfermos con RGE.

Otro campo de investigación en los resultados de la $\mathrm{CB}$ es la determinación del grado de satisfacción y la mejora de la calidad de vida de los pacientes tras la intervención. Citando nuevamente el artículo de L. Sjöström con los resultados actualizados del Swedish Obese Subjects (193), la calidad de vida a más de 10 años mejora en la cohorte de CB frente a los controles no intervenidos en los siguientes aspectos: percepción de salud actual, la interacción social, el funcionamiento psicosocial y la depresión. En la misma línea, el metaanálisis de Gloy et al. (165) concluye que la calidad de vida de los obesos sometidos a CB mejora tras la intervención en varios de los 8 campos que componen el cuestionario SF-36 (función física, rol físico, salud general, energía y rol emocional), aunque son aún pocos los artículos que emplean este cuestionario. Resulta de gran interés, mencionar un método de evaluación global de los resultados en CB, publicado en Obesity Surgery en 1998 (196), validado en 2003 y actualizado diez años más tarde: el Bariatric Analysis and Reporting Outcome System (BAROS). Este cuestionario ha ganado gran aceptación entre los cirujanos 
bariátricos por ser muy completo, incluyendo resultados ponderales, resultados de resolución de CAO y un cuestionario de calidad de vida, con influencia de la aparición de complicaciones mayores o menores y de reoperación sobre la puntuación final. Con estos items se establece una escala de puntos que informa del resultado global de la CB sobre el paciente en cuestión: excelente, muy bueno, bueno, aceptable y fracaso [Véase figura 1].

Figura 1. Cuestionario BAROS para la evaluación global de resultados en CB. Tomado de Oria et al. (196).

\begin{tabular}{|c|c|c|c|c|}
\hline $\begin{array}{l}\text { WEIGHT LOSS } \\
\% \text { OF EXCESS } \\
\text { (points) }\end{array}$ & $\begin{array}{l}\text { MEDICAL } \\
\text { CONDITIONS } \\
\text { (points) }\end{array}$ & $\begin{array}{l}\text { QUALITY OF LIFI } \\
\text { QUESTIONNAIRE }\end{array}$ & & \\
\hline $\begin{array}{l}\text { Weight gain } \\
\qquad(-1)\end{array}$ & $\begin{array}{l}\text { Aggravated } \\
\qquad(-1)\end{array}$ & \multirow{6}{*}{\multicolumn{3}{|c|}{ 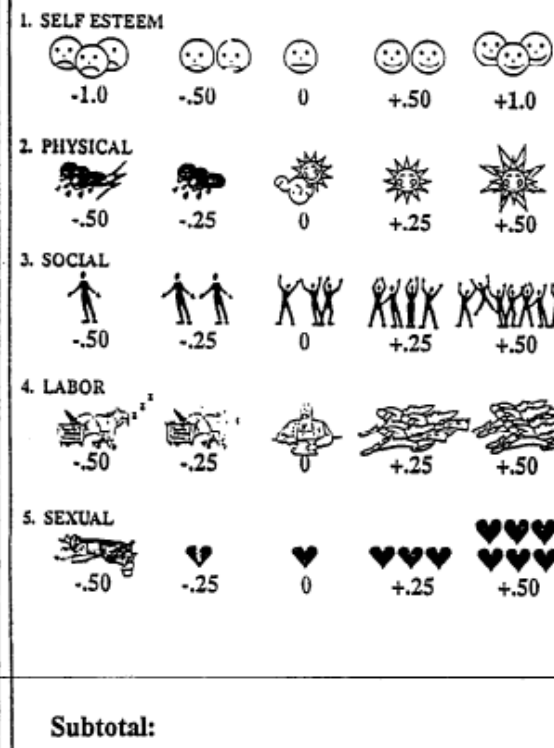 }} \\
\hline $\begin{array}{l}0-24 \\
(0)\end{array}$ & $\begin{array}{l}\text { Unchanged } \\
\qquad(0)\end{array}$ & & & \\
\hline $\begin{array}{c}25-49 \\
(1)\end{array}$ & $\begin{array}{l}\text { Improved } \\
\text { (1) }\end{array}$ & & & \\
\hline $\begin{array}{c}50-74 \\
(2)\end{array}$ & $\begin{array}{l}\text { One major resolved } \\
\text { Others improved } \\
\text { (2) }\end{array}$ & & & \\
\hline $\begin{array}{c}75-100 \\
(3)\end{array}$ & $\begin{array}{l}\text { All major resolved } \\
\text { Others improved } \\
\text { (3) }\end{array}$ & & & \\
\hline Subtotal: & Subtotal: & & & \\
\hline
\end{tabular}

COMPLICATHONS

Minor: Deduct 0.2 point

Major: Deduct 1 point

TOTALSCORE

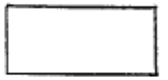

\section{REOPERATION}

Deduct 1 point

\section{OUTCOME GROUPS} SCORING KEY 
Finalmente, en necesario hacer mención a los estándares de calidad aceptados en lo que respecta a la morbimortalidad de la CB. Así pues, cualquier procedimiento bariátrico no debe superar unas tasas globales de morbilidad mayor del 10\% y de mortalidad superior al 1\%, al tiempo que la necesidad de cirugía de revisión no sea mayor del 2\% anual, entendida ésta como la cirugía de de las complicaciones y la cirugía de conversión de técnica fallida (187). No obstante, la tasa de mortalidad en función de las características de cada obeso sometido CA está establecida en la literatura empleando escalas de riesgo tales como el OS-MRS (183) [Véase epígrafe 1.5.2.- Contraindicaciones]. En la actualidad y según el meta-análisis de Chang et al. (166), las cifras globales de mortalidad precoz y tardía, morbilidad y reoperación son las que se muestran en la tabla 18. En relación a las diferencias de morbimortalidad según las diferentes técnicas de $\mathrm{CB}$, este autor concluye que el BGYR obtiene mejores resultados ponderales a expensas de una mayor morbimortalidad, mientras que la BGA es un procedimiento más seguro en cuanto a complicaciones se refiere, aunque sus resultados son menos sustanciales y su tasa de reoperación es mayor que la de GV y BGYR.

Tabla 18. Tasas de morbimortalidad en CB, según los tipos de estudios, expresadas en porcentaje con su IC 95\%. Tomado de Chang et al. (166).

\begin{tabular}{|c|c|c|}
\hline \multicolumn{2}{|c|}{ RESULTADOS DE MORBIMORTALIDAD EN CB } \\
\hline \multirow{2}{*}{ VARIABLE } & \multicolumn{2}{|c|}{ TIPO DE ESTUDIO } \\
\cline { 2 - 3 } & $\begin{array}{c}\text { ENSAYOS } \\
\text { CLÍNICOS }\end{array}$ & $\begin{array}{c}\text { ESTUDIOS } \\
\text { OBSERVACIONALES }\end{array}$ \\
\hline $\begin{array}{c}\text { Mortalidad } \\
<30 \text { días }\end{array}$ & $0,08 \%[0,01-0,24]$ & $0,22 \%[0,14-0,31]$ \\
\hline $\begin{array}{c}\text { Mortalidad } \\
>30 \text { días }\end{array}$ & $0,31 \%[0,01-0,75]$ & $0,35 \%[0,20-0,52]$ \\
\hline $\begin{array}{c}\text { Morbilidad } \\
\text { global }\end{array}$ & $17,00 \%[11,00-23,00]$ & $9,80 \%[7,40-13,00]$ \\
\hline Reoperación & $6,95 \%[3,27-12,04]$ & $5,75 \%[4,05-7,83]$ \\
\hline
\end{tabular}




\subsection{4.- TÉCNICAS QUIRÚRGICAS Y MECANISMOS DE ACCIÓN}

Desde los inicios de la CB las técnicas descritas en la literatura y desarrolladas en la práctica clínica persiguen dos objetivos: limitar el volumen de alimento ingerido (procedimientos restrictivos) o excluir determinados tramos intestinales del tránsito alimentario a fin de limitar la absorción de los nutrientes (procedimientos malabsortivos o derivativos). Además, algunas intervenciones aúnan en una sola los dos tipos descritos, en lo que se ha denominado procedimientos mixtos, aunque, por lo general, siempre predomina uno de los componentes. Ello es así, en base a un aforismo clásico de la $\mathrm{CB}$ en relación a estas técnicas mixtas que sostiene lo siguiente: si la capacidad malabsortiva del procedimiento es alta, la restrictiva ha de ser baja y a la inversa, evitando de éste modo severas complicaciones nutricionales para el paciente en el postoperatorio.

\subsubsection{1.- Técnicas restrictivas}

El mecanismo de este grupo de técnicas consiste en minimizar el aporte calórico a expensas de reducir las dimensiones del estómago o de generar un pequeño reservorio gástrico (volumen final de 30-50 ml), con la doble intención de limitar la ingesta alimentaria e inducir una sensación de saciedad precoz (177). Esto último tiene una base bioquímica más allá del efecto puramente restrictivo y mecánico de la técnica y que se ha relacionado con las hormonas del eje entero-encefálico [Véase epígrafe 1.1.3.2.- Factores neurohumorales y hormonales], especialmente con la ghrelina, hormona con acción orexígena, como ya se ha expuesto anteriormente. La síntesis de esta molécula a nivel gástrico y, por ende sus niveles plasmáticos, se reducen notablemente tras una GV, quedando confirmado en una reciente revisión sistemática del tema publicada en Obesity Surgery (197). 
La primera técnica restrictiva, como tal, fue la gastroplastia vertical anillada [Véase figura 2a], descrita por Mason en 1982 (198). Ella fue el último escalón del desarrollo de las gastroplastias (inicialmente, horizontales y verticales después), que éste y otros autores como W.G. Pace y L.C. Carey habían aplicado con el fin de crear un pequeño reservorio gástrico que alojara el alimento con paso posterior al resto del estómago a través de un "falso neo-píloro", mediante la utilización de grapadoras quirúrgicas. Este procedimiento se encuentra actualmente en franco retroceso, a tenor de las cifras presentadas por Angrisani et al. en el ya citado estudio sobre las técnicas de CB realizadas a nivel mundial: 231 gastroplastias verticales anilladas sobre un total de 468.609 intervenciones bariátricas en 2013 a nivel mundial (169). Ello está justificado por los peores resultados que aporta esta técnica: empleando el cuestionario BAROS a largo plazo, se obtienen resultados buenos, muy buenos o excelentes tan sólo en el 57,8\% de los pacientes, frente al 83,9\% que obtiene la BGA (199).

En 1990, Kuzmak et al. (200) publicaron la serie inicial de BGA [Véase figura 2b]. El fundamento fisiológico reside en la capacidad restrictiva y en el efecto de saciedad precoz, incluso se ha llegado a definir como un procedimiento conductual de adaptación hacia un hábito alimentario saludable, más que como procedimiento quirúrgico (177). El paciente candidato idóneo para la BGA es, preferentemente, una mujer joven obesa pero con IMC $<50 \mathrm{Kg} / \mathrm{m}^{2}$, elevado nivel sociocultural y motivada para modificar su estilo de vida, con dieta y ejercicio físico (177). Esta técnica, con varias modificaciones posteriores y desarrollo de nuevos dispositivos de banda, se convirtió en la segunda intervención de CB más realizada a nivel mundial en 2008, especialmente en las áreas anglosajona y norteamericana, alcanzando un 42,3\%, aunque posteriormente ha decaído hasta el $10 \%$ (169). Como ya se ha mencionado anteriormente, es un procedimiento con peores 
resultados ponderales y de resolución de CAO frente a otros restrictivos como la GV, y además se asocia a una tasa no desdeñable de reintervención $(165,166)$.

Figura 2. Técnicas de gastroplastia vertical anillada (2a) y BGA (2b).
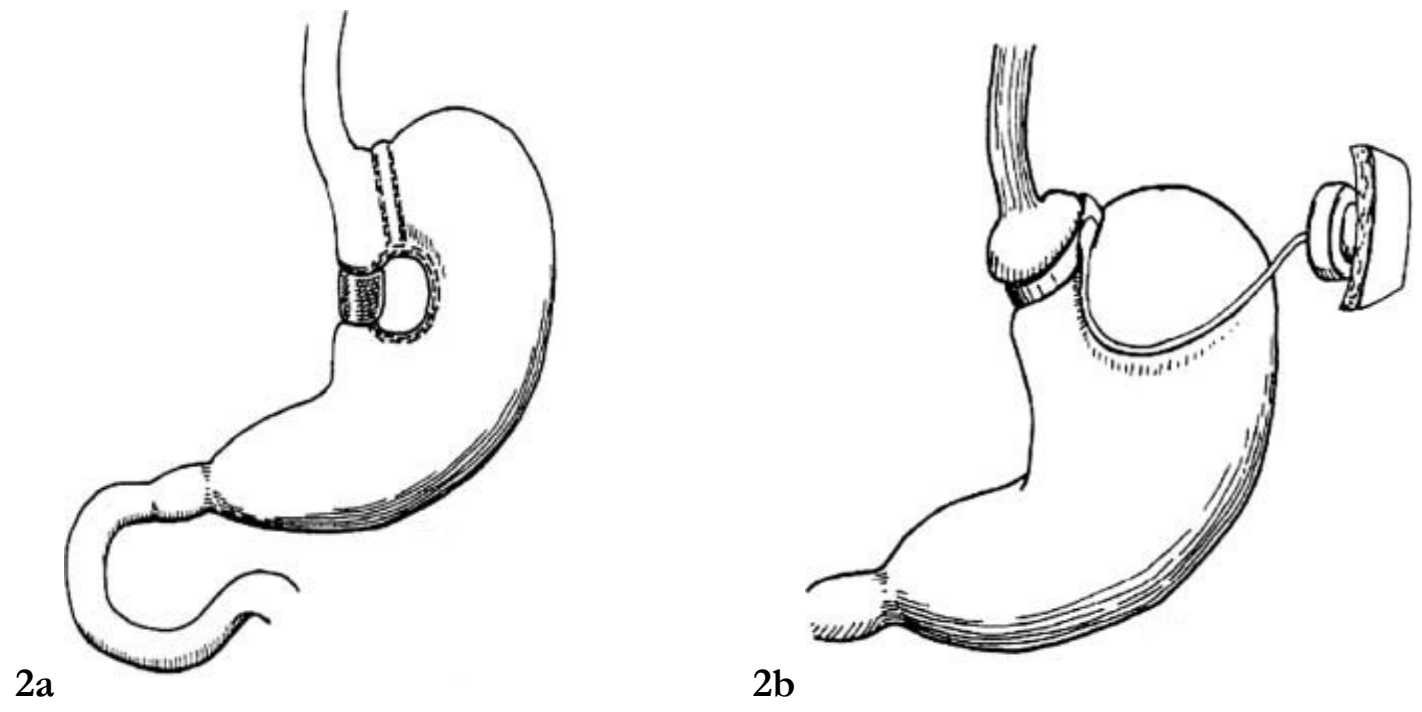

Gagner et al. describieron la GV [Véase figura 3a] en 1988 como un procedimiento restrictivo puente, con la intención de favorecer pérdida de peso y mejoría de comorbilidades que, posteriormente, facilitaran la realización de una técnica mixta definitiva como el CD (201). Sin embargo, dada su menor dificultad técnica y unos resultados aceptables, ha ido consolidándose como un intervención primaria en sí misma, y así lo refrenda la ASBMS (180). Según el artículo de Chang et al. (166), la PEPP al primer año es del 69,7\% y al tercero, 59,42\%, sin existir datos en la literatura más allá de este periodo de seguimiento hasta la fecha de publicación de este meta-análisis. La resolución de las CAO empleando esta técnica bariátrica resulta, igualmente, favorable a pesar de que tampoco existen estudios de alto nivel de evidencia científica con resultados a largo plazo: remisión de DM en un 85,53\%, remisión de HTA en un 82,23\%, remisión de dislipemia en 
un $82,86 \%$ y remisión de SAOS en un $90,77 \%$ (166). Merced a todo ello, el número de enfermos intervenidos mediante GV se ha incrementado progresivamente hasta ser, en la actualidad, el segundo procedimiento bariátrico más realizado en todo el mundo después del BGYR: 37\% (169).

El último grupo de dispositivos con mecanismo restrictivo, son los llamados marcapasos gástricos, cuya primera referencia en la literatura data de 2002, aunque la cohorte de pacientes de ese estudio comenzó a reclutarse en 1995 (202). Estos aparatos se implantan en la pared gástrica, siendo capaces de detectar la repleción del estómago tras la ingesta de alimentos y emitir pulsos de estimulación eléctrica de baja intensidad que provocan al portador una sensación de distensión, saciedad precoz y ausencia de apetito en los periodos interprandiales, mediados por bloqueo vagal, entre otros mecanismos (177). La Food and Drug Administration de los EE.UU. ya ha aprobado su uso en la práctica clínica (155) y los resultados publicados en una revisión sistemática de 2014 (203) son alentadores aunque los artículos incluidos no alcanzan alto nivel de evidencia, existiendo además diferencias en función del modelo comercial implantado. Según este artículo y para el dispositivo Transcend ${ }^{\circledR}$ Implantable Gastric Stimulator (Medtronics Inc., Minneapolis, Minnesota, EE.UU.) el PEPP es del 20-25\% en estudios con seguimiento mayor de 1 año.

Finalmente, existen otras técnicas restrictivas que completan este grupo, a pesar de no ser procedimientos quirúrgicos propiamente dichos (177). Ellas son la ya mencionada plicatura gástrica endoscópica [Véase epígrafe 1.4.3.- Otros tratamientos], aunque también está descrita su realización por vía laparoscópica (204) y el balón intragástrico. Este último método supone la implantación por vía endoscópica de un dispositivo esférico de unos 600 $\mathrm{ml}$ de volumen [Véase figura 3b], ejerciendo un efecto puramente restrictivo. Sin embargo, 
en la actualidad, no tiene indicación como procedimiento bariátrico primario dados sus malos resultados ponderales y de resolución de las CAO a medio y largo plazo, además de presentar una restricción temporal de 6 meses como máximo, tras los cuales el dispositivo debe ser retirado. Por todo ello, se emplea como un adyuvante para lograr pérdida de peso preoperatoria y un cierto grado de control de CAO en aquellos pacientes obesos candidatos a CB de alto riesgo (177).

Figura 3. Técnica de GV (3a) y de balón intragástrico (3b).

$3 a$

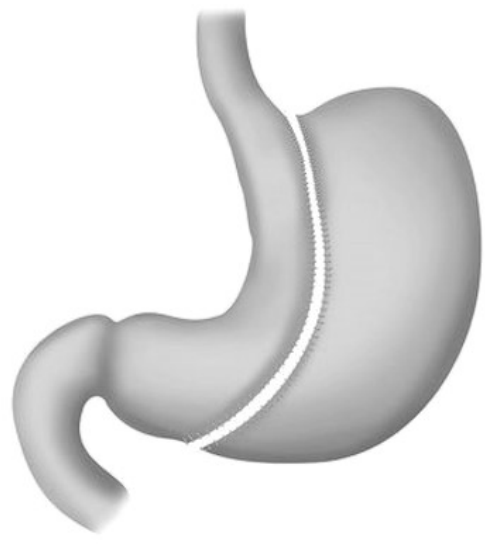

$3 b$

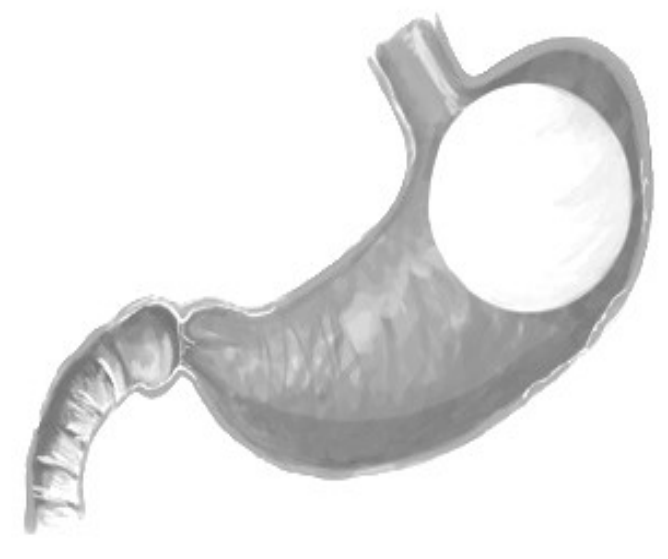

\subsubsection{2.- Técnicas malabsortivas y mixtas}

Desde el punto de vista histórico, este grupo de técnicas fueron las primeras en describirse en los años 50 por J.H. Payne para el tratamiento quirúrgico de la OM. Su base fisiopatológica reside en la exclusión al tránsito alimentario de ciertos tramos del tubo digestivo, merced a la cual se impide la mezcla de las secrecciones biliopancreáticas con el alimento, minimizando su acción enzimática y emulsionante, al tiempo que se reduce el segmento efectivo real para absorber los nutrientes (177). Las primeras intervenciones descritas fueron los llamados bypass yeyuno-cólico, inicialmente y, más tarde, yeyuno-ileal, las cuales se basaban en un efecto malabsortivo puro. Estos procedimientos lograron 
resultados ponderales adecuados, aunque a expensas de severas complicaciones médicas y quirúrgicas [Véase epígrafe 1.5.5.- Complicaciones], como por ejemplo unas tasas de reintervención hasta el 50\% y de mortalidad del 8\% a 10 años de seguimiento, según la serie del propio Payne (205), motivo por el cual fueron abandonadas.

A finales de los años 70, un grupo italiano de CB liderado por N. Scopinaro, comenzó a realizar una nueva técnica quirúrgica con mecanismo mixto (mayor acción malabsortiva que restrictiva) conocida como DBP [Véase figura 4a], que, tras sus inicios experimentales en perros (206), se llevó a cabo en humanos, proponiéndose como la alternativa al bypass yeyuno-ileal en una publicación del Bristish Journal of Surgery (207). Esta técnica sentó las bases de la modificación anatómica inherente a casi todo el grupo de técnicas mixtas: construcción de un reservorio gástrico de mayor o menor volumen que aporta el componente restrictivo, en el cual se realiza una anastomosis gastroentérica que constituye la vía de salida del contenido hacia la denominada asa alimentaria. La bilis y el jugo pancreático circulan sin contacto con los nutrientes por el asa biliopancreática hasta una segunda anastomosis entre ella y el asa alimentaria, dado que el paso de contenido alimentario por el duodeno está excluido. A continuación, se mezcla el alimento con las secreciones digestivas y avanza por el llamado asa común, donde acontece una absorción minimizada de los nutrientes, principalmente de las grasas, lo cual constituye el componente malabsortivo de la técnica (177).

Pasados diez años tras la descripción de la DBP de Scopinaro, comenzó a ponerse en práctica, por el grupo de D. Hess, una nueva técnica que modificaba a aquélla con un mayor componente restrictivo basado en una gastrectomía vertical con anastomosis a nivel de la primera porción duodenal, aunque alargando el asa común a fin de reducir la 
incidencia de complicaciones nutricionales: la derivación biliopancreática con CD [Véase figura 4b]. El trabajo de Hess et al. (208) con la descripción de resultados de esta técnica fue publicado en 1998, al igual que el del grupo de Marceau et al. (209).

Figura 4. DBP de Scopinaro (4a) y CD (4b).

$4 \mathrm{a}$

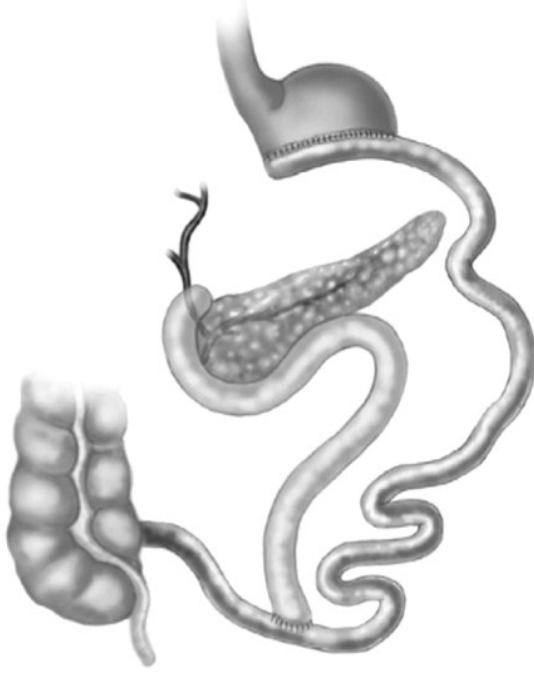

$4 \mathrm{~b}$

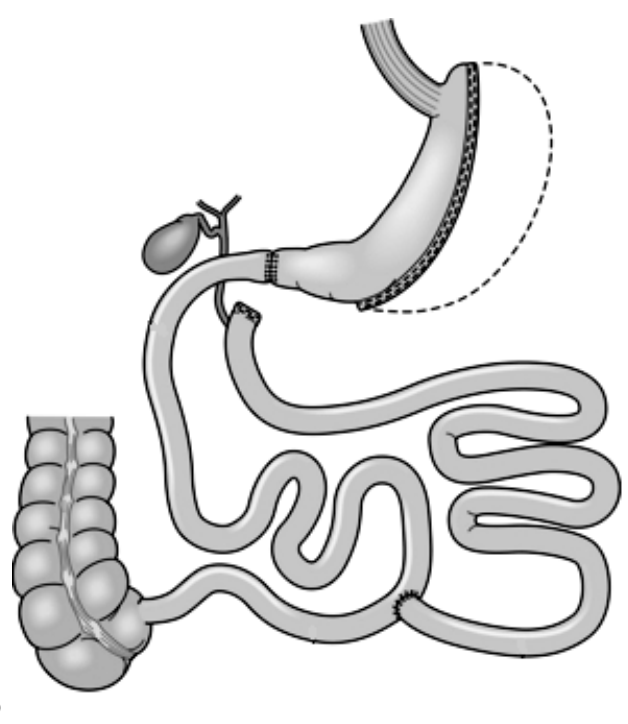

En 1967, E.E. Mason y C. Ito publicaron (210) un procedimiento bariátrico que consistía en una transección gástrica preservando únicamente el $10 \%$ proximal del estómago como reservorio, junto con una anastomosis lateral gastroentérica similar a la reconstrucción de Billroth tipo II. Esta técnica mixta, con acción restrictiva y mínimamente derivativa, sufriría ulteriores modificaciones con el fin de evitar la úlcera de boca anastomótica, quedando finalmente establecida la reconstrucción en Y de Roux con un reservorio gástrico de muy pequeño volumen $(30 \mathrm{ml})$ como características fundamentales del BGYR [Véase figura 5a] (177). Durante las tres últimas décadas, se describieron además las modificaciones del BGYR: el llamado bypass de asa alimentaria corta $(<100 \mathrm{~cm}$, también llamado proximal), el de asa alimentaria larga $(>100 \mathrm{~cm}$,) y denominado "distal" (200-250 cm de asa alimentaria con 100-150 cm de asa común) que ofrece mayor componente 
derivativo aproximándose a una DBP (177), la técnica de Salmon y, por último, el BGYR anillado descrito por Capella et al. (211) y Fobi et al. (212) para aumentar el efecto restrictivo, y en el caso de la técnica de Fobi, descomprimir el estómago residual mediante una gastrostomía. El desarrollo de este procedimiento culminó con su realización por vía laparoscópica por Wittgrove et al. en 1994 (213).

Recientemente, se han descrito nuevos procedimientos mixtos que no siguen el esquema anatómico general ya mencionado, volviendo a reconstrucciones que remedan un Billroth II tal y como describieron inicialmente Mason e Ito: técnica del Single Anastomosis Duodeno-Ileal Bypass with Sleeve Gastrectomy [Véase figura 5b] publicada por el español Sánchez-Pernaute et al. (214) y técnica del Mini-Gastric Bypass de R. Rutledge (215).

Figura 5. Técnica de BGYR (5a) y de Single Anastomosis Duodeno-Ileal Bypass with Sleeve Gastrectomy (5b).

$5 a$

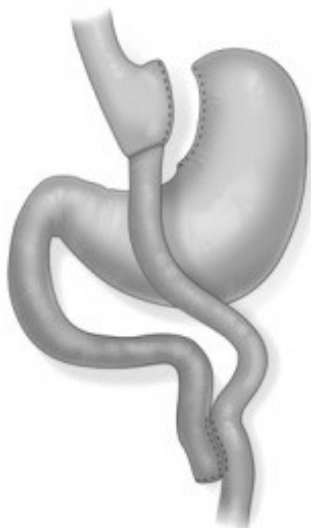

$5 b$

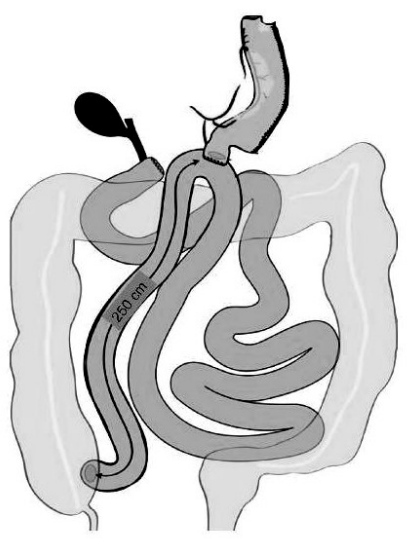

El mecanismo de acción de las técnicas mixtas consiste, de forma genérica, en la conjunción del componente restrictivo, ya explicado en el epígrafe anterior, y del malabsortivo mencionado al inicio de éste, especialmente debido a la menor absorción lipídica, ya que ésta sólo tiene lugar en el asa común. Además de este doble mecanismo 
para la pérdida ponderal, se suman otros efectos de este grupo de procedimientos bariátricos como son (177):

- Sd. Dumping. Considerado como una complicación en la cirugía resectiva gástrica y también de los procedimientos mixtos de $\mathrm{CB}$, ha sido interpretado por algunos autores como un efecto beneficioso, que contribuye al mecanismo restrictivo, debido a la desagradable respuesta fisiopatológica que implica en el enfermo. El contenido gástrico, insuficientemente digerido y que progresa hacia el intestino directamente en ausencia de válvula pilórica, es hiperosmolar y desencadena hipovolemia relativa y una reacción vagal, generando dolor abdominal, náuseas, mareos, debilidad y taquicardia pasados unos 30-60 minutos de la ingesta, especialmente en el caso de alimentos de alta densidad energética.

- Modificación hormonal. Además del efecto sobre la ghrelina previamente expuesto [Véase epígrafe 1.5.4.1.- Técnicas restrictivas], existen otras alteraciones secundarias al mecanismo derivativo que resultan favorables, en especial sobre la DM2, habiéndose postulado dos hipótesis basadas en las hormonas incretinas, las cuales favorecen la liberación de insulina, y que son comunes con la cirugía metabólica. La teoría del intestino proximal establece que la exclusión del tránsito alimentario por el duodeno desactivaría la síntesis de factores anti-incretínicos (aún no identificados) y promovería los efectos pro-incretínicos, con aumento de los niveles de Glucagon Like Peptide-1, el cual estimula las células $\beta$ pancreáticas. La hipótesis del intestino distal sostiene que el lugar de máxima estimulación de los efectos incretínicos sería el yeyuno distal y el íleon, de modo que la 
llegada precoz de nutrientes a este tramo de intestino liberaría el GlucagonLike Peptide-1 y el péptido YY, el cual mejora la RI.

En relación a la tendencia actual en $\mathrm{CB}$, se debe exponer que el BGYR se ha propugnado como la técnica mixta de referencia, manteniéndose las cifras de realización prácticamente estables entre 2008 (49\%), 2011 (46,6\%) y 2013 (45\%), según el artículo de Angrisani et al (169). Una situación análoga, aunque a mucha menor escala, ocurre con las técnicas predominantemente malabsortivas (DBP y CD), las cuales, según confirma este mismo artículo, suponen desde 2008 en torno al 2\% del total de las indicaciones de CB a nivel mundial, siendo el área de América Latina donde mayor porcentaje se acumula $(2,4 \%$ en 2013).

Respecto a los resultados, el ya mencionado meta-análisis de Chang et al. (166) sostiene que los procedimientos mixtos, que se encuentran englobados conjuntamente en este artículo como gastric bypass, son las técnicas que mayor pérdida ponderal a largo plazo consiguen. La PEPP al primer año es del $72,32 \%$ en estudios aleatorizados y al quinto, de 64,92\%, aunque el dato procede únicamente de estudios observacionales. La tasa de resolución de las CAO empleando este grupo de procedimientos son, asimismo, más elevadas frente a otras intervenciones de CB: remisión de DM en un 95,15\%, remisión de HTA en un $80.98 \%$, remisión de dislipemia en un 80,16\% y remisión de SAOS en un 95,41\% (todas ellas son cifras procedentes de ensayos clínicos). Un reciente artículo de revisión publicado en el British Journal of Surgery (216) sobre los resultados de algunos procedimientos bariátricos, concluye que la DBP y el CD son las que alcanzan mejores resultados ponderales a largo plazo (71,7\% de PEPP tras 10 años), dato que también sostiene la última revisión de la Cocbrane Collaboration sobre $\mathrm{CB}$, aunque a expensas de 
mayor tasa de reintervención en el grupo de CD (16,1-27,6\%) que en el de BGYR (4,3$8,3 \%)(168)$.

\subsection{5.- COMPLICACIONES}

Como ya se expuso en el epígrafe 1.5.3.- Resultados y criterios de calidad, existen unas cifras máximas de morbilidad y mortalidad propuestas como estándares de calidad en CB. A continuación, se desarrollan las complicaciones médicas y quirúrgicas de mayor trascendencia, algunas de las cuales son específicas de un grupo concreto de técnicas. Para una mejor comprensión, se clasificarán y expondrán según su presentación temporal.

\subsubsection{1.- Complicaciones médicas}

En el postoperatorio precoz, las complicaciones médicas de mayor relevancia que puede sufrir el obeso intervenido son la TVP y el TEP. Una publicación de 2011 empleando datos del Bariatric Outcomes Longitudinal Database con casi 74000 pacientes estudiados (217) sostiene que la incidencia de esta complicación es del 0,42\%, aconteciendo preferentemente tras el alta hospitalaria en los primeros 90 días de postoperatorio. El análisis de subgrupos de este estudio reveló que la DBP con o sin CD y la cirugía por vía abierta están gravadas con mayor tasa de TEP. La insuficiencia respiratoria postquirúrgica, así como las complicaciones pulmonares infecciosas, alcanzan frecuencias del $0,6 \%$, lo que supone el 18,7\% de la morbilidad global del obeso sometido a CB en los primeros 30 días, tal y como sostiene un artículo que empleó la base de datos de CB del American College of Surgeons (218). Las consecuencias de las complicaciones respiratorias, según este trabajo, suponen mayor estancia hospitalaria y mayor mortalidad y, de nuevo, las técnicas más agresivas, como el $\mathrm{CD}$, se asociaron con un riesgo incrementado de aparición de morbilidad pulmonar en el análisis multivariante (OR $=13.89)$. Las complicaciones 
cardiológicas, en concreto el IAM postquirúrgico precoz, se ha estimado en un 0,2\% (219). Por último, es necesario mencionar el riesgo de hipoglucemias hiperinsulinémicas que pueden desencadenarse en el postoperatorio temprano y tardío, especialmente tras la realización de técnicas mixtas como el BGYR, y que obliga a una monitorización glucémica exhaustiva. La incidencia de este trastorno no supera el 1\% y en su etiología se encuentran implicadas las hormonas incretinas y la nesidioblastosis pancreática (220).

A medio y largo plazo, cobran una importancia capital los déficits nutricionales, entre ellos la ferropenia, que según el meta-análisis de Gloy et al. (165) es el más frecuente. Generalmente estos déficits son más habituales y graves tras los procedimientos mixtos preferentemente malabsortivos (DBP y CD), pero también pueden establecerse con otros tipos de técnicas. No obstante, en algunos obesos ya se encuentran presentes incluso antes de someterse a CB, tal y como sostienen De Luis et al. (221). Los estados carenciales postbariátricos se clasifican de la siguiente manera (177,221-225):

- Déficit de macronutrientes. La desnutrición proteica, con una incidencia global de hasta el $8 \%$ tras un procedimiento mixto (hasta $24 \%$ en DBP y CD), es una entidad grave que repercute sobre el compartimento muscular y visceral y se manifiesta analíticamente como hipoalbuminemia e hipotransferrinemia. Se recomienda una ingesta proteica mínima de 60 gramos (g)/día.

- Déficit de micronutrientes: vitaminas. En primer lugar, las hipovitaminosis de vitaminas hidrosolubles son de gran interés tras $\mathrm{CB}$. Los vómitos de repetición, que pueden desencadenarse tras procedimientos restrictivos, son la causa de déficit de tiamina, aunque su incidencia global es muy baja. La alteración de la absorción de vitamina B12 y su consiguiente carencia, por 
hipoclorhidria y por ausencia de factor intrínseco sintetizado en las células parietales gástricas, es muy frecuente tras el BGYR (hasta el $70 \%$ en las series más desfavorables). Las necesidades diarias de esta vitamina no quedan cubiertas con la ingesta alimentaria, incluso a veces, tampoco con suplementos polivitamínicos orales, obligando a administración intramuscular. La carencia de ácido fólico es debida a la exclusión duodenal, por lo que también es muy común tras el BGYR (hasta 30\%). En segundo lugar, las hipovitaminosis de vitaminas liposolubles (A, D, E, K) no son infrecuentes tras los procedimientos malabsortivos. La carencia de vitamina D, con el consecuente trastorno del metabolismo fosfocálcico, reviste gran importancia, ya que es causa de enfermedad mineral ósea a medio y largo plazo y es muy común no sólo en el seguimiento postbariátrico, sino también en muchos obesos antes de someterse a CB (en nuestro entorno, hasta en el $71,3 \%$ según el citado artículo de De Luis et al.). La hipovitaminosis D y la hipocalcemia son el resultado de una insuficiente absorción intestinal por la propia intervención, además de una ingesta oral deficiente y una escasa exposición solar de los obesos. De este modo, la hipocalcemia desencadena un estado de hiperparatiroidismo secundario cuyo objetivo es mantener en rango normal los niveles plasmáticos de calcio, a expensas de pérdida de densidad mineral ósea. Por todo ello, la suplementación con calcio y colecalciferol, así como el estudio regular mediante densitometría ósea, está completamente avalado en la literatura. La incidencia de hipovitaminosis A, E y $\mathrm{K}$ es variable según las series publicadas, estando favorecidas por la técnica de DBP, preferentemente. 
- Déficit de micronutrientes: oligoelementos minerales. La ferropenia es muy frecuente tras CB, especialmente tras BGYR (incidencia hasta 50\%) y su etiología responde a una pléyade de mecanismos: hipoclorhidria gástrica, que dificulta la liberación de hierro alimentario con menor reducción de hierro férrico a ferroso (más soluble para ser absorbido) y malabsorción por exclusión duodenal. Por ello, es necesaria una suplementación con 40-60 $\mathrm{mg} /$ día, que en caso de no alcanzarse por vía oral, obligaría a ferroterapia intravenosa. Otras carencias de minerales son las de cobre, magnesio, selenio y, por último, la de zinc, la segunda en frecuencia de este grupo tras la de hierro. El déficit de calcio y fósforo ya ha sido mencionado conjuntamente con la hipovitaminosis de vitamina D.

El riesgo potencial de aparición de este grupo de complicaciones obliga a un seguimiento analítico estricto tras $\mathrm{CB}$ y a una suplementación oral de por vida, tal y como recomiendan las actuales guías de CB europeas y norteamericanas $(172,175)$, ya que pueden desencadenarse funestas consecuencias clínicas para el obeso intervenido. Los estados carenciales inducen trastornos sobre diversos órganos y sistemas que se enumeran, de forma sucinta, a continuación (226): edemas y anasarca por hipoproteinemia, insuficiencia cardíaca de alto gasto en el beri-beri por déficit de tiamina; diarrea por déficit de niacina y esteatorrea por malabsorción lipídica; manifestaciones cutáneas asociadas mayoritariamente a hipovitaminosis A; afectación oftalmológica (nictalopia y retinopatía) por déficit de vitaminas A y E; clínica neurológica variada (encefalopatía de Wernicke por déficit de tiamina, neuropatía periférica por hipovitaminosis B12, manifestaciones neuropsíquicas del beri-beri y la pelagra) y, finalmente, anemia que suele ser secundaria a ferropenia y a 
carencia de vitamina B12, pero también, aunque con menor frecuencia, a otros déficits tales como, ácido fólico, cobre, proteínas o vitaminas A y E.

\subsubsection{2.- Complicaciones quirúrgicas}

En primer lugar, como puede suceder en cualquier intervención quirúrgica, existen complicaciones intraoperatorias que, aunque suelen poder resolverse sin compromiso vital para el paciente, generan situaciones de riesgo y estrés para el cirujano bariátrico y el anestesiológo. Algunas de ellas son (177,227-229): laceraciones sobre vísceras macizas del abdomen provocadas por los separadores (especialmente en cirugía laparoscópica), perforación yatrógena de víscera hueca (durante la manipulación del intestino delgado o en las maniobras de disección para confeccionar el reservorio gástrico) y complicaciones relacionadas con grapados inadvertidos de dispositivos tales como sondas de calibración o sondas nasogástricas, etc.

En segundo lugar, están descritas numerosas complicaciones propias del periodo postoperatorio precoz, aunque la mayoría son comunes a las que acontecen en intervenciones abdominales diferentes a la $\mathrm{CB}$, como por ejemplo el íleo paralítico. Su tratamiento puede ser conservador o endoscópico en algunas de ellas, mientras que en otros casos y, en función del estado del paciente, puede ser necesaria una reintervención. Se describen, seguidamente, las complicaciones precoces más características de los procedimientos bariátricos $(177,228-230)$ :

- Hemorragia intraabdominal. Esta complicación está desencadenada por sangrado a diferentes niveles: líneas de grapado, puertos laparoscópicos, laceraciones inadvertidas hepato-esplénicas causadas por separadores, hemorragia por lesión sobre los mesos de las asas intestinales, etc. De forma 
genérica, la hemorragia, ya sea intraabdominal o luminal, presenta una incidencia del 4,4\%, habiéndose descrito mayor riesgo en cirugía laparoscópica.

- Hemorragia luminal. Su presentación es en forma de hemorragia digestiva alta o baja y se manifiesta, respectivamente, como hematemesis o melenas acompañadas de un grado variable de hipovolemia y repercusión hemodinámica. La etiología es, habitualmente, el sangrado procedente de las líneas de grapado y de las anastomosis, pero también de una úlcera de estrés, situación idéntica a cualquier otro postoperatorio de cirugía mayor abdominal o extraabdominal. En el periodo postquirúrgico precoz no es frecuente la úlcera de boca anastomótica.

- Fuga. Las líneas de grapado y las anastomosis son áreas de debilidad de tracto digestivo tras la $\mathrm{CB}$, de modo que ante un eventual defecto mecánico o por incorrecta cicatrización, puede establecerse una solución de continuidad con salida de contenido a la cavidad peritoneal. Las consecuencias puede ser devastadoras, desencadenándose un absceso intraabdominal en los casos más leves, o bien una peritonitis aguda difusa que obliga a la reintervención urgente. Esta complicación es la segunda causa de exitus en pacientes sometidos a BGYR, con tasas de mortalidad que alcanzan el 37,5-50\%. En el caso de la GV, el Consenso Internacional ha descrito 4 periodos para clasificar las fugas de la "manga" gástrica, las cuales, habitualmente, se presentan en la proximidad de la unión esofagogástrica, mientras que en el caso de técnicas mixtas, la dehiscencia asienta en la gastroyeyunostomía de forma preferente. 
- Oclusión intestinal precoz. Aunque no es frecuente, las causas no difieren de la presentación de esta complicación a medio y largo plazo, por lo que serán descritas a continuación.

A medio y largo plazo, se pueden establecer diversas complicaciones tras la CB que se exponen a continuación (177,228-233):

- Litiasis biliar. Como ya se expuso al hablar de las CAO del aparato digestivo [Véase epígrafe 1.3.7.- Patología digestiva], la pérdida ponderal rápida inducida por la $\mathrm{CB}$, especialmente en el caso de técnicas mixtas, genera un estado litogénico incrementado, motivo por el cual esta complicación alcanza incidencias de hasta el 40\% según algunas series en el primer año de postoperatorio. A pesar de ello, la colecistectomía profiláctica no está actualmente indicada en $\mathrm{CB}$, si bien se ha preconizadola administración de ácido ursodesoxicólico a fin de minimizar el desarrollo de colelitiasis, en el ya citado meta-análisis de Uy et al. (147). La presentación y el manejo clínicos no difiere de la colelitiasis en pacientes no sometidos a $\mathrm{CB}$, salvo aquellos casos de presencia de coledocolitiasis en el contexto de técnicas derivativas, puesto que no es posible el acceso estándar para la realización de una colangiopancreatografía retrógrada endoscópica.

- Litiasis renal. Los desequilibrios hidroelectrolíticos que se pueden establecer tras la realización de técnicas mixtas, preferentemente, originan un riesgo incrementado de nefrolitiasis de oxalato cálcico $(\mathrm{OR}=1,71)$, con una incidencia global de esta complicación en pacientes sometidos a BGYR de 7,65\%, lo cual incrementa la probabilidad de precisar tratamiento quirúrgico urológico por este motivo $(\mathrm{OR}=3,65)$. 
- RGE. Esta patología se encuentra ya presente en muchos obesos antes de la $\mathrm{CB}$, favorecida a veces por la coexistencia de hernia de hiato [Véase epígrafe 1.3.7.- Patología digestiva], no obstante la propia intervención puede ser factor desencadenante de RGE, en especial las técnicas restrictivas (BGA y GV) que alteran manifiestamente la fisiología del estómago, aunque no existe evidencia científica clara al respecto. Según algunas series de BGA con seguimientos largos, hasta el 15\% de los pacientes sometidos a esta técnica refieren síntomas de novo de RGE. La aparición de síntomas secundarios a esta complicación obliga a la administración de inhibidores de la bomba de protones como tratamiento de primera línea y, en casos refractarios, a una cirugía de conversión a BGYR.

- Oclusión intestinal. La CB, como cualquier intervención quirúrgica abdominal genera un riesgo potencial de oclusión intestinal postquirúrgica. Es una de las complicaciones tardías más comunes y su etiología es variada: adherencial, incarceración de eventraciones de la laparotomía o de los puertos laparoscópicos, estenosis anastomóticas, presencia de bezóares en la luz intestinal y, finalmente, las secundarias a vólvulos o hernias internas. Éstas últimas son las causas más frecuentes de obstrucción intestinal tras CB $(>50 \%)$ y, además, son características de las técnicas mixtas. Esta complicación es debida a la configuración anatómica del intestino en Y de Roux, por la cual se establecen espacios entre los mesos en los cuales las asas intestinales pueden quedar incarceradas, o bien la anastomosis del pie de asa puede actuar como eje de torsión, originando un vólvulo. El abordaje laparoscópico se asocia, en diversos artículos de revisión, con una mayor incidencia de hernias internas que la cirugía abierta. El diagnóstico es, en 
ocasiones, complejo puesto que la clínica obstructiva típica puede no estar presente, requiriendo pruebas de imagen avanzadas (tomografía computerizada) y un tratamiento quirúrgico sin demora para evitar el compromiso vascular del segmento intestinal afectado.

- Diarrea, esteatorrea y patología proctológica secundaria. Esta complicación es más propia de las técnicas preferentemente malabsortivas y supone la manifestación del exceso de lípidos no absorbidos que alcanza el colon. Ello genera un incremento de la frecuencia y disminución de la consistencia de las heces, junto con un especial mal olor de las mismas. La afectación anal secundaria a esta complicación acontece hasta en el 18\% de los enfermos sometidos a DBP, según un estudio de un grupo español publicado en 2008 (231), siendo la fisura la patología proctológica más frecuente $(8 \%)$, seguida de las hemorroides $(6 \%)$.

- Eventración. Esta complicación puede aparecer después de cualquier intervención quirúrgica abdominal, incluida por supuesto, la CB. El abordaje laparoscópico presenta tasas de eventración de puerto no mayores del $2 \%$ en la mayoría de las series, mientras que la cirugía abierta está gravada con cifras de hasta $20 \%$.

- Sd. Dumping. Aunque algunos autores, como ya se ha mencionado anteriormente [Véase epígrafe 1.5.4.2.- Técnicas malabsortivas y mixtas], no lo consideran una complicación, lo cierto es que en muchos enfermos sometidos a técnicas mixtas en las que se anula la acción del píloro (BGYR y DBP), la presencia de esta entidad obliga a un reajuste dietético y en ocasiones a tratamiento farmacológico. 
Algunas complicaciones quirúrgicas son específicas de una técnica bariátrica concreta y pueden establecerse tanto en el postoperatorio precoz, como a medio-largo plazo. Se exponen resumidamente, a continuación, algunas de las más relevantes y conocidas $(177,228-230)$ :

- BGA. Disfagia aguda postoperatoria secundaria al edema generado por la banda o complicaciones derivadas de la propia banda: erosión y perforación de la banda a nivel de la pared gástrica, efecto estenosante con dilatación del reservorio y del esófago y, por último, deslizamiento de la banda (conocido por el término inglés slippage), que es la más frecuente con hasta un $20 \%$ de incidencia en algunas series. También están descritas las complicaciones derivadas del circuito de llenado de la banda y del reservorio (perforación y fuga de líquido, sobreinfección).

- GV. Estenosis de la "manga" gástrica, que suele precisar dilataciones endoscópicas, y en casos rebeldes se han descrito otras opciones terapéuticas como la seromiotomía extramucosa o la cirugía de conversión a BGYR. No obstante, la frecuencia de esta complicación es baja, sin superar el $1 \%$ en la mayoría de las series publicadas.

- Técnicas mixtas. Algunas de las complicaciones específicas de estas técnicas son la estenosis anastomótica gastroyeyunal (se manifiesta en forma de intolerancia alimentaria a partir de la tercera semana de postoperatorio, tras un periodo de ingesta normal) y la úlcera de boca anastomótica cuya etiología no está completamente aclarada, habiéndose definido como factores favorecedores el tabaquismo, el sexo femenino, administración de antiinflamatorios no esteroideos y la presencia de Helicobacter pylori. 
Existe, por último, una complicación en $\mathrm{CB}$ consistente en la insuficiente pérdida de peso o incluso la reganancia del mismo, definida en la mayoría de los artículos como una PEPP $<50 \%$ tras 18 meses aunque sin un consenso claramente establecido (234), o bien un inadecuado control de las CAO, de tal modo que el obeso sometido a CB puede llegar a requerir la realización de la llamada cirugía de revisión. La frecuencia varía desde el 5\% en las técnicas preferentemente malabsortivas, hasta el 50\% en las series más desfavorables de BGA (235). La evaluación ha de ser exhaustiva, determinando otras causas subyacentes no relacionadas con la propia CB: trasgresiones dietéticas por parte del enfermo, incorrecto despistaje de patología endocrino-metabólica como responsable de la $\mathrm{OM}$ antes de la primera $\mathrm{CB}$ o, en ocasiones, trastornos psiquiátricos que interfieren con una adecuada evolución postbariátrica. Sin embargo en otros pacientes, la etiología de la insuficiente pérdida ponderal sí es secundaria a defectos de la CB: mala indicación de la técnica en función de las características del paciente, readaptación del tracto digestivo a la técnica (dilatación del reservorio gástrico, hiperplasia de las vellosidades intestinales en el asa común) y problemas técnicos relacionados con el procedimiento primario (reservorios o anastomosis muy grandes o dilatadas, fístula reservorio-gástrica, incorrecta configuración anatómica de las asas en los procedimientos derivativos, problemas relacionados con bandas o anillas en el reservorio). Los resultados de la CB revisional, al igual que la morbimortalidad asociada a ella, son peores que en las intervenciones primarias (235), aunque la descripción pormenorizada de los mismos y de las opciones quirúrgicas propiamente dichas excede el alcance de esta Introducción.

\subsection{6.- LA DERIVACIÓN BILIOPANCREÁTICA DE SCOPINARO}

En 1976, N. Scopinaro, de la Universidad de Génova, publicó un trabajo preliminar en la revista italiana Minerva Chirurgica (236) acerca de una nueva técnica de CB que 
denominó DBP y que presentaba ventajas notables frente al bypass yeyuno-ileal, como demostró posteriormente tras la realización de la intervención en perros (206):

- Evita la presencia de un asa ciega en el tracto digestivo.

- No altera la absorción hidroelectrolítica ni de sales biliares con una normal recirculación enterohepática.

- La readaptación de la capacidad absortiva es lenta.

En base a ello, presentó resultados favorables en una muestra de 18 obesos sometidos a DBP tras un año de seguimiento en 1979: PTPP del 33,7\% y mejora histológica al realizar controles de biopsia hepática, registrando únicamente, un caso de dehiscencia de herida quirúrgica como complicación (207). El propio Scopinaro publicó, un año más tarde, la serie de 66 pacientes sobre los que se aplicaron siete variantes de su procedimiento, modificando las longitudes de las asas para determinar el grado de malabsorción y pérdida de peso tras cada una de ellas, y notificando el primer exitus por TEP de la cohorte (231). La técnica quedó, inicialmente, definida como una transección gástrica horizontal con resección distal y sección en la primera porción duodenal, preservando un reservorio a expensas del fundus de unos 200-500 $\mathrm{ml}$ de volumen, seguido de anastomosis gastroentérica no calibrada, y reconstrucción en Y de Roux mediante pie de asa en ileon terminal, siendo $50 \mathrm{~cm}$ la longitud del asa común y $150 \mathrm{~cm}$ la del asa alimentaria (237).

La técnica original de DBP fue modificada por el propio N. Scopinaro, definiendo la variante ad-hoc stomach. En ella, el volumen del reservorio gástrico se ajusta según el grado de exceso de peso del paciente con el fin de de asegurar una pérdida ponderal progresiva durante el primer año y el riesgo malnutrición proteica queda restringido, únicamente, a 
aquellos obesos intervenidos con IMC muy elevados. Posteriormente, se añadió una segunda modificación conocida como ad-hoc stomach/ad-hoc alimentary limb, en la cual se añadían cambios en la longitud del asa alimentaria en función de los hábitos de ingesta del paciente, logrando resultados ponderales satisfactorios con un mínimo de complicaciones $(237,238)$. La viabilidad de realizar la DBP por vía laparoscópica también ha sido confirmada por el grupo de Scopinaro, notificando resultados similares a la cirugía abierta (239).

Otros autores de nuestro país, como M. Martínez Díez, A. Larrad o J.J. Resa, han realizado sus propias modificaciones de la DBP original de Scopinaro consistentes en: transección gástrica sin hemigastrectomía distal, alargar el asa común, alargar el asa alimentaria a expensas de una menor longitud de asa biliopancreática, etc. La finalidad de ellas es (177):

- Reducir las complicaciones por carencias nutricionales especialmente de vitaminas liposolubles e, igualmente, garantizar una adecuada producción de ácido clorhídrico y factor intrínseco a fin de minimizar el riesgo de ferropenia e hipovitaminosis B12.

- Evitar la existencia de un cierre de muñón duodenal que pudiera incrementar el riesgo de fístula digestiva.

- Hacer el procedimiento más rápido y seguro acortando el tiempo quirúrgico-anestésico.

- Permitir la posibilidad de revertir completamente la técnica dado que no existe resección gástrica. 
El mecanismo de acción de la DBP, indistintamente de la variante técnica empleada, es el de un procedimiento mixto como ya se ha expuesto anteriormente [Véase epígrafe 1.5.4.2.- Técnicas malabsortivas y mixtas]. En términos del propio N. Scopinaro, existe un mecanismo inicial de pérdida de peso merced al componente restrictivo y al paso rápido del contenido gástrico al asa eferente. Ello genera un síndrome postprandial al paciente que limita el apetito pero sin desencadenar las manifestaciones vasomotoras desagradables del Sd. Dumping. Este efecto decrece progresivamente a lo largo del primer año postoperatorio por distensión del reservorio, permitiendo al enfermo un volumen de ingesta normal, quedando compensado por el efecto malabsortivo sobre los lípidos y el almidón que perdura en el tiempo, hecho que garantiza el mantenimiento de la pérdida ponderal y la resolución de las CAO a medio-largo plazo $(177,237,238)$. No obstante, según publicaron Stock-Damgé et al. (240), del grupo de Scopinaro, se produce una adaptación intestinal con incremento de la altura de los villi de los enterocitos, así como de la actividad enzimática, que intenta compensar el efecto malabsortivo de la DBP.

El autor de la técnica de DBP, sostiene en un artículo publicado en 2006 en Obesity Surgery que su técnica es una "potente arma" para el tratamiento quirúrgico de la OM, logrando, en la serie de pacientes sometidos a la variante ad-hoc stomach/ad-hoc alimentary limb, una tasa de reintervención del 1\%, una incidencia de malnutrición proteica $<3 \%$ y de aparición de úlcera marginal del 4\%, junto con una desaparición completa de complicaciones neurológicas postbariátricas secundarias a déficit vitamínicos (237). Estas cifras se correlacionaron con unos valores muy positivos aplicando el cuestionario BAROS [Véase epígrafe 1.5.3.- Resultados y criterios de calidad], según publicaron Marinari et al. (241), también del grupo de Scopinaro, sobre 858 pacientes con 15 años de seguimiento máximo: un 22,8\% con score de buenos resultados; muy buenos resultados en el 39,5\%, y el 
$23,2 \%$ alcanzaron excelentes resultados, existiendo diferencias favorables a la cohorte de obesos con DBP variante ad-hoc stomach/ad-hoc alimentary limb [Véase tabla 19]. En relación a la mejoría de CAO tras DBP, según este mismo artículo, se registró 100\% de resolución para la DM2, la dislipemia, el SAOS y el Sd. Pickwick y un 87\% para la HTA.

Tabla 19. Resultados de la técnica de Scopinaro aplicando el cuestionario BAROS, con 15 de años de seguimiento, según subgrupos de las variantes técnicas de DBP (241).

\begin{tabular}{|c|c|c|c|}
\hline \multicolumn{4}{|c|}{ RESULTADOS DEL CUESTIONARIO BAROS EN DBP } \\
\hline RESULTADO & $\begin{array}{c}\text { DBP (SERIE } \\
\text { COMBINADA) }\end{array}$ & $\begin{array}{c}\text { DBP } \\
\text { (ad-hoc stomach) })\end{array}$ & $\begin{array}{c}\text { DBP (ad-hoc } \\
\text { stomach/ad-hoc } \\
\text { alimentary limb) }\end{array}$ \\
\hline Score de fracaso & $3,5 \%$ & $6 \%$ & $2 \%$ \\
\hline $\begin{array}{c}\text { Score de resultados } \\
\text { aceptables }\end{array}$ & $11 \%$ & $11 \%$ & $6 \%$ \\
\hline $\begin{array}{c}\text { Score de resultados } \\
\text { buenos }\end{array}$ & $22,8 \%$ & $24 \%$ & $20 \%$ \\
\hline $\begin{array}{c}\text { Score de resultados } \\
\text { muy buenos }\end{array}$ & $39,5 \%$ & $36 \%$ & $47 \%$ \\
\hline $\begin{array}{c}\text { Score de resultados } \\
\text { excelentes }\end{array}$ & $23,2 \%$ & $23 \%$ & $25 \%$ \\
\hline PEPP a 15 años & $69 \pm 15 \%$ & $70,5 \pm 23 \%$ & $64,7 \pm 17 \%$ \\
\hline
\end{tabular}

Por último, cabe mencionar que, recientemente, el grupo de Scopinaro también ha publicado resultados de la técnica de DBP empleada como cirugía metabólica en pacientes con DM2 sin OM. Esta intervención mejora el control metabólico en todos los individuos pero sólo se alcanza remisión de la DM2 $(\mathrm{HbA} 1 \mathrm{C}<6.5 \%$ y test de tolerancia oral a la glucosa normal) en un tercio. Además, los autores observaron que el principal predictor de este efecto es el grado preoperatorio de incompetencia de las células $\beta$, mientras que la pérdida ponderal inducida por la DBP posee menor influencia en los resultados (242). 


\section{6.- JUSTIFICACIÓN}

Aunque la técnica de DBP está perfectamente analizada y contrastada, gracias especialmente a los trabajos del grupo del autor que la describió, N. Scopinaro, su tasa de indicación a nivel mundial es muy escasa, tal y como describieron Angrisani et al. (169). Por tanto, es de esperar que cada vez se publiquen menos estudios de obesos sometidos a este procedimiento, con la consecuente restricción de conocimiento de sus resultados a largo plazo presentada por grupos de CB diversos, diferentes del italiano.

Así pues, con este trabajo se pretenderá, en primer lugar, analizar los resultados ponderales, metabólicos y de morbimortalidad postquirúrgica, actualizando los datos ya publicados por nuestra Unidad de OM en 2005 (243) y 2008 (244). De igual modo, se realizará una comparación entre los obesos con resultado poderal insuficiente y aquellos con buena pérdida de peso a fin de detectar las características preoperatorias que puedan comportarse como predictores de fracaso ponderal, dada la controversia existente en la literatura, y más aún para la técnica de DBP.

En relación a la mejora de las $\mathrm{CAO}$, se emplearán los criterios establecidos en el consenso de SM de 2009 publicados por Alberti et al. (96), los cuales son más estrictos que los propuestos por otras sociedades científicas, a fin de relacionar con la máxima exactitud y homogeneidad posible todas las variables asociadas a la modificación del metabolismo de la glucosa y de los lípidos así como a la PA. De igual modo, se analizarán los parámetros de estado nutricional y del metabolismo del calcio y la vitamina $\mathrm{D}$, dado que la DBP provoca de forma característica, una alteración en los mismos, al tratarse de una técnica bariátrica mixta predominantemente malasbsortiva. 
Finalmente, el OS-MRS es un score útil y validado para estimar la mortalidad postbariátrica precoz, aunque apenas hay datos publicados en relación a la técnica bariátrica que se analizará en este trabajo. En consecuencia, también se pretenderá con este estudio comprobar su capacidad predictora en nuestra serie de obesos intervenidos con DBP. Igualmente, compararemos las tres categorías de este índice con la intención de determinar su utilidad, no sólo como predictor de mortalidad, sino también de los resultados postbariátricos, en términos de descenso ponderal y de resolución de $\mathrm{CAO}$, teniendo en cuenta que hasta la fecha no existe ningún estudio que lo analice. 


\section{2.- OBJETIVOS}





\section{2.- OBJETIVOS}

1. Describir una muestra de pacientes con obesidad mórbida intervenidos mediante derivación biliopancreática en el Hospital Universitario Río Hortega de Valladolid.

2. Analizar la pérdida de peso en los pacientes con obesidad mórbida tratados mediante derivación biliopancreática que realizan su seguimiento en el Hospital Universitario Río Hortega de Valladolid y determinar las características predictoras de fracaso ponderal tras cirugía bariátrica.

3. Valorar los efectos sobre los criterios de glucemia, presión arterial y triglicéridos para el síndrome metabólico y sobre los marcadores analíticos de desnutrición en los pacientes con obesidad mórbida tratados mediante derivación biliopancreática y con seguimiento en el Hospital Universitario Río Hortega de Valladolid.

4. Analizar los efectos de la derivación biliopancreática sobre la morbimortalidad postoperatoria precoz en los pacientes obesos tratados con esta técnica bariátrica en el Hospital Universitario Río Hortega de Valladolid.

5. Valorar en nuestra serie la utilidad del Obesity Surgery-Mortality Risk Score como predictor de morbilidad grave y mortalidad postquirúrgicas.

6. Evaluar el Obesity Surgery-Mortality Risk Score como predictor de los efectos ponderales y metabólicos y de la estancia hospitalaria tras derivación biliopancreática en pacientes con obesidad mórbida tratados en el Hospital Universitario Río Hortega de Valladolid. 



\section{3.- PACIENTES Y MÉTODOS}





\section{3.- PACIENTES Y MÉTODOS}

\section{1.- TIPO DE ESTUDIO}

El diseño del estudio será observacional comparativo de tipo cohortes históricas (retrospectivas) a partir de la base electrónica de datos clínicos de nuestro centro.

\section{2.- POBLACIÓN A ESTUDIO}

La población a estudio de este trabajo serán los pacientes sometidos a CB con técnica de DBP de Scopinaro en el Hospital Universitario Río Hortega (HURH) de Valladolid (España), desde el inicio de la actividad quirúrgica (marzo de 2001) hasta marzo de 2013.

La técnica de DBP de Scopinaro, realizada por dos cirujanos expertos en procedimientos bariátricos (doctores A. A. y D. P.), ha sido la empleada mayoritariamente en los enfermos intervenidos en nuestro centro. Recientemente, se han llevado a cabo algunas $\mathrm{GV}$, pero con un corto período de seguimiento, motivo por el cual se ha desestimado establecer un análisis comparativo entre ambas técnicas. Asimismo, también se ha practicado en algunos enfermos el BGYR laparoscópico pero, dado su reducido número, no ha sido posible tampoco llevar a cabo un estudio comparativo que alcanzara significación estadística. 
Nuestra Unidad de OM y CB es de referencia para las Áreas sanitarias Este y Oeste de Valladolid, así como para las Áreas de Palencia y Segovia, por lo que la muestra de enfermos corresponderá a la población sometida a CB de estas tres provincias en particular, pudiendo ser extrapolable a Comunidad Autónoma de Castilla y León en general.

Los enfermos que se incluyan para obtener resultados de las variables postoperatorias serán aquellos que pertenecen al Área sanitaria Oeste de Valladolid, a quienes les corresponde, por tanto, nuestro centro a efectos de seguimiento endocrinológico tras la CB. De todos ellos se dispone de datos ponderales, clínicos, analíticos y terapéuticos actualizados y fidedignos, sin menoscabo de otros obesos intervenidos y que no pertenecen al Área Oeste de Valladolid, aunque, por distintos motivos, también reciben seguimiento en nuestra unidad. Por esta razón, serán incluidos igualmente para el estudio de las variables postoperatorias.

\subsection{1.- CRITERIOS DE INCLUSIÓN}

Los criterios empleados para la inclusión de enfermos en la muestra que se analizará en este estudio serán los siguientes:

- Pacientes con indicación de CB según las guías europeas (175), en los que se ha practicado la técnica de DBP de Scopinaro en el HURH de Valladolid (España), desde marzo de 2001 hasta marzo de 2013.

- Firma de consentimiento informado para la participación en el estudio.

Todos los enfermos candidatos a $\mathrm{CB}$ que se valoran en la Unidad de $\mathrm{OM}$ de nuestro centro, lo hacen siguiendo el "Protocolo para la práctica de Cirugía de la Obesidad", debiendo cumplir los criterios clínicos establecidos en el mismo para ser 
intervenidos, así como realizar el seguimiento postoperatorio en base a los controles que están reflejados en dicho protocolo. De este modo, se garantiza un manejo global del paciente obeso sometido a CB que es homogéneo desde el punto de vista clínico y acorde al estado del arte desde el punto de vista científico [Véase epígrafe 3.3.- Protocolo clínico empleado].

\subsection{2.- CRITERIOS DE EXCLUSIÓN}

Se excluirán del presente estudio todos aquellos pacientes que presenten uno o más de los siguientes criterios, a saber:

- Ausencia de cumplimiento de los criterios para CB señalados en el "Protocolo para la práctica de Cirugía de la Obesidad" de la Unidad de OM de nuestro centro.

- Técnica bariátrica diferente de la DBP de Scopinaro.

- $\mathrm{CB}$ no primaria, es decir, aquellas intervenciones realizadas como cirugía de conversión a DBP tras otra técnica previa fallida.

- Para los pacientes con seguimiento postbariátrico en nuestro centro, se desestimarán, a efectos del análisis de las variables postoperatorias, todos aquellos con seguimiento menor de 60 días.

\subsection{3.- TAMAÑO MUESTRAL Y MUESTREO}

La selección de la muestra se ha realizado mediante reclutamiento de casos consecutivos (muestreo no probabilístico), identificando todos los individuos que cumplían criterios de inclusión y exclusión en el periodo de estudio, mediante el empleo de la base de datos de CB de nuestra Unidad de OM. 
Tal y como se ha especificado anteriormente, para el análisis de las variables demográficas, las variables preoperatorias y las variables asociadas al ingreso hospitalario, se empleará la muestra completa de enfermos sometidos a CB en el HURH de Valladolid siguiendo los criterios descritos. Sin embargo, solamente se analizarán resultados de variables postoperatorias en los pacientes con seguimiento postbariátrico realizado en nuestro centro más allá del día 60 de postoperatorio, según lo indicado en los criterios de exclusión. Con estas directrices, el tamaño muestral conseguido es de 274 pacientes intervenidos de CB mediante DBP de Scopinaro en el HURH y de 113 con seguimiento postbariátrico en nuestra Unidad de OM y CB. 


\section{3.- PROTOCOLO CLÍNICO EMPLEADO}

Se expone a continuación, de forma resumida, el manejo general de los pacientes con $\mathrm{OM}$ que son valorados y tratados mediante $\mathrm{CB}$ en nuestro centro, en base al "Protocolo para la práctica de Cirugía de la Obesidad", el cual fue redactado y se mantiene periódicamente actualizado por el endocrinólogo y el cirujano bariátrico responsables de la Unidad (doctores D. d. L. y D. P.). 


\title{
PROTOCOLO PARA LA PRÁCTICA DE CIRUGÍA DE LA OBESIDAD
}

\author{
HOSPITAL U. RÍO HORTEGA DE VALLADOLID
}

\section{1.- CRITERIOS DE DERIVACIÓN DE PACIENTES}

Los pacientes con $\mathrm{OM}$ y potenciales candidatos a $\mathrm{CB}$ podrán ser derivados a esta Unidad desde Atención Primaria del Área Sanitaria de Valladolid Oeste, o bien desde los servicios/secciones de Endocrinología de otras Áreas Sanitarias (Valladolid Este, Palencia, Segovia). Se muestra a continuación los criterios necesarios para esta remisión de los pacientes.

\section{1.- DERIVACIÓN DE PACIENTES DESDE ATENCIÓN PRIMARIA}

Se remitirán para valoración en la consulta de Endocrinología y Nutrición con vistas a posible CB solamente los pacientes del Área Oeste de Valladolid a través de su médico de Atención Primaria, siempre y cuando se cumplan los siguientes criterios:

- $\quad \mathrm{IMC}>35 \mathrm{Kg} / \mathrm{m}^{2}$.

- Edad entre 18 y 65 años

- Ausencia de psicopatología grave: retraso mental severo, bulimia nerviosa, psicosis, etilismo, drogadicción.

- Ausencia de patología orgánica del tipo: cirrosis hepática, insuficiencia renal grave, enfermedad inflamatoria intestinal, infarto agudo de miocardio hace menos de 6 meses.

La hoja de derivación desde Atención Primaria debe ir acompañada de la Hoja Específica de Obesidad Mórbida adecuadamente cumplimentada (ver anexo I).

\section{2.- DERIVACIÓN DE PACIENTES DESDE LAS SECCIONES DE ENDOCRINOLOGÍA DE OTRAS ÁREAS SANITARIAS}

La Sección de Endocrinología y Nutrición del Hospital U. Río Hortega recibirá pacientes remitidos por especialistas de Endocrinología y Nutrición de su ámbito de actuación: Hospital Clínico de Valladolid, H. Río Carrión de Palencia y Hospital General de Segovia. La hoja de derivación remitida por estos especialistas debe ir acompañada de un Informe Clínico, de la Hoja Especifica de Obesidad Mórbida adecuadamente cumplimentada, así como de las pruebas complementarias que se detallan en la hoja anteriormente referida (véase anexo II). 


\section{2.- CIRCUITO ASISTENCIAL}

Tras la selección definitiva de los obesos candidatos a $C B$ en la consulta de Endocrinología, previa realización de una batería de pruebas diagnósticas, el enfermo será remitido a consulta de Cirugía Bariátrica (Servicio de Cirugía General y Digestiva del Hospital U. Río Hortega), donde se dictaminará definitivamente la indicación de CB, así como de la técnica más adecuada. A continuación, se solicitará el estudio preoperatorio, incluyendo en caso necesario nuevas pruebas complementarias, junto con la valoración preanestésica.

\section{1- CONSULTA DE ENDOCRINOLOGÍA}

\section{A.- SELECCIÓN DE PACIENTES}

Los pacientes candidatos a Cirugía de la Obesidad deben cumplir los siguientes criterios:

- $\quad I M C>40 \mathrm{Kg} / \mathrm{m}^{2}$ mantenido más de 3-5 años.

- IMC entre 35 y $40 \mathrm{Kg} / \mathrm{m}^{2}$, si se presentan comorbilidades asociadas que limitan su vida diaria y son susceptibles de mejorar con la pérdida de peso: diabetes mellitus, hipertensión arterial, hiperlipemia, síndrome de apnea obstructiva del serio, artropatía en articulaciones de carga, afectación psicosocial.

- Edad entre 18 y 65 años.

- Ausencia de endocrinopatías tratables que generan obesidad o que no estén controladas (hipotiroidismo y Sd. Cushing).

- Ausencia de patología orgánica de tipo: cirrosis hepática, insuficiencia renal grave, evento agudo de cardiopatía isquémica hace menos de 6 meses, enfermedad inflamatoria intestinal, insuficiencia cardiaca descompensada, neoplasia de pronóstico incierto.

- Estabilidad psicológica y ausencia de trastornos psiquiátricos: retraso mental severo, psicosis, bulimia nerviosa, drogadicción, etilismo.

- En mujeres en edad fértil compromiso de adoptar medidas anticonceptivas durante un periodo de dos años tras la cirugía.

\section{B.- INFORMACIÓN AL PACIENTE}

Los pacientes recibirán una adecuada y comprensible información, tanto verbal como escrita, sobre el proceso que padecen así como de la solución quirúrgica propuesta.

Para ello, la información verbal se complementará con el documento titulado "Información al paciente candidato a Cirugía Bariátrica" (véase anexo III) que se entregará a cada paciente, y que incluye los siguientes datos:

- Riesgos de la obesidad y beneficios de la pérdida de peso.

- Cuándo está indicada la Cirugía de la Obesidad y qué riesgos conlleva.

- Necesidad de seguir controles periódicos postoperatorios. 
El Consentimiento Informado, propiamente dicho, se entregará en la Consulta de Cirugía y en la de Preanestesia.

\section{C. - ESTUDIO ENDOCRINOLÓGICO}

Este estudio tiene como fin el despistaje de entidades clínicas que puedan interferir con la $\mathrm{CB}$ o bien suponer un riesgo incrementado para el enfermo en el postoperatorio de la misma, tanto a corto como a largo plazo.

- Valoración clínica:

- Anamnesis: hábitos alimentarios e identificación de patologías secundarias y asociadas a la obesidad, posibles factores de riesgo cardiovascular.

- Exploración física general.

- Parámetros antropométricos: talla, peso, IMC, circunferencia de la cintura, tensión arterial

- Exploraciones complementarias:

- Analítica general: hemograma, estudio de coagulación, glucemia, función renal, pruebas hepáticas, ácido úrico, lípidos, proteínas totales, albúmina, prealbúmina, transferrina, calcio, calcio iónico, fósforo, magnesio.

- Otras determinaciones: hierro con ferritina, vitamina B12, ácido fólico, vitaminas liposolubles $(A ; \quad E ; \quad K ; \quad$ 25-hidroxicolecalciferol, 1,25dihidroxicolecalciferol, zinc, cobre).

- Determinaciones hormonales: hormonas tiroideas, cortisol libre en orina de 24 horas o plasmático tras un miligramo de dexametasona nocturna, PTH intacta.

- Análisis de la composición corporal por impedanciometría.

- Espirometría y gasometría.

- Radiografía simple de tórax, electrocardiograma.

- Ecocardiograma.

- Consulta a Psiquiatría, cuya valoración podrá hacer que se desestime la CB, en caso de coexistencia de alteración mental grave.

- Considerar, según criterio clínico, la solicitud de:

- Estudio polisomnográfico por neumología.

- Densitometría ósea convencional.

- Educación nutricional precirugía.

\section{2- CONSULTA DE CIRUGÍA BARIÁTRICA}

\section{A.- ESTABLECIMIENTO DE LA INDICACIÓN QUIRÚRGICA}

Revisión de la historia clínica del paciente y de las exploraciones complementarias para establecer, en su caso, la indicación de tratamiento quirúrgico y la técnica quirúrgica. La técnica de elección para obesos con IMC $>50 \mathrm{Kg} / \mathrm{m}^{2}$ será la derivación biliopancreática 
(procedimiento de Scopinaro modificado con transección gástrica sin gastrectomía manteniendo un reservorio gástrico de 200 mililitros y con unas longitudes estándar de asa común de $70 \mathrm{~cm}$ y de asa alimentaria de $230 \mathrm{~cm}$, variando volumen y longitud según el grado de obesidad del paciente), mientras que para IMC menor de esa cifra se podrá plantear al paciente la DBP o la gastrectomía vertical laparoscópica. El bypass gástrico en $Y$ de Roux será considerado a criterio del cirujano.

\section{B.- INFORMACIÓN AL PACIENTE.}

Se le explicará la técnica quirúrgica, de tal forma, que el paciente adquiera un conocimiento básico del objetivo que se persigue con la cirugía y de los mecanismos por los que el procedimiento quirúrgico hace perder peso. Asimismo, será informado de los riesgos quirúrgicos de la $\mathrm{CB}$ en general, y de la técnica que se va a emplear en particular, tanto a corto como a largo plazo. Finalmente, se explicará al paciente la potencial necesidad de la toma de ciertos fármacos tras la intervención quirúrgica y de la obligatoriedad de un correcto seguimiento postoperatorio a corto, medio y largo plazo.

\section{C.- SOLICITUD DEL CONSENTIMIENTO INFORMADO}

Una vez informado, al paciente se le solicitará por escrito, según el modelo existente (anexo IV), el consentimiento para realizar la intervención quirúrgica, autorizando con su rúbrica la realización de la técnica bariátrica elegida y asumiendo el riesgo de la misma.

\section{D.- INCLUSIÓN EN LA LISTA DE ESPERA QUIRÚRGICA}

Al igual que en otros procesos quirúrgicos se rellenará adecuadamente la Hoja de Inclusión en Lista de Espera Quirúrgica. En dicho impreso se marcará la casilla de solicitud de Consulta de Preanestesia.

\section{E.- PRUEBAS COMPLEMENTARIAS}

Se ha de considerar, según criterio clínico, la solicitud de:

- Ecografía abdominal.

- Estudio radiológico gastroduodenal o gastroscopia.

\section{3- CONSULTA DE PREANESTESIA}

El anestesiólogo recopilará la información clínica del proceso asistencial del enfermo, revisando y evaluando todos los datos (situación clínica del paciente, pruebas complementarias realizadas). Determinará el grado de riesgo anestésico según la escala A.S.A. (American Society of Anaesthesiologists) y se valorará cuidadosamente la vía aérea, estableciendo en caso necesario la activación del protocolo de vía aérea difícil, según los criterios anestésicos vigentes. De igual modo, se considerará, según 
criterio clínico, la solicitud de fisioterapia respiratoria o cualquier otra prueba o procedimiento, a la vez que determinará el ajuste de medicación del enfermo previo a la intervención.

Por último, se informará al paciente de la técnica anestésica (general balanceada) y de los riesgos inherentes a la misma, así como de los específicos en la cirugía bariátrica y de la necesidad de estancia en la Unidad de Reanimación, al menos las primeras 24 horas de postoperatorio. Una vez informado, se solicitará al paciente por escrito el consentimiento para la anestesia en CB.

\section{4- INGRESO HOSPITALARIO}

Se establecen las siguientes etapas con sus correspondientes actuaciones durante el ingreso hospitalario en el que se realizará la intervención quirúrgica.

\section{A.- PREOPERATORIO INMEDIATO}

Revisión por parte del cirujano de la historia clínica, de las pruebas complementarias y exploración del paciente, para comprobar que no existe ninguna contraindicación para realizar la intervención.

Se pautará la profilaxis antitrombótica y antibiótica preoperatoria:

- Administración de antibiótico en el momento del traslado al quirófano: Amoxicilina/clavulánico $2 \mathrm{~g}$ por vía intravenosa. En alérgicos a betalactámicos, se administrará ciprofloxacino $400 \mathrm{mg}$ más metronidazol $1 \mathrm{~g}$ por vía intravenosa.

- Administración de heparina de bajo peso molecular a dosis adecuada (intervención clasificada como de riesgo elevado en paciente de riesgo elevado) por vía subcutánea. Vendaje de compresión gradual en las extremidades inferiores o dispositivos neumáticos antitrombosis.

\section{B.- TÉCNICA QUIRÚRGICA}

El paciente se colocará sobre una mesa de quirófano especialmente diseñada para $\mathrm{CB}$, en posición de decúbito supino, con mesa neutra para la DBP y con mesa en posición de ligero anti-Trendelemburg y piernas separadas para los procedimientos laparoscópicos. Se llevará a cabo anestesia general balanceada con intubación orotraqueal (se empleará fibroscopio en los enfermos catalogados como "vía aérea difícil) y se canularán vías (una vía venosa periférica de grueso calibre así como, preferentemente, una vía venosa yugular derecha y vía arterial radial izquierda). La monitorización de constantes vitales (frecuencia cardiaca, electrocardiograma, presión arterial invasiva y no invasiva, presión venosa central, etc.) se hará según criterio del anestesiólogo. Se colocará sonda vesical con termómetro incorporado a todos los pacientes, extremando las medidas de asepsia. La intervención se llevará a cabo por los cirujanos bariátricos de la Unidad como primer cirujano, asistidos por 
otro cirujano y por un residente, ambos del servicio de Cirugía General y Digestiva como primer y segundo ayudantes, según los partes de quirófano que determine el Jefe de servicio. El procedimiento elegido para cada obeso será realizado según el estado del arte y los manuales de técnica quirúrgica actuales. En concreto, para la DBP se empleará, de elección, el abordaje abierto mediante laparotomía media supraumbilical. El material e instrumental necesario será el habitual para este tipo de intervenciones y se encuentra inventariado en el registro del Área Quirúrgica del Hospital U. Río Hortega. En el quirófano estarán presentes dos enfermeras, una actuando como instrumentista y otra como circulante, además una auxiliar en la zona intermedia.

\section{C.- PROTOCOLO POSTOPERATORIO}

Los pacientes pasarán desde el quirófano a la Unidad de Reanimación Quirúrgica para el control hemodinámico, respiratorio y balance hidroelectrolítico. Cuando el paciente esté estabilizado, a criterio del anestesiólogo, será trasladado a la planta, pasadas las primeras 24 horas.

Los cuidados requeridos son:

- Profilaxis de la úlcera de stress: se administrará inhibidor de la bomba de protones a las dosis habituales por vía intravenosa hasta la tolerancia oral. Continuar después por vía oral, manteniendo el tratamiento al menos durante el primer año.

- Profilaxis de la enfermedad tromboembólica: mantener el vendaje compresivo en extremidades inferiores hasta el alta hospitalaria. Se continuará con la administración de heparina de bajo peso molecular a dosis adecuadas durante un mes. Levantar al sillón desde el $2^{\circ}$ día postoperatorio y estimular la deambulación precoz.

- Controles analíticos en las primeras 24 horas del postoperatorio y posteriormente según la evolución clínica del enfermo.

- Retirada de la SNG a la mayor brevedad posible y retirada de la sonda vesical a las 24 horas, siempre que la situación clínica lo permita.

- Control del débito de los drenajes en caso de que se hayan colocado. Retirada de los mismos a la mayor brevedad posible, siempre que la situación clínica lo permita.

- Retirada de material de sutura entre los días 8-10 del postoperatorio (podrá realizarse de forma ambulatoria en su Centro de Salud).

Ante el eventual diagnóstico de complicaciones postoperatorias, ya sean médicas o quirúrgicas, se actuará convenientemente, con el tratamiento más adecuado, incluyendo un nuevo traslado a la Unidad de Reanimación o una reintervención, si fuera necesario.

\section{D.- REINTRODUCCIÓN DE LA DIETA}

Iniciar la tolerancia a líquidos en el primer o segundo día postoperatorio, si es posible, 
seguida de una dieta progresiva, codificada como CB1, CB2, CB3, CB4 y CB5 para cada uno de los siguientes días de postoperatorio. Dichas dietas están diseñadas por los endocrinólogos y nutricionistas de la Unidad (volumen, composición) y que se encuentran perfectamente establecidas en el servicio de Cocina del Hospital U. Río Hortega. Si el paciente no es subsidiario de alimentación oral y precisa soporte nutricional artificial (enteral o parenteral), éste será pautado y seguido por Endocrinología y Nutrición.

Tras la intervención, se realizará interconsulta a Endocrinología, quienes se encargarán de la indicación de los suplementos vitamínicos, nutricionales y minerales necesarios, así como de explicar las instrucciones dietéticas a los pacientes y de establecer la revisión en consulta.

\section{5- SEGUIMIENTO POSTBARIÁTRICO}

\section{A.- CONTROL POR ENDOCRINOLOGÍA Y NUTRICIÓN}

Todos los pacientes han de seguir una vigilancia estricta de por vida tras la realización de CB. Ésta se llevará a cabo en la consulta de Endocrinología y Nutrición del Hospital U. Río Hortega. Aquellos pacientes procedentes de otras áreas sanitarias serán remitidos, para su seguimiento, al especialista de Endocrinología y Nutrición que los derivó, quien será responsable del control, diagnóstico y tratamiento de complicaciones médicas, e incluso de nueva derivación a nuestra Unidad, en caso necesario.

Los pacientes serán evaluados en la consulta con la siguiente periodicidad: $1^{\circ}$ mes, $3^{\circ}$ mes, $6^{\circ}$ mes, $9^{\circ}$ mes y $12^{\circ}$ mes. Las revisiones posteriores serán cada 6 meses durante el segundo y tercer año. A partir de esa fecha, se realizará una revisión anual. El plan previsto para realizar en cada una de ellas es el siguiente:

- En la primera revisión:

- Valoración de la situación clínica, estado general, tolerancia y ajuste de dieta.

- Analítica general y otras determinaciones: hemograma, estudio de coagulación, glucemia, función renal, pruebas hepáticas, ácido úrico, lípidos, proteínas totales, albúmina, prealbúmina, transferrina, calcio, calcio iónico, fósforo, magnesio, hierro con ferritina.

- Revisiones posteriores:

- Valoración de la situación clínica, estado general, tolerancia y ajuste de dieta.

Se darán recomendaciones e instrucciones nutricionales $y$, también, se establecerá un programa de ejercicio físico.

Exploración general, constantes vitales y determinación de parámetros antropométricos: peso, talla, IMC, presión arterial.

- Analítica general: hemograma, estudio de coagulación, glucemia, función renal, pruebas hepáticas, ácido úrico, lípidos, proteínas totales, albúmina, prealbúmina. 
- Otras determinaciones analíticas: hierro con ferritina, vitamina B12, ácido fólico, vitaminas liposolubles (A; E; K; vitamina D), zinc, cobre, PTH.

- Análisis de la composición corporal.

Se pondrá especial atención en el diagnóstico y tratamiento de déficits nutricionales (macro y micronutrientes). Asimismo, se considerará llevar a cabo una encuesta nutricional y, también, nueva valoración psiquiátrica, especialmente dirigidas a aquellos enfermos con ausencia de pérdida de peso o reganancia de mismo.

En la revisión de los 12 meses, se considerará según criterio clínico, solicitar una densitometría ósea.

Se insistirá a aquellas mujeres en edad fértil que, durante los dos primeros años tras la CB (periodo de máxima pérdida de peso), está desaconsejado el embarazo, por la posibilidad de malformaciones fetales a consecuencia de la malabsorción materna.

\section{B.- CONTROL POR CIRUGIA GENERAL}

Se revisará a los pacientes aproximadamente al mes del alta hospitalaria y a los 6, 12, 18 y 24 meses. Se valorará la pérdida ponderal, los hábitos alimentarios, los síntomas gastrointestinales (vómitos, diarrea...) y las complicaciones quirúrgicas más frecuentes (hernias incisionales, suboclusión intestinal...). Se pondrá especial atención al diagnóstico de hernia incisional en puertos laparoscópicos o en la laparotomía. La indicación de eventroplastia debe ser cuidadosa y ha de tener en cuenta los riesgos, el momento adecuado en función del grado de pérdida de peso, la vía de abordaje para la reparación, el material protésico, etc., según el estado del arte de la cirugía de pared abdominal.

En caso de insuficiente pérdida ponderal o reganancia de peso durante el seguimiento, se deberá plantear el caso conjuntamente con Endocrinología, a fin de determinar las causas, y si fuera menester, indicar una cirugía de revisión o de conversión de técnica.

En caso de excesiva pérdida ponderal con aparición durante el seguimiento de déficits nutricionales imposibles de compensar mediante suplementación oral o intravenosa, se deberá plantear el caso conjuntamente con Endocrinología, a fin de determinar las causas, y si fuera menester, indicar una cirugía de reversión o de conversión de técnica.

Tras 24 meses postcirugía y dependiendo del paciente, se contempla la posibilidad de cirugía plástica reductora.

\section{C.- DERIVACIÓN A CIRUGÍA PLÁSTICA}

Tras dos años desde la $\mathrm{CB}$, se puede establecer el criterio de derivación a Cirugía Plástica. Los pacientes de otras áreas sanitarias serán remitidos al Servicio de Cirugía Plástica de referencia en su área correspondiente. Los pacientes de otras áreas sanitarias serán derivados al Servicio de Cirugía Plástica de referencia. 
Criterios para la realización de cirugía plástica reductora:

- Al menos 24 meses tras la cirugía de la obesidad, constatándose pérdida de peso establecida.

- Edad menor a 55 años.

- No presentar patología asociada que pueda "contraindicar" la intervención (diabetes, etc.).

- Se remitirá solamente para valorar la cirugía del "faldón abdominal".

- En cualquier caso la indicación de la cirugía reductora será potestad del cirujano plástico.

\section{3.- EVALUACIÓN}

Se diseñará una Hoja de Evaluación que permita analizar la adherencia al protocolo y los resultados asistenciales obtenidos.

Se realizará una primera evaluación a los seis meses de la puesta en práctica del presente protocolo. Si se detectan errores en su diseño o aplicación se realizarán las oportunas correcciones. Posteriormente se realizará una evaluación con periodicidad anual. 
4.- ANEXO I: Hoja de derivación desde Atención Primaria a Endocrinología para valoración de posibles candidatos a CB.

\section{HOJA DE DERIVACIÓN DESDE ATENCIÓN PRIMARIA A PRIMARIA A ENDOCRINOLOGIA PARA VALORACIÓN DE POSIBLES CANDIDATOS A CIRUGÍA BARIÁTRICA}

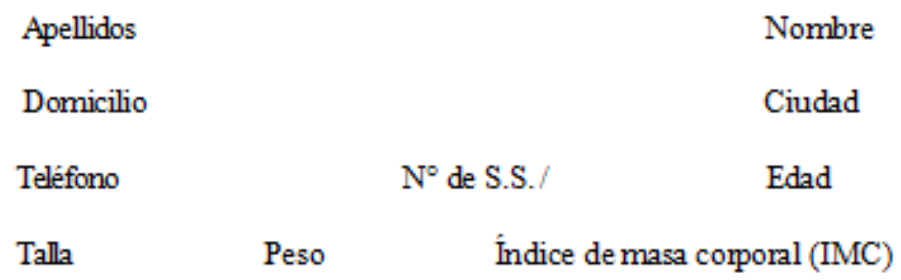

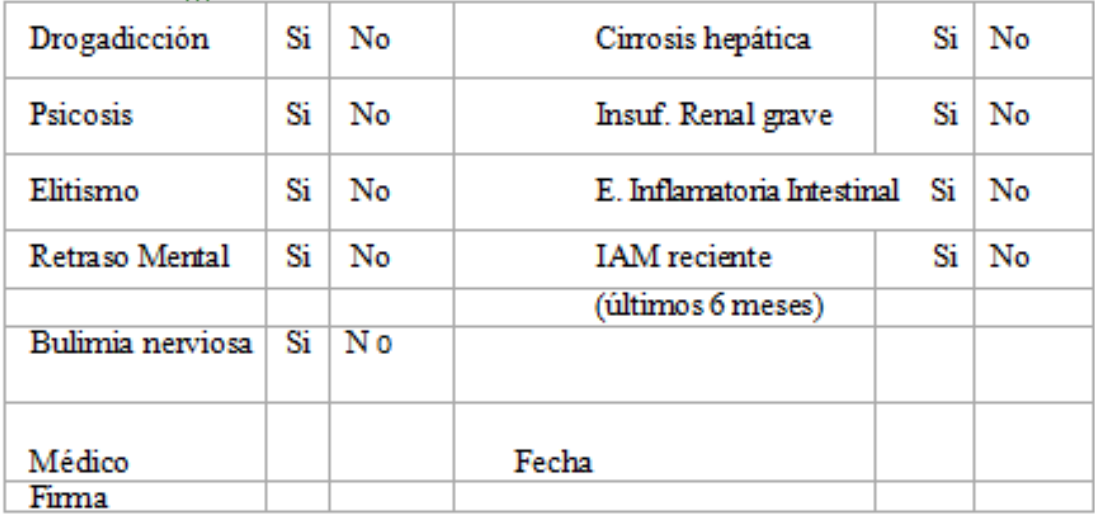


5.- ANEXO II: Hoja de derivación desde las secciones de Endocrinología de otras áreas sanitarias.

HOJA DE DERIVACIÓN DESDE LAS SECCIONES DE ENDOCRINOL OGÍA DE OTRAS ÁREAS SANITARIAS.

Apellidos

Nombre

Domicilio

Ciudad

Teléfono

$\mathrm{N}^{\circ}$ de S.S. $/$

Edad

Talla

Peso

Índice de masa corporal (IMC)

$\underline{\text { Rodear con un circulo: }}$

\begin{tabular}{|c|c|c|c|c|c|}
\hline Drogadicción & $\mathrm{Si}$ & No & Cirrosis hepática & $\mathrm{Si}$ & No \\
\hline Psicosis & $\mathrm{Si}$ & No & Insuf. Renal grave & $\mathrm{Si}$ & No \\
\hline Etilismo & $\mathrm{Si}$ & No & \multicolumn{2}{|c|}{ E. Inflamatoria Intestinal $\mathrm{Si}$} & No \\
\hline Retraso Mental & $\mathrm{Si}$ & No & IAM reciente & $\mathrm{Si}$ & No \\
\hline & & & (últimos 6 meses) & & \\
\hline Bulimia nerviosa & $\mathrm{Si}$ & No & & & \\
\hline
\end{tabular}

\section{$\underline{\text { Rodear conun círculo }}$}

\begin{tabular}{|l|l|l|l|l|l|}
\hline Bioquímica & $\mathrm{Si}$ & No & PTHi & $\mathrm{Si}$ & No \\
\hline Hemograma & $\mathrm{Si}$ & No & Vit. A & $\mathrm{Si}$ & No \\
\hline Coagulación & $\mathrm{Si}$ & No & Vit E & $\mathrm{Si}$ & No \\
\hline Ferntina & $\mathrm{Si}$ & No & Vit K & $\mathrm{Si}$ & No \\
\hline Vit. B12 & $\mathrm{Si}$ & $\mathrm{No}$ & Cinc & $\mathrm{Si}$ & No \\
\hline Ac. Fólico & $\mathrm{Si}$ & No & Cobre & $\mathrm{Si}$ & No \\
\hline H. Tiroideas & $\mathrm{Si}$ & No & Albúmina & $\mathrm{Si}$ & No \\
\hline Cortisol libre & $\mathrm{Si}$ & No & Prealbúmina & $\mathrm{Si}$ & No \\
\hline (o tras dexamatasona) & & & & & \\
\hline ECG & $\mathrm{Si}$ & No & Ecocardiograma & $\mathrm{Si}$ & No \\
\hline Rx Tórax & $\mathrm{Si}$ & No & Estudio psiquiátrico & $\mathrm{Si}$ & No \\
\hline Espirometría & $\mathrm{Si}$ & No & Gasometrical & $\mathrm{Si}$ & No \\
& & & & & \\
\hline & & & & & \\
\hline Médico & & & Fecha & & \\
\hline
\end{tabular}


6.- ANEXO III: Información al paciente candidato a CB.

\section{ESTIMADO PACIENTE:}

Su médico le ha informado que padece obesidad mórbida y ha considerado que el tratamiento más adecuado para su enfermedad es la intervención quirúrgica, lo que se conoce como cirugía bariátrica o cirugía de la obesidad. Su obesidad es una enfermedad crónica que no se cura mediante la cirugía, pero si se controla puesto que la intervención es un medio de facilitar que usted pueda variar sus hábitos alimentarios y seguir un tipo de alimentación adecuado a sus necesidades y que permite la pérdida de peso necesaria para mejorar su salud. Debe usted saber que no se trata de una cirugía estética, sino de un procedimiento encaminado a prevenir o mejorar las complicaciones médicas que pueda ocasionar su obesidad a través de una pérdida de peso suficiente.

La cirugía de la obesidad no está indicada en todos los pacientes obesos. En principio, para ser candidato a esta cirugía el paciente debe de cumplir algunos requisitos como:

- Pacientes obesos de alto riesgo: Obesidad mórbida u obesidad severa asociada a complicaciones.

- Pacientes bien informados y motivados y con riesgo quirúrgico/anestésico aceptable.

- Ausencia de patología médica o psiquiátrica que contraindiquen la intervención.

- Comprometerse a seguir un control postoperatorio en las consultas de los Servicios de Endocrinología y Cirugía.

La cirugía de la obesidad está considerada como cirugía mayor. Esto quiere decir que, dependiendo de la situación clínica del paciente y de las técnicas empleadas, pueden aparecer complicaciones graves hasta en un $10 \%$ de los casos y el riesgo de muerte es 1 $2 \%$. Si es usted mujer, se desaconseja el embarazo durante los dos primeros años tras la cirugía, puesto que la malabsorción producida durante este periodo puede representar un riesgo para el feto. Para asegurar las posibilidades de éxito y disminuir las posibles complicaciones, debe usted acudir a las consultas de su cirujano y endocrinólogo tal y como se le indique, y seguir adecuadamente el tratamiento que se le prescriba. Aunque usted se encuentre bien tras la intervención, necesitará tomar suplementos de vitaminas y minerales para prevenir complicaciones. A continuación, trataremos de responder a algunas preguntas que usted puede estarse planteando, pero no dude en preguntar a su endocrinólogo/cirujano si necesita alguna otra aclaración.

1.- ¿QUÉ PODRÉ COMER DESPUÉS DE LA CIRUGÍA? Los primeros días, recibirá una dieta especial postoperatoria. Posteriormente, el endocrinólogo le explicará el tipo de dieta habitual. Como ya se ha explicado, la cirugía es un medio que le permite hacer una dieta 
equilibrada y adecuada a sus necesidades, no una manera de comer lo que quiera sin engordar. Hay que recordar siempre que no solamente se debe comer poco, sino que se debe comer lentamente y masticando muy bien todo lo que se ingiere.

2.- ¿NECESITARÉ COMPLEMENTOS ALIMENTARIOS? Por lo menos necesitará un suplemento de vitaminas, que le será prescrito al alta y posteriormente cualquier déficit nutricional será detectado y corregido por su endocrinólogo.

\section{3.- ¿CUANDO PODRÉ VOLVER A TRABAJAR Y REALIZAR MIS ACTIVIDADES} NORMALES? En general si su trabajo es sedentario, podrá volver a trabajar en un mes tras la intervención. No deberá conducir hasta por lo menos dos semanas después del alta hospitalario. Durante las primeras dos o tres semanas, podrá hacer pequeñas labores domésticas sin esfuerzos. La actividad sexual se podrá reanudar aproximadamente a las cuatro semanas tras la operación.

4.- ¿QUE TIPO DE EJERCICIO FÍSICO PODRÉ HACER? Inicialmente, pasear es el mejor ejercicio, y podrá hacerlo desde los primeros días. Después podrá progresivamente hacer otro tipo de ejercicios manteniendo el plazo de dos meses antes de pasar a levantamiento de pesos y ejercicios fuertes. Mas adelante, el límite lo darán sus propias posibilidades, y la respuesta cardiopulmonar. En cualquier caso, un plan de ejercicios de rehabilitación no solo es posible, sino que es muy efectivo en la recuperación de un peso mes cercano al ideal.

5.-¿DEBERÉ SEGUIR CONTROLES TRAS LA INTERVENCIÓN? Se realizarán controles periódicos dependiendo de su evolución clínica. En muchas de estas visitas será necesario hacer controles mediante análisis de sangre. La evolución será controlada por el endocrinólogo y el cirujano. 
7.- ANEXO IV: Documento de consentimiento informado para cirugía de la obesidad.

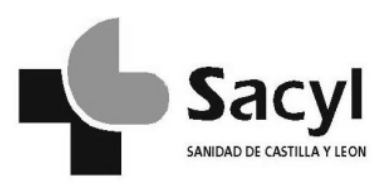

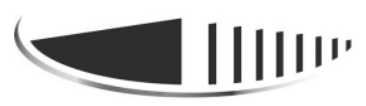

HOSPITAL UNIVERSITARIO RÍO HORTEGA

DATOS DE FILIACIÓN O

PEGATINA IDENTIFICADORA

DECLARO:

Que el/la Doctor/a D./Dña. : me ha explicado que es conveniente proceder, en mi situación, al tratamiento quirúrgico de la OBESIDAD.

Mediante este procedimiento se pretende conseguir la perdida del exceso de peso que no se ha podido tratar por métodos convencionales y que me producen las complicaciones hemodinámicas, vasculares, pulmonares, endocrinas u osteoarticulares.

La realización del procedimiento puede ser filmada con fines científicos o didácticos.

El médico me ha advertido que el procedimiento requiere la administración de anestesia y que es posible que durante o después de la intervención sea necesaria la utilización de sangre y/o hemoderivados, de cuyos riesgos me informarán los servicios de anestesia y de hematología.

Mediante este procedimiento se va a reducir la capacidad de mi estómago, o desviar el alimento en el intestino de forma que no va a pasar por todos sus tramos, o ambas cosas. Con esto se intenta disminuir el volumen de alimento que preciso para encontrarme satisfecho, una disminución en la absorción de nutrientes, o ambas cosas.

También sé que cabe la posibilidad que durante la cirugía haya que realizar modificaciones del procedimiento por los hallazgos intraoperatorios para proporcionarle el tratamiento más adecuado.

Comprendo que a pesar de la adecuada elección de la técnica y de su correcta realización pueden presentarse efectos indeseables, tanto los comunes derivados de toda intervención y que pueden afectar a todos los órganos y sistemas, como otros específicos del procedimiento: poco graves y frecuentes (infección o sangrado de herida quirúrgica, flebitis, alteraciones digestivas transitorias, retención aguda de orina, derrame pleural, dolor prolongado en la zona de la operación) o poco frecuentes y graves (infección o sangrado intraabdominal, fístulas intestinales por fallo en la cicatrización de las suturas, alteraciones digestivas definitivas como diarreas o vómitos, déficit nutricional, pérdida excesiva de peso, estrechez de las anastomosis, fallo del procedimiento con no reducción del peso). El médico me ha explicado que estas complicaciones habitualmente se resuelven con tratamiento médico (medicamentos, sueros, etc.) pero pueden llegar a requerir una reintervención, generalmente de urgencia, incluyendo un riesgo de mortalidad.

El médico me ha indicado que para la realización de esta técnica puede ser necesaria una preparación previa.

También me ha indicado la necesidad de advertir de mis posibles alergias medicamentosas, alteraciones de la coagulación, enfermedades cardiopulmonares, existencia de prótesis, marcapasos, medicaciones actuales o cualquier otra circunstancia. 
Por mi situación vital actual (diabetes, obesidad, hipertensión, anemia, edad avanzada...) puede aumentar la frecuencia 0 la gravedad de riesgos 0 complicaciones como

El médico me ha explicado que en mi caso no existe una alternativa eficaz de tratamiento, ya que han fallado los métodos convencionales.

He comprendido las explicaciones que se me han facilitado en un lenguaje claro y sencillo, y el facultativo que me ha atendido me ha permitido realizar todas las observaciones y me ha aclarado todas las dudas que le he planteado.

También comprendo que, en cualquier momento y sin necesidad de dar ninguna explicación, puedo revocar el consentimiento que ahora presto.

Por ello, manifiesto que estoy satisfecho con la información recibida y que comprendo el alcance y los riesgos del tratamiento y en tales condiciones

CONSIENTO que se me realice un tratamiento quirúrgico de la obesidad.

En Valladolid, a de de 20

Fdo,: El/la Médico

Fdo.: El Paciente

Fdo.: El representante legal, familiar o allegado

\section{REVOCACIÓN}

YO:

REVOCO el consentimiento prestado en fecha doy con esta fecha por finalizado. y no deseo proseguir el tratamiento, que de de 20

Fdo,: El/la Médico

Fdo.: El Paciente

Fdo.: El representante legal, familiar o allegado 


\section{4.- VARIABLES DEL ESTUDIO}

Las variables incluidas en este estudio se presentan seguidamente clasificadas según su tipología. No obstante, en los sucesivos epígrafes, se detallarán siguiendo su secuencia cronológica a lo largo del proceso asistencial de los pacientes, para una mejor comprensión, siendo también la forma en que se expondrán los resultados del análisis estadístico.

- Variables de tipo demográfico: edad y sexo.

- Variables de tipo clínico: parámetros antropométricos, parámetros de cuantificación de la pérdida ponderal tras $\mathrm{CB}, \mathrm{PA}$, algunas de las CAO con su tratamiento correspondiente, diversas entidades nosológicas definidas como complicación postoperatoria, y la vía de abordaje quirúrgico.

- Variables de tipo analítico: parámetros de laboratorio (glucemia, colesterol total, colesterol HDL, colesterol LDL y TAG, entre otras).

- Variables de tipo temporal: estancia hospitalaria y tiempo de seguimiento.

\subsection{1.- VARIABLES DEMOGRÁFICAS}

Las variables demográficas estudiadas serán las siguientes:

- Sexo. Variable dicotómica (varón, mujer).

- Edad en el momento de la intervención de CB. Variable cuantitativa continua, medida en años. A partir de ella, se establecerá una nueva variable cualitativa denominada "grupos de edad" y que incluirá las siguientes categorías, definidas según el valor de edad a partir del cual se incrementa el riesgo de la CB según el OS-MRS de DeMaria et al. (183):

- Cohorte de pacientes con edad $<45$ años.

- Cohorte de pacientes con edad $\geq 45$ años. 


\subsection{2.- VARIABLES PREOPERATORIAS}

Las variables preoperatorias estudiadas serán las siguientes:

- Peso en el momento de la indicación de CB. Variable cuantitativa continua, medida con un decimal en $\mathrm{Kg}$, y determinada en consulta sin ropa, empleando una báscula manual (precisión de $\pm 0,1 \mathrm{Kg}$ ).

- Peso ideal en el momento de la indicación de CB. Variable cuantitativa continua, medida con un decimal en $\mathrm{Kg}$, y determinada con la siguiente fórmula (187):

- Mujer adulta a partir de $152 \mathrm{~cm}$ de altura y 54,09 Kg de peso: por cada 2,54 cm de altura, añadir 1,36 Kg de peso.

- Varón adulto a partir de 159,6 cm de altura y 61,36 Kg de peso: por cada 2,54 cm de altura, añadir 1,36 Kg de peso.

- Talla en el momento de la indicación de CB. Variable cuantitativa continua, medida en cm, y determinada en consulta con el paciente en posición erguida empleando un estadiómetro, hasta el centímetro más cercano.

- IMC en el momento de la indicación de CB. Variable cuantitativa continua, medida con un decimal en $\mathrm{Kg} / \mathrm{m}^{2}$, y calculada aplicando la fórmula de Quetelet $(20,21)$. A partir de ella, se definirá una nueva variable cualitativa denominada "grupos de IMC" y que incluirá las siguientes categorías, definidas según el valor de IMC a partir del cual se incrementa el riesgo de la CB según el OS-MRS de DeMaria et al. (183):

- Cohorte de pacientes con IMC $<50 \mathrm{Kg} / \mathrm{m}^{2}$.

- Cohorte de pacientes con IMC $\geq 50 \mathrm{Kg} / \mathrm{m}^{2}$.

- Glucemia basal en la analítica solicitada por el endocrinólogo antes de la indicación de CB. Variable cuantitativa continua, medida en $\mathrm{mg} / \mathrm{dl}$, y 
determinada en los dispositivos autoanalizadores del Laboratorio Central del HURH (Beckman Coulter Inc., California, EE.UU. y A. Menarini Diagnostics, Florencia, Italia).

- Diagnóstico de DM2 en el momento de la indicación de CB. Variable dicotómica (sí, no), establecida según los criterios de la American Diabetes Association (97).

- Medicación antidiabética en el momento de la indicación de CB. Variable cuantitativa discreta que expresa el número de antidiabéticos orales de distinto grupo farmacológico pautados.

- Administración de insulina subcutánea en el momento de la indicación de CB. Variable dicotómica (sí, no). Del subgrupo de pacientes que sí precisan insulina, se obtendrá una nueva variable cuantitativa continua denominada "número de UI de insulina en el momento de la indicación de CB", que expresa el número de UI de insulina total diaria pautada, indiferentemente del tipo farmacológico de la misma. Se determinará el número de enfermos que precisan conjuntamente insulina y fármacos antidiabéticos orales.

- Criterio de glucemia para SM antes de la indicación de CB. Variable dicotómica (sí, no), según el consenso del año 2009 de Alberti et al. (96) [Véase epígrafe 1.3.1.1.- Definición y etiopatogenia del síndrome metabólico].

- Colesterol total en ayunas en la analítica solicitada por el endocrinólogo antes de la indicación de CB. Variable cuantitativa continua, medida en $\mathrm{mg} / \mathrm{dl}$, y determinada en los dispositivos autoanalizadores del Laboratorio Central del HURH (Beckman Coulter Inc., California, EE.UU. y A. Menarini Diagnostics, Florencia, Italia). 
- TAG en ayunas en la analítica solicitada por el endocrinólogo antes de la indicación de CB. Variable cuantitativa continua, medida en $\mathrm{mg} / \mathrm{dl}$, y determinada en los dispositivos autoanalizadores del Laboratorio Central del HURH (Beckman Coulter Inc., California, EE.UU. y A. Menarini Diagnostics, Florencia, Italia).

- Criterio de TAG para SM antes de la indicación de CB. Variable dicotómica (sí, no), según el consenso de 2009 de Alberti et al. (96).

- PA sistólica en la consulta del endocrinólogo antes de la indicación de CB. Variable cuantitativa continua, medida en $\mathrm{mmHg}$, determinada en sedestación mediante un esfigmomanómetro de mercurio, dos veces con un descanso intermedio de 10 minutos y haciendo el promedio entre ambas mediciones.

- PA diastólica en la consulta del endocrinólogo antes de la indicación de CB. Variable cuantitativa continua, medida en $\mathrm{mmHg}$, determinada en sedestación mediante un esfigmomanómetro de mercurio, dos veces con un descanso intermedio de 10 minutos y haciendo el promedio entre ambas mediciones.

- Medicación antihipertensiva en el momento de la indicación de CB. Variable cuantitativa discreta que expresa el número de hipotensores de distinto grupo farmacológico pautados.

- Criterio de HTA para SM antes de la indicación de CB. Variable dicotómica (sí, no), según el consenso de 2009 de Alberti et al. (96).

- Hemoglobina en la analítica solicitada por el endocrinólogo antes de la indicación de CB. Variable cuantitativa continua, medida en $\mathrm{g} / \mathrm{dl}$, y determinada en los dispositivos autoanalizadores del Laboratorio Central 
del HURH (Beckman Coulter Inc., California, EE.UU. y A. Menarini Diagnostics, Florencia, Italia).

- Albúmina en la analítica solicitada por el endocrinólogo antes de la indicación de CB. Variable cuantitativa continua, medida en $\mathrm{g} / \mathrm{dl}$, y determinada en los dispositivos autoanalizadores del Laboratorio Central del HURH (Beckman Coulter Inc., California, EE.UU. y A. Menarini Diagnostics, Florencia, Italia).

- Calcio total en la analítica solicitada por el endocrinólogo antes de la indicación de CB. Variable cuantitativa continua, medida en $\mathrm{mg} / \mathrm{dl}$, y determinada en los dispositivos autoanalizadores del Laboratorio Central del HURH (Beckman Coulter Inc., California, EE.UU. y A. Menarini Diagnostics, Florencia, Italia).

- 25-OH Vitamina D en la analítica solicitada por el endocrinólogo antes de la indicación de CB. Variable cuantitativa continua, medida en microgramos $[\mu \mathrm{g}] / 1$, y determinada en los dispositivos autoanalizadores del Laboratorio Central del HURH (Beckman Coulter Inc., California, EE.UU. y A. Menarini Diagnostics, Florencia, Italia).

- PTH en la analítica solicitada por el endocrinólogo antes de la indicación de CB. Variable cuantitativa continua, medida en picogramo $[\mathrm{pg}] / \mathrm{ml}$, y determinada en los dispositivos autoanalizadores del Laboratorio Central del HURH (Beckman Coulter Inc., California, EE.UU. y A. Menarini Diagnostics, Florencia, Italia).

- Grupos de HTA. Variable cualitativa que incluirá las siguientes categorías, en base a los criterios de HTA del OS-MRS de DeMaria et al. (183): 
- Cohorte con HTA, definida como PA sistólica $\geq 150 \mathrm{mmHg}$ y/o PA diastólica $\geq 90 \mathrm{mmHg}$ y/o tratamiento antihipertensivo.

- Cohorte sin HTA, cuando no cumplen ninguno de los criterios que se acaban de mencionar.

- Grupos de riesgo de TEP. Variable cualitativa que incluirá las siguientes categorías, en base a los criterios de riesgo de TEP del OS-MRS de DeMaria et al. (183):

- Grupo con riesgo de TEP, definido como antecedente personal de TEP previo y/o TVP previa y/o úlcera por estasis venoso en extremidades inferiores $y / o$ presencia de filtro de vena cava $y / o$ presencia de fallo cardíaco y/o presencia de hipertensión pulmonar y/o presencia de SAOS.

- Grupo sin riesgo de TEP, cuando no cumplen ninguno de los criterios que se acaban de mencionar.

- Puntuación en el Obesity Surgery-Mortality Risk Score. Variable cuantitativa discreta, entre 0 y 5 puntos, según el número de variables positivas obtenidas en el OS-MRS de DeMaria et al. (183). Se añadirá un punto por cada uno de los siguientes criterios: sexo varón, edad $\geq 45$ años, IMC $\geq 50$ $\mathrm{Kg} / \mathrm{m}^{2}$, pertenencia al grupo con HTA y pertenencia al grupo con riesgo de TEP. A partir de esta puntuación, se definirá una nueva variable cualitativa denominada "clase del OS-MRS" y que incluirá las siguientes categorías, tal y como establecieron DeMaria et al. (182):

- Clase A, definida como una puntación de 0 o 1.

- Clase B, definida como una puntación de 2 o 3.

- Clase C, definida como una puntación de 4 o 5. 


\subsection{3.- VARIABLES ASOCIADAS AL INGRESO HOSPITALARIO}

Las variables asociadas al ingreso hospitalario estudiadas serán las siguientes:

- Vía de abordaje para la intervención. Variable cualitativa que incluirá las siguientes categorías:

- Cirugía abierta, definida como acceso mediante laparotomía media o subcostal.

- Cirugía laparoscópica, definida como acceso mediante puertos para trócares con creación de neumoperitoneo.

- Cirugía convertida, definida como aquella que se inicia por vía laparoscópica y que requiere, en cualquier momento del acto operatorio, el acceso laparotómico.

- Estancia hospitalaria postoperatoria. Variable cuantitativa discreta, medida en días de pernocta del paciente entre la fecha de la intervención y la del alta. Asimismo, se presentará los valores de esta variable tras identificar el grupo pacientes operados hasta el año 2009 (denominado "época 1") y los operados a partir de ese momento (denominado “época 2"). Se ha decidido arbitrariamente este año, ya que coincidió con el cambio del HURH a su nuevo emplazamiento. De igual modo, se determinará la estancia en los pacientes incluidos en cada una de las clases del OS-MRS.

- Complicaciones médicas durante el ingreso. Variable dicotómica (sí, no). En caso afirmativo, se establecerá una nueva variable cualitativa a partir de la anterior llamada “Tipo de complicación médica” y que incluirá las siguientes categorías:

- Hiperglucemia, definida como aquella elevación de la glucemia capilar que precisa control con insulina rápida. 
- Respiratoria, definida como cualquier trastorno del aparato respiratorio que cause clínica, quedando excluido el derrame pleural postoperatorio asintomático detectado mediante prueba de imagen. Se excluye también de esta categoría el TEP.

- TVP, definida mediante estudio ecográfico con doppler en el que se objetiva ausencia de colapso y/o de flujo y/o presencia de trombo visible en el sistema venoso profundo de una o ambas extremidades inferiores.

- TEP, definida mediante tomografía computarizada con contraste intravenoso, en la que se objetive la presencia de trombo en la arteria pulmonar o alguna de sus ramas lobares o segmentarias.

- Síncope, definido como la pérdida transitoria de la conciencia con recuperación espontánea y sin secuelas neurológicas.

- Infección del tracto urinario, definida como la presencia de bacteriuria y/o leucocituria con nitritos positivos en el análisis del sedimento de orina, según el informe emitido por el Laboratorio Central del HURH.

- Rash cutáneo, definido como la aparición de eritema maculopapuloso y/o de habones en la piel del enfermo y que remite con medicación antihistamínica.

- Otra, definida como cualquier complicación no incluida en las categorías anteriores y que requiere tratamiento médico.

- Complicaciones quirúrgicas durante el ingreso. Variable dicotómica (sí, no). En caso afirmativo, se establecerá una nueva variable cualitativa a partir de 
la anterior llamada "tipo de complicación quirúrgica" y que incluirá las siguientes categorías:

- Infección del sitio quirúrgico superficial y/o profunda, definida como la infección postoperatoria que interesa a la piel, partes blandas y plano muscular, siguiendo los criterios del Center for Disease Control norteamericano (245).

- Infección del sitio quirúrgico de órgano o espacio, definida como la infección postoperatoria que interesa al interior de la cavidad abdominal, siguiendo los criterios del Center for Disease Control norteamericano (245).

- Fuga, definida como la presencia de débito con contenido intestinal por el drenaje quirúrgico o bien por extravasación de contraste radiológico hidrosoluble administrado por vía oral en una prueba de imagen.

- Íleo paralítico o retraso de vaciamiento gástrico, definido como ausencia de tolerancia a dieta oral al quinto día postoperatorio que precisa colocación o mantenimiento de sonda nasogástrica, descartado un proceso oclusivo.

- Oclusión, definido como la ausencia de paso a colon de contraste radiológico hidrosoluble administrado por vía oral en una prueba de imagen.

- Hemorragia luminal, definida como la pérdida hemática por el tubo digestivo, con datos clínicos y analíticos de hemorragia digestiva alta o baja. 
- Hemoperitoneo, definido como la presencia de líquido libre hemático en la cavidad abdominal, diagnosticado intraoperatoriamente.

- Severidad de las complicaciones postquirúrgicas siguiendo la clasificación de Dindo-Clavien (246). Variable cualitativa que puede tomar los valores descritos en la tabla 20, excluyendo a efectos de nuestro estudio el sufijo " $d$ " que aparece reflejado en la misma. En caso de coexistencia de dos o más complicaciones, se aplicará el grado más alto correspondiente. Para aquellos pacientes con complicaciones mayores (grados IIIa, IIIb, IV y V), se notificará el tipo de complicación médica y/o quirúrgica que dio lugar a esa puntación en la clasificación de Dindo-Clavien, según las categorías mencionadas anteriormente en ambas variables. 
Tabla 20. Clasificación de Dindo-Clavien de las complicaciones quirúrgicas. Tomado de Dindo et al. (246).

\begin{tabular}{|c|l|}
\hline \multicolumn{2}{|l|}{ CLASIFICACIÓN DE DINDO-CLAVIEN } \\
\hline GRADO & \multicolumn{1}{|c|}{ DESCRIPCIÓN } \\
\hline I & $\begin{array}{l}\text { Cualquier desviación del curso postoperatorio normal sin } \\
\text { necesidad de tratamiento farmacológico (se permiten } \\
\text { medicamentos como antieméticos, antipiréticos, analgésicos, } \\
\text { diuréticos, o electrolitos), quirúrgico, endoscópico ni } \\
\text { intervencionismo radiológico. La fisioterapia o el drenaje de } \\
\text { infección de herida quirúrgica a pie de cama se incluyen en } \\
\text { este grado. }\end{array}$ \\
\hline II & $\begin{array}{l}\text { Complicación que requiere tratamiento farmacológico con } \\
\text { fármacos diferentes de los señalados para el grado I. También } \\
\text { se incluyen transfusiones de sangre y nutrición parenteral } \\
\text { total. }\end{array}$ \\
\hline III & $\begin{array}{l}\text { Complicación que precisa tratamiento quirúrgico, } \\
\text { endoscópico o intervención radiológica. } \\
\text { IIIa: realizado sin necesidad de anestesia general. }\end{array}$ \\
\hline IV & $\begin{array}{l}\text { IIIb: realizado bajo anestesia general. } \\
\text { Complicación potencialmente mortal que precisa manejo en } \\
\text { una Unidad de Cuidados Críticos (incluidas las siguientes } \\
\text { complicaciones del SNC: ACV isquémico o hemorrágico, } \\
\text { hemorragia subaracnoidea; pero excluido el ataque isquémico } \\
\text { transitorio). }\end{array}$ \\
\hline V & $\begin{array}{l}\text { Complicación que desencadena la muerte del enfermo. } \\
\text { Complicación que sigue presente en el momento del alta y se } \\
\text { ñade al grado correspondiente (del inglés disability). }\end{array}$ \\
\hline Sufijo
\end{tabular}

\subsection{4.- VARIABLES POSTOPERATORIAS}

Las variables postoperatorias que se analizarán en este trabajo se agrupan como se enumera a continuación.

\subsubsection{1.- Seguimiento}

La variable de seguimiento estudiada es la siguiente: 
- Tiempo de seguimiento. Variable cuantitativa discreta, medida en días desde la fecha de la intervención quirúrgica hasta la fecha de la última revisión en consulta de Endocrinología. Se notificará la proporción de pacientes de la muestra que alcancen un seguimiento postbariátrico mayor de 1825 días (5 años).

\subsubsection{2.- Ponderales}

Las variables ponderales postoperatorias estudiadas serán las siguientes:

- Peso en la última revisión de Endocrinología tras CB. Variable cuantitativa continua, medida con un decimal en $\mathrm{Kg}$, y determinada en consulta sin ropa, empleando una báscula manual (precisión de \pm 0,1 Kg).

- IMC en la última revisión de Endocrinología tras CB. Variable cuantitativa continua, medida con un decimal en $\mathrm{Kg} / \mathrm{m}^{2}$, y calculada aplicando la fórmula de Quetelet $(20,21)$.

- Descenso de IMC en la última revisión de Endocrinología tras CB. Variable cuantitativa continua, medida con un decimal en $\mathrm{Kg} / \mathrm{m}^{2}$, y calculada realizando la diferencia entre la variable IMC en el momento de la indicación de $\mathrm{CB}$ y la variable IMC en la última revisión de Endocrinología tras CB.

- PEPP (porcentaje de exceso de peso perdido) en la última revisión de Endocrinología tras CB. Variable cuantitativa continua, medida con un decimal en $\%$, según la fórmula ya mencionada en epígrafe 1.5.3.Resultados y criterios de calidad $(187,188)$. Se proporcionarán los resultados de esta variable para el subgrupo de pacientes que han cumplido más de 5 años de seguimiento postbariátrico en nuestra Unidad de OM. 
- PEIMCP (porcentaje de exceso de índice de masa corporal perdido) en la última revisión de Endocrinología tras CB. Variable cuantitativa continua, medida con un decimal en \%, según la fórmula ya mencionada en epígrafe 1.5.3.- Resultados y criterios de calidad $(187,188)$. Se proporcionarán los resultados de esta variable para el subgrupo de pacientes que han cumplido más de 5 años de seguimiento postbariátrico en nuestra Unidad de OM.

- PPTP (porcentaje de peso total perdido) en la última revisión de Endocrinología tras CB. Variable cuantitativa continua, medida con un decimal en $\%$, según la fórmula ya mencionada en epígrafe 1.5.3.Resultados y criterios de calidad $(187,188)$.

\subsubsection{3.- Clínicas y analíticas}

Las variables clínicas y analíticas postoperatorias estudiadas serán las siguientes:

- Glucemia basal en la última analítica solicitada por el endocrinólogo tras CB. Variable cuantitativa continua, medida en $\mathrm{mg} / \mathrm{dl}$, y determinada en los dispositivos autoanalizadores del Laboratorio Central del HURH (Beckman Coulter Inc., California, EE.UU. y A. Menarini Diagnostics, Florencia, Italia).

- HbA1C en la última analítica solicitada por el endocrinólogo tras CB. Variable cuantitativa continua, expresada en $\%$, y determinada en los dispositivos autoanalizadores del Laboratorio Central del HURH (Beckman Coulter Inc., California, EE.UU. y A. Menarini Diagnostics, Florencia, Italia).

- Medicación antidiabética en la última revisión de Endocrinología tras CB. Variable cuantitativa discreta que expresa el número de antidiabéticos orales de distinto grupo farmacológico pautados. 
- Administración de insulina subcutánea en la última revisión de Endocrinología tras CB. Variable dicotómica (sí, no). Del subgrupo de pacientes que sí precisan insulina, se obtendrá una nueva variable cuantitativa continua denominada "número de UI de insulina en la última revisión de Endocrinología tras CB”, que expresa el número de UI de insulina total diaria pautada, indiferentemente del tipo farmacológico de la misma.

- Criterio de glucemia para SM en la última revisión de Endocrinología tras CB. Variable dicotómica (sí, no), según el consenso de 2009 de Alberti et al. (96).

- Diagnóstico de DM en la última revisión de Endocrinología tras CB. Variable dicotómica (sí, no), establecida según los criterios de la American Diabetes Association (97).

- Resolución de la DM en la última revisión de Endocrinología tras CB. Variable cualitativa que incluye las categorías de remisión total, remisión parcial y no resolución ni mejoría de la DM, de acuerdo con los criterios de la American Diabetes Association publicados por Buse et al. en 2009 (190) [Véase epígrafe 1.5.3.- Resultados y criterios de calidad].

- Colesterol total en ayunas en la última analítica solicitada por el endocrinólogo tras CB. Variable cuantitativa continua, medida en mg/dl, y determinada en los dispositivos autoanalizadores del Laboratorio Central del HURH (Beckman Coulter Inc., California, EE.UU. y A. Menarini Diagnostics, Florencia, Italia).

- Colesterol HDL en ayunas en la última analítica solicitada por el endocrinólogo tras CB. Variable cuantitativa continua, medida en mg/dl, y 
determinada en los dispositivos autoanalizadores del Laboratorio Central del HURH (Beckman Coulter Inc., California, EE.UU. y A. Menarini Diagnostics, Florencia, Italia).

- Colesterol LDL en ayunas en la última analítica solicitada por el endocrinólogo tras CB. Variable cuantitativa continua, medida en $\mathrm{mg} / \mathrm{dl}$, y determinada en los dispositivos autoanalizadores del Laboratorio Central del HURH (Beckman Coulter Inc., California, EE.UU. y A. Menarini Diagnostics, Florencia, Italia).

- TAG en ayunas en la última analítica solicitada por el endocrinólogo tras CB. Variable cuantitativa continua, medida en $\mathrm{mg} / \mathrm{dl}$, y determinada en los dispositivos autoanalizadores del Laboratorio Central del HURH (Beckman Coulter Inc., California, EE.UU. y A. Menarini Diagnostics, Florencia, Italia).

- Tratamiento hipolipemiante en la última revisión de Endocrinología tras CB. Variable dicotómica (sí, no).

- Criterio de HDL para SM en la última revisión de Endocrinología tras CB. Variable dicotómica (sí, no), según el consenso de 2009 de Alberti et al. (96).

- Criterio de TAG para SM en la última revisión de Endocrinología tras CB. Variable dicotómica (sí, no), según el consenso de 2009 de Alberti et al. (96).

- PA sistólica en la última revisión de Endocrinología tras CB. Variable cuantitativa continua, medida en $\mathrm{mmHg}$, determinada en sedestación mediante un esfigmomanómetro de mercurio, dos veces con un descanso intermedio de 10 minutos y haciendo el promedio entre ambas mediciones. 
- PA diastólica en la última revisión de Endocrinología tras CB. Variable cuantitativa continua, medida en $\mathrm{mmHg}$, determinada en sedestación mediante un esfigmomanómetro de mercurio, dos veces con un descanso intermedio de 10 minutos y haciendo el promedio entre ambas mediciones.

- Medicación antihipertensiva en la última revisión de Endocrinología tras CB. Variable cuantitativa discreta que expresa el número de hipotensores de distinto grupo farmacológico pautados.

- Criterio de PA para SM en la última revisión de Endocrinología tras CB. Variable dicotómica (sí, no), según el consenso de 2009 de Alberti et al. (96).

- Hemoglobina en la última analítica solicitada por el endocrinólogo tras CB. Variable cuantitativa continua, medida en $\mathrm{g} / \mathrm{dl}$, y determinada en los dispositivos autoanalizadores del Laboratorio Central del HURH (Beckman Coulter Inc., California, EE.UU. y A. Menarini Diagnostics, Florencia, Italia).

- Albúmina en la última analítica solicitada por el endocrinólogo tras CB. Variable cuantitativa continua, medida en $\mathrm{g} / \mathrm{dl}$, y determinada en los dispositivos autoanalizadores del Laboratorio Central del HURH (Beckman Coulter Inc., California, EE.UU. y A. Menarini Diagnostics, Florencia, Italia).

- Calcio total en la última analítica solicitada por el endocrinólogo tras CB. Variable cuantitativa continua, medida en $\mathrm{mg} / \mathrm{dl}$, y determinada en los dispositivos autoanalizadores del Laboratorio Central del HURH (Beckman Coulter Inc., California, EE.UU. y A. Menarini Diagnostics, Florencia, Italia).

- 25-OH Vitamina D en la última analítica solicitada por el endocrinólogo tras CB. Variable cuantitativa continua, medida en $\mu \mathrm{g} / 1$, y determinada en los dispositivos autoanalizadores del Laboratorio Central del HURH 
(Beckman Coulter Inc., California, EE.UU. y A. Menarini Diagnostics, Florencia, Italia).

- PTH en la última analítica solicitada por el endocrinólogo tras CB. Variable cuantitativa continua, medida en $\mathrm{pg} / \mathrm{ml}$, y determinada en los dispositivos autoanalizadores del Laboratorio Central del HURH (Beckman Coulter Inc., California, EE.UU. y A. Menarini Diagnostics, Florencia, Italia). 


\section{5.- ANÁLISIS ESTADÍSTICO}

\subsection{1.- RECOGIDA Y TRATAMIENTO DE DATOS}

Para la recogida de los datos se confeccionará una base de datos con el paquete estadístico SPSS $^{\circledR}$ versión 18.0 (IBM Corporation, Armonk, New York, EE.UU.). Los datos serán introducidos por una sola persona y revisados por un experto. Tras su depuración, serán analizados utilizando el mismo programa estadístico. La pérdida de valores superior al $15 \%$ en una determinada variable será considerada como un posible sesgo del estudio e informada en el análisis de resultados. Para la determinación del IMC, del peso ideal y de los parámetros de cuantificación de la pérdida de peso se realizarán los cálculos, en base a las fórmulas mencionadas en la Introducción, utilizando el programa Excel ${ }^{\circledR}$ de Microsoft Office $^{\circledR}$ versión 2003 (Microsoft Corporation, Redmond, Washington, EE.UU.).

\subsection{2.- ESTADÍSTICA DESCRIPTIVA}

La normalidad de las variables cuantitativas será establecida con la prueba de Kolmogorov-Smirnov. Las variables de distribución normal serán descritas como media \pm desviación estándar y las de distribución no normal y/o discretas como mediana y rango intercuartílico (RIQ). Por su parte, las variables cualitativas y cuantitativas discretas serán descritas mediante las frecuencias absolutas y relativas (porcentajes) de sus categorías. Se calcularán los intervalos de confianza al 95\% (IC 95\%) de los parámetros. Finalmente, se utilizarán histogramas de frecuencia, barras de error (variables normales) o diagramas de cajas (variables no normales) para representar las variables cuantitativas y gráficos de barras o de sectores para las cualitativas. 


\subsection{3.- ESTADÍSTICA INFERENCIAL}

Para estudiar la asociación entre variables cualitativas se utilizará la prueba de Chi cuadrado con test exacto de Fisher (tablas 2x2) o razón de verosimilitud (más de 2 categorías), dependiendo de sus condiciones de aplicación (frecuencia esperada $<5$ en más del $20 \%$ de las casillas).

Para estudiar las diferencias entre dos proporciones relacionadas se utilizará la prueba de MacNemar o la Q de Cochran, dependiendo de sus condiciones de aplicación.

Para estudiar las diferencias entre medias independientes se utilizará la prueba de la T de Student o la U de Mann-Whitney, dependiendo de las condiciones de aplicación (normalidad), para 2 grupos, y el ANOVA o la $\mathrm{H}$ de Kruskal-Wallis, dependiendo nuevamente de las condiciones de aplicación (normalidad), para más de 2 grupos.

Para estudiar las diferencias entre medias relacionadas (basales frente a evolución) se utilizará la prueba $\mathrm{T}$ de Student para muestras relacionadas o la prueba de Wilcoxon, dependiendo de sus condiciones de aplicación (normalidad).

El nivel de significación estadística para todas las pruebas citadas se considerará con un valor de $\mathrm{p} \leq 0,05$ 


\section{6.- ÉTICA Y ASPECTOS LEGALES}

Este trabajo se realizará siguiendo las recomendaciones de la Declaración de Helsinki de 1964 (última enmienda de 2013).

Se obtendrá consentimiento informado para la participación en el estudio y para el uso con fines científicos y de investigación de toda la información referente al proceso asistencial de los pacientes incluidos en la muestra.

No existe conflicto de intereses por parte de los investigadores ni se dispone de becas ni financiación por parte de entidades públicas o privadas para la realización de este estudio. 


\section{7.- BÚSQUEDA BIBLIOGRÁFICA}

La búsqueda bibliográfica se realizará en la base de datos MEDLINE, uno de los componentes de PubMed, cuyos datos han sido desarrollados y se mantienen actualizados por el National Center for Biotechnology Information de la National Library of Medicine, la cual forma parte, a su vez, de los National Institutes of Health en los EE.UU., con el siguiente acceso:

http://www.ncbi.nlm.nih.gov/pubmed

La búsqueda inicial se planteará en base a términos libres y la definitiva mediante términos MeSH (Medical Subject Headings), utilizando los operadores boléanos, los límites de tiempo y el filtro de idioma para confeccionar la estrategia más adecuada. Los términos MeSH empleados serán: morbid obesity, anthropometry, metabolic syndrome, weight loss, bariatric surgery, biliopancreatic diversion y biliopancreatic bypass. El límite de tiempo de las publicaciones corresponderá a los 10 últimos años, aunque no será considerado para trabajos históricos de referencia. Los idiomas seleccionados serán inglés y español.

Esta búsqueda bibliográfica se completará con la consulta de manuales y libros de texto actualizados, la consulta de las páginas web de diversas sociedades científicas y la comunicación directa con expertos. 

4.- RESULTADOS 



\section{4.- RESULTADOS}

Tras aplicar los criterios de inclusión y exclusión descritos sobre un total aproximado de 400 procedimientos bariátricos realizados en nuestro centro hasta la fecha, se han recogido los datos de aquellos enfermos sometidos a DBP desde marzo de 2001 (inicio de la actividad) hasta marzo de 2013, cifra que alcanza un valor de 274. De ellos, 113 pacientes $(41,2 \%)$ son los que realizan su seguimiento endocrinológico tras CB en nuestro centro (en su mayoría pertenecientes al Área sanitaria Oeste de Valladolid), obteniéndose de éstos, por tanto, los datos de las variables postoperatorias.

\section{1.- ANÁLISIS DESCRIPTIVO}

\subsection{1.- VARIABLES DEMOGRÁFICAS}

La distribución de la variable "sexo" entre los 274 enfermos intervenidos de CB es la siguiente: 74 varones $(27 \%)$ y 200 mujeres (73\%) [Véase gráfico 1].

La variable "edad en el momento de la intervención de CB" sigue una distribución normal, con una media de 41,28 \pm 10,70 años (rango de 18 a 66 años) [Véase gráfico 2]. A su vez, la variable "grupos de edad" presenta la siguiente distribución: la cohorte con edad $<45$ años incluye 173 pacientes (63,1\% de la muestra) y la cohorte de $\geq 45$ años incluye 101 enfermos (36,9\%). 
Gráfico 1. Diagrama de sectores que muestra la distribución por sexo en la muestra.

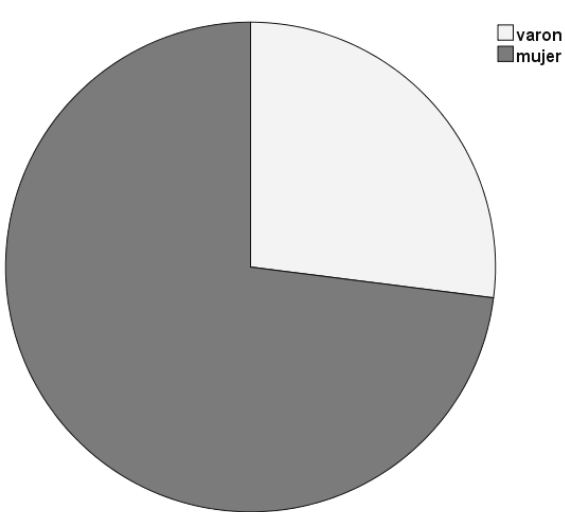

Gráfico 2. Histograma de la distribución por edad de la muestra en el momento de la CB

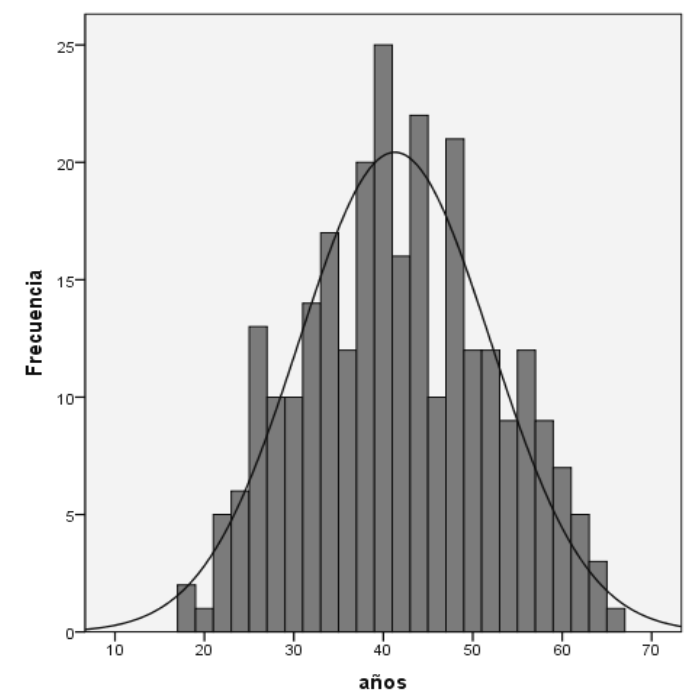

\subsection{2.- VARIABLES PREOPERATORIAS}

La variable "peso en el momento de la indicación de CB" sigue una distribución no normal, con una mediana de $125 \mathrm{Kg}$ y un RIQ de 112-143 Kg [Véase gráfico 3].

La variable "peso ideal en el momento de la indicación de CB" presenta una distribución no normal, con una mediana de 59,4 Kg y un RIQ de 56,2-64,8 Kg. 
La variable "talla en el momento de la indicación de CB" sigue una distribución no normal, con una mediana de $162 \mathrm{~cm}$ y un RIQ de 156-159 cm [Véase gráfico 3].

Gráfico 3. Histogramas de la distribución del peso y la talla en el momento de la indicación de CB.
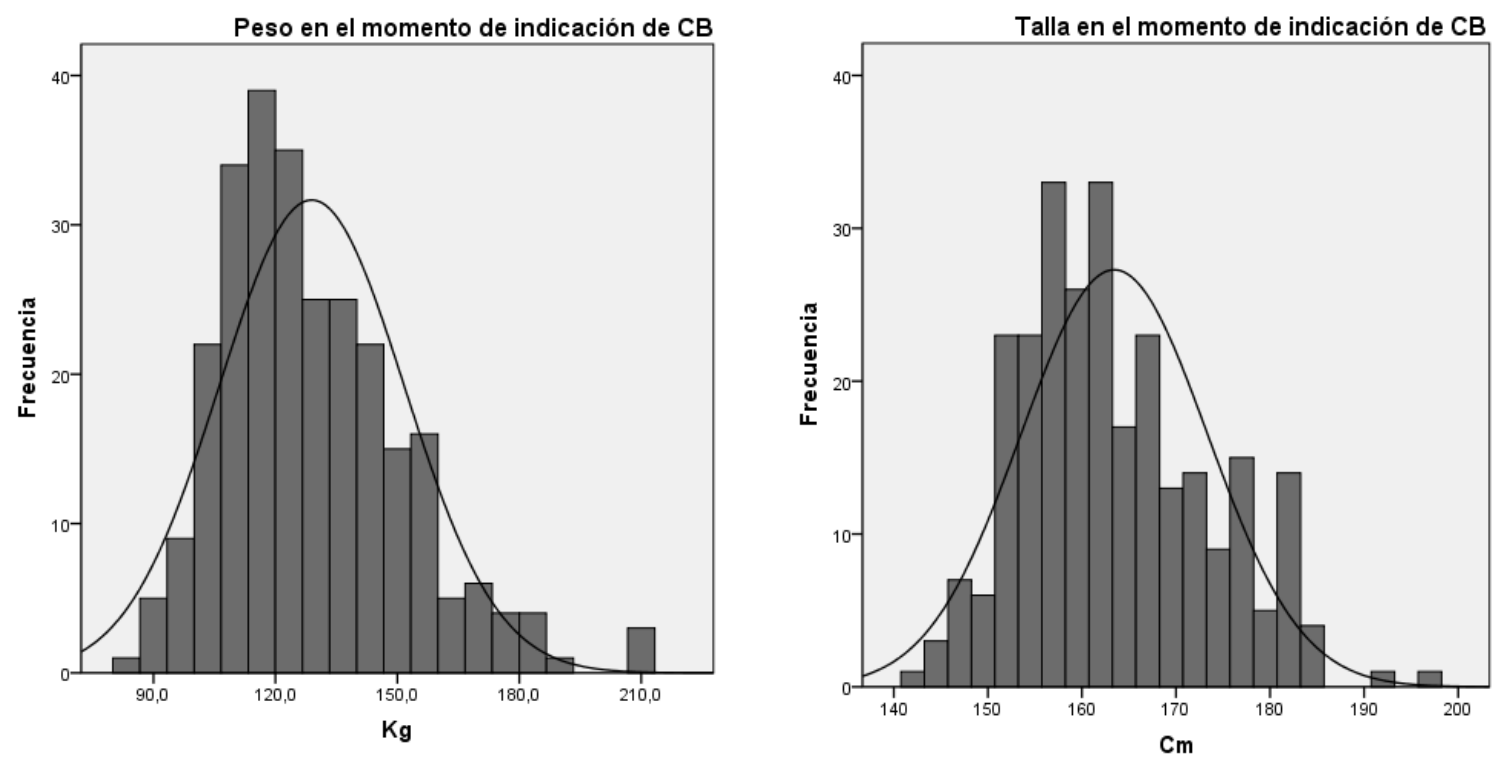

La distribución de la variable "IMC en el momento de la indicación de CB" es no normal, con una mediana de $47,2 \mathrm{Kg} / \mathrm{m}^{2}$ y un RIQ de 43,7-52,6 $\mathrm{Kg} / \mathrm{m}^{2}$ [Véase gráfico 4]. A su vez, la distribución de la variable "grupos de IMC" es la siguiente: la cohorte de pacientes con IMC $<50 \mathrm{Kg} / \mathrm{m}^{2}$ incluye 183 individuos $(67,8 \%)$ y la cohorte con IMC $\geq 50$ $\mathrm{Kg} / \mathrm{m}^{2}, 87$ pacientes $(32,2 \%)$. 
Gráfico 4. Histograma de la distribución del IMC en el momento de la indicación de CB.

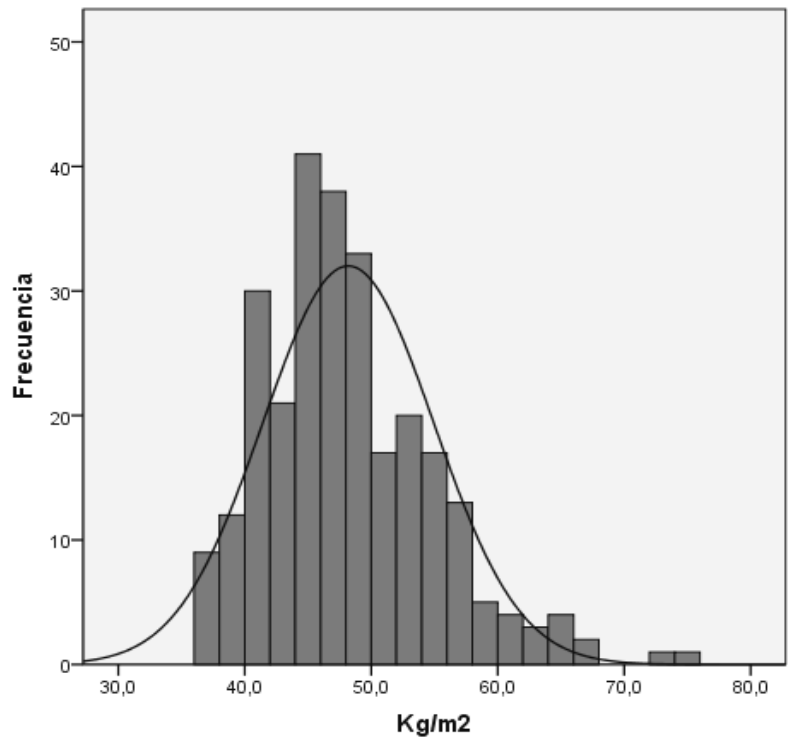

La variable "glucemia basal en la analítica solicitada por el endocrinólogo antes de la indicación de CB" sigue una distribución no normal, con una mediana de $101 \mathrm{mg} / \mathrm{dl}$ y un RIQ de 93-114 mg/dl [Véase gráfico 5].

Gráfico 5. Histograma de la distribución de la glucemia basal del paciente en la última analítica solicitada por el endocrinólogo antes de la indicación de CB.

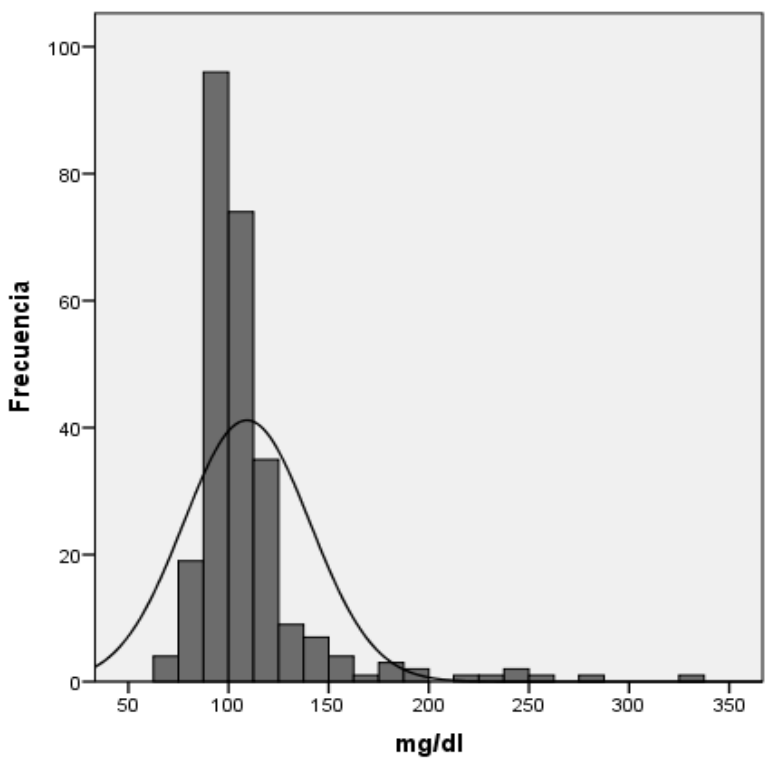


La variable “diagnóstico de DM2 en el momento de la indicación de CB" presenta la siguiente distribución: sí en 131 pacientes (47,8\%) y no en 143 (52,2\%) [Véase gráfico 6].

Gráfico 6. Diagramas de sectores que muestra la distribución según el diagnóstico de DM2, en el momento de la indicación de CB.

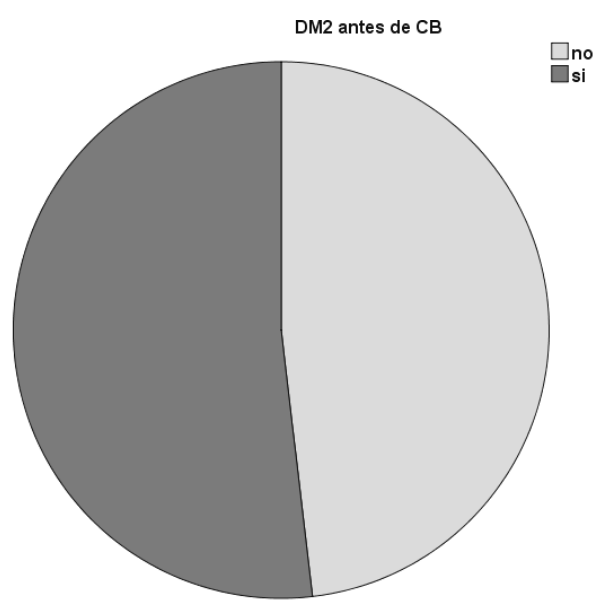

La distribución de variable "medicación antidiabética en el momento de la indicación de CB" es la siguiente: ningún fármaco antidiabético en 223 pacientes (83,2\%), un fármaco pautado en $34(12,7 \%)$, dos fármacos en $6(2,2 \%)$ y, por último, tres fármacos de distinto grupo pautados en 5 enfermos (1,9\%) [Véase gráfico 7].

La distribución de la variable "administración de insulina subcutánea en el momento de la indicación de CB" es la siguiente: del total de la muestra, 254 pacientes no precisaban insulina $(95,1 \%)$ y 13 sí (4,9\%) [Véase gráfico 7]. En este subgrupo de pacientes con administración de insulina, la variable "número de UI de insulina en el momento de la indicación de CB" sigue una distribución normal, con una media de 86,23 $\pm 57,25$ UI de insulina. De los 13 pacientes con pauta de insulina, 6 no reciben simultáneamente ningún antidiabético oral, 5 reciben un solo fármaco y dos individuos precisan conjuntamente insulina y tres antidiabéticos. 
Gráfico 7. Diagramas de sectores con el número de fármacos antidiabéticos orales que precisan los enfermos y la distribución de los pacientes que se administran o no insulina para el tratamiento de la DM en el momento de la indicación de CB.
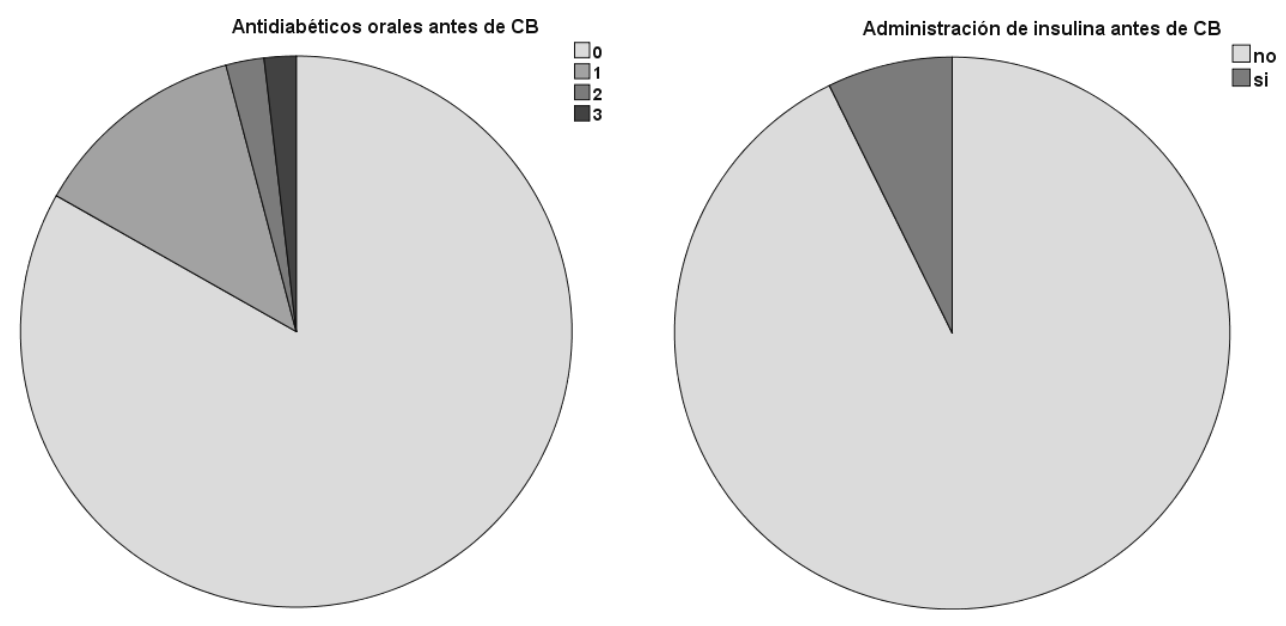

La distribución de la variable "criterio de glucemia para SM antes de la indicación de CB" es la siguiente: 107 pacientes no presentaban este criterio (41\%), frente a 154 que sí $(59 \%)$.

La variable "colesterol total en ayunas en la analítica solicitada por el endocrinólogo antes de la indicación de CB" sigue una distribución normal, con una media de 206,1 \pm $41,2 \mathrm{mg} / \mathrm{dl}$ [Véase gráfico 8].

La variable "TAG en ayunas en la analítica solicitada por el endocrinólogo antes de la indicación de CB" sigue una distribución no normal, con una mediana de 125,5 mg/dl y un RIQ de 87,5-172 mg/dl [Véase gráfico 8]. 
Gráfico 8. Histogramas de la distribución de las cifras de colesterol total y TAG antes de la indicación de CB.
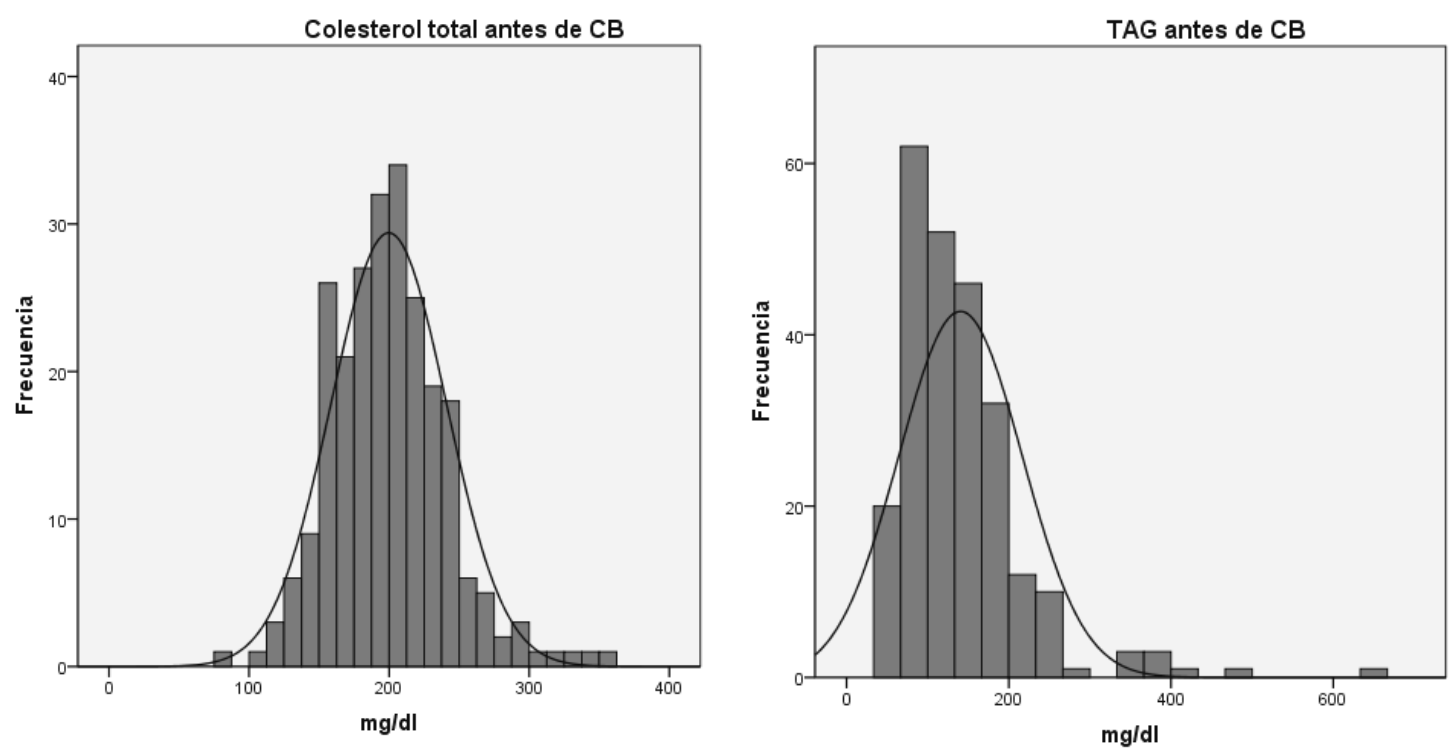

La distribución de la variable "criterio de TAG para SM antes de la indicación de CB' es la siguiente: 158 individuos no presentaban este criterio (64,8\%), frente a 86 que sí $(35,2 \%)$.

La variable "PA sistólica en consulta del endocrinólogo antes de la indicación de CB” sigue una distribución normal, con una media 143,4 \pm 19,4 mmHg [Véase gráfico 9].

La variable "PA diastólica en consulta del endocrinólogo antes de la indicación de CB" sigue una distribución no normal, con una mediana de $88 \mathrm{mmHg}$ y un RIQ de 80-94 mmHg [Véase gráfico 9]. 
Gráfico 9. Histogramas de la distribución de los valores de PA sistólica y diastólica antes de la indicación de CB.
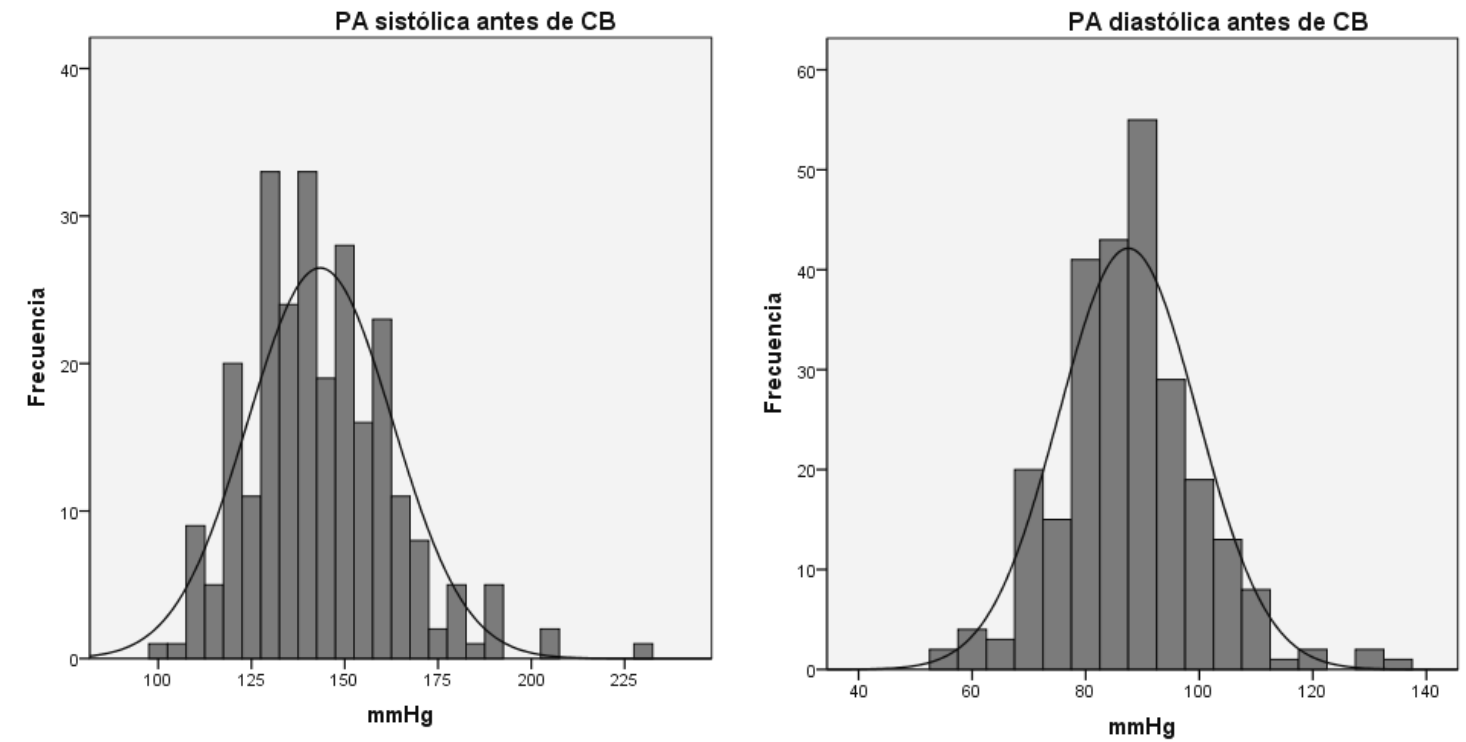

La variable "medicación antihipertensiva en el momento de la indicación de CB" presenta la siguiente distribución: ningún fármaco en 165 pacientes (61,6\%), un hipotensor en $52(19,4 \%)$, dos en 29 individuos (10,8\%), tres en $13(4,9 \%)$, cuatro en $7(2,6 \%)$ y cinco fármacos de distinto grupo en 2 pacientes $(0,7 \%)$ [Véase gráfico 10].

La distribución de la variable "criterio de HTA para SM antes de establecer la indicación de $\mathrm{CB}^{\prime}$ " es la siguiente: 29 pacientes no presentaban dicho criterio $(11,1 \%)$, mientras que 232 sí $(88,9 \%)$. 
Gráfico 10. Gráfico de barras del número de fármacos antihipertensivos pautados antes de la indicación de CB.

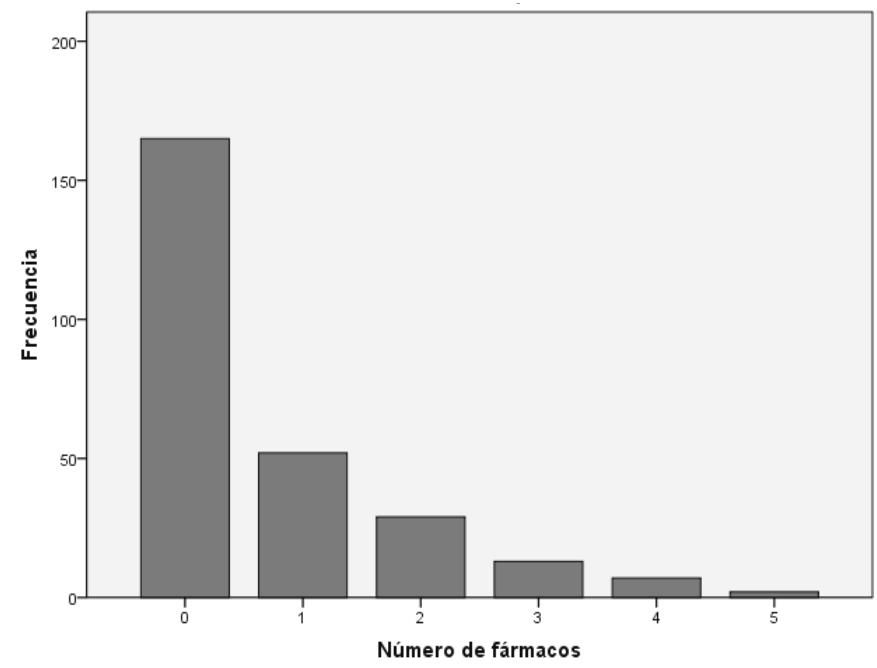

La variable "hemoglobina en la analítica solicitada por el endocrinólogo antes de la indicación de CB” presenta una distribución normal, con una media de 13,9 $\pm 1,3 \mathrm{~g} / \mathrm{dl}$.

La variable "albúmina en la analítica solicitada por el endocrinólogo antes de la indicación de CB" presenta una distribución normal, con una media de 4,1 $\pm 0,5 \mathrm{~g} / \mathrm{dl}$.

La variable "calcio total en la analítica solicitada por el endocrinólogo antes de la indicación de CB" presenta una distribución normal, con una media de 9,4 \pm 0,4 mg/dl.

La variable "25-OH Vitamina D en la analítica solicitada por el endocrinólogo antes de la indicación de CB” presenta una distribución normal, con una media de 28,2 \pm 14,5 $\mu \mathrm{g} / \mathrm{l}$ 
La variable "PTH en la analítica solicitada por el endocrinólogo antes de la indicación de CB” presenta una distribución normal, con una media de 61,3 $\pm 29,3 \mathrm{pg} / \mathrm{ml}$.

Notificamos que para estas cinco últimas variables, sólo se dispone de datos en los 113 pacientes con seguimiento postbariátrico en nuestra Unidad de OM.

La variable "grupos de HTA" presenta la siguiente distribución: 99 pacientes (36,7\%) pertenecen a la cohorte sin HTA según el OS-MRS, mientras que 171 individuos $(63,3 \%)$ se incluyen en la cohorte con HTA.

La variable "grupos de riesgo de TEP" presenta la siguiente distribución: 210 pacientes $(76,6 \%)$ pertenecen a la cohorte sin riesgo de TEP según el OS-MRS, frente a 64 que sí presentan riesgo de TEP (23,4\%).

La “puntuación en el OS-MRS” para la muestra de pacientes sometidos a DBP en el HURH es la siguiente:

- 39 pacientes obtienen 0 puntos $(14,2 \%)$

- 72 pacientes, 1 punto $(26,5 \%)$.

- 86 pacientes, 2 puntos $(31,3 \%)$.

- 56 pacientes, 3 puntos (20,4\%).

- 19 pacientes, 4 puntos $(6,9 \%)$.

- 2 pacientes, 5 puntos $(0,7 \%)$. 
En base a esta puntuación, la variable "Clase del OS-MRS" presenta la siguiente distribución: 111 pacientes son clase A (40,5\%), 142 son clase B (51,7\%) y 21 individuos son clase $\mathrm{C}(7,8 \%)$.

\subsection{3.- VARIABLES ASOCIADAS AL INGRESO HOSPITALARIO}

La distribución de la variable "vía de abordaje para la intervención" es la siguiente: cirugía abierta en 264 pacientes $(97,0 \%)$, cirugía laparoscópica en 4 individuos (1,5\%) y cirugía convertida en otros $4(1,5 \%)$.

La variable "estancia hospitalaria postoperatoria" sigue una distribución no normal, con una mediana de 9 días y un RIQ de 7-11 días [Véase gráfico 11]. Tras identificar los pacientes intervenidos en la "época 1" (182 individuos, 66,4\% de la muestra de 274 obesos), obtenemos que la estancia sigue una distribución no normal, con una mediana de 9 días y un RIQ de 8-12 días. Para los enfermos de la "época 2" (92 individuos, 33,4\%), la estancia en este subgrupo sigue una distribución no normal con una mediana de 7 días y un RIQ de 6-9 días. De manera análoga, se ha calculado la estancia para cada una de las categorías del OS-MRS. En los 111 pacientes incluidos en la clase A, la estancia postoperatoria sigue una distribución no normal, con una mediana de 8 días y un RIQ de 710 días. En los 142 pacientes de la clase B, la distribución de la estancia es no normal, con una mediana de 9 días y un RIQ de 7-12 días. En los 21 pacientes de la clase C, la estancia postoperatoria sigue una distribución normal, con una media de 10,8 \pm 7,2 días. 
Gráfico 11. Histograma de la estancia hospitalaria postoperatoria.

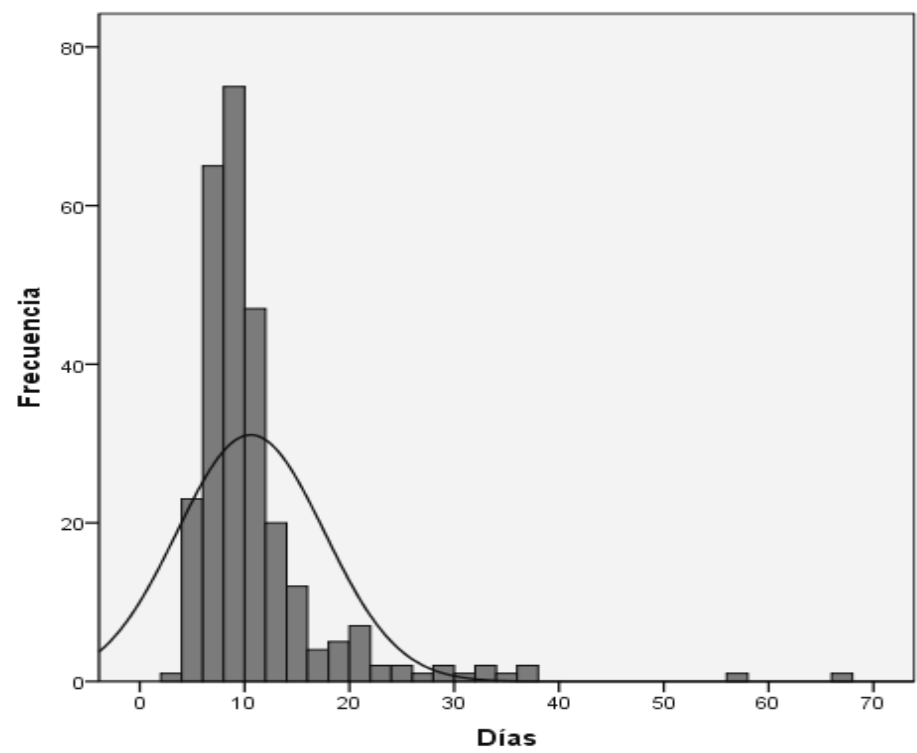

La distribución de la variable "complicaciones médicas durante el ingreso" es la siguiente: 34 obesos intervenidos presentaron complicaciones médicas (12,4\%), mientras que 240 no las presentaron $(87,6 \%$ ) [Véase gráfico 13]. La variable "tipo de complicación médica" presenta la siguiente distribución [Véase gráfico 12]:

- Hiperglucemia en 3 pacientes $(1,1 \%)$.

- Complicaciones respiratorias en 9 pacientes $(3,3 \%)$.

- TVP en un paciente $(0,4 \%)$.

- TEP en un paciente $(0,4 \%)$.

- Síncope en 2 pacientes $(0,7 \%)$.

- Infección del tracto urinario en 9 pacientes $(3,3 \%)$

- Rash cutáneo en 2 pacientes $(0,7 \%)$.

- Otras complicaciones médicas en 7 pacientes $(2,6 \%)$. 
Gráfico 12. Diagrama de sectores representando la presencia o no de complicaciones médicas y gráfico de barras con la frecuencia de cada tipo de complicación médica.
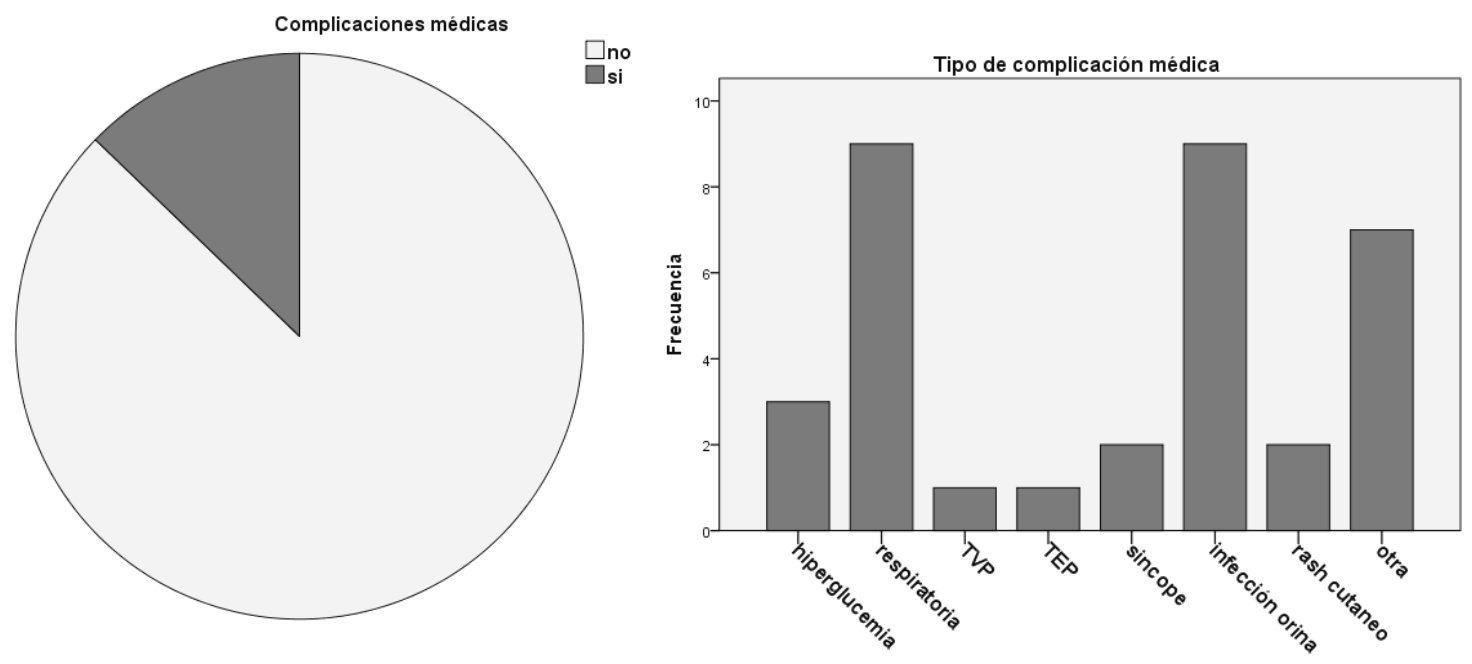

La distribución de la variable "complicaciones quirúrgicas durante el ingreso" es la siguiente: 71 pacientes sufrieron complicaciones quirúrgicas (25,9\%), mientras que 203 no las presentaron (74,1\%) [Véase gráfico 13]. La distribución de la variable "tipo de complicación quirúrgica" sobre el total de la muestra es la siguiente [Véase gráfico 13]:

- Infección del sitio quirúrgico superficial y/o profunda en 36 pacientes $(13,2 \%)$.

- Infección del sitio quirúrgico de órgano o espacio en 4 pacientes (1,5\%).

- Fuga en 7 pacientes $(2,6 \%)$

- Íleo paralítico o retraso de vaciamiento gástrico en 14 pacientes (5,1\%).

- Oclusión en un paciente $(0,4 \%)$.

- Hemorragia luminal en 7 pacientes (2,6\%).

- Hemoperitoneo en 2 pacientes $(0,7 \%)$. 
Se han registrado 14 pacientes $(5,1 \%)$ que desarrollaron complicaciones de tipo médico y quirúrgico, concomitantemente, durante el periodo de ingreso postoperatorio.

Gráfico 13. Diagrama de sectores de la presencia o no de complicaciones quirúrgicas y gráfico de barras con la frecuencia de cada tipo de complicación quirúrgica.
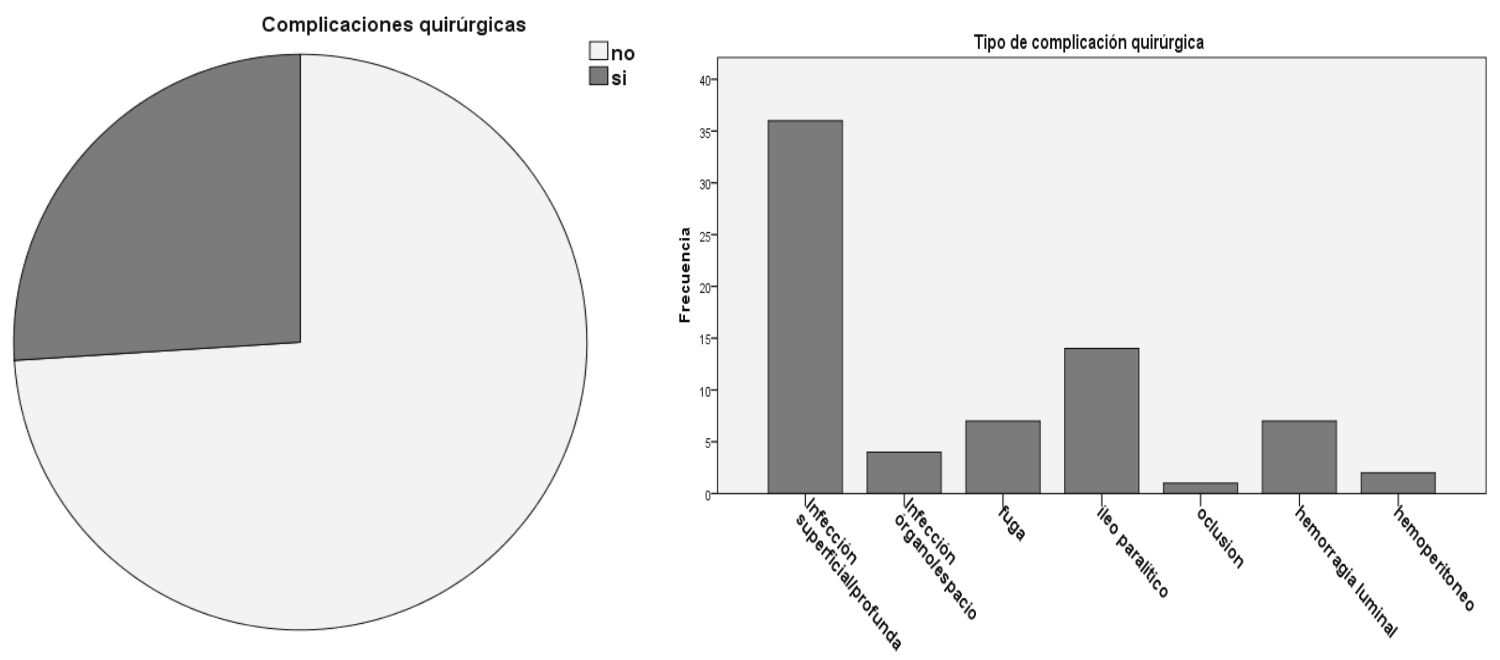

La distribución de la variable "severidad de las complicaciones postquirúrgicas siguiendo la clasificación de Dindo-Clavien” es la siguiente [Véase gráfico 14]:

- 182 pacientes no sufrieron ninguna incidencia que alterara el curso postoperatorio $(66,4 \%)$.

- 28 pacientes presentaron complicaciones de grado I (10,2\%).

- 43 pacientes de grado II $(15,7 \%)$.

- 10 pacientes de grado IIIa (3,6\%).

- 3 pacientes de grado IIIb $(1,1 \%)$.

- 5 pacientes sufrieron complicaciones de grado IV (1,8\%).

- 3 pacientes fallecieron en el postoperatorio inmediato, correspondiente al grado V de la clasificación de Dindo-Clavien $(1,1 \%)$. 
Gráfico 14. Gráfico de barras con la frecuencia de complicaciones postquirúrgicas según la clasificación de Dindo-Clavien.

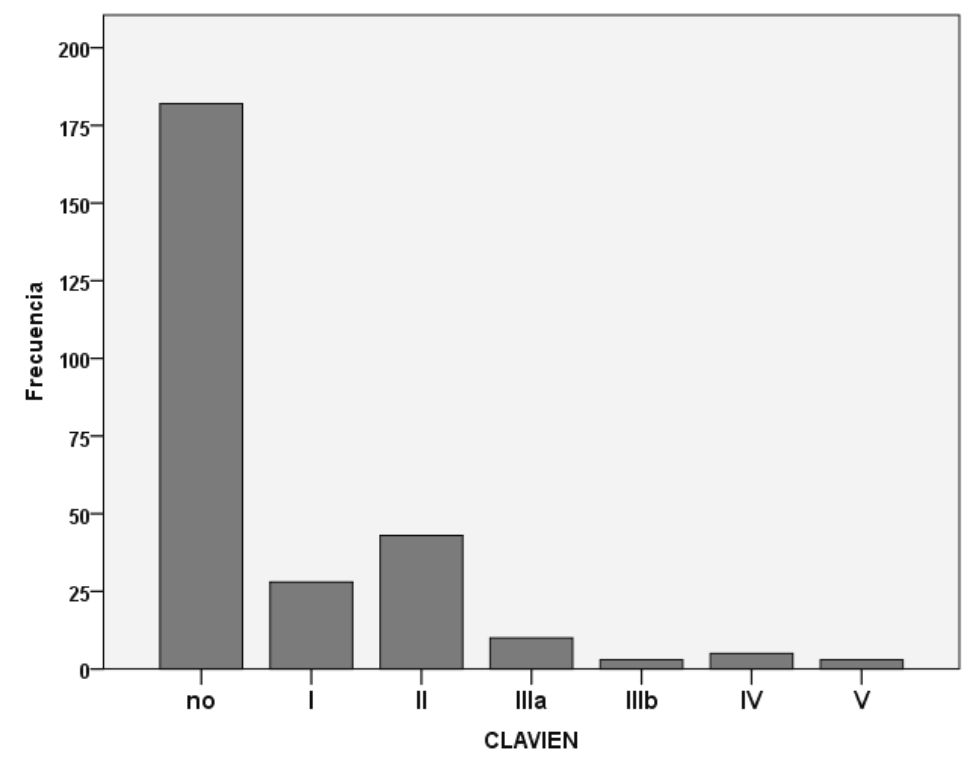

Las complicaciones mayores (grados IIIa, IIIb, IV y V) supusieron el 7,6\% del total de pacientes de la muestra de 274 pacientes intervenidos. El análisis del tipo de complicación correspondiente a los citados grados se muestra a continuación:

- Grado IIIa: 3 pacientes con hemorragia luminal, 3 pacientes con fuga (uno de ellos desarrolló también complicación respiratoria y otro presentó una TVP concomitante) y 4 pacientes con infección del sitio quirúrgico de órgano o espacio, de los cuales uno sufrió además síncope y otro presentó complicación médica respiratoria en el postoperatorio.

- Grado IIIb: un paciente con hemorragia luminal, un paciente con oclusión y un paciente con del sitio quirúrgico superficial y/o profunda.

- Grado IV: un paciente con TEP, 3 pacientes con complicación médica respiratoria diferente de TEP y otro paciente con fuga y complicación respiratoria simultáneas. 
- Grado V: dos pacientes fallecieron tras complicación quirúrgica de tipo hemoperitoneo, habiendo sido por tanto reintervenidos, de los cuales uno además presentó complicación respiratoria. El tercer exitus de esta serie fue debido a complicación de tipo respiratorio (broncoaspiración masiva secundaria a vómito por trasgresión dietética del paciente).

\subsection{4.- VARIABLES POSTOPERATORIAS}

Los resultados que se muestran a continuación corresponden exclusivamente a los 113 obesos intervenidos que realizan su seguimiento postbariátrico en la Unidad de OM del HURH.

\subsubsection{1.- Seguimiento}

Notificamos que 113 de los 274 pacientes de la muestra inicial $(41,2 \%)$ son los que realizan su seguimiento postbariátrico en la Unidad de OM y CB del HURH. Para estos 113 obesos intervenidos mediante DBP, la variable "tiempo de seguimiento" sigue una distribución normal, con una media de 1997,6 \pm 1102,8 días (rango de 75 a 4227 días) [Véase gráfico 15]. Al analizar los individuos con seguimiento postbariátrico mayor de 1825 días (5 años), obtenemos que este subgrupo incluye 62 pacientes de 113 (54,8\%). 
Gráfico 15. Histograma de la distribución del tiempo de seguimiento.

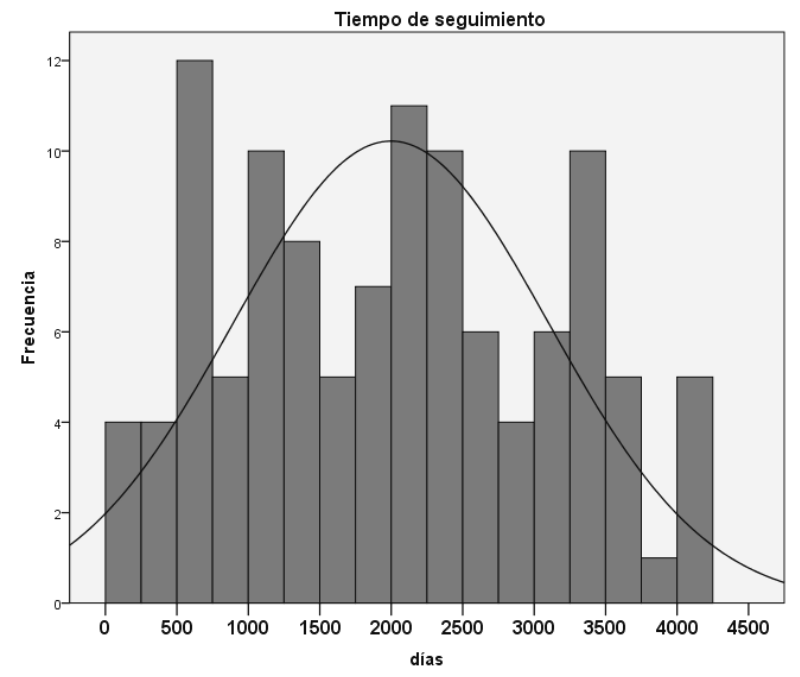

\subsubsection{2.- Ponderales}

La variable "peso en la última revisión de Endocrinología tras CB" sigue una distribución normal, con una media de 88,2 \pm 18,1 $\mathrm{Kg}$ [Véase gráfico 16]. Notificamos que ninguno de nuestros pacientes $(0 \%)$ tras DBP ha sufrido una reganancia de peso tal que su peso en la última revisión supere al peso basal.

La variable "IMC en la última revisión de Endocrinología tras CB" sigue una distribución normal, con una media de 32,9 $\pm 5,4 \mathrm{Kg} / \mathrm{m}^{2}$ [Véase gráfico 16]. 
Gráfico 16. Histogramas de la distribución del peso del paciente y su IMC en la última revisión del endocrinólogo tras $\mathrm{CB}$.
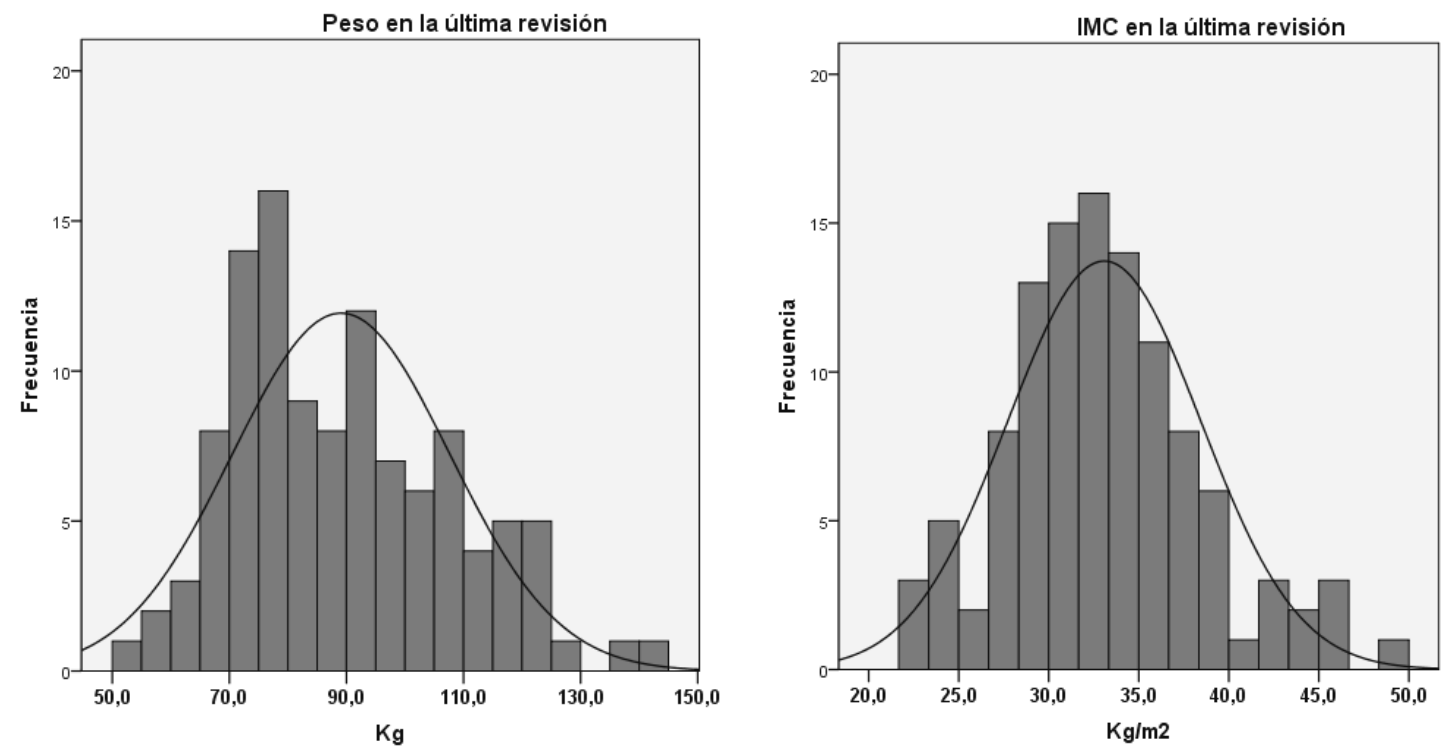

La variable "descenso de IMC en la última revisión de de Endocrinología tras CB" sigue una distribución normal, con una media de $14,1 \pm 6,1 \mathrm{Kg} / \mathrm{m}^{2}$.

La variable "PEPP en la última revisión de Endocrinología tras CB" sigue una distribución normal, con una media de 58,3 \pm 19,4\% [Véase gráfico 17]. Tras seleccionar a los 62 obesos intervenidos que cumplen más de 5 años de seguimiento en el HURH [Véase epígrafe 4.1.4.3.- Seguimiento], obtenemos una distribución igualmente normal en esta variable, con una media de $62,3 \pm 19,5 \%$. De este subgrupo de individuos, 15 pacientes $(24,2 \%)$ no alcanzaron un PEPP $>50 \%$.

La variable "PEIMCP en la última revisión de Endocrinología tras CB" sigue una distribución normal, con una media de 64,6 $\pm 22,0 \%$ [Véase gráfico 17]. De nuevo, tras seleccionar a los 62 obesos intervenidos con más de 5 años de seguimiento en nuestra Unidad de CB, se mantiene la distribución normal de la variable, con una media de 68,9 \pm 
22,4\%. Para este subgrupo y empleando la clasificación de Larrad et al. (187), 34 individuos $(54,8 \%)$ alcanzan excelente resultado ponderal (PEIMCP >65\%), 17 obesos intervenidos $(27,2 \%)$ obtienen resultado ponderal bueno (PEIMCP entre el 50 y el 65\%) y 11 pacientes $(17,7 \%)$ se catalogan como fracaso (PEIMCP $<50 \%)$.

La variable "PPTP del paciente en la última revisión de Endocrinología tras CB" sigue una distribución normal, con una media de 29,4 $\pm 10,3 \%$.

Gráfico 17. Histogramas de la distribución del peso del PEPP y PEIMCP en la última revisión en consulta de Endocrinología.
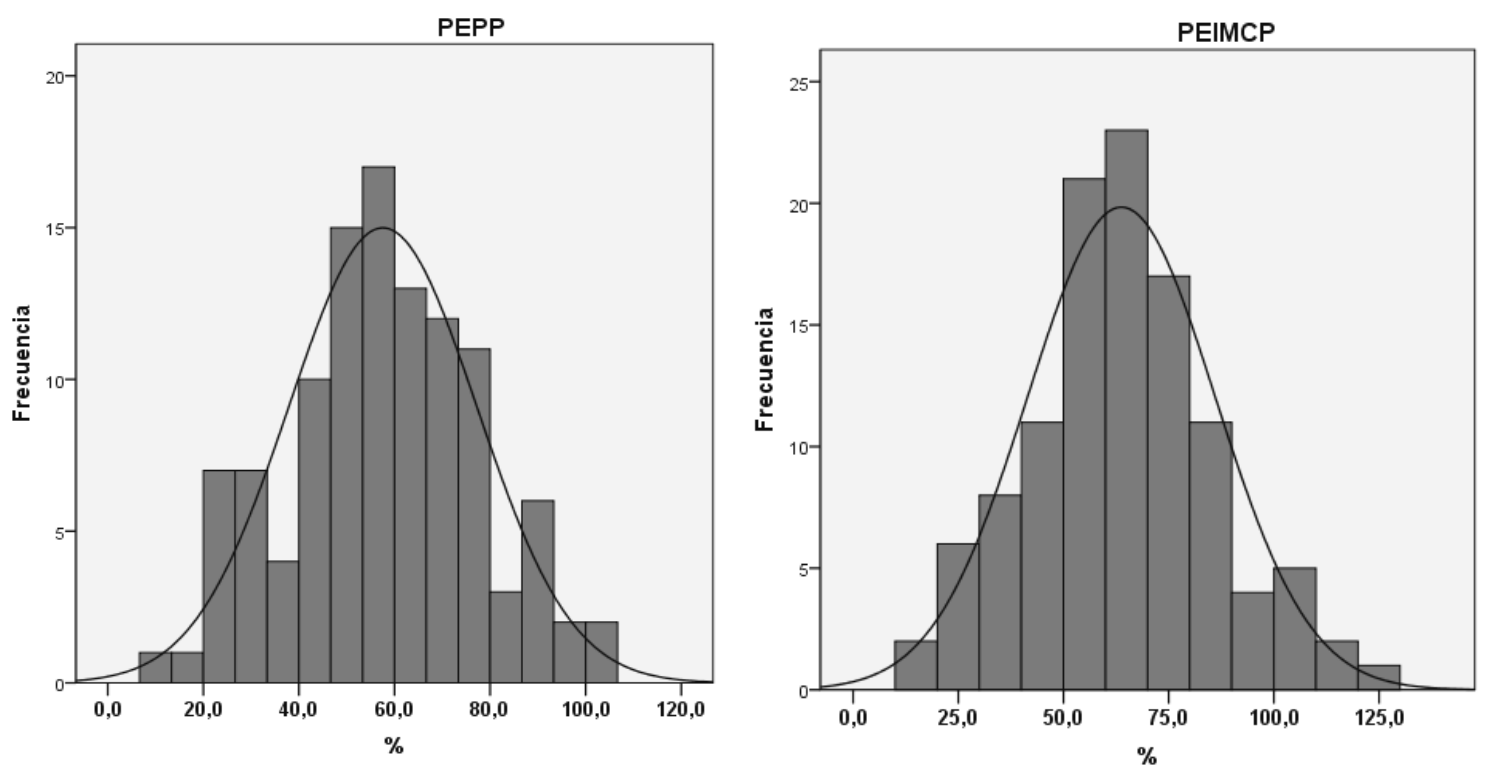

\subsubsection{3.- Clínicas y analíticas}

La variable "glucemia basal en la última analítica solicitada por el endocrinólogo tras CB” sigue una distribución normal, con una media de $86,6 \pm 8,1 \mathrm{mg} / \mathrm{dl}$ [Véase gráfico 18].

La variable "HbA1C en la última analítica solicitada por el endocrinólogo tras CB" sigue una distribución normal entre los 53 obesos intervenidos con diagnóstico de DM2 
antes de la indicación de $\mathrm{CB}$ y que realizan seguimiento en nuestra Unidad, con una media de $4,9 \pm 0,7 \%$ [Véase gráfico 18]. Se notifica un $69,8 \%$ de pérdidas para esta variable.

Gráfico 18. Histogramas de la distribución de la glucemia basal y la HbA1C en la última analítica solicitada por el endocrinólogo tras CB.
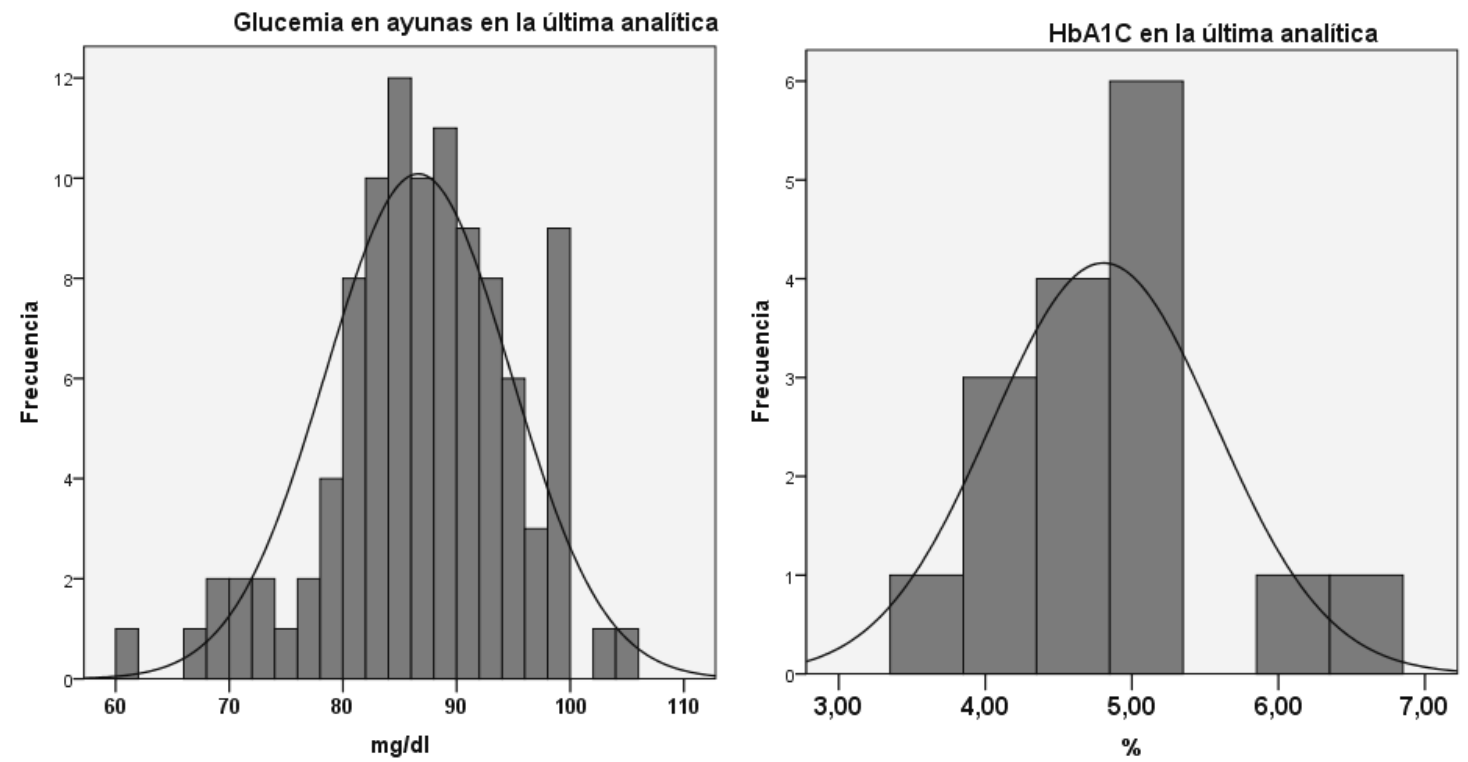

La distribución de la variable "medicación antidiabética en la última revisión de Endocrinología tras CB" es la siguiente: ningún paciente de la muestra precisa fármacos antidiabéticos orales $(0 \%)$.

La distribución de la variable "administración de insulina subcutánea en la última revisión de Endocrinología tras CB” es la siguiente: 103 pacientes no precisan insulina $(98,1 \%)$ y 2 sí $(1,9 \%)$. En estos 2 individuos, la variable "número de UI de insulina en la última revisión en consulta de Endocrinología” es de 23 UI pautadas en un paciente y de 30 UI en el otro. El primero precisaba la administración de 174 UI de insulina antes de la CB y el segundo, de 80 UI de insulina antes de la CB. 
La distribución de la variable "criterio de glucemia para SM en la última revisión de Endocrinología tras CB" es la siguiente: 101 pacientes no cumplen este criterio (96,2\%), frente a 4 que sí $(3,8 \%)$.

La variable "DM en la última revisión de Endocrinología tras CB" presenta la siguiente distribución: 103 pacientes $(98,1 \%)$ no cumplen criterio frente a $2(1,9 \%)$ que sí.

La distribución de la variable "resolución de la DM2 en la última revisión de Endocrinología tras CB", para los 53 pacientes obesos con DM2 sometidos a CB y seguimiento postbariátrico en el HURH, es la siguiente [Véase gráfico 19]: 14 pacientes (87,5\%) con criterio de remisión total según la American Diabetes Association (190), un paciente $(6,3 \%)$ con remisión parcial y otro paciente $(6,3 \%)$ sin mejoría de la DM2. Se notifica un $69,8 \%$ de pérdidas para esta variable derivada de la pérdida de datos de la variable "HbA1C en la última analítica solicitada por el endocrinólogo tras CB”.

Gráfico 19. Diagrama de sectores con la distribución de la resolución de la DM2 en la última revisión del endocrinólogo tras $\mathrm{CB}$, siguiendo los criterios de la American Diabetes Association (190).

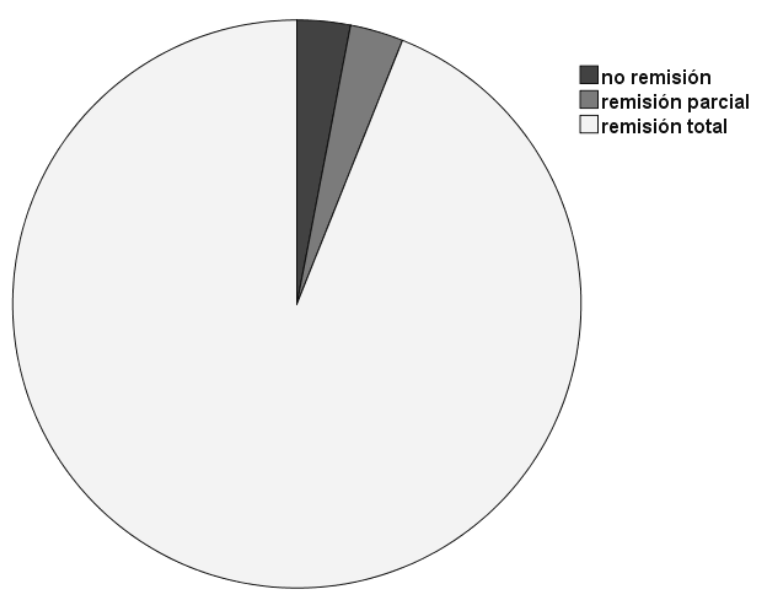


La variable "colesterol total en ayunas en la última analítica solicitada por el endocrinólogo tras CB" sigue una distribución normal, con una media de 145,2 \pm 32,4 $\mathrm{mg} / \mathrm{dl}$ [Véase gráfico 20].

La variable "colesterol HDL en la última analítica solicitada por el endocrinólogo tras CB” sigue una distribución normal, con una media de 52,5 $\pm 13,9 \mathrm{mg} / \mathrm{dl}$ [Véase gráfico 20].

Gráfico 20. Histogramas de la distribución del colesterol total y del HDL en la última analítica de control tras CB.
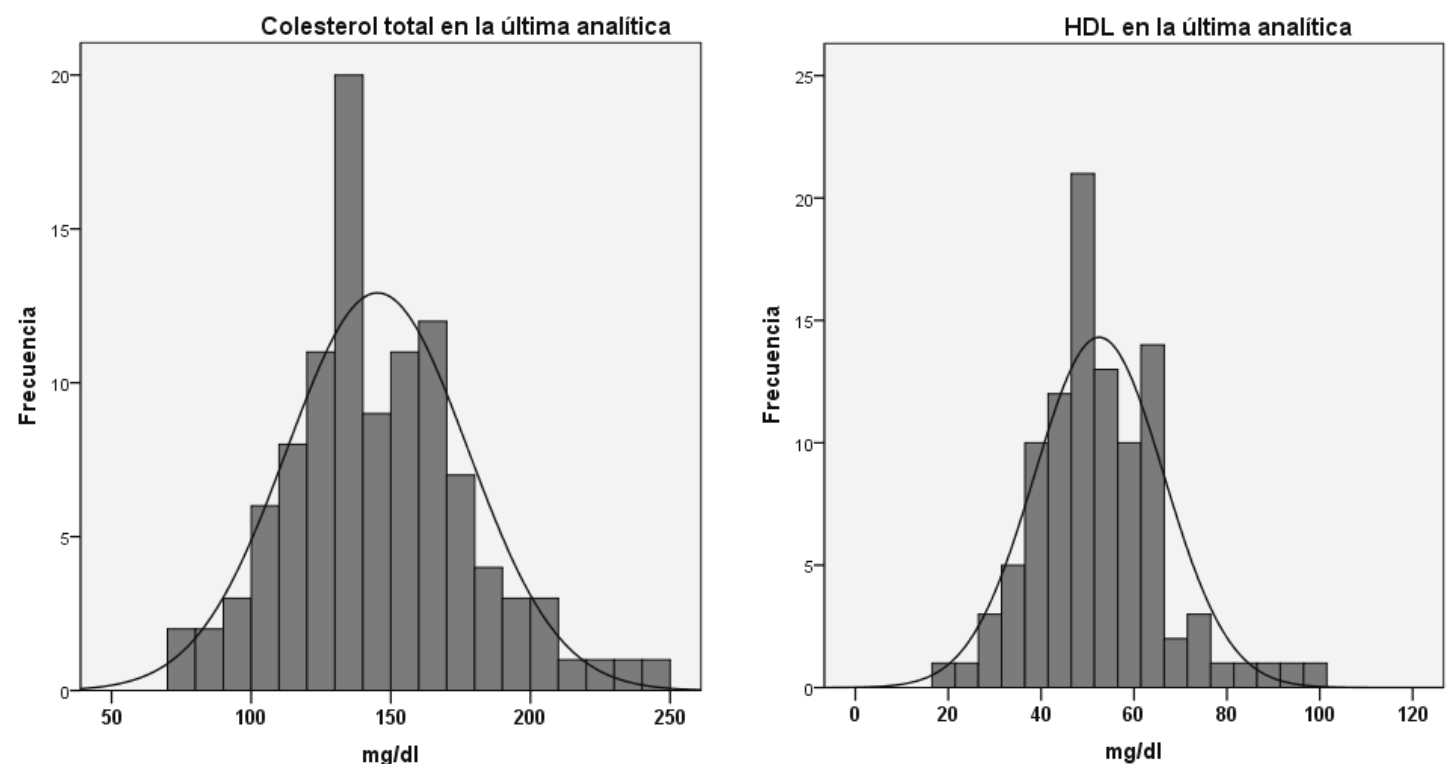

La variable "colesterol LDL en ayunas en la última analítica solicitada por el endocrinólogo tras CB" sigue una distribución normal, con una media de 72,3 $\pm 24,8$ $\mathrm{mg} / \mathrm{dl}$ [Véase gráfico 21]. 
La variable "TAG en ayunas en la última analítica solicitada por el endocrinólogo tras CB" sigue una distribución no normal, con una mediana de $98 \mathrm{mg} / \mathrm{dl}$ y un RIQ de 74$157,5 \mathrm{mg} / \mathrm{dl}$ [Véase gráfico 21].

Gráfico 21. Histogramas de la distribución del LDL y de TAG en la última analítica de control tras CB.
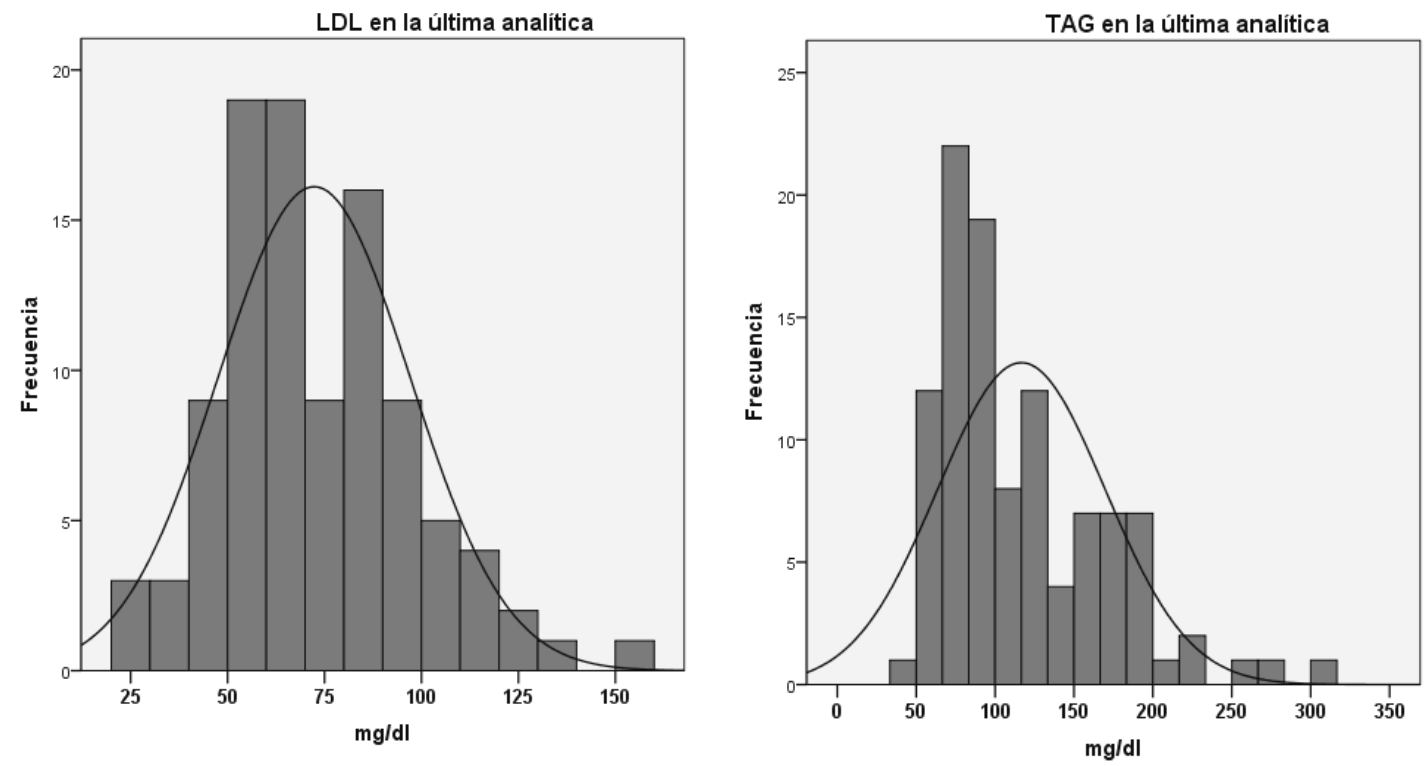

La variable "tratamiento hipolipemiante en la última revisión de Endocrinología tras CB" presenta la siguiente distribución: 101 pacientes sin este tratamiento (95,3\%), frente a 5 que sí lo precisan (4,7\%).

La distribución de la variable "criterio de HDL para SM en la última revisión de Endocrinología tras CB" es la siguiente: 59 pacientes no presentan dicho criterio (59\%), frente a 41 que sí lo cumplen (41\%). 
La distribución de la variable "criterio de TAG para SM en la última revisión de Endocrinología tras CB” es la siguiente: 75 individuos (71,4\%) no presentan este criterio, mientras que 30 sí lo cumplen (28,6\%).

La variable "PA sistólica en la última revisión de Endocrinología tras CB" sigue una distribución normal, con una media de 127,2 \pm 17,1 mmHg [Véase gráfico 22].

La variable "PA diastólica en la última revisión de Endocrinología tras CB" sigue una distribución normal, con una media de 75,2 \pm 11,8 mmHg [Véase gráfico 22].

Gráfico 22. Histogramas de la distribución de la PA sistólica y diastólica en la última revisión del endocrinólogo tras $\mathrm{CB}$.
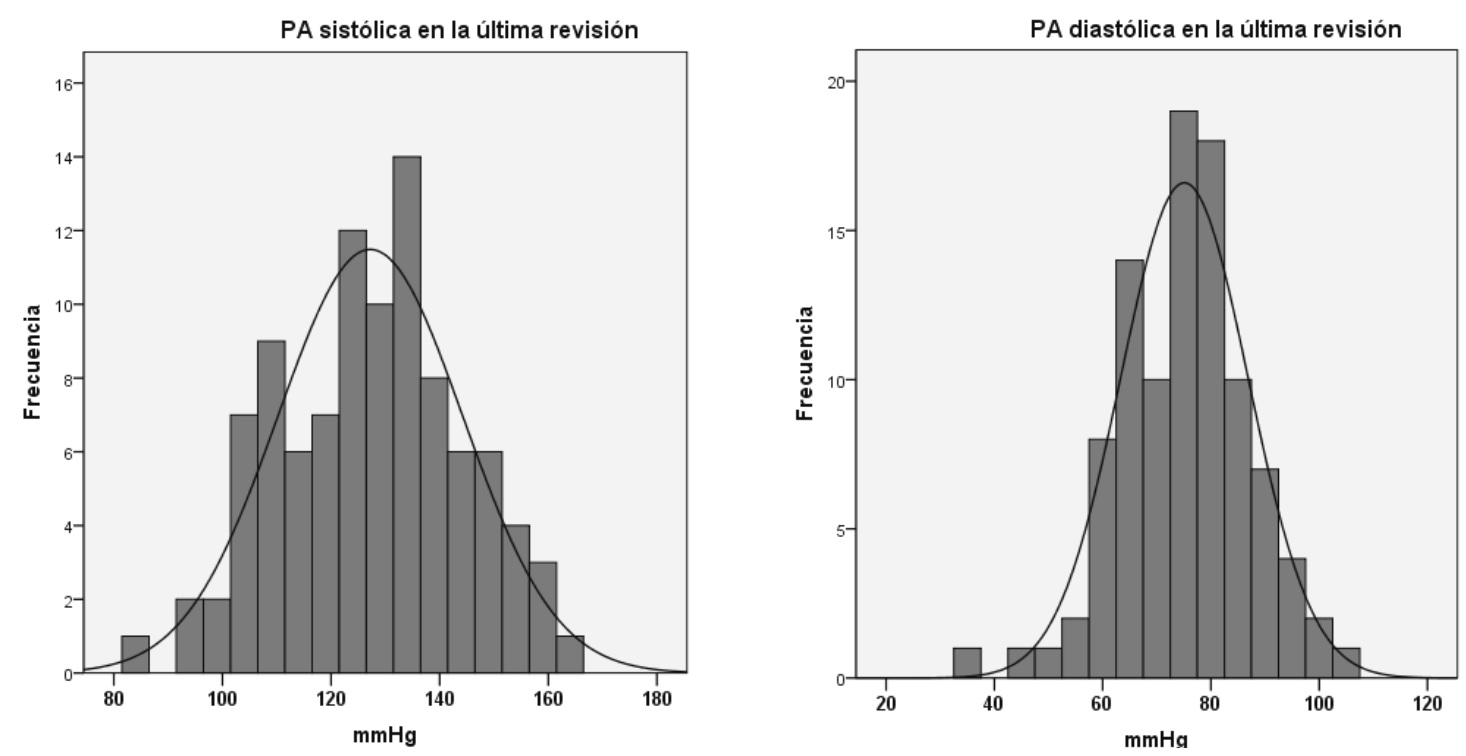

La distribución de la variable "medicación antihipertensiva en la última revisión de Endocrinología tras CB" es la siguiente: 82 pacientes de la muestra con seguimiento postbariátrico en el HURH no precisan ningún hipotensor $(78,1 \%)$, un fármaco en 15 
pacientes $(15,2 \%)$, dos en 4 individuos $(3,8 \%)$ y tres antihipertensivos en 3 enfermos $(2,9 \%)$ [Véase gráfico 23].

Gráfico 23. Gráfico de barras de la distribución del número de antihipertensivos pautados en la última revisión en consulta de Endocrinología.

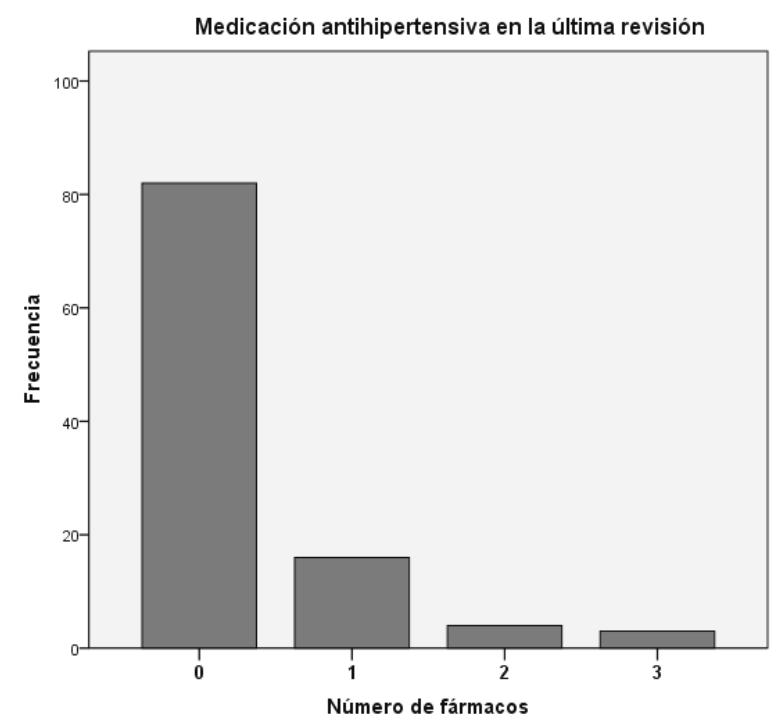

La distribución de la variable "criterio de PA para SM en la última revisión de Endocrinología tras CB" es la siguiente: 42 pacientes no cumplen este criterio $(42,4 \%)$, frente a 57 que sí (57,6\%).

La variable "Hemoglobina en la última analítica solicitada por el endocrinólogo tras CB” sigue una distribución normal, con una media de 12,7 $\pm 1,4 \mathrm{~g} / \mathrm{dl}$ [Véase gráfico 24].

La variable "Albúmina en la última analítica solicitada por el endocrinólogo tras CB" sigue una distribución no normal, con una mediana de $4 \mathrm{~g} / \mathrm{dl}$ y un RIQ de 3,8-4,3 $\mathrm{g} / \mathrm{dl}$ [Véase gráfico 24]. 
Gráfico 24. Histogramas de la distribución de hemoglobina y albúmina en la última analítica de control solicitada por el endocrinólogo.
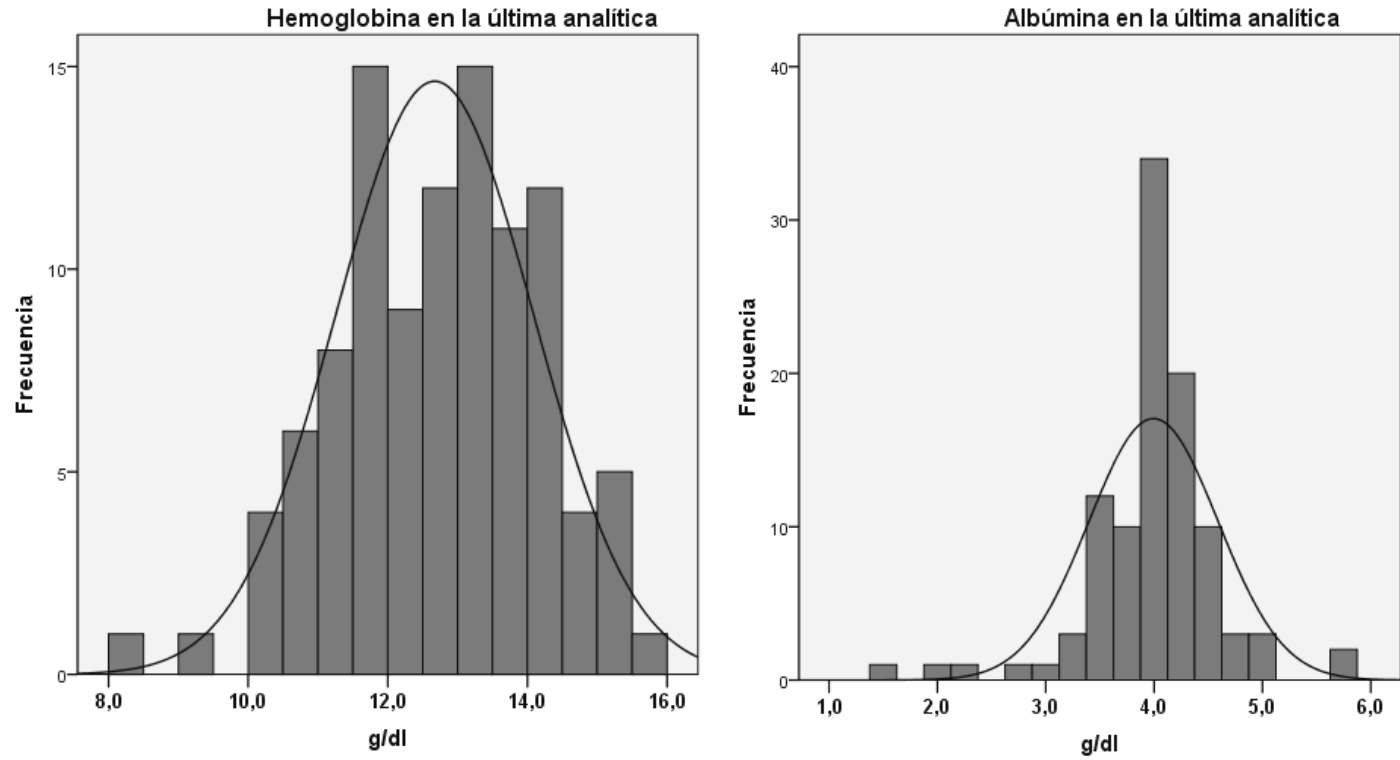

La variable "Calcio total en la última analítica solicitada por el endocrinólogo tras CB” sigue una distribución normal, con una media de 8,9 \pm 0,6 $\mathrm{mg} / \mathrm{dl}$ [Véase gráfico 25].

La variable "25-OH Vitamina $\mathrm{D}$ en la última analítica solicitada por el endocrinólogo tras CB" sigue una distribución no normal, con una mediana de 18,0 $\mu \mathrm{g} / 1$ y un RIQ de 10-38,1 $\mu \mathrm{g} / 1$ [Véase gráfico 25].

La variable "PTH en la última analítica solicitada por el endocrinólogo tras CB" sigue una distribución no normal, con una mediana de 82,8 pg/ml y un RIQ de 50,3-122,7 $\mathrm{pg} / \mathrm{ml}$ [Véase gráfico 26]. 
Gráfico 25. Histogramas de la distribución de calcio total y 25-OH Vitamina D en la última analítica de control solicitada por el endocrinólogo.
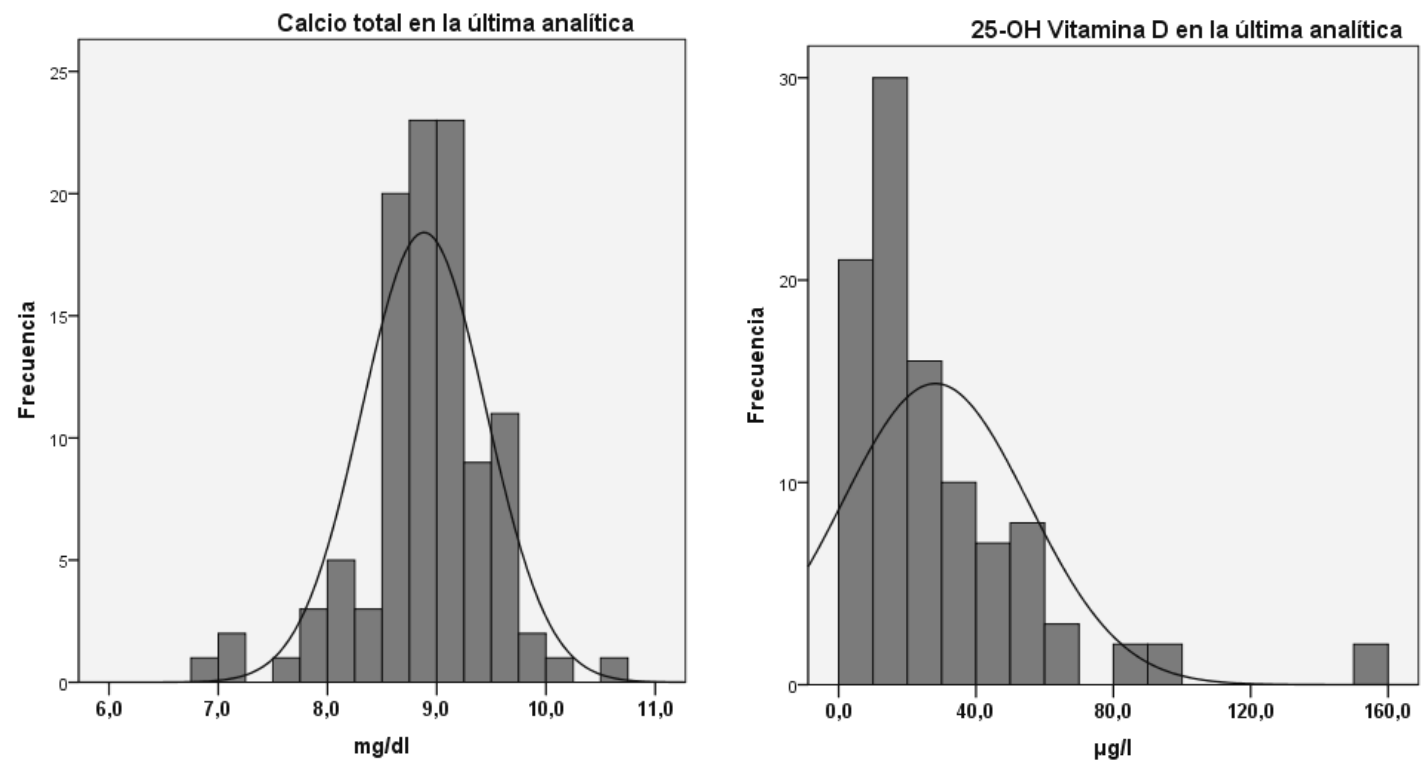

Gráfico 26. Histogramas de la distribución de PTH en la última analítica de control solicitada por el endocrinólogo.

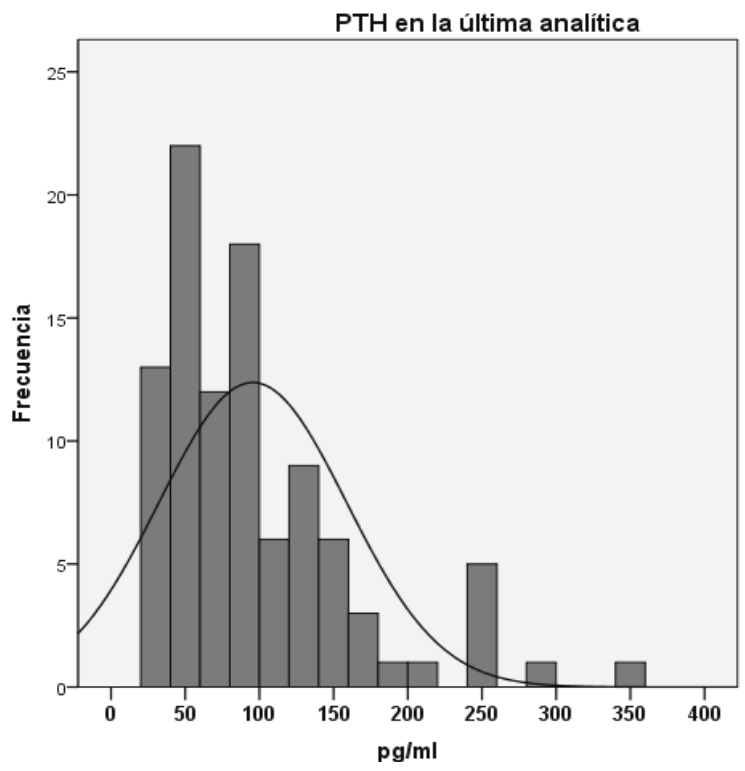




\section{2.- ANÁLISIS COMPARATIVO DE LOS EFECTOS Y RESULTADOS DE LA DERIVACIÓN}

\section{BILIOPANCREÁTICA}

En este epígrafe se presentará el análisis estadístico inferencial de las diferencias existentes en los 113 obesos de nuestra muestra entre el momento basal (antes de la indicación de $\mathrm{CB}$ ) y en la última revisión del seguimiento tras DBP, el cual se corresponde con una media de 1997,6 días, obteniendo que el 54,8\% de estos 113 pacientes alcanzan un seguimiento postbariátrico superior a 5 años (1825 días), tal y como se acaba de exponer.

\subsection{1.- ANÁLISIS COMPARATIVO DE LOS RESULTADOS}

\section{PONDERALES}

Para los 113 individuos de la muestra con seguimiento postbariátrico en el HURH, existe un descenso estadísticamente significativo entre las medias del peso y del IMC en el momento de la indicación de $\mathrm{CB}$ y la última revisión en consulta de Endocrinología tras CB [Véase tabla 21]:

- Descenso medio de peso de 37,4 $\pm 16,4 \mathrm{Kg}$ (IC 95\% = 34,2 - 40,5 Kg, $\mathrm{p}<0,001)$.

- Descenso medio de IMC de 14,1 $\pm 6,1 \mathrm{Kg} / \mathrm{m}^{2}$ (IC 95\% = 12,9 - 15,2 $\left.\mathrm{Kg} / \mathrm{m}^{2}, \mathrm{p}<0,001\right)$ 
Tabla 21. Análisis comparativo de las diferencias de medias de peso e IMC antes de la DBP y en la última revisión del seguimiento.

\begin{tabular}{|c|c|c|c|}
\hline \multicolumn{4}{|c|}{ COMPARACIÓN DE MEDIAS DE PESO E IMC } \\
\hline & $\begin{array}{c}\text { ANTES DE LA } \\
\text { DBP }\end{array}$ & $\begin{array}{c}\text { EN LA ÚLTIMA } \\
\text { REVISIÓN }\end{array}$ & $\begin{array}{c}\text { SIGNIFICACIÓN } \\
\text { ESTADÍSTICA }\end{array}$ \\
\hline Peso & $125,6 \pm 21,9 \mathrm{Kg}$ & $88,2 \pm 18,1 \mathrm{Kg}$ & $\mathrm{p}<0,001$ \\
\hline IMC & $46,9 \pm 6,7 \mathrm{Kg} / \mathrm{m}^{2}$ & $32,9 \pm 5,4 \mathrm{Kg} / \mathrm{m}^{2}$ & $\mathrm{p}<0,001$ \\
\hline
\end{tabular}

El análisis comparativo de los 11 pacientes definidos como fracaso ponderal frente a los 51 que alcanzaron resultados ponderales buenos y excelentes tras 5 años de seguimiento, según definieron Larrad et al. (187), no obtuvo diferencias estadísticamente significativas para ninguno de los factores preoperatorios analizados, tal y como se puede observar en las tablas 22, 23 y 24.

Tabla 22. Comparación de medias para las variables edad e IMC en el momento de la indicación de $\mathrm{CB}$ de los pacientes clasificados como fracaso ponderal a los 5 años frente a los de buenos o excelentes resultados ponderales.

\begin{tabular}{|c|c|c|c|}
\hline $\begin{array}{c}\text { COMPARACIÓN DE FACTORES PREOPERATORIOS Y DEL INGRESO } \\
\text { HOSPITALARIO ENTRE PACIENTES CON BUEN RESULTADO } \\
\text { PONDERAL FRENTE A LOS DE FRACASO PONDERAL (I) }\end{array}$ \\
\hline VARIABLE & $\begin{array}{c}\text { FRACASO } \\
\text { PONDERAL }\end{array}$ & $\begin{array}{c}\text { BUEN RESULTADO } \\
\text { PONDERAL }\end{array}$ & $\begin{array}{c}\text { SIGNIFICACIÓN } \\
\text { ESTADÍSTICA }\end{array}$ \\
\hline Edad & $42,6 \pm 8,3$ años & $\begin{array}{c}40,1 \pm 10,2 \\
\text { años }\end{array}$ & n.s. \\
\hline $\begin{array}{c}\text { IMC antes de } \\
\text { la DBP }\end{array}$ & $\begin{array}{c}46,5 \pm 10,2 \\
\mathrm{Kg} / \mathrm{m}^{2}\end{array}$ & $\begin{array}{c}47,2 \pm 6,7 \\
\mathrm{Kg} / \mathrm{m}^{2}\end{array}$ & n.s. \\
\hline
\end{tabular}


Tabla 23. Comparación de proporciones entre los pacientes clasificados como fracaso ponderal frente a los que obtuvieron buenos o excelentes resultados ponderales a los 5 años para las variables sexo, grupo de edad, grupo de IMC y clase del OS-MRS.

\begin{tabular}{|c|c|c|c|c|}
\hline \multicolumn{5}{|c|}{$\begin{array}{c}\text { COMPARACIÓN DE FACTORES PREOPERATORIOS Y DEL INGRESO } \\
\text { HOSPITALARIO ENTRE PACIENTES CON BUEN RESULTADO } \\
\text { PONDERAL FRENTE A LOS DE FRACASO PONDERAL (II) }\end{array}$} \\
\hline \multicolumn{2}{|c|}{ VARIABLE } & \multirow{2}{*}{$\begin{array}{l}\text { FRACASO } \\
\text { PONDERAL } \\
4 \text { de } 11 \\
(36,4 \%)\end{array}$} & \multirow{2}{*}{$\begin{array}{c}\text { BUEN } \\
\text { RESULTADO } \\
\text { PONDERAL } \\
13 \text { de } 51 \\
(25,5 \%)\end{array}$} & $\begin{array}{l}\text { SIGNIFICACIÓN } \\
\text { ESTADÍSTICA }\end{array}$ \\
\hline \multirow{2}{*}{ Sexo } & Varones & & & \multirow{2}{*}{ n.s. } \\
\hline & Mujeres & $\begin{array}{l}7 \text { de } 11 \\
(63,3 \%)\end{array}$ & $\begin{array}{c}38 \text { de } 51 \\
(74,5 \%)\end{array}$ & \\
\hline \multirow{2}{*}{ Grupo de edad } & $<45$ años & $\begin{array}{l}8 \text { de } 11 \\
(72,7 \%)\end{array}$ & $\begin{array}{l}36 \text { de } 51 \\
(70,6 \%)\end{array}$ & \multirow[b]{2}{*}{ n.s. } \\
\hline & $\geq 45$ años & $\begin{array}{l}3 \text { de } 11 \\
(27,3 \%)\end{array}$ & $\begin{array}{l}15 \text { de } 51 \\
(29,4 \%)\end{array}$ & \\
\hline \multirow{2}{*}{ Grupo de IMC } & $<50 \mathrm{Kg} / \mathrm{m}^{2}$ & $\begin{array}{l}8 \text { de } 11 \\
(72,7 \%)\end{array}$ & $\begin{array}{l}37 \text { de } 51 \\
(72,5 \%)\end{array}$ & \multirow[b]{2}{*}{ n.s. } \\
\hline & $\geq 50 \mathrm{Kg} / \mathrm{m}^{2}$ & $\begin{array}{l}3 \text { de } 11 \\
(27,3 \%)\end{array}$ & $\begin{array}{l}14 \text { de } 51 \\
(27,5 \%)\end{array}$ & \\
\hline \multirow{3}{*}{$\begin{array}{l}\text { Clase del } \\
\text { OS-MRS }\end{array}$} & Clase A & $\begin{array}{l}6 \text { de } 11 \\
(54,5 \%)\end{array}$ & $\begin{array}{c}27 \text { de } 51 \\
(52,9 \%)\end{array}$ & \multirow{3}{*}{ n.s. } \\
\hline & Clase B & $\begin{array}{l}4 \text { de } 11 \\
(36,4 \%)\end{array}$ & $\begin{array}{l}22 \text { de } 51 \\
(43,1 \%)\end{array}$ & \\
\hline & Clase C & $\begin{array}{l}1 \text { de } 11 \\
(9,1 \%)\end{array}$ & $\begin{array}{c}2 \text { de } 51 \\
\left(3,9^{\circ} \%\right)\end{array}$ & \\
\hline
\end{tabular}


Tabla 24. Comparación de proporciones entre los pacientes clasificados como fracaso ponderal frente a los que obtuvieron buenos o excelentes resultados ponderales a los 5 años para las siguientes variables: criterio de glucemia, criterio de TAG y criterio de PA para SM antes de la indicación de $\mathrm{CB}$, así como la severidad de las complicaciones postquirúrgicas (complicaciones mayores - grados IIIa, IIIb, IV y V de la clasificación de Dindo-Clavien - frente a complicaciones menores - grados I y II de la clasificación de Dindo-Clavien - y sin complicaciones).

\begin{tabular}{|c|c|c|c|c|}
\hline \multicolumn{5}{|c|}{$\begin{array}{l}\text { COMPARACIÓN DE FACTORES PREOPERATORIOS Y DEL INGRESO } \\
\text { HOSPITALARIO ENTRE PACIENTES CON BUEN RESULTADO } \\
\text { PONDERAL FRENTE A LOS DE FRACASO PONDERAL (III) }\end{array}$} \\
\hline \multicolumn{2}{|c|}{ VARIABLE } & \multirow{2}{*}{$\begin{array}{c}\text { FRACASO } \\
\text { PONDERAL } \\
5 \text { de } 11 \\
(45,5 \%)\end{array}$} & \multirow{2}{*}{$\begin{array}{c}\text { BUEN } \\
\text { RESULTADO } \\
\text { PONDERAL } \\
21 \text { de } 48 \\
(43,8 \%)\end{array}$} & $\begin{array}{l}\text { SIGNIFICACIÓN } \\
\text { ESTADÍSTICA }\end{array}$ \\
\hline \multirow{2}{*}{$\begin{array}{c}\text { Criterio de } \\
\text { glucemia para } \\
\text { SM }\end{array}$} & Negativo & & & \multirow{2}{*}{ n.s. } \\
\hline & Positivo & $\begin{array}{c}6 \text { de } 11 \\
(54,5 \%)\end{array}$ & $\begin{array}{c}27 \text { de } 48 \\
(56,2 \%) \\
\end{array}$ & \\
\hline \multirow{2}{*}{$\begin{array}{c}\text { Criterio de } \\
\text { TAG para SM }\end{array}$} & Negativo & $\begin{array}{c}8 \text { de } 9 \\
\left(88,9^{\circ} \%\right)\end{array}$ & $\begin{array}{c}27 \text { de } 44 \\
(61,4 \%)\end{array}$ & \multirow{2}{*}{ n.s. } \\
\hline & Positivo & $\begin{array}{c}1 \text { de } 9 \\
(11,1 \%)\end{array}$ & $\begin{array}{l}17 \text { de } 44 \\
(38,6 \%)\end{array}$ & \\
\hline \multirow{2}{*}{$\begin{array}{c}\text { Criterio de PA } \\
\text { para SM }\end{array}$} & Negativo & $\begin{array}{l}1 \text { de } 11 \\
(9,1 \%)\end{array}$ & $\begin{array}{l}3 \text { de } 48 \\
(6,3 \%)\end{array}$ & \multirow{2}{*}{ n.s. } \\
\hline & Positivo & $\begin{array}{l}10 \text { de } 11 \\
(90,9 \%)\end{array}$ & $\begin{array}{l}45 \text { de } 48 \\
(93,7 \%)\end{array}$ & \\
\hline \multirow{2}{*}{$\begin{array}{l}\text { Severidad de } \\
\text { las } \\
\text { complicaciones }\end{array}$} & $\begin{array}{c}\text { Sin } \\
\text { complicaciones } \\
\text { o I y II de } \\
\text { Dindo-Clavien }\end{array}$ & $\begin{array}{c}11 \text { de } 11 \\
(100 \%)\end{array}$ & $\begin{array}{l}49 \text { de } 51 \\
(96,1 \%)\end{array}$ & \multirow[t]{2}{*}{ n.s. } \\
\hline & $\begin{array}{l}\text { III, IV y V de } \\
\text { Dindo-Clavien }\end{array}$ & $\begin{array}{c}0 \text { de } 11 \\
(0 \%)\end{array}$ & $\begin{array}{l}2 \text { de } 51 \\
\left(3,9^{\circ} \%\right)\end{array}$ & \\
\hline
\end{tabular}

\subsection{2.- ANÁLISIS COMPARATIVO DE LOS EFECTOS CLÍNICOS Y}

\section{$\underline{\text { ANALÍTICOS }}$}

Como se puede apreciar en la tabla 25, se ha encontrado una reducción estadísticamente significativa de los niveles de glucemia, colesterol total y de TAG en la 
última analítica de control solicitada por el endocrinólogo respecto a los valores antes de la indicación de CB.

Tabla 25. Análisis comparativo de las diferencias de medias entre glucemia, colesterol total y TAG en la última analítica antes de la indicación de CB y en la analítica más reciente del seguimiento postbariátrico.

\begin{tabular}{|}
$\mid$\begin{tabular}{|c|c|c|c|}
\hline \multicolumn{7}{|c|}{ COMPARACIÓN DE MEDIAS DE GLUCEMIA, COLESTEROL TOTAL Y } \\
TAG CON SUS DIFERENCIAS DE MEDIAS
\end{tabular} \\
\hline \begin{tabular}{c|c|c|c|c|} 
ANTES DE \\
LA DBP
\end{tabular} & $\begin{array}{c}\text { EN LA ÚLTIMA } \\
\text { ANALÍTICA }\end{array}$ & $\begin{array}{c}\text { DIFERENCIA } \\
\text { DE MEDIAS }\end{array}$ & $\begin{array}{c}\text { SIGNIFICACIÓN } \\
\text { ESTADÍSTICA }\end{array}$ \\
\hline Glucemia & $\begin{array}{c}106,9 \pm 27,3 \\
\mathrm{mg} / \mathrm{dl}\end{array}$ & $\begin{array}{c}86,5 \pm 8,1 \\
\mathrm{mg} / \mathrm{dl}\end{array}$ & $\begin{array}{c}20,4 \pm 27,9 \\
\mathrm{mg} / \mathrm{dl}\end{array}$ & $\mathrm{p}<0,001$ \\
\hline $\begin{array}{c}\text { Colesterol } \\
\text { total }\end{array}$ & $\begin{array}{c}206,1 \pm 41,2 \\
\mathrm{mg} / \mathrm{dl}\end{array}$ & $\begin{array}{c}145,2 \pm 32,4 \\
\mathrm{mg} / \mathrm{dl}\end{array}$ & $\begin{array}{c}61,7 \pm 42,0 \\
\mathrm{mg} / \mathrm{dl}\end{array}$ & $\mathrm{p}<0,001$ \\
\hline TAG & $\begin{array}{c}138,3 \pm 76,0 \\
\mathrm{mg} / \mathrm{dl}\end{array}$ & $\begin{array}{c}115,2 \pm 52,3 \\
\mathrm{mg} / \mathrm{dl}\end{array}$ & $\begin{array}{c}23,6 \pm 81,2 \\
\mathrm{mg} / \mathrm{dl}\end{array}$ & $\mathrm{p}=0,006$ \\
\hline
\end{tabular}

Al realizar el cálculo de los valores medios para la glucemia y los TAG exclusivamente en los individuos con criterio positivo para SM de ambas variables antes de la indicación de CB, obtenemos [Véase tabla 26]:

- Descenso medio de glucemia de 31,0 mg/dl (IC 95\% = 22,6 - 39,4 mg/dl, $\mathrm{p}<0,001)$.

- Descenso medio de TAG de 78,5 mg/dl (IC 95\% = 39,6 - 117,3 mg/dl, $\mathrm{p}<0,001)$.

Idéntica inferencia se ha realizado para la cohorte de pacientes con criterios de glucemia y TAG negativos para SM en el preoperatorio, obteniendo también resultados significativos para el primer criterio, mientras que el segundo ha obtenido un mínimo ascenso aunque no significativo [Véase tabla 27 ]: 
- Descenso medio de glucemia de 5,8 md/dl (IC 95\% = 3,0 - 8,6 mg/dl, $\mathrm{p}<0,001)$.

- Descenso medio de TAG de -3,5 md/dl (IC 95\% = -15,2 - 8,5 mg/dl, n.s.).

Tabla 26. Análisis comparativo de las diferencias de medias entre glucemia y TAG en la última analítica antes de la indicación de $\mathrm{CB}$ y en la analítica más reciente del seguimiento postbariátrico para los pacientes con los criterios de SM positivos para cada una de estas variables antes de la DBP.

\begin{tabular}{|c|c|c|c|}
\hline \multicolumn{4}{|c|}{ COMPARACIÓN DE MEDIAS DE GLUCEMIA Y TAG EN } \\
INDIVIDUOS CON CRITERIO SM POSITIVO ANTES DE CB \\
\hline \multirow{2}{*}{\begin{tabular}{c|c|c|c|} 
ANTES DE \\
LA DBP
\end{tabular}} & $\begin{array}{c}\text { EN LA ÚLTIMA } \\
\text { ANALÍTICA }\end{array}$ & $\begin{array}{c}\text { SIGNIFICACIÓN } \\
\text { ESTADÍSTICA }\end{array}$ \\
\hline Glucemia & $\begin{array}{c}118,8 \pm 30,3 \\
\mathrm{mg} / \mathrm{dl}\end{array}$ & $\begin{array}{c}87,5 \pm 9,2 \\
\mathrm{mg} / \mathrm{dl}\end{array}$ & $\mathrm{p}<0,001$ \\
\hline TAG & $\begin{array}{c}218,8 \pm 80,0 \\
\mathrm{mg} / \mathrm{dl}\end{array}$ & $\begin{array}{c}140,3 \pm 62,2 \\
\mathrm{mg} / \mathrm{dl}\end{array}$ & $\mathrm{p}<0,001$ \\
\hline
\end{tabular}

Tabla 27. Análisis comparativo de las diferencias de medias entre glucemia y TAG en la última analítica antes de la indicación de CB y en la analítica más reciente del seguimiento postbariátrico para los pacientes con los criterios de SM negativos para cada una de estas variables antes de la DBP.

\begin{tabular}{|}
\hline \multicolumn{4}{|c|}{ COMPARACIÓN DE MEDIAS DE GLUCEMIA Y TAG EN } \\
INDIVIDUOS CON CRITERIO SM NEGATIVO ANTES DE CB \\
\hline \multirow{2}{*}{\begin{tabular}{c|c|c|c|} 
ANTES DE \\
LA DBP
\end{tabular}} & $\begin{array}{c}\text { EN LA ÚLTIMA } \\
\text { ANALÍTICA }\end{array}$ & $\begin{array}{c}\text { SIGNIFICACIÓN } \\
\text { ESTADÍSTICA }\end{array}$ \\
\hline Glucemia & $\begin{array}{c}90,4 \pm 6,3 \\
\mathrm{mg} / \mathrm{dl}\end{array}$ & $\begin{array}{c}84,6 \pm 6,0 \\
\mathrm{mg} / \mathrm{dl}\end{array}$ & $\mathrm{p}<0,001$ \\
\hline TAG & $\begin{array}{c}99,5 \pm 28,4 \\
\mathrm{mg} / \mathrm{dl}\end{array}$ & $\begin{array}{c}102,8 \pm 41,9 \\
\mathrm{mg} / \mathrm{dl}\end{array}$ & n.s. \\
\hline
\end{tabular}


En lo referente a la modificación de la HTA para los obesos con seguimiento en nuestra Unidad, existe un descenso con clara significación estadística entre la determinación de PA sistólica antes de indicar la CB y en la última revisión en consulta de Endocrinología, así como para la PA diastólica entre ambos momentos del estudio [Véase tabla 28].

Tabla 28. Análisis comparativo de las diferencias de medias para la PA sistólica y diastólica entre en el momento de la indicación de $\mathrm{CB}$ y en la última revisión tras CB.

\begin{tabular}{|c|c|c|c|c|}
\hline \multicolumn{5}{|c|}{$\begin{array}{l}\text { COMPARACIÓN DE MEDIAS DE PA SISTÓLICA Y DIASTÓLICA CON } \\
\text { SUS DIFERENCIAS DE MEDIAS }\end{array}$} \\
\hline & $\begin{array}{l}\text { ANTES DE } \\
\text { LA DBP }\end{array}$ & $\begin{array}{l}\text { EN LA ÚLTIMA } \\
\text { REVISIÓN }\end{array}$ & $\begin{array}{l}\text { DIFERENCIA } \\
\text { DE MEDIAS }\end{array}$ & $\begin{array}{l}\text { SIGNIFICACIÓN } \\
\text { ESTADÍSTICA }\end{array}$ \\
\hline $\begin{array}{c}\text { PA } \\
\text { sistólica }\end{array}$ & $\begin{array}{l}143,7 \pm 20,4 \\
\mathrm{mmHg}\end{array}$ & $\begin{array}{l}127,2 \pm 17,1 \\
\mathrm{mmHg}\end{array}$ & $\begin{array}{l}16,4 \pm 24,4 \\
\mathrm{mmHg}\end{array}$ & $\mathrm{p}<0,001$ \\
\hline $\begin{array}{c}\text { PA } \\
\text { diastólica }\end{array}$ & $\begin{array}{l}87,7 \pm 12,2 \\
\mathrm{mmHg}\end{array}$ & $\begin{array}{l}75,2 \pm 11,8 \\
\mathrm{mmHg}\end{array}$ & $\begin{array}{l}12,5 \pm 15,4 \\
\mathrm{mmHg}\end{array}$ & $\mathrm{p}<0,001$ \\
\hline
\end{tabular}

Al realizar el cálculo de los valores medios para la PA sistólica y diastólica exclusivamente en aquellos individuos con criterio positivo de PA para SM antes de la indicación de CB, obtenemos [Véase tabla 29]:

- Descenso medio de PA sistólica de 18,2 mmHg (IC 95\% = 12,8 - 23,5 $\mathrm{mmHg}, \mathrm{p}<0,001)$.

- Descenso medio de PA diastólica de 13,0 $\mathrm{mmHg}$ (IC 95\% = 9,7 - 16,4 $\mathrm{mmHg}, \mathrm{p}<0,001)$.

El análisis de la cohorte de pacientes con criterios de PA negativo para SM en el preoperatorio arroja resultados no significativos, tanto para PA sistólica como para PA diastólica [Véase tabla 30]: 
- Descenso medio de PA sistólica de $-0,2 \mathrm{mmHg}$ (IC 95\% = -7,3 - 6,9 $\mathrm{mmHg}$, n.s.).

- Descenso medio de PA diastólica de 6,8 mmHg (IC 95\% = -1,6 - 15,2 $\mathrm{mmHg}$, n.s.)

Tabla 29. Análisis comparativo de las diferencias de medias de PA sistólica y diastólica entre los valores antes de la indicación de $\mathrm{CB}$ y los de la última determinación en consulta de Endocrinología para los pacientes con criterio positivo de SM para esta variable antes de la DBP.

\begin{tabular}{|c|c|c|c|}
\hline \multicolumn{4}{|c|}{$\begin{array}{l}\text { COMPARACIÓN DE MEDIAS DE PA SISTÓLICA Y } \\
\text { DIASTÓLICA EN INDIVIDUOS CON CRITERIO SM } \\
\text { POSITIVO ANTES DE CB }\end{array}$} \\
\hline & $\begin{array}{l}\text { ANTES DE } \\
\text { LA DBP }\end{array}$ & $\begin{array}{l}\text { EN LA ÚLTIMA } \\
\text { REVISIÓN }\end{array}$ & $\begin{array}{l}\text { SIGNIFICACIÓN } \\
\text { ESTADÍSTICA }\end{array}$ \\
\hline $\begin{array}{c}\text { PA } \\
\text { sistólica }\end{array}$ & $\begin{array}{c}146,5 \pm 19,2 \\
\mathrm{mmHg}\end{array}$ & $\begin{array}{c}128,3 \pm 17,3 \\
\mathrm{mmHg}\end{array}$ & $\mathrm{p}<0,001$ \\
\hline $\begin{array}{c}\text { PA } \\
\text { diastólica }\end{array}$ & $\begin{array}{c}88,8 \pm 10,8 \\
\mathrm{mmHg}\end{array}$ & $\begin{array}{c}75,7 \pm 12,0 \\
\mathrm{mmHg}\end{array}$ & $\mathrm{p}<0,001$ \\
\hline
\end{tabular}

Tabla 30. Análisis comparativo de las diferencias de medias de PA sistólica y diastólica entre los valores antes de la indicación de CB y los de la última determinación en consulta de Endocrinología para los pacientes con criterio negativo de SM para esta variable antes de la DBP.

\begin{tabular}{|}
$\mid$\begin{tabular}{c|c|c|}
\hline \multicolumn{4}{|c|}{ COMPARACIÓN DE MEDIAS DE PA SISTÓLICA Y } \\
DIASTÓLICA EN INDIVIDUOS CON CRITERIO SM \\
NEGATIVO ANTES DE CB
\end{tabular} \\
\hline & $\begin{array}{c}\text { ANTES DE } \\
\text { LA DBP }\end{array}$ & $\begin{array}{c}\text { EN LA ÚLTIMA } \\
\text { REVISIÓN }\end{array}$ & $\begin{array}{c}\text { SIGNIFICACIÓN } \\
\text { ESTADÍSTICA }\end{array}$ \\
\hline PA & $\begin{array}{c}116,8 \pm 8,7 \\
\mathrm{mmHg}\end{array}$ & $\begin{array}{c}117,0 \pm 12,5 \\
\mathrm{mmHg}\end{array}$ & n.s. \\
sistólica & $\begin{array}{c}77,2 \pm 4,9 \\
\text { PA }\end{array}$ & $\begin{array}{c}70,4 \pm 10,2 \\
\mathrm{mmHg}\end{array}$ & n.s. \\
diastólica & $\mathrm{mmHg}$ & &
\end{tabular}


Para la medicación antihipertensiva en los 113 pacientes con seguimiento en nuestra Unidad de OM, se ha obtenido un descenso estadísticamente significativo $(\mathrm{p}<0,001)$ al comparar el número de fármacos pautados en el momento de la indicación de $\mathrm{CB}$ y el número en la última revisión en consulta de Endocrinología. El análisis es el siguiente:

- De los 60 pacientes sin hipotensores antes de la DBP, sólo 3 (2,9\% del total de individuos con seguimiento en nuestro centro) han precisado la administración de un nuevo fármaco en el seguimiento.

- De los 44 pacientes con uno o más agentes antihipertensivos pautados antes de la $\mathrm{CB}, 13(12,5 \%)$ mantienen el mismo número de fármacos de distinto grupo en la última revisión, 3 enfermos $(2,9 \%)$ han precisado incrementar el número pautado y en $28(27 \%)$ se ha reducido en uno o más el número de fármacos.

En otras palabras, tras calcular la media por enfermo del número de antihipertensivos pautados (excluyendo aquellos que no los precisan), se obtiene 1,61 $\pm 0,9$ fármacos en el momento de la indicación de $\mathrm{CB}$ y $0,68 \pm 0,9$ en la última revisión en consulta de Endocrinología. Existe, por tanto, un descenso significativo en 0,9 fármacos hipotensores (IC 95\% $=0,57-1,29, \mathrm{p}<0,001)$ entre ambos momentos.

En cuanto a la DM en los pacientes con seguimiento en el HURH, se ha detectado un descenso significativo del número de individuos que presentaban esta $\mathrm{CAO}$ antes de la indicación de $\mathrm{CB}$ y, asimismo, ninguno de los obesos no diabéticos antes de la intervención ha desarrollado DM en el seguimiento [Véase tabla 31]. Los resultados de descenso de glucemia ya han sido expuestos anteriormente tanto en el grupo de los 113 pacientes con 
seguimiento, como en los subgrupos con criterio preoperatorio positivo y negativo de glucemia para SM.

El análisis comparativo de la medicación antidiabética arroja el siguiente resultado: de los 10 pacientes $(9,1 \%)$ que precisaban estos fármacos antes de someterse a DBP, ninguno de ellos los requiere en la última revisión en consulta. Igualmente, a ninguno de los obesos no tomadores de antidiabéticos se les han pautado estos fármacos durante el seguimiento, siendo estas diferencias estadísticamente significativas. Procediendo de forma análoga a los fármacos antihipertensivos, tras calcular la media por enfermo del número de antidiabéticos pautados (excluyendo aquellos que no los precisan), se obtiene 1,25 $\pm 0,7$ fármacos en el momento de la indicación de $\mathrm{CB}$ y $0,0 \pm 0,0$ en la última revisión en consulta de Endocrinología. Existe, por tanto, un descenso significativo en 1,25 fármacos antidiabéticos (IC 95\% = 0,66 - 1,84, p = 0,002) entre ambos momentos. De igual modo, hay una reducción significativa del número de pacientes diabéticos con pauta de insulina [Véase tabla 31], y además los dos enfermos que aún la precisaban en la última revisión en consulta de Endocrinología, lograron reducir las dosis diarias de esta hormona. 
Tabla 31. Análisis comparativo de las diferencias de proporciones de pacientes con DM, con medicación antidiabética y con administración de insulina entre el momento de la indicación de $\mathrm{CB}$ y la última revisión en consulta de Endocrinología, para los 113 pacientes con seguimiento postbariátrico en el HURH.

\begin{tabular}{|c|c|c|c|}
\hline \multicolumn{4}{|c|}{$\begin{array}{c}\text { COMPARACIÓN DE PROPORCIONES DE DIAGNÓSTICO } \\
\text { DE DM, ANTIDIABÉTICOS ORALES E INSULINA }\end{array}$} \\
\hline & $\begin{array}{c}\text { ANTES DE } \\
\text { LA DBP }\end{array}$ & $\begin{array}{c}\text { EN LA ÚLTIMA } \\
\text { REVISIÓN }\end{array}$ & $\begin{array}{c}\text { SIGNIFICACIÓN } \\
\text { ESTADÍSTICA }\end{array}$ \\
\hline DM & $\begin{array}{c}48 \text { pacientes } \\
(46,6 \%)\end{array}$ & $\begin{array}{c}2 \text { pacientes } \\
(1,9 \%)\end{array}$ & $\mathrm{p}<0,001$ \\
\hline $\begin{array}{c}\text { Antidiabéticos } \\
\text { orales }\end{array}$ & $\begin{array}{c}10 \text { pacientes } \\
(9,1 \%)\end{array}$ & $\begin{array}{c}0 \text { pacientes } \\
(0 \%)\end{array}$ & $\mathrm{p}=0,002$ \\
\hline Insulina & $\begin{array}{c}5 \text { pacientes } \\
(4,8 \%)\end{array}$ & $\begin{array}{c}2 \text { pacientes } \\
(1,9 \%)\end{array}$ & $\mathrm{p}=0,002$ \\
\hline
\end{tabular}

Finalmente, se expone el análisis comparativo entre el momento antes de la CB y en el seguimiento para las variables analíticas que reflejan el estado nutricional y el metabolismo del cálcico de los 113 pacientes obesos tratados mediante DBP:

- Descenso medio de hemoglobina de $1,2 \mathrm{~g} / \mathrm{dl}(\mathrm{IC} 95 \%=0,8-1,6 \mathrm{~g} / \mathrm{dl}$, $\mathrm{p}<0,001)$

- Descenso medio de albúmina de 0,1 g/dl (IC 95\% = -0,04-0,2 g/dl, n.s.).

- Descenso medio de calcio total de 0,5 mg/dl (IC 95\% = 0,4 - 0,6 mg/dl, $\mathrm{p}<0,001)$

- Descenso medio de 25-OH vitamina D de 0,02 $\mu \mathrm{g} / 1$ (IC 95\% $=-5,7-5,8$ $\mu \mathrm{g} / \mathrm{l}, \mathrm{n} . \mathrm{s}$.$) .$

- Ascenso medio de PTH de 34,2 pg/ml (IC 95\% = 21,1 - 47,3 pg/ml, $\mathrm{p}<0,001)$ 


\subsection{3.- ANÁLISIS COMPARATIVO DE LA MODIFICACIÓN DE LOS}

\section{CRITERIOS DE SÍNDROME METÁBOLICO}

Con los datos de las variables que constituyen los criterios para evaluar el SM disponibles en este estudio, se ha obtenido una reducción significativa de la proporción de pacientes con el criterio de glucemia y de PA para SM, mientras que para el criterio de TAG, existe una tendencia al descenso con fuerte asociación estadística aunque sin alcanzar significación $(p=0,076)$ [Véase tabla 32]. Es necesario indicar que se ha positivizado el criterio de TAG durante el seguimiento en 13 pacientes (13,8\%), los cuales no presentaban dicho criterio para SM antes de la DBP. También se ha observado este mismo efecto para el criterio de PA en 2 individuos (2,1\%). Notificamos un 16,8\% de pérdidas en la comparación del criterio de TAG para SM.

Tabla 32. Análisis comparativo de las diferencias de proporciones entre pacientes con criterio positivo de glucemia, de TAG y de PA para SM entre el momento de la indicación de CB y la última revisión en consulta de Endocrinología.

\begin{tabular}{|c|c|c|c|}
\hline \multicolumn{4}{|c|}{ COMPARACIÓN DE PROPORCIONES DE LOS CRITERIOS } \\
DE GLUCEMIA, TAG Y PA PARA SM \\
\hline $\begin{array}{c}\text { ANTES DE } \\
\text { LA DBP }\end{array}$ & $\begin{array}{c}\text { EN LA ÚLTIMA } \\
\text { REVISIÓN }\end{array}$ & $\begin{array}{c}\text { SIGNIFICACIÓN } \\
\text { ESTADÍSTICA }\end{array}$ \\
\hline $\begin{array}{c}\text { Criterio de } \\
\text { glucemia }\end{array}$ & $\begin{array}{c}58 \text { pacientes } \\
(56,9 \%)\end{array}$ & $\begin{array}{c}4 \text { pacientes } \\
(3,8 \%)\end{array}$ & $\mathrm{p}<0,001$ \\
\hline $\begin{array}{c}\text { Criterio de } \\
\text { TAG }\end{array}$ & $\begin{array}{c}31 \text { pacientes } \\
(33 \%)\end{array}$ & $\begin{array}{c}12 \text { pacientes } \\
(12,8 \%)\end{array}$ & n.s. \\
\hline $\begin{array}{c}\text { Criterio de } \\
\text { PA }\end{array}$ & $\begin{array}{c}88 \text { pacientes } \\
(90,7 \%)\end{array}$ & $\begin{array}{c}57 \text { pacientes } \\
(57,6 \%)\end{array}$ & $\mathrm{p}=0,024$ \\
\hline
\end{tabular}




\section{3.- ANÁlISIS COMPARATIVO DE COHORTES SEGÚN}

EL OBESITY SURGERY-MORTALITY RISK SCORE

\subsection{1.- ANÁLISIS DE MORBIMORTALIDAD SEGÚN EL OBESITY SURGERY-MORTALITY RISK SCORE}

En este epígrafe se presenta el análisis estadístico de las diferencias existentes en morbimortalidad postoperatoria precoz (durante el ingreso hospitalario) según las cohortes de pacientes para cada variable y cada categoría establecidas en el OS-MRS en la muestra completa de 274 enfermos sometidos a DBP en el HURH.

4.3.1.1.- Riesgo de morbimortalidad por factores del Obesity Surgery-Mortality Risk Score

Al calcular el RR para la mortalidad en el ingreso empleando cada uno de los factores que componen el OS-MRS, se obtienen los siguientes resultados [Véase tabla 33]:

- Cohorte de varones. $\mathrm{RR}=1,4$ (IC $95 \%=0,2-15,2$, n.s.).

- Cohorte de edad $\geq 45$ años. $\mathrm{RR}=3,5$ (IC $95 \%=0,3-38,8$, n.s.).

- Cohorte de IMC $\geq 50 \mathrm{Kg} / \mathrm{m}^{2}$. Dato no disponible por pérdida de los valores de IMC en el los pacientes que sufrieron exitus.

- Cohorte de HTA. Dato no disponible por pérdida de los valores de PA sistólica y diastólica en el los pacientes que sufrieron exitus.

- Cohorte con riesgo de TEP. RR $=6,7$ (IC 95\% $=0,6-75,6$, n.s.). 
Tabla 33. Análisis comparativo de las proporciones de pacientes que sufren exitus en el postoperatorio inmediato tras la DBP entre las cohortes de cada uno de los factores que integran el OS-MRS.

\begin{tabular}{|c|c|c|c|}
\hline \multicolumn{4}{|c|}{$\begin{array}{l}\text { COMPARACIÓN DE LA PROPORCIÓN DE EXITUS DURANTE EL } \\
\text { INGRESO SEGÚN LOS FACTORES DEL OS-MRS }\end{array}$} \\
\hline \multicolumn{2}{|c|}{ VARIABLE } & $\begin{array}{l}\text { EXITUS EN EL } \\
\text { INGRESO }\end{array}$ & $\begin{array}{c}\text { SIGNIFICACIÓN } \\
\text { ESTADÍSTICA }\end{array}$ \\
\hline \multirow{2}{*}{ SEXO } & Mujeres & 2 de $200(1,0 \%)$ & \multirow{2}{*}{ n.s. } \\
\hline & Varones & 1 de $74(1,4 \%)$ & \\
\hline \multirow{2}{*}{$\begin{array}{l}\text { GRUPOS DE } \\
\text { EDAD }\end{array}$} & $<45$ años & 1 de $173(0,6 \%)$ & \multirow{2}{*}{ n.s. } \\
\hline & $\geq 45$ años & 2 de $101(2 \%)$ & \\
\hline \multirow{2}{*}{ GRUPOS DE IMC } & $<50 \mathrm{Kg} / \mathrm{m}^{2}$ & pérdida & \multirow{2}{*}{ pérdida } \\
\hline & $\geq 50 \mathrm{Kg} / \mathrm{m}^{2}$ & pérdida & \\
\hline \multirow{2}{*}{ GRUPOS DE HTA } & Sin HTA & pérdida & \multirow{2}{*}{ pérdida } \\
\hline & Con HTA & pérdida & \\
\hline \multirow{2}{*}{$\begin{array}{c}\text { GRUPOS DE } \\
\text { RIESGO DE TEP }\end{array}$} & Sin riesgo & 1 de $210(0,5 \%)$ & \multirow{2}{*}{ n.s. } \\
\hline & Con riesgo & 2 de $64(3,1 \%)$ & \\
\hline
\end{tabular}

Análogamente, al calcular el RR de mortalidad y morbilidad grave en el ingreso (grados IIIa, IIIb, IV y V de la clasificación de Dindo-Clavien) para cada uno de los factores que integran el OS-MRS, se obtienen los siguientes resultados [Véase tabla 34]:

- $\quad$ Cohorte de varones. $\mathrm{RR}=1,7$ (IC $95 \%=0,7-4,4$, n.s.).

- Cohorte de edad $\geq 45$ años. $\mathrm{RR}=0,8$ (IC $95 \%=0,3-2,2$, n.s.).

- Cohorte de IMC $\geq 50 \mathrm{Kg} / \mathrm{m}^{2} . \mathrm{RR}=2,8(\mathrm{IC} 95 \%=1,1-7,4, \mathrm{p}=0,03)$.

- Cohorte de HTA. RR = 2,1 (IC 95\% = 0,7 - 6,6, n.s.).

- Cohorte con riesgo de TEP. RR $=1,4$ (IC 95\% $=0,5-3,6$, n.s.). 
Tabla 34. Análisis comparativo de las proporciones de pacientes que sufren complicaciones graves y/o mortalidad (grados IIIa, IIIb, IV y V de la clasificación de Dindo-Clavien) en el postoperatorio inmediato tras la DBP entre las cohortes de cada uno de los factores que integran el OS-MRS.

\begin{tabular}{|c|c|c|c|}
\hline \multicolumn{4}{|c|}{$\begin{array}{l}\text { COMPARACIÓN DE LA PROPORCIÓN DE MORBILIDAD } \\
\text { GRAVE Y MORTALIDAD SEGÚN LOS FACTORES DEL OS-MRS }\end{array}$} \\
\hline \multicolumn{2}{|c|}{ VARIABLE } & GRADOS IIIa, & SIGNIFICACIÓN \\
\hline \multirow{2}{*}{ Sexo } & Mujeres & 13 de $200(6,5 \%)$ & \multirow{2}{*}{ n.s. } \\
\hline & Varones & 8 de $74(10,8 \%)$ & \\
\hline \multirow{2}{*}{ Grupos de edad } & $<45$ años & 14 de $173(8,1 \%)$ & \multirow{2}{*}{ n.s. } \\
\hline & $\geq 45$ años & 7 de $101(6,9 \%)$ & \\
\hline \multirow{2}{*}{ Grupos de IMC } & $<50 \mathrm{Kg} / \mathrm{m}^{2}$ & 8 de $183(4,4 \%)$ & \multirow{2}{*}{$\mathrm{p}=0,028$} \\
\hline & $\geq 50 \mathrm{Kg} / \mathrm{m}^{2}$ & 10 de $87(11,5 \%)$ & \\
\hline \multirow{2}{*}{ Grupos de HTA } & Sin HTA & 4 de $99(4 \%)$ & \multirow{2}{*}{ n.s. } \\
\hline & Con HTA & 14 de $171(8,2 \%)$ & \\
\hline \multirow{2}{*}{$\begin{array}{c}\text { Grupos de riesgo } \\
\text { de TEP }\end{array}$} & Sin riesgo & 15 de $210(7,1 \%)$ & \multirow{2}{*}{ n.s. } \\
\hline & Con riesgo & 6 de $64(9,4 \%)$ & \\
\hline
\end{tabular}

\subsubsection{2.- Riesgo de morbimortalidad por categorías del Obesity Surgery-Mortality}

\section{Risk Score}

Tras calcular el riesgo de mortalidad en el ingreso empleando las categorías que integran el OS-MRS, obtenemos los siguientes RR para la clase B y la clase C respecto de la clase A, así como para las clases B y C conjuntamente frente a la clase A [Véase tabla 35]:

- Clase B frente a clase A. RR $=1,6$ (IC $95 \%=0,1-17,6$, n.s.).

- Clase C frente a clase A. RR $=1$ (IC 95\% = 0,9 - 1,1, n.s.).

- Clase B y C conjuntamente frente a clase A. RR = 1,4 (IC 95\% $=0,1-$ 15,3, n.s.). 
Tabla 35. Análisis comparativo de las proporciones de pacientes que fallecieron en el postoperatorio inmediato tras la DBP entre las cohortes de cada categoría definidas por el OS-MRS.

\begin{tabular}{|c|c|c|}
\hline \multicolumn{2}{|c|}{$\begin{array}{c}\text { COMPARACIÓN DE LA PROPORCIÓN DE EXITUS } \\
\text { SEGÚN LAS CATEGORÍAS DEL OS-MRS }\end{array}$} \\
\hline CATEGORÍA & EXITUS EN EL INGRESO & $\begin{array}{c}\text { SIGNIFICACIÓN } \\
\text { ESTADÍSTICA }\end{array}$ \\
\hline Clase A & 1 de $111(0,9 \%)$ & \multirow{2}{*}{ n.s. } \\
\hline Clase B & 2 de $142(1,4 \%)$ & \\
\hline Clase C & 0 de $21(0 \%)$ & \\
\hline
\end{tabular}

$\mathrm{Al}$ evaluar la proporción de morbimortalidad grave en el ingreso (grados IIIa, IIIb, IV y V de la clasificación de Dindo-Clavien) entre las tres categorías del OS-MRS, no se obtienen diferencias estadísticamente significativas, ni tampoco en el análisis del riesgo conjunto de las clases B y C frente a la clase A [Véase tabla 36].

- Clase B frente a clase A. RR = 2,5 (IC 95\% = 0,9 - 7,1, n.s.).

- Clase C frente a clase A. RR = 1,1 (IC 95\% = 0,2 - 9,6, n.s.).

- Clase B y C conjuntamente frente a clase A. RR = 2,3 (IC 95\% $=0,8-2,5$, n.s.). 
Tabla 36. Análisis comparativo de las proporciones de pacientes que sufren complicaciones graves y/o mortalidad (grados IIIa, IIIb, IV y V de la clasificación de Dindo-Clavien) en el postoperatorio inmediato tras la DBP entre las cohortes de cada categoría definida por el OS-MRS.

\begin{tabular}{|c|c|c|}
\hline \multicolumn{3}{|c|}{ COMPARACIÓN DE LA PROPORCIÓN DE } \\
MORBIMORTALIDAD GRAVE Y SEGÚN LAS \\
CATEGORÍAS DEL OS-MRS \\
\cline { 1 - 2 } CATEGORÍA & GRADOS IIIa, IIIb, IV y V & $\begin{array}{c}\text { SIGNIFICACIÓN } \\
\text { ESTADÍSTICA }\end{array}$ \\
\cline { 1 - 2 } Clase A & 5 de $111(4,5 \%)$ & \multirow{2}{*}{ n.s. } \\
\hline Clase B & 15 de $142(10,6 \%)$ & \\
\hline Clase C & 1 de $21(4,8 \%)$ & \\
\hline
\end{tabular}

\subsection{2.- ANÁLISIS DE RESULTADOS Y EFECTOS SEGÚN EL OBESITY}

\section{SURGERY-MORTALITY RISK SCORE}

En este epígrafe se presentará el análisis estadístico de las diferencias existentes en los resultados ponderales y en los efectos sobre los componentes del SM según las cohortes de pacientes incluidos en cada categoría establecida por el OS-MRS en la muestra de 113 enfermos sometidos a DBP y con seguimiento postbariátrico en el HURH.

\subsubsection{1.- Resultados ponderales según las categorías del Obesity Surgery-Mortality}

\section{Risk Score}

Se han calculado las diferencias de medias para cada categoría del OS-MRS entre las variables "peso en el momento de la indicación de CB" y "peso en la última revisión de Endocrinología tras CB", así como "IMC en el momento de la indicación de CB" e "IMC en la última revisión de Endocrinología tras CB”. Los resultados se muestran en la tabla 37. 
Tabla 37. Análisis comparativo de las medias entre las categorías para el peso e el IMC en el momento de la indicación de CB frente a la última revisión de Endocrinología tras CB.

\begin{tabular}{|c|c|c|c|c|}
\hline \multicolumn{6}{|c|}{ COMPARACIÓN DE PESO E IMC ANTES DE LA CB Y EN EL } \\
SEGUIMIENTO SEGÚN CATEGORÍAS DEL OS-MRS \\
\hline VARIABLE & CLASE A & CLASE B & CLASE C & $\begin{array}{c}\text { SIGNIFICACIÓN } \\
\text { ESTADÍSTICA }\end{array}$ \\
\hline Peso antes de CB & $\begin{array}{c}117,7 \pm \\
17,2 \mathrm{Kg}\end{array}$ & $\begin{array}{c}128,3 \pm \\
22,1 \mathrm{Kg}\end{array}$ & $\begin{array}{c}152,3 \pm \\
19,4 \mathrm{Kg}\end{array}$ & $\mathrm{p}<0,001$ \\
\hline $\begin{array}{c}\text { Peso en la última } \\
\text { revisión tras CB }\end{array}$ & $\begin{array}{c}8,3 \pm \\
15,5 \mathrm{Kg}\end{array}$ & $\begin{array}{c}89,1 \pm \\
17,4 \mathrm{Kg}\end{array}$ & $\begin{array}{c}113,4 \pm \\
17,3 \mathrm{Kg}\end{array}$ & $\mathrm{p}<0,001$ \\
\hline IMC antes de CB & $\begin{array}{c}44,7 \pm 5,9 \\
\mathrm{Kg} / \mathrm{m}^{2}\end{array}$ & $\begin{array}{c}48,9 \pm 6,9 \\
\mathrm{Kg} / \mathrm{m}^{2}\end{array}$ & $\begin{array}{c}50,3 \pm 8,8 \\
\mathrm{Kg} / \mathrm{m}^{2}\end{array}$ & $\mathrm{p}=0,003$ \\
\hline $\begin{array}{c}\text { IMC en la última } \\
\text { revisión tras CB }\end{array}$ & $\begin{array}{c}31,7 \pm 5,3 \\
\mathrm{Kg} / \mathrm{m}^{2}\end{array}$ & $\begin{array}{c}33,6 \pm 4,9 \\
\mathrm{Kg} / \mathrm{m}^{2}\end{array}$ & $\begin{array}{c}37,2 \pm 5,6 \\
\mathrm{Kg} / \mathrm{m}^{2}\end{array}$ & $\mathrm{p}=0,009$ \\
\hline
\end{tabular}

$\mathrm{Al}$ contrastar las medias de la variable "descenso de IMC en la última revisión de Endocrinología tras CB” entre cada una de las clases definidas en el OS-MRS se obtienen diferencias no significativas, al solaparse los valores de los respectivos IC 95\%:

- Clase A: $13,4 \pm 4,8 \mathrm{Kg} / \mathrm{m}^{2}\left(\mathrm{IC} 95 \%=11,7-15,1 \mathrm{Kg} / \mathrm{m}^{2}\right)$.

- Clase B: 17,2 \pm 7,9 Kg/m $\left(\mathrm{IC} 95 \%=13,9-20,4 \mathrm{Kg} / \mathrm{m}^{2}\right)$.

- Clase C: $15,9 \pm 9,5 \mathrm{Kg} / \mathrm{m}^{2}\left(\mathrm{IC} 95 \%=7,6-39,4 \mathrm{Kg} / \mathrm{m}^{2}\right)$.

En el estudio de los parámetros de estimación de pérdida ponderal (PEPP y PEIMCP) entre las cohortes de pacientes que pertenecen a cada clase del OS-MRS se observa una tendencia con fuerte asociación estadística aunque no significativa $(p=0,072)$ para los pacientes de la clase $\mathrm{C}$, quienes obtienen peores resultados en los parámetros de evaluación de pérdida ponderal, como se puede apreciar en la tabla 38 y en el gráfico 27. 
Tabla 38. Análisis comparativo de las medias entre las categorías para los parámetros de evaluación de pérdida ponderal tras CB.

\begin{tabular}{|c|c|c|c|c|}
\hline \multicolumn{5}{|c|}{ COMPARACIÓN DE PARÁMETROS DE PÉRDIDA PONDERAL } \\
TRAS CB SEGÚN CATEGORÍAS DEL OS-MRS \\
\hline VARIABLE & CLASE A & CLASE B & CLASE C & $\begin{array}{c}\text { SIGNIFICACIÓN } \\
\text { ESTADÍSTICA }\end{array}$ \\
\hline PEPP & $\begin{array}{c}60,5 \pm 19,8 \\
\%\end{array}$ & $\begin{array}{c}58,1 \pm 18,7 \\
\%\end{array}$ & $\begin{array}{c}45,4 \pm 18,3 \\
\%\end{array}$ & n.s. \\
\hline PEIMCP & $\begin{array}{c}68,4 \pm 23,5 \\
\%\end{array}$ & $\begin{array}{c}63,1 \pm 20,2 \\
\%\end{array}$ & $\begin{array}{c}49,9 \pm 18,5 \\
\%\end{array}$ & n.s. \\
\hline
\end{tabular}

Gráfico 27. Diagrama de barras de error mostrando las medias de PEIMCP con sus respectivos IC 95\% entre las tres clases del OS-MRS.

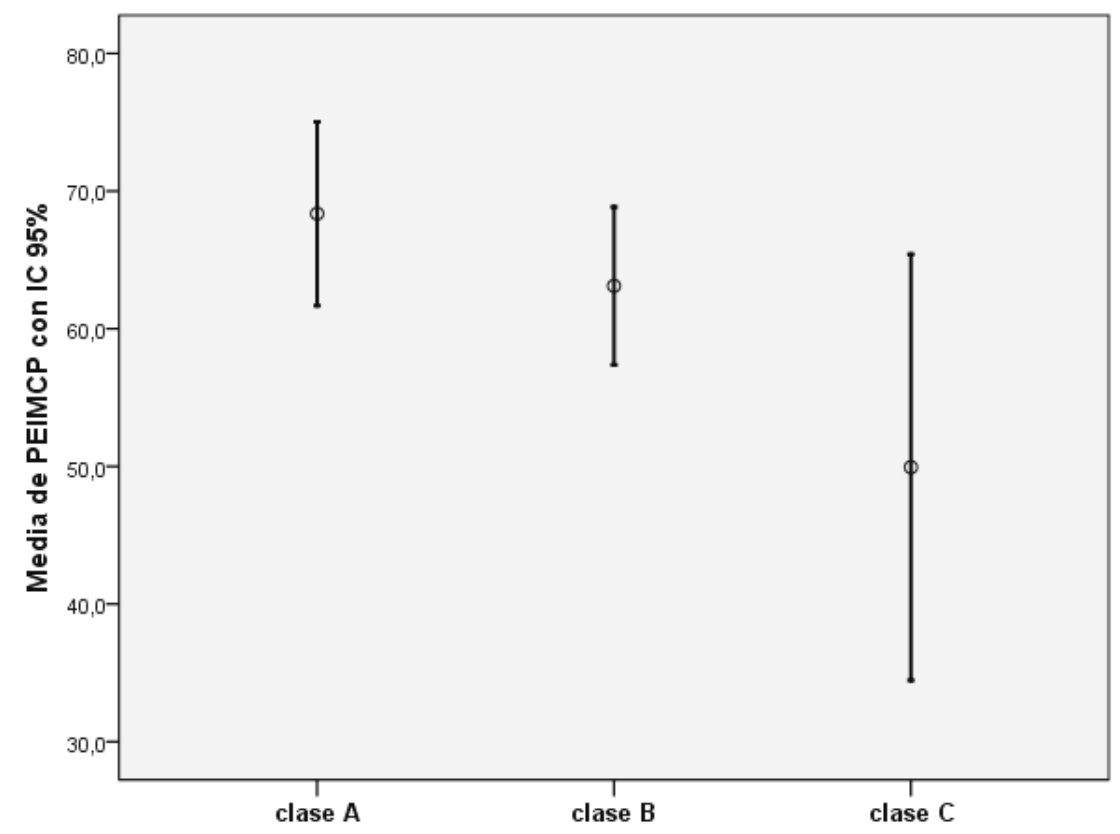

4.3.2.2.- Efectos sobre las variables del síndrome metabólico según las categorías del Obesity Surgery-Mortality Risk Score

En la tabla 39 se muestra el análisis estadístico, comparando la proporción de pacientes con los criterios de glucemia, TAG y glucemia para SM en el momento de la 
indicación de $\mathrm{CB}$ y en la última revisión de Endocrinología tras $\mathrm{CB}$ en cada una de las clases del OS-MRS. Se presenta, además, la diferencia de proporciones con su IC 95\%, demostrando que existe un solapamiento de los valores de este intervalo entre las catergorías del score para los tres criterios de SM analizados en este estudio. Ello se interpreta como la ausencia de significación estadística en dichas diferencias de proporciones.

Se ha calculado, además, la diferencia de medias en cada categoría del OS-MRS para otras variables cuantitativas analíticas y clínicas relacionadas con el estado metabólico (glucemia, colesterol total, TAG, PA sistólica y PA diastólica), entre el momento antes de la CB y la última analítica o revisión en consulta de Endocrinología, con un análisis comparativo entre las tres clases del score. Se observa, igualmente, que no existen diferencias significativas entre las categorías del OS-MRS para las diferencias de medias de cada una de estas variables [Véase tabla 40]. 
Tabla 39. Análisis comparativo de las diferencias de proporciones y su IC 95\% en pacientes con criterio positivo de glucemia, de TAG y de PA para SM entre el momento de la indicación de $\mathrm{CB}$ y la última revisión en consulta de Endocrinología para cada categoría del OS-MRS.

\begin{tabular}{|c|c|c|c|c|}
\hline \multicolumn{5}{|c|}{$\begin{array}{c}\text { COMPARACIÓN DE PROPORCIONES DE LOS CRITERIOS DE } \\
\text { GLUCEMIA, TAG Y PA PARA SM ANTES Y DESPUÉS DE CB } \\
\text { ENTRE LAS CATERGORÍAS DEL OS-MRS }\end{array}$} \\
\hline \multicolumn{2}{|c|}{$\begin{array}{l}\text { CRITERIO Y } \\
\text { CATEGORÍA }\end{array}$} & $\begin{array}{c}\text { ANTES DE LA } \\
\text { DBP }\end{array}$ & $\begin{array}{l}\text { EN LA ÚLTIMA } \\
\text { REVISIÓN }\end{array}$ & $\begin{array}{l}\text { DIFERENCIA DE } \\
\text { PROPORCIÓN }\end{array}$ \\
\hline \multirow{3}{*}{$\begin{array}{l}\text { Criterio } \\
\text { de } \\
\text { glucemia }\end{array}$} & $\begin{array}{c}\text { Clase } \\
\text { A }\end{array}$ & $\begin{array}{l}24 \text { de } 50(48,0 \%) \\
\text { IC } 95 \%= \\
33,1-62,8 \%\end{array}$ & $\begin{array}{l}2 \text { de } 50(4,0 \%) \\
\quad \text { IC } 95 \%= \\
0,5-13,7 \%\end{array}$ & $\begin{array}{c}22 \text { de } 50(44,0 \%) \\
\text { IC } 95 \%= \\
29,2-58,7 \%\end{array}$ \\
\hline & $\begin{array}{c}\text { Clase } \\
\text { B }\end{array}$ & $\begin{array}{l}29 \text { de } 44(65,9 \%) \\
\text { IC } 95 \%= \\
50,8-81,0 \%\end{array}$ & $\begin{array}{l}1 \text { de } 44(2,3 \%) \\
\text { IC } 95 \%= \\
0,1-12,0 \%\end{array}$ & $\begin{array}{c}28 \text { de } 50(63,3 \%) \\
\text { IC } 95 \%= \\
48,3-79,0 \%\end{array}$ \\
\hline & $\begin{array}{c}\text { Clase } \\
\text { C }\end{array}$ & $\begin{array}{l}5 \text { de } 8(62,5 \%) \\
\quad \text { IC } 95 \%= \\
24,5-91,5 \%\end{array}$ & $\begin{array}{l}1 \text { de } 8(12,5 \%) \\
\text { IC } 95 \%= \\
0,3-52,6 \%\end{array}$ & $\begin{array}{l}4 \text { de } 50(50,0 \%) \\
\text { IC } 95 \%= \\
15,7-84,3 \%\end{array}$ \\
\hline \multirow{3}{*}{$\begin{array}{l}\text { Criterio } \\
\text { de TAG }\end{array}$} & $\begin{array}{c}\text { Clase } \\
\text { A }\end{array}$ & $\begin{array}{c}11 \text { de } 46(23,9 \%) \\
\text { IC } 95 \%= \\
10,5-37,3 \%\end{array}$ & $\begin{array}{c}3 \text { de } 46(6,5 \%) \\
\text { IC } 95 \%= \\
1,4-17,9 \%\end{array}$ & $\begin{array}{c}8 \text { de } 46(17,4 \%) \\
\text { IC } 95 \%= \\
5,3-29,4 \%\end{array}$ \\
\hline & $\begin{array}{c}\text { Clase } \\
\text { B }\end{array}$ & $\begin{array}{c}16 \text { de } 41(39,0 \%) \\
\text { IC } 95 \%= \\
22,9-55,2 \%\end{array}$ & $\begin{array}{c}8 \text { de } 41(19,5 \%) \\
\text { IC } 95 \%= \\
6,2-32,9 \%\end{array}$ & $\begin{array}{c}8 \text { de } 41(19,5 \%) \\
\text { IC } 95 \%= \\
6,2-32,9 \%\end{array}$ \\
\hline & $\begin{array}{c}\text { Clase } \\
\text { C }\end{array}$ & $\begin{array}{c}4 \text { de } 7(57,1 \%) \\
\text { IC } 95 \%= \\
18,4-90,1 \%\end{array}$ & $\begin{array}{c}1 \text { de } 7(14,3 \%) \\
\text { IC } 95 \%= \\
0,4-57,9 \%\end{array}$ & $\begin{array}{c}3 \text { de } 7(42,8 \%) \\
\text { IC } 95 \%= \\
9,9-81,6 \%\end{array}$ \\
\hline \multirow{3}{*}{$\begin{array}{l}\text { Criterio } \\
\text { de PA }\end{array}$} & $\begin{array}{c}\text { Clase } \\
\text { A }\end{array}$ & $\begin{array}{c}36 \text { de } 45(80,0 \%) \\
\text { IC } 95 \%= \\
67,2-92,8 \%\end{array}$ & $\begin{array}{c}15 \text { de } 45(33,3 \%) \\
\text { IC } 95 \%= \\
18,4-48,2 \%\end{array}$ & $\begin{array}{c}21 \text { de } 45(46,7 \%) \\
\text { IC } 95 \%= \\
31,0-62,3 \%\end{array}$ \\
\hline & $\begin{array}{c}\text { Clase } \\
\text { B }\end{array}$ & $\begin{array}{c}44 \text { de } 44(100 \%) \\
\text { IC } 95 \%= \\
91,9-100 \%\end{array}$ & $\begin{array}{c}34 \text { de } 44(77,3 \%) \\
\text { IC } 95 \%= \\
63,7-90,8 \%\end{array}$ & $\begin{array}{c}10 \text { de } 44(22,7 \%) \\
\text { IC } 95 \%= \\
9,2-36,2 \%\end{array}$ \\
\hline & $\begin{array}{c}\text { Clase } \\
\text { C }\end{array}$ & $\begin{array}{c}8 \text { de } 8(100 \%) \\
\text { IC } 95 \%= \\
63,0-100 \%\end{array}$ & $\begin{array}{c}5 \text { de } 8(62,5 \%) \\
\text { IC } 95 \%= \\
24,5-91,5 \%\end{array}$ & $\begin{array}{c}3 \text { de } 8(37,5 \%) \\
\text { IC } 95 \%= \\
8,5-75,5 \%\end{array}$ \\
\hline
\end{tabular}


Tabla 40. Análisis comparativo de las diferencias de medias para variables analíticas y presión arterial sistólica y diastólica entre el momento de la indicación de $\mathrm{CB}$ y la última revisión en consulta de Endocrinología para cada categoría del OS-MRS.

\begin{tabular}{|c|c|c|c|}
\hline \multicolumn{4}{|c|}{$\begin{array}{l}\text { COMPARACIÓN DE MEDIAS DE VARIABLES ANALÍTICAS Y DE } \\
\text { PRESIÓN ARTERIAL ENTRE LAS CATERGORÍAS DEL OS-MRS }\end{array}$} \\
\hline \multirow{2}{*}{\multicolumn{2}{|c|}{$\begin{array}{l}\text { VARIABLE Y } \\
\text { CATEGORÍA }\end{array}$}} & DIFERENCIA DE MEDIAS & SIGNIFICACIÓN \\
\hline & & ANTES Y DESPUES DE CB & ESTADISTICA \\
\hline \multirow{4}{*}{ Glucemia } & $\begin{array}{c}\text { Clase } \\
\text { A }\end{array}$ & $\begin{array}{l}14,4 \pm 15,9 \mathrm{mg} / \mathrm{dl}(\mathrm{IC} 95 \%= \\
9,8-18,9 \mathrm{mg} / \mathrm{dl}, \mathrm{p}<0,001)\end{array}$ & \multirow{4}{*}{ n.s. } \\
\hline & Clase & $25,1 \pm 34,0 \mathrm{mg} / \mathrm{dl}(\mathrm{IC} 95 \%=$ & \\
\hline & & $14,5-35,7 \mathrm{mg} / \mathrm{dl}, \mathrm{p}<0,001)$ & \\
\hline & $\begin{array}{c}\text { Clase } \\
\text { C }\end{array}$ & $\begin{array}{l}33,4 \pm 43,3 \mathrm{mg} / \mathrm{dl}(\mathrm{IC} 95 \%= \\
-2,9-69,7 \mathrm{mg} / \mathrm{dl}, \text { n.s. })\end{array}$ & \\
\hline \multirow{4}{*}{$\begin{array}{l}\text { Colesterol } \\
\text { total }\end{array}$} & $\begin{array}{c}\text { Clase } \\
\text { A }\end{array}$ & $\begin{array}{l}60,5 \pm 38,6 \mathrm{mg} / \mathrm{dl}(\mathrm{IC} 95 \%= \\
492-718 \mathrm{mg} / \mathrm{dl} \mathrm{p}<0001)\end{array}$ & \multirow{4}{*}{ n.s. } \\
\hline & Clase & $59,7 \pm 41,9 \mathrm{mg} / \mathrm{dl}(\mathrm{IC} 95 \%=$ & \\
\hline & B & $46,3-73,1 \mathrm{mg} / \mathrm{dl}, \mathrm{p}=0,015)$ & \\
\hline & $\begin{array}{c}\text { Clase } \\
\text { C }\end{array}$ & $\begin{array}{l}81,1 \pm 63,3 \mathrm{mg} / \mathrm{dl}(\mathrm{IC} 95 \%= \\
22,6-139,7 \mathrm{mg} / \mathrm{dl}, \mathrm{p}<0,001)\end{array}$ & \\
\hline \multirow{3}{*}{ TAG } & $\begin{array}{c}\text { Clase } \\
\text { A }\end{array}$ & $\begin{array}{l}14,6 \pm 58,4 \mathrm{mg} / \mathrm{dl}(\mathrm{IC} 95 \%= \\
-2,8-31,9 \mathrm{mg} / \mathrm{dl}, \text { n.s. })\end{array}$ & \multirow{3}{*}{ n.s. } \\
\hline & $\begin{array}{c}\text { Clase } \\
\text { B }\end{array}$ & $\begin{array}{l}28,7 \pm 98,3 \mathrm{mg} / \mathrm{dl}(\mathrm{IC} 95 \%= \\
-2,8-59,3 \mathrm{mg} / \mathrm{dl}, \text { n.s. })\end{array}$ & \\
\hline & $\begin{array}{c}\text { Clase } \\
\text { C }\end{array}$ & $\begin{array}{l}56,0 \pm 100,3 \mathrm{mg} / \mathrm{dl}(\mathrm{IC} 95 \%= \\
-36,7-148,7 \mathrm{mg} / \mathrm{dl}, \text { n.s. })\end{array}$ & \\
\hline \multirow{3}{*}{$\begin{array}{c}\text { PA } \\
\text { sistólica }\end{array}$} & $\begin{array}{c}\text { Clase } \\
\text { A }\end{array}$ & $\begin{array}{l}14,2 \pm 21,2 \mathrm{mmHg}(\mathrm{IC} 95 \%= \\
7,8-20,7 \mathrm{mmHg}, \mathrm{p}<0,001)\end{array}$ & \multirow{3}{*}{ n.s. } \\
\hline & $\begin{array}{c}\text { Clase } \\
\text { B }\end{array}$ & $\begin{array}{l}20,1 \pm 26,3 \mathrm{mmHg}(\mathrm{IC} 95 \%= \\
12,0-28,2 \mathrm{mmHg}, \mathrm{p}<0,001)\end{array}$ & \\
\hline & $\begin{array}{c}\text { Clase } \\
\text { C }\end{array}$ & $\begin{array}{c}8,9 \pm 29,6 \mathrm{mmHg} \text { (IC 95\% }= \\
-15,9-33,6 \mathrm{mmHg}, \text { n.s. })\end{array}$ & \\
\hline \multirow{3}{*}{$\begin{array}{c}\text { PA } \\
\text { diastólica }\end{array}$} & $\begin{array}{c}\text { Clase } \\
\text { A }\end{array}$ & $\begin{array}{c}13,0 \pm 14,8 \mathrm{mmHg}(\mathrm{IC} 95 \%= \\
8,5-17,5 \mathrm{mmHg}, \mathrm{p}<0,001)\end{array}$ & \multirow{3}{*}{ n.s. } \\
\hline & $\begin{array}{c}\text { Clase } \\
\text { B }\end{array}$ & $\begin{array}{c}13,6 \pm 14,2 \mathrm{mmHg}(\mathrm{IC} 95 \%= \\
9,2-18,0 \mathrm{mmHg}, \mathrm{p}<0,001)\end{array}$ & \\
\hline & $\begin{array}{c}\text { Clase } \\
\text { C }\end{array}$ & $\begin{array}{c}3,5 \pm 22,3 \mathrm{mmHg} \text { (IC } 95 \%= \\
-15,1-22,1 \mathrm{mmHg}, \text { n.s. })\end{array}$ & \\
\hline
\end{tabular}




\subsubsection{3.- Comparación de estancia hospitalaria según las categorías del Obesity}

\section{Surgery-Mortality Risk Score}

El análisis comparativo de las medias de estancia hospitalaria para las tres cohortes de pacientes según las categorías del OS-MRS muestra que las diferencias no son estadísticamente significativas, al solaparse los valores de los respectivos IC 95\%.

- Media de estancia hospitalaria para la clase A del OS-MRS: 9,5 \pm 5,8 días. (IC 95\% = 8,4 - 10,6 días).

- Media de estancia hospitalaria para la clase B del OS-MRS: 11,7 \pm 7,8 días (IC $95 \%=10,1-12,6$ días).

- Media de estancia hospitalaria para la clase C del OS-MRS: 10,8 \pm 7,2 días (IC $95 \%=7,5-14,3$ días).

Sin embargo, el análisis de subgrupos sí alcanza significación entre la media de conjunta de estancia para las clase B y C del score respecto a la clase A [Véase en la tabla 41].

Tabla 41. Comparación de medias de estancia hospitalaria entre la categoría A frente a las categorías B y C conjuntamente.

\begin{tabular}{|c|c|c|}
\hline \multicolumn{3}{|c|}{$\begin{array}{c}\text { COMPARACIÓN DE LA ESTANCIA HOSPITALARIAS } \\
\text { SEGÚN LAS CATEGORÍAS DEL OS-MRS }\end{array}$} \\
\cline { 1 - 2 } CATEGORÍA & $\begin{array}{c}\text { MEDIA DE ESTANCIA } \\
\text { HOSPITALARIA }\end{array}$ & $\begin{array}{c}\text { SIGNIFICACIÓN } \\
\text { ESTADÍSTICA }\end{array}$ \\
\hline Clase A & $9,5 \pm 5,8$ días & $\mathrm{p}=0,028$ \\
\hline Clase B y C & $11,3 \pm 7,7$ días & \\
\hline
\end{tabular}




\section{5.- DISCUSIÓN}





\section{5.- DISCUSIÓN}

\section{1.- TAMAÑO MUESTRAL Y RESULTADOS DEMOGRÁFICOS}

En primer lugar, se debe mencionar que, de la muestra inicial de 274 pacientes que cumplían criterios de inclusión y exclusión, se han presentado los resultados postoperatorios de 113. Esto supone que, aproximadamente, dos de cada cinco obesos $(41,2 \%)$ sometidos a derivación biliopancreática (DBP) en el Hospital Universitario Río Hortega (HURH) llevan a cabo su seguimiento en el Área sanitaria de Valladolid Oeste. Sin embargo, ello no implica un fracaso del objetivo de calidad propuesto por el Registro Internacional de Cirugía Bariátrica, según el cual la tasa de seguimiento postbariátrico de ser superior al $60 \%$, dado que el porcentaje restante $(58,8 \%)$ no son enfermos perdidos, sino que le corresponde al endocrinólogo de su área sanitaria llevar a cabo esta tarea, de acuerdo al "Protocolo para la práctica de Cirugía de la Obesidad" de nuestra Unidad de obesidad mórbida $(\mathrm{OM})$ y cirugía bariátrica (CB). Este hecho podría limitar la extrapolación de los resultados postoperatorios aquí expuestos a toda la población de obesos intervenidos mediante DBP que cubre nuestra Unidad; no obstante, ello no es un objetivo de este trabajo.

Nuestros resultados de distribución por sexo en la muestra de obesos evaluados (73\% mujeres, $27 \%$ varones) se aproxima en gran medida a los resultados presentados en los recientes meta-análisis que incluyen series muy largas de pacientes, como el de Chang et al. (166), con un 79\% de pacientes de sexo femenino sometidos a $\mathrm{CB}$, aunque sin clasificar 
por técnica quirúrgica. En la misma línea, la mayoría de los trabajos revisados por Gloy et al. (165) notificaron predominio de mujeres, a excepción de dos de ellos correspondientes a artículos que revisaron resultados de bypass gástrico en Y de Roux (BGYR) y de banda gástrica ajustable (BGA). Asimismo, Ribaric et al. (167) presentaron un valor casi idéntico a nuestra serie $(72 \%$ de mujeres) en la cohorte de pacientes sometidos a $\mathrm{CB}$ de su metaanálisis. Comparando nuestro resultado con otros trabajos sobre DBP exclusivamente, observamos una cifra intermedia entre la serie del propio N. Scopinaro (238), con una proporción de mujeres del 68,0\%, y de la serie de Ballesteros-Pomar et al. (247), del grupo del Hospital de León (España) recientemente publicada, con una cifra del 76,1\%. También en nuestro entorno próximo, Sánchez et al. (248), del Hospital de Burgos (España), han notificado un claro predominio de mujeres en su serie con una proporción muy similar a nuestro estudio (74\%), aunque en este trabajo los autores incluyen un discreto porcentaje de pacientes sometidos a otras técnicas diferentes de la DBP de Scopinaro, sin presentar un análisis de subgrupos entre los procedimientos bariátricos incluidos.

Los resultados relativos a la edad de nuestros pacientes, con una media de 41,28 años, no difieren llamativamente de la media de 44,6 años, presentada igualmente por Chang et al. (166). No obstante, según Ribaric et al. (167), la edad media en la cohorte de tratamiento quirúrgico de la $\mathrm{OM}$ es notablemente más elevada que la nuestra, con una cifra de 47,0 años. Gloy et al. (165) obtuvieron, en su meta-análisis, valores medios de edad que comprendían desde 36,7 a 50,8 años para el grupo de CB. De nuevo, al revisar exclusivamente publicaciones de obesos sometidos a DBP, la cifra de edad de nuestro estudio es intermedia entre la de Ballesteros-Pomar et al. (247), con 43,0 años de media, y los resultados del grupo del autor que describió esta técnica, con 37 años (238). El grupo 
burgalés de F.J. Sánchez presenta, al igual que ocurre con la distribución por sexo, los resultados de edad más próximos a los nuestros (media de 40,3 años) (248). 


\section{2.- RESULTADOS PONDERALES}

\subsection{1.- PARÁMETROS ANTROPOMÉTRICOS}

Como se ha expuesto en la Introducción, el compartimento corporal según el modelo de Wang et al. (5) se evalúa mediante los parámetros antropométricos, siendo el peso, la talla, el índice de masa corporal (IMC) y la circunferencia de cintura (CC), los empleados habitualmente, estando recomendada su determinación por la Organización Mundial de la Salud (OMS) para catalogar el estado nutricional, y avalado por diversas publicaciones (17-19).

En primer lugar, cabe reseñar que la descripción aislada de la talla no aparece reflejada en los meta-análisis ya mencionados (165-167), ni tampoco en los trabajos de Ballesteros-Pomar et al. (247), Sánchez et al. (248) ni Scopinaro et al. (238). Este hallazgo es comprensible dado que en todos ellos se presenta el dato de IMC antes de la CB, acompañado o no de la cifra preoperatoria de peso. Por este motivo, carece de especial interés la discusión de esta variable.

El peso mediano antes de la indicación de CB alcanza los 125 kilogramos $(\mathrm{Kg})$ en nuestra serie, un valor próximo a los otros estudios con pacientes sometidos a DBP: media de 132,3 Kg en los obesos del grupo del Hospital de León (247) y 128 Kg según los datos del grupo de N. Scopinaro (238) [Véase tabla 42]. Asimismo, en el meta-análisis de Chang et al. (166), la cifra es casi idéntica a la nuestra: $124,5 \mathrm{Kg}$. Sin embargo, el grupo burgalés no informa de la cifra de esta variable en su artículo (248). 
El peso ideal de los pacientes se ha calculado siguiendo la fórmula descrita en el artículo de Larrad et al. (187), ya que según estos autores "las Metropolitan Tables o las tablas para la población catalana de Alastrué et al. (249) no son totalmente representativas". La determinación del peso ideal es necesaria, a su vez, para incluir este valor en la fórmula del porcentaje de exceso de peso perdido (PEPP), tal y como proponen numerosos autores, entre ellos Larrad et al. (187). La mediana de peso ideal de nuestros obesos empleando los valores de peso y talla antes de la indicación de $\mathrm{CB}$ es de 59,4 $\mathrm{Kg}$, un dato casi idéntico al publicado por Scopinaro et al. (238), quienes presentan una cifra media de exceso de peso de $69 \mathrm{Kg}$ sobre un valor de peso medio antes de la DBP de $128 \mathrm{Kg}$, como acabamos de exponer. La diferencia entre ambos se corresponde con el peso ideal, obteniendo un resultado de $59 \mathrm{Kg}$. Desafortunadamente, Ballesteros-Pomar et al. (247) no han incluido este dato en su estudio, y en cambio, sí han aportado la modificación del porcentaje de grasa corporal, mediante impedanciometría, antes y después de la DBP. Tampoco se incluye esta variable en el artículo del grupo de Burgos (248) ni en los meta-análisis de Chang et al. (166) ni de Gloy et al. (165).

El IMC es el principal factor, junto con la existencia de comorbilidades asociadas a la obesidad (CAO), para realizar la indicación de CB actualmente $(172,175,177)$, de ahí la importancia de su determinación preoperatoria. De forma superponible a la variable anterior, nuestra mediana de IMC antes de la indicación de $\mathrm{CB}, 47,2 \mathrm{Kg} /$ metro (m) ${ }^{2}$, apenas difiere respecto a lo publicado por Chang et al. (166): 45,6 Kg/ $\mathrm{m}^{2}$. De igual modo, las cifras de este parámetro antropométrico en la serie de Scopinaro et al. (238) y de Sánchez et al. (248) son muy próximas a la nuestra $\left(47,0\right.$ y $48,6 \mathrm{Kg} / \mathrm{m}^{2}$, respectivamente), mientras que Ballesteros-Pomar et al. (247) publican un IMC algo más elevado: 50,1 Kg/m² [Véase tabla 42]. 
Es necesario puntualizar que estas variables están tomadas en el momento de la indicación de $\mathrm{CB}$, tal y como se ha descrito en el epígrafe 3.4.2.- Variables preoperatorias. Ello genera un sesgo potencial ya que la cifra de peso puede variar, preferentemente con tendencia ascendente, durante el periodo de espera hasta la realización del procedimiento, un fenómeno que no se encuentra analizado ampliamente en la literatura. En 1998, De Witt Hamer et al. (250) publicaron una ganancia estadísticamente significativa de 4,4 $\mathrm{Kg}$ entre el momento de la evaluación preoperatoria de los candidatos a CB y la medida del peso en el momento de la intervención. Eisenberg et al. (251) identificaron 104 de 256 pacientes candidatos a BGYR (40,6\%) con aumento de peso antes de la cirugía, de los cuales, 83 incrementaron su IMC un $0,1-2,0 \%$, veinticinco de ellos un 2,1-5\% y dos pacientes $>5 \%$ respecto a la cifra registrada en el momento de la indicación del procedimiento. Por último, según Taylor et al. (252), 17 obesos de los 76 de su serie (22,3\%) llegaron a la cirugía con un IMC superior al 2,5\% respecto del calculado en consulta.

Por el contrario, sí existen numerosas publicaciones en relación a la utilidad de la pérdida de peso preoperatoria, corroborando la hipótesis de que esta práctica optimiza las CAO y reduce el riesgo de complicaciones perioperatorias $(177,181)$. El más reciente artículo de revisión sobre este tema, publicado por Gerber et al. (253), notifica que no existe un elevado nivel de evidencia en la literatura, aunque todo apunta hacia un efecto beneficioso de la pérdida de peso preoperatoria, concluyendo, igualmente, que es controvertido el uso de esta práctica de forma obligatoria en todos los obesos candidatos a CB. Sin embargo, los detractores sostienen que los resultados postbariátricos no están influidos por la ganancia de peso preoperatoria $(251,252,254,255)$, de modo que carece de fundamento desestimar la intervención en aquellos pacientes que no cumplan este objetivo. 
Por todo ello, en nuestra Unidad de $\mathrm{OM}$ y CB no se ha contemplado aún la incorporación de esta actitud en el protocolo clínico.

Tras un tiempo medio de seguimiento que supera los 5 años en el 54,8\% de los 113 pacientes con revisión endocrinológica en nuestro centro, se observa que el peso y el IMC en la última revisión de Endocrinología descienden a valores medios de 88,2 $\mathrm{Kg}$ y 32,9 $\mathrm{Kg} / \mathrm{m}^{2}$, respectivamente. El grupo del Hospital Universitario de Burgos no incluye datos sobre estas variables en su estudio (248), mientras que Ballesteros-Pomar et al. (247) sí lo hacen. Estas cifras, en su cohorte de obesos con 5 años de seguimiento, son casi superponibles a las nuestras [Véase tabla 42]. Sin embargo, Scopinaro et al. (238) no presentan estas mismas variables más allá del tercer año tras DBP, notificando únicamente el PEPP. No obstante, es necesario tener en cuenta que el dato bruto de peso e IMC postoperatorio carece de especial importancia. Por ello, se ha presentado el análisis comparativo entre los valores antes de la indicación de $\mathrm{CB}$ y en la última revisión postbariátrica, obteniendo en nuestra serie una reducción estadísticamente significativa, con valores medios de descenso de $37,4 \mathrm{Kg}$ y $14,1 \mathrm{Kg} / \mathrm{m}^{2}$, respectivamente. Al realizar los cálculos empleando los datos expuestos por el grupo del Hospital de León para 5 años de seguimiento, obtenemos un descenso mayor que en nuestros pacientes tanto de peso $(47,4$ $\mathrm{Kg})$, como de IMC $\left(17,3 \mathrm{Kg} / \mathrm{m}^{2}\right)$, lo cual resulta teóricamente más favorable para la serie leonesa, teniendo en cuenta que el valor preoperatorio de ambas variables era más elevado que en nuestro estudio, tal y como se acaba de exponer anteriormente. Sin embargo, este planteamiento no queda tan patente, tras comparar las variables PEPP y porcentaje de exceso de IMC perdido (PEIMCP), que también se han evaluado en este estudio, como se desarrolla en el siguiente epígrafe. 
Tabla 42. Medias y/o medianas de las variables peso e IMC antes de la indicación de CB y en la última revisión del seguimiento (con una mediana de seguimiento de 5 años como mínimo), comparando resultados propios con los publicados en la literatura [artículos de Ballesteros-Pomar et al. (247), Sánchez et al. (248) y Scopinaro et al. (209)].

\begin{tabular}{|c|c|c|c|c|}
\hline \multicolumn{5}{|c|}{$\begin{array}{l}\text { COMPARACIÓN CON LA LITERATURA DE LAS MEDIAS Y/O } \\
\text { MEDIANAS DEL PESO Y DEL IMC ANTES DE LA } \\
\text { INDICACIÓN DE CB Y EN EL SEGUIMIENTO }\end{array}$} \\
\hline VARIABLE & $\begin{array}{c}\text { Resultados } \\
\text { propios }\end{array}$ & $\begin{array}{l}\text { Ballesteros-Pomar } \\
\quad \text { et al. (247) }\end{array}$ & $\begin{array}{l}\text { Sánchez et } \\
\text { al. (248) }\end{array}$ & $\begin{array}{l}\text { Scopinaro } \\
\text { et al. (209) }\end{array}$ \\
\hline $\begin{array}{c}\text { Peso antes de } \\
\text { CB }\end{array}$ & $125 \mathrm{Kg}$ & $132,3 \mathrm{Kg}$ & n.n. & $128 \mathrm{Kg}$ \\
\hline $\begin{array}{c}\text { Peso en la } \\
\text { última revisión }\end{array}$ & $88,2 \mathrm{Kg}$ & $84,6 \mathrm{Kg}$ & n.n. & $79,4 \mathrm{Kg} *$ \\
\hline $\begin{array}{c}\text { IMC antes de } \\
\text { CB }\end{array}$ & $\begin{array}{c}47,2 \\
\mathrm{Kg} / \mathrm{m}^{2}\end{array}$ & $50,1 \mathrm{Kg} / \mathrm{m}^{2}$ & $\begin{array}{c}48,6 \\
\mathrm{Kg} / \mathrm{m}^{2}\end{array}$ & $\begin{array}{c}47,0 \\
\mathrm{Kg} / \mathrm{m}^{2}\end{array}$ \\
\hline $\begin{array}{c}\text { IMC en la } \\
\text { última revisión }\end{array}$ & $\begin{array}{c}32,9 \\
\mathrm{Kg} / \mathrm{m}^{2} \\
\end{array}$ & $32,8 \mathrm{Kg} / \mathrm{m}^{2}$ & n.n. & $\begin{array}{c}29,4 \\
\mathrm{Kg} / \mathrm{m}^{2 *} \\
\end{array}$ \\
\hline
\end{tabular}

\subsection{2.- PARÁMETROS DE EVALUACIÓN DE RESULTADOS} PONDERALES TRAS CIRUGÍA BARIÁTRICA

Las cifras medias obtenidas para los parámetros de evaluación de pérdida ponderal, son en toda la serie de 58,3\% para el PEPP y de 64,6\% para el PEIMCP, y en aquellos pacientes con un tiempo medio de seguimiento superior a 5 años son de $62,3 \%$ y $68,9 \%$, respectivamente. Empleando estas variables, las diferencias para el descenso de peso e IMC de la serie de Ballesteros-Pomar et al. (247) respecto a nuestro trabajo son menos evidentes que las apreciadas en el epígrafe anterior, puesto que se elimina la influencia de los datos brutos pre y postbariátricos de peso e IMC (187), tal y como se acaba de exponer. Sánchez et al. (248) publicaron cifras superiores a nuestra serie y también a la serie leonesa (PEPP = $68 \%$ y PEIMCP $=74 \%$, a los 5 años) [Véase tabla 43], aunque no alcanzan el resultado del grupo de N. Scopinaro (238), cuyo PEPP se eleva hasta el 75\%. Sin embargo, los resultados 
del meta-análisis de Chang et al. (166) son más cercanos a los nuestros, con un PEPP al quinto año de seguimiento de $64,9 \%$ en los estudios observacionales analizados para el grupo denominado gastric bypass, que incluye BGYR, DBP y cruce duodenal (CD). Así pues, nuestros resultados ponderales pueden considerarse favorables, como se expondrá al final de este epígrafe, aunque algo menos satisfactorios que los descritos en la literatura para la técnica de DBP.

Tabla 43. Valores medios a 5 años de seguimiento para el descenso de peso, descenso de IMC, PEPP y PEIMCP, comparando resultados propios con los publicados en la literatura por grupos de CB de nuestro entorno próximo [artículos de Ballesteros-Pomar et al. (247) y Sánchez et al. (248)].

\begin{tabular}{|c|c|c|c|}
\hline \multicolumn{4}{|c|}{$\begin{array}{c}\text { COMPARACIÓN CON LA LITERATURA DE LAS MEDIAS } \\
\text { DE LOS PARÁMETROS DE EVALUACIÓN PONDERAL } \\
\text { TRAS } 5 \text { AÑOS DE SEGUIMIENTO }\end{array}$} \\
\hline VARIABLE & $\begin{array}{l}\text { Resultados } \\
\text { propios }\end{array}$ & $\begin{array}{c}\text { Ballesteros-Pomar } \\
\text { et al. (247) }\end{array}$ & $\begin{array}{l}\text { Sánchez et } \\
\text { al. (248) }\end{array}$ \\
\hline $\begin{array}{l}\text { Descenso medio } \\
\text { de peso }\end{array}$ & $37,4 \mathrm{Kg}$ & $47,4 \mathrm{Kg}$ & n.n. \\
\hline $\begin{array}{l}\text { Descenso medio } \\
\text { de IMC }\end{array}$ & $14,1 \mathrm{Kg} / \mathrm{m}^{2}$ & $17,3 \mathrm{Kg} / \mathrm{m}^{2}$ & n.n. \\
\hline PEPP & $62,3 \pm 19,5 \%$ & $65,3 \pm 17,3 \%$ & $68 \%$ \\
\hline PEIMCP & $68,9 \pm 22,4 \%$ & $71,4 \pm 19,2 \%$ & $74 \%$ \\
\hline
\end{tabular}

La variable porcentaje de peso total perdido (PPTP) también se ha incluido en este estudio en base a las publicaciones de Van der Laar et al. $(188,189)$ con datos del Bariatric Outcomes Longitudinal Database, en las que se sugiere que este parámetro de evaluación de pérdida ponderal es más fiable que el PEPP o el PEIMCP, tal y como se citó en la Introducción. Nuestro resultado de PPTP (29,4\%) supera ampliamente el criterio propuesto por la Sociedad Española para el Estudio De la Obesidad (SEEDO) (4), según el 
cual los individuos con IMC $\geq 40 \mathrm{Kg} / \mathrm{m}^{2}$ han de perder, como mínimo, un $20 \%$ de su peso total. Comparando esta cifra de PPTP con los mencionados trabajos de Van der Laar et al. $(188,189)$, se observa una diferencia de casi 10 puntos porcentuales menor $(38,5 \%)$, aunque es necesario tener en consideración que este dato se ha calculado para una mediana de seguimiento mucho más corta ( 2 años) que en nuestro trabajo y que estos autores emplean el BGYR como técnica bariátrica. Tras revisar los artículos de grupos de nuestro entorno que emplean la DBP $(247,248)$ así como los datos de N. Scopinaro $(238)$, constatamos que ninguno de ellos emplean este parámetro de pérdida ponderal en sus estudios. En los EE.UU., Dorman et al. (256), empleando una cohorte de obesos sometidos a CD, notificaron un PPTP mayor que en nuestro estudio (39\% a los 5 años), aunque sólo 23 pacientes alcanzan este tiempo de seguimiento frente a 62 en nuestra serie.

Al evaluar nuestros resultados ponderales en base al criterio de calidad definido por autores de la categoría de M. Fobi o A. Baltasar y recogido en el artículo de Larrad et al. (187), obtenemos que la técnica de DBP realizada en el HURH es efectiva, con PEPP $>50 \%$ en más del 75\% de los pacientes a los 5 años de seguimiento. Asimismo, tras analizar a los pacientes siguiendo la clasificación propuesta por el propio A. Larrad, se observa que el $82 \%$ de nuestros obesos intervenidos con más de 5 años de seguimiento logran resultados ponderales buenos o excelentes. Estas cifras son discretamente inferiores a las publicadas en 2007 por este autor y sus colaboradores, empleando la modificación técnica de la BDP que él mismo describió: tras 5 años de seguimiento, se alcanzaron resultados excelentes o buenos en el 90,8\% de los pacientes con IMC $<50 \mathrm{Kg} / \mathrm{m}^{2}$ y en el $87,8 \%$ de aquellos con IMC $\geq 50 \mathrm{Kg} / \mathrm{m}^{2}(257)$ 
Con todo lo expuesto, se aprecia una tendencia global en nuestra serie a resultados ponderales discretamente inferiores a los presentados por otros autores que emplean la DBP como técnica quirúrgica. Entendemos que ello es debido a la infraestimación de los parámetros de evaluación (PEPP, PEIMCP y PPTP) como consecuencia de la medida de peso basal en la última consulta de Endocrinología y no inmediatamente antes de la intervención quirúrgica. El ya mencionado incremento ponderal que acontece en un porcentaje no desdeñable de obesos, entre la evaluación previa a $\mathrm{CB}$ y el momento de la intervención (250-252),supondría una estimación inferior a la real de la pérdida de peso inducida por el procedimiento quirúrgico.

Finalmente, cabe mencionar la limitación que supone presentar los valores medios de estas variables a lo largo de todo el seguimiento, y no con la cifra en cada año de evolución postbariátrica, forma como lo han expuesto los grupos leonés (247) e italiano (238) en sus respectivos estudios. Al ser una medida de tendencia central, se atenúan las diferencias entre los valores extremos. En el caso de las variables PEPP y PEIMC, estos valores fluctúan a lo largo de la evolución, siendo los 3 primeros años el momento de máxima pérdida ponderal, estabilizándose posteriormente (238).

\subsection{3.- CARACTERÍSTICAS DE LOS PACIENTES CON INSUFICIENTE PÉRDIDA DE PESO}

Tomando como criterio de fracaso ponderal un PEIMCP $<50 \%$ al quinto año de seguimiento según definieron Larrad et al. (187), hemos encontrado 11 enfermos de los 62 con seguimiento mayor de 5 años $(17,7 \%)$ en los que la DBP no ha resultado efectiva. Se ha realizado un análisis inferencial para determinar qué variables de nuestro estudio (preoperatorias y asociadas al ingreso hospitalario) se asocian con esta ausencia de 
respuesta adecuada a $\mathrm{CB}$, a fin de caracterizar el perfil de obeso candidato con potencial riesgo de no alcanzar resultados ponderales satisfactorios. A continuación se desarrollan las diferencias encontradas con los 51 obesos que sí alcanzaron resultados ponderales buenos o excelentes según el mencionado criterio de Larrad et al. (187) para las siguientes variables:

- Edad. Nuestros pacientes clasificados como fracaso ponderal no presentan diferencias significativas en la media de edad respecto a los que obtuvieron buen resultado ponderal. Idéntico resultado se obtuvo con la variable "grupos de edad según el Obesity Surgery-Mortality Risk Score (OS-MRS)", con diferencias no estadísticamente significativas para la proporción de enfermos con buenos resultados frente a los de fracaso ponderal incluidos en cada cohorte ( $<45$ años $\mathrm{y} \geq 45$ años).

- Sexo. No se encontraron diferencias significativas para esta variable.

- IMC antes de la indicación de CB. La diferencia entre la media de este parámetro antropométrico en el grupo de fracaso ponderal frente al grupo de resultado bueno o excelente no alcanzó significación estadística. Tampoco la obtuvo el análisis por grupos de IMC según el OS-MRS (cohorte de $<50$ y de $\geq 50 \mathrm{Kg} / \mathrm{m}^{2}$ ).

- Las cohortes con HTA y riesgo de TEP según el OS-MRS tampoco mostraron diferencias significativas con las respectivas cohortes sin HTA y sin riesgo de TEP.

- Categorías del OS-MRS (cohorte de pacientes de la clase A, clase B y clase C). No hubo diferencias significativas en la proporción de pacientes incluidos en cada una de las categorías de este score tras comparar aquellos con insuficiente pérdida ponderal frente a aquellos con buen resultado. 
- Criterio de glucemia, de triglicéridos (TAG) y de presión arterial (PA) para síndrome metabólico (SM) antes de la indicación de CB (cohortes con criterio positivo y con criterio negativo). No se han encontrado diferencias significativas para ninguno de los 3 criterios evaluados.

- Complicaciones durante el ingreso hospitalario (cohorte sin complicaciones o con complicaciones menores - grados I y II de la clasificación de DindoClavien - frente a la cohorte con complicaciones mayores - grados IIIa, IIIb, IV y V de la citada clasificación). La proporción de pacientes incluidos en estas dos cohortes no presenta diferencias significativas al evaluar los resultados ponderales.

Al comparar estos resultados con los datos publicados, se aprecian algunas discordancias. Sin embargo, es necesario puntualizar que existe notable heterogeneidad en la literatura en referencia a los factores que influyen en la mayor o menor pérdida ponderal. En primer lugar, la revisión sistemática de 2012 de Livhits et al. (258) evaluó el IMC preoperatorio y diversos factores psicológicos, concluyendo que los individuos superobesos $\left(\mathrm{IMC} \geq 50 \mathrm{Kg} / \mathrm{m}^{2}\right)$ alcanzan PEPP un 10,1\% inferior a los pacientes con IMC inferiores a esa cifra y que los candidatos a $\mathrm{CB}$ con trastorno por atracones (binge eating disorder) obtienen PEPP un 5,9\% mayor que los que no presentan. En el análisis multivariante del trabajo de Courcoulas et al. (259), con resultados a 3 años tras BGYR, se aprecia que las variables que generan mayor pérdida de peso proporcionalmente son el hábito tabáquico actual o reciente, el empleo de sustitutos alimenticios y la función renal alterada (PEPP un $2,3 \%, 3,0 \%$ y $2,7 \%$ mayor, respectivamente), mientras que la raza negra o el diagnóstico preoperatorio de diabetes mellitus (DM) son predictores de peor resultado ponderal (PEPP un $2,7 \%$ y $3,7 \%$ menor, respectivamente), al igual que otros factores entre los que se 
incluye la edad, aunque con una influencia mínima (PEPP un 0,6\% menor por cada 10 años de incremento de edad). El artículo de Still et al. (260), con resultados de 2365 obesos sometidos a BGYR, sí incluye la edad mayor de 50 años como predictor de menor respuesta ponderal así como la DM2, con o sin tratamiento antidiabético oral, y el mayor IMC preoperatorio, aunque este último pierde la significación estadística tras el tercer año de seguimiento postbariátrico. El estudio de Parri et al. (261), con 4 años de seguimiento, concluye que la edad y el IMC inicial tienen una relación inversamente proporcional con el descenso ponderal y que el BGYR frente a la gastrectomía vertical (GV) tiene una asociación directamente proporcional con la pérdida de peso al cuarto año. Finalmente, la publicación de Benoit et al. (262) resulta de gran interés ya que incluye casi 74.000 pacientes de la Bariatric Outcomes Longitudinal Database sometidos a BGA, BGYR y GV con resultados a 12 meses. Los autores aportan cuáles son los factores que influyen sobre la pérdida ponderal: el tipo de técnica supone una influencia del 44,8\% y el peso preoperatorio del 18,5\%, mientras que la edad, el sexo, la DM o la raza suponen una influencia mínima que no supera el 1\% para cada uno de ellos. Sin embargo, hay causas desconocidas que influyen en el 34,2\% del resultado ponderal de la CB.

Por todo lo expuesto, consideramos que la ausencia de significación estadística en nuestras variables analizadas para detectar los pacientes con peor resultado ponderal no resulta discordante, teniendo en cuenta la mencionada diversidad de criterios existente en la literatura. Ello incluye el tipo de diseño del estudio, el tiempo de seguimiento, las variables analizadas, la técnica bariátrica empleada e, incluso, la definición de fracaso ponderal, puesto que algunos artículos sólo presentan las diferencias brutas de PEPP entre los factores analizados sin clasificar a los pacientes con fracaso ponderal frente a los de buen resultado de pérdida de peso, como hemos realizado en nuestro estudio [Véase tabla 44]. 
De todos los trabajos mencionados, la edad es la única variable común con influencia sobre la cuestión que estamos desarrollando en este epígrafe. No obstante, en nuestra serie no existen diferencias significativas para este factor, lo cual coincide con el modelo de predicción cuidadosamente elaborado que propusieron Dallal et al. (263), el cual desestima la edad como factor independiente de los resultados ponderales, encontrando exclusivamente significación estadística para las variables sexo y peso preoperatorio.

Tras una exhaustiva revisión de la literatura, no se han encontrado trabajos publicados recientemente en los que se describan factores predictores de insuficiente pérdida de peso para la técnica de DBP de manera exclusiva. Asimismo, nuestro análisis no ha encontrado asociación estadística entre el resultado ponderal insuficiente y los factores incluidos en el OS-MRS, ni tampoco con la aparición de complicaciones graves en el periodo postquirúrgico inmediato. Nuevamente, la búsqueda de publicaciones recientes que relacionen el OS-MRS y las complicaciones postoperatorias con el fracaso de la CB ha resultado infructuosa, de ahí la novedad que aporta nuestro trabajo. 
Tabla 44. Factores que influyen en la pérdida ponderal insuficiente, comparando nuestros resultados con los publicados en la literatura [artículos de Courcoulas et al. (259), Still et al. (260), Parri et al. (261) y Benoit et al. (262)].

\begin{tabular}{|c|c|c|c|c|c|}
\hline \multicolumn{6}{|c|}{$\begin{array}{r}\text { COMPARACIÓN CON LA LITERATURA DE FACTORES QUE } \\
\text { INFLUYEN EN LOS RESULTADOS PONDERALES }\end{array}$} \\
\hline VARIABLE & $\begin{array}{c}\text { Resultados } \\
\text { propios }\end{array}$ & $\begin{array}{c}\text { Courcoulas } \\
\text { et al. }(259)\end{array}$ & $\begin{array}{c}\text { Still et al. } \\
(260)\end{array}$ & $\begin{array}{c}\text { Parri et } \\
\text { al. }(261)\end{array}$ & $\begin{array}{c}\text { Benoit et } \\
\text { al. }(262)\end{array}$ \\
\hline Sexo & n.s. & n.s. & n.s. & n.s. & Sí \\
\hline Edad & n.s. & Sí & Sí & Sí & Sí \\
\hline $\begin{array}{c}\text { IMC } \\
\text { preoperatorio }\end{array}$ & n.s. & n.s & Sí $(*)$ & Sí & Sí \\
\hline $\begin{array}{c}\text { Categoría del } \\
\text { OS-MRS }\end{array}$ & n.s. & n.n. & n.n. & n.n & n.n \\
\hline $\begin{array}{c}\text { Criterio de } \\
\text { glucemia para } \\
\text { SM }\end{array}$ & n.s. & Sí & Sí & n.n & n.n \\
\hline $\begin{array}{c}\text { Criterio de } \\
\text { TAG para SM }\end{array}$ & n.s. & n.n. & n.n. & n.n & n.n \\
\hline $\begin{array}{c}\text { Criterio de PA } \\
\text { para SM }\end{array}$ & n.s. & n.n. & n.n. & n.n & n.n \\
\hline
\end{tabular}

* : A partir del tercer año desaparece la significación estadística. 


\section{3.- RESULTADOS CLÍNICOS Y ANALÍTICOS}

\subsection{1.- MODIFICACIÓN DEL METABOLISMO DE LA GLUCOSA}

La CB obtiene una mejoría de la DM2 perfectamente avalada en recientes metaanálisis y revisiones sistemáticas (165-168,264), tal y como se expuso en la Introducción. En nuestros obesos, se ha observado un descenso estadísticamente significativo de la glucemia en ayunas, desde una cifra media de 106,9 miligramos (mg)/decilitro (dl) hasta $86,6 \mathrm{mg} / \mathrm{dl}$ en la última analítica de control, entre los 113 pacientes con seguimiento postbariátrico en nuestra Unidad de OM y CB. El meta-análisis de Ribaric et al. (165), sobre el efecto en el peso y la DM de la CB y el tratamiento médico-dietético, muestra una cifra preoperatoria de glucosa notablemente mayor que la nuestra $(150,3 \mathrm{mg} / \mathrm{dl})$ con reducción hasta un valor medio de 95,3 $\mathrm{mg} / \mathrm{dl}$. Ello supone que el descenso medio de glucemia es más patente que el nuestro según los datos analizados por estos autores, aunque la media de glucemia tras CB sea superior a la obtenida en nuestro estudio. Marinari et al. (265), del grupo de N. Scopinaro, presentaron en 2006 un análisis de la técnica de DBP en relación con la DM2. Sus hallazgos se asemejan a los aportados por Ribaric et al. (167): el descenso medio de la glucemia es mayor que en nuestro estudio, especialmente entre los obesos con diagnóstico de DM2, quienes presentaban cifras de glucosa de 178 y $86 \mathrm{mg} / \mathrm{dl}$, respectivamente en el momento basal y a los 5 años de seguimiento. En nuestro entorno, Sánchez et al. (248) no han presentado datos acerca de la modificación del metabolismo de glucosa en su estudio realizado en el Hospital de Burgos, mientras que Ballesteros-Pomar et al. (247) sí lo hacen, notificando una media de glucosa en ayunas preoperatoria de $93 \mathrm{mg} / \mathrm{dl}$ en la serie completa de sus obesos, aunque se eleva a $126 \mathrm{mg} / \mathrm{dl}$ tras seleccionar a los obesos diabéticos, cifra discretamente mayor que la de nuestros obesos diabéticos $(118,8 \mathrm{mg} / \mathrm{dl})$. Tras 5 años de seguimiento, el grupo del Hospital de 
León presenta glucemias de 85 y $87,5 \mathrm{mg} / \mathrm{dl}$, respectivamente en la serie completa y en los obesos diabéticos, cifra que resulta casi idéntica a la obtenida en nuestro estudio.

Hemos observado, además, que el nivel de significación se mantiene al analizar, separadamente, el descenso de las cifras de glucemia en los pacientes con y sin positividad del criterio de SM, según el consenso de Alberti et al. (96). Esto implica que el efecto beneficioso de la DBP se extiende además a los llamados obesos mórbidos metabólicamente sanos en lo referente al metabolismo glucídico. Sin embargo, este hallazgo no se mantiene al analizar los descensos de TAG y de PA en los pacientes intervenidos con sendos criterios negativos preoperatoriamente, como se verá en los dos siguientes epígrafes, donde se discutirá con profundidad, dada la controversia existente en los escasos trabajos publicados.

En relación al tratamiento farmacológico de la DM2, hemos observado en nuestra serie una reducción estadísticamente significativa en 1,25 fármacos antidiabéticos orales por paciente, así como un descenso también significativo de la proporción de individuos con pauta tanto de antidiabéticos orales (los 10 pacientes que los precisaban preoperatoriamente han logrado suspenderlos, correspondiendo al 100\%), como de insulina ( 3 pacientes de 5 han suspendido la administración, correspondiendo al 60\%, y los 2 restantes continúan administrándose esta hormona aunque han reducido las dosis que precisaban). De este modo, en nuestra serie de 113 obesos con seguimiento en el HURH obtenemos que 13 de 15 pacientes $(86,7 \%$ ) que precisaban tratamiento farmacológico de la DM2 antes de la CB han logrado suspenderlo y los dos restantes (13,3\%), reducirlo, con lo que obtenemos un 100\% de tasa de reducción o suspensión de la medicación. Siguiendo a Gloy et al. (165), la proporción de pacientes que logran reducir o suspender el tratamiento 
antidiabético y/o la insulina oscila entre el 54\% y el 100\%, según las técnicas bariátricas empleadas. Los datos concretos sobre medicación para la DM2 no aparecen reflejados en el clásico meta-análisis de Buchwald et al. (264) de 2004, ni tampoco en los más recientes de Ribaric et al. (167) o Chang et al. (166). Desafortunadamente, Marinari et al. (265) tampoco aportan datos del tratamiento antidiabético en el mencionado análisis sobre la DBP y la DM2. En la larga serie de CD publicada por Marceau et al. (266), el 96\% de sus obesos diabéticos sometidos a esta técnica lograron suspender los antidiabéticos orales a los 10 años, una cifra discretamente inferior a la nuestra. La tasa de suspensión del tratamiento insulínico fue del 81\% según los canadienses, lo que supone mejor dato que en nuestro estudio. No obstante, para ese mismo tiempo de seguimiento, ha de tenerse en cuenta que estos autores registraron un 13\% de recurrencia de la DM2 entre los pacientes insulindependientes antes de la CB, a diferencia de nuestros obesos, aunque la mediana de seguimiento es ostensiblemente menor. En nuestro entorno, el grupo del Hospital de Burgos no aporta datos objetivos sobre resolución de CAO tras DBP y otras técnicas realizadas en dicho centro en su artículo de 2012 (248), y Ballesteros-Pomar et al. (247) sí muestran detalles sobre los valores plasmáticos de glucosa, insulina y hemoglobina glicosilada (HbA1C) aunque no acerca de la medicación antidiabética en los obesos sometidos a DBP en el Hospital de León.

En relación al análisis de la HbA1C, nuestra cifra media en el postoperatorio es de 4,9\%, aunque debemos notificar como sesgo del estudio la elevada tasa de pérdidas de este dato $(69,8 \%)$ entre los 113 pacientes con seguimiento postbariátrico en nuestra Unidad de OM y CB. Desafortunadamente, tampoco disponemos de los valores basales de esta variable, por lo que no ha sido posible realizar un estudio inferencial sobre la reducción de su valor tras la DBP. Este dato hubiera resultado de interés para comparar nuestro 
resultado con los meta-análisis de Buchwald et al. (264) y de Gloy et al. (165) en los cuales sólo se informa de la reducción en el porcentaje de HbA1C, y no de la cifra concreta. La literatura muestra datos dispares en relación a la HbA1C a lo largo del seguimiento. El meta-análisis de Ribaric et al. (167) registró una cifra bruta postoperatoria de 6,1\%, sin diferenciar por técnicas ni tiempo de evolución. Ni Marinari et al. (265) ni Marceau et al. (266) presentaron en sus respectivos artículos esta variable, a diferencia de Ballesteros-

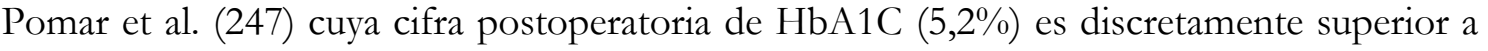
la nuestra, empleando la misma técnica quirúrgica y para el mismo tiempo de seguimiento que en nuestro estudio.

Por último, los resultados globales de mejoría de la DM2, para una mediana de seguimiento de 5 años tras la intervención, son favorables y estadísticamente significativos en lo referente a la reducción de la proporción tanto de los pacientes con diagnóstico de DM2 (46 pacientes de 48, correspondiente al 95,8\%), como de los pacientes con criterio positivo de glucemia para SM (54 individuos de 58, correspondiente al 98,3\%), empleando respectivamente la definición de la American Diabetes Association (97) y el consenso de Alberti et al. (96). Es necesario notificar que la prevalencia de esta CAO entre nuestros obesos candidatos a CB, es superior a la notificada por la mayoría de las series y meta-análisis, ya que el 46,6\% cumple criterios de DM según la American Diabetes Association (97), mientras que esta proporción asciende 10,3 puntos porcentuales si empleamos el criterio de glucemia para SM, el cual es más estricto que el anterior, tal y como se expuso en la Introducción. Las cifras presentadas por otros autores son: 41,1\% según el meta-análisis de de Buchwald et al. (264) (incluyendo pacientes con DM2 y con tolerancia a la glucosa alterada), 38,1\% según Marinari et al. (265), 38,8\% según Marceau et al. (266) o cifras tan bajas como el 17\% que presentaron Larrad et al. (257) en su artículo de 2007, revisando 343 obesos sometidos 
a una variante técnica de DBP. Solamente el artículo de Ballesteros-Pomar et al. (247) obtuvo una tasa similar a la nuestra: $56,6 \%$ sumando pacientes con DM2 y estado de prediabetes. Es necesario puntualizar que existe diferencia en los criterios empleados según los artículos, como se puede apreciar en esta breve revisión.

Idéntica situación ocurre al valorar las proporciones de enfermos con remisión o mejora de la DM2, tal y como se ha reseñado en el párrafo anterior. Para Marinari et al. (265) el criterio de remisión de DM2 fue una cifra postoperatoria de glucemia inferior a 110 $\mathrm{mg} / \mathrm{dl}$, lo cual implica demasiada laxitud en esta definición, a diferencia de la recomendada por la American Diabetes Association (190), aunque ha de tenerse en cuenta que esta recomendación se publicó tres años después. Según los datos de grupo italiano (265), y empleando el criterio anteriormente descrito, el 100\% de los obesos diabéticos alcanzan remisión de esta $\mathrm{CAO}$ en el primer año de seguimiento, manteniéndose hasta el quinto. Cabe mencionar que, salvo el grupo del autor que describió la técnica de DBP, ninguna otra publicación obtiene un 100\% de remisión. El meta-análisis de Buchwald et al. (264) muestra una tasa de resolución de la DM2 del 98,1\% según los trabajos revisados que empleaban las técnicas mixtas predominantemente malabsortivas. Nuestros datos son muy próximos a los del grupo de N. Scopinaro (265), si tenemos en cuenta las cifras expuestas en el párrafo anterior, e idénticos a los del citado meta-análisis. No obstante, si empleamos el consenso actual de la American Diabetes Association (190), nuestro resultado es moderadamente inferior, con una tasa de remisión total del 87,5\% y de remisión parcial del 6,3\%. Es necesario volver a puntualizar el sesgo existente para esta variable, condicionado por las pérdidas registradas en la variable $\mathrm{HbA1C}$ en la última analítica tras $\mathrm{CB}$, la cual es uno de los parámetros incluidos en la definición de la citada sociedad científica. El metaanálisis más reciente, publicado en Obesity Surgery por Yu et al. (267), muestra una tasa de 
remisión total de DM2 del 89,2\% globalmente, aunque no especifica si se han seguido los criterios de la American Diabetes Association (190). Por su parte, el trabajo de Miras et al. (268) sí que lo hace, obteniendo unas tasas de remisión completa y parcial del 36\% y del 67\%, respectivamente, para el grupo de obesos sometidos a BGYR con dos años de seguimiento. Nuestros resultados son, por tanto, notablemente mejores que los de estos autores porque la DBP es superior al BGYR para resolver la DM2 (264,267,269), aunque no alcanzan las cifras registradas por Marceau et al. (266) con una tasa de remisión total del 93,4\% en sus obesos tratados con CD [Véase tabla 45]. El grupo del Hospital de León no incluyó las tasas de remisión de la DM2 en su reciente artículo (247).

Tabla 45. Datos de modificación del metabolismo de la glucosa empleando los criterios de la American Diabetes Association (190), comparando nuestros resultados con los publicados en la literatura [artículos de Miras et al. (268) y Marceau et al. (266)]. [n.n.: no notificado].

\begin{tabular}{|c|c|c|c|}
\hline \multicolumn{4}{|c|}{$\begin{array}{l}\text { COMPARACIÓN CON LA LITERATURA DE LA } \\
\text { REMISIÓN TOTAL Y PARCIAL DE LA DM2 }\end{array}$} \\
\hline CRITERIO & $\begin{array}{c}\text { Resultados } \\
\text { propios }\end{array}$ & $\begin{array}{c}\text { Miras et al. } \\
(268)^{\#}\end{array}$ & $\begin{array}{c}\text { Marceau et } \\
\text { al. }(266)^{+}\end{array}$ \\
\hline Remisión total & $87,5 \%$ & $36 \%$ & $93,4 \%$ \\
\hline Remisión parcial & $6,3 \%$ & $67 \%$ & n.n. \\
\hline
\end{tabular}

\subsection{2.- MODIFICACIÓN DEL METABOLISMO LIPÍDICO}

La proporción de obesos sometidos a CB que obtienen mejoría de la dislipemia es menor que para la DM2, tal y como se expuso en la Introducción, a la luz de los datos publicados por diversos meta-análisis y revisiones sistemáticas, aunque la técnicas mixtas como la DBP alcanzan los mejores resultados (166,264,269). El más reciente meta-análisis 
de Ricci et al. (270) notificó que tras la CB existe un descenso del riesgo del 30\% para la DM2 por cada $5 \mathrm{Kg} / \mathrm{m}^{2}$ de pérdida de IMC, mientras que para la dislipemia es del $25 \%$. En relación a la técnica quirúrgica que nos ocupa, cabe decir que el mecanismo de mejora de la dislipemia, según el propio N. Scopinaro, se fundamenta "en la interrupción calibrada de la recirculación enterohepática de los ácidos biliares, provocando un aumento de la neosíntesis hepática del colesterol y, por otro lado, en una fuerte reducción de la absorción intestinal de colesterol endógeno, debido a la malabsorción de los lípidos” (271).

En primer lugar, nuestro estudio muestra unos valores basales de colesterol total casi idénticos a los registrados por N. Scopinaro, no así para los triacilgliceroles/triglicéridos (TAG) que en nuestra serie son moderadamente inferiores al grupo italiano $(138,3 \mathrm{mg} / \mathrm{dl}$ frente a $161 \mathrm{mg} / \mathrm{dl}$ ) (271). Tras el análisis de las cifras postoperatorias, hemos encontrado un descenso estadísticamente significativo en ambos parámetros bioquímicos. En nuestra serie, la media de reducción del colesterol total es muy próxima a los datos publicados en el meta-análisis de 2004 de Buchwald et al. (264) (61,7 $\mathrm{mg} / \mathrm{dl}$ y $69,8 \mathrm{mg} / \mathrm{dl}$, respectivamente). Sin embargo, nuestro descenso medio de TAG es llamativamente menor que la de estos autores $(23,6 \mathrm{mg} / \mathrm{dl}$ frente a 70,8 mg/dl). De igual modo, la cifra mediana postbariátrica de TAG en nuestros obesos es mayor que la presentada por N. Scopinaro a 5 años de seguimiento $(98 \mathrm{mg} / \mathrm{dl}$ frente a $80 \mathrm{mg} / \mathrm{dl}$ ) (271). No obstante, estas discrepancias se anulan, e incluso resultan más favorable en nuestro análisis, tras seleccionar a aquellos obesos con criterio positivo de TAG para SM antes de la intervención, cuyo descenso medio es de $78,5 \mathrm{mg} / \mathrm{dl}$. Por el contrario, nuestros enfermos sin hipertrigliceridemia en el momento basal no se benefician tras la DBP de reducir las cifras de este lípido plasmático, con un resultado de mínimo ascenso que no ha sido significativo. Este efecto contrasta con el observado para la DM2, ya que aquellos obesos 
metabólicamente sanos para esta CAO sí alcanzan un descenso significativo de las cifras de glucemia. En el siguiente epígrafe se desarrollará conjuntamente la controversia actual que existe a este respecto, tras presentar los resultados de modificación de la PA para el grupo de obesos no hipertensos preoperatoriamente y sometidos a DBP en nuestra Unidad de $\mathrm{OM}$ y $\mathrm{CB}$.

En relación a la hipertrigliceridemia, entendida en este trabajo como criterio positivo de TAG para SM aplicando el consenso de Alberti et al. (96), se observa que nuestra prevalencia preoperatoria de esta $\mathrm{CAO}(31$ pacientes, 33\%) es intermedia a la publicada por otros grupos: 24,2\% según Marceau et al. (266) y 41,2\% según BallesterosPomar et al. (247). Ello es debido a la diferencia de criterios en su definición, dado que se considera criterio positivo una cifra de $\mathrm{TAG} \geq 150 \mathrm{mg} / \mathrm{dl}$, según el consenso de SM (96), mientras que los canadienses lo consideran con valor $\geq 200 \mathrm{mg} / \mathrm{dl}$, y en el caso del grupo leonés, no notifican el criterio empleado. En nuestra serie de pacientes con seguimiento en el HURH, hemos obtenido globalmente que 30 obesos $(28,6 \%)$ presentan criterio positivo de TAG para SM en el postoperatorio, de los cuales 5 son los que precisan tratamiento hipolipemiante de novo, son 12 los pacientes con criterio positivo en el momento basal y que no han negativizado tras la DBP y los 13 restantes son enfermos en los que se ha positivizado el criterio y cuya explicación se discutirá en este mismo párrafo. Con todo ello, la tasa de mejora de hipertrigliceridemia, es de 19 obesos sobre $31(61,3 \%)$ en quienes se ha negativizado el criterio de TAG para SM tras la DBP. La cifra es discretamente inferior a los datos publicados por Chang et al. (166), quienes mostraron, para el grupo de técnicas mixtas (denominado en dicho trabajo gastric bypass), una remisión de la dislipemia en el $63,22 \%$ y $80,16 \%$ de los pacientes, respectivamente para los estudios observacionales y los ensayos clínicos revisados. Este análisis presenta una fuerte asociación estadística aunque 
no significativa, justificada probablemente por el hallazgo de los 13 enfermos que han positivizado el criterio de TAG para SM durante el seguimiento postbariátrico y por la tasa de pérdidas registradas en este análisis comparativo (16,8\%). No obstante, se ha de tener en cuenta que el ascenso medio de TAG encontrado para el grupo de pacientes con criterio negativo antes de la $\mathrm{CB}$ es mínimo $(3,5 \mathrm{mg} / \mathrm{dl})$ y no significativo. Además, el consenso de Alberti et al. (96) es mucho más estricto que el concepto genérico de dislipemia empleado habitualmente en los trabajos de CB (colesterol total > $200 \mathrm{mg} / \mathrm{dl}$ ), motivo por el cual hemos desestimado emplearlo en nuestro trabajo para realizar el análisis comparativo de la mejora del metabolismo lipídico. Aplicando este criterio tan laxo, el propio N. Scopinaro en el ya citado trabajo de revisión sobre su propia técnica publicado en 2012 (271), sostiene que el 99\% de sus pacientes alcanzan resolución de la dislipemia, e idéntico hallazgo muestra el artículo de Buchwald et al. (264) en el subgrupo de obesos del meta-análisis que fueron tratados con DBP.

Otra limitación dentro de este apartado es la ausencia de datos acerca de la medicación hipolipemiante antes de la DBP. Ello implica que la proporción de obesos con criterio positivo de TAG para SM preoperatoriamente puede haber sido infraestimada. Teniendo en cuenta que la proporción de enfermos con criterio positivo en el seguimiento postbariátrico no presenta sesgo alguno, puesto que sí disponemos de la variable "tratamiento hipolipemiante en la última revisión de Endocrinología", la tasa de mejora de la hipertrigliceridemia también habría sufrido, consecuentemente, una infraestimación. En relación a esta variable, cabe decir que la proporción de enfermos que la precisan es del 4,7\%, correspondiente a los 5 enfermos mencionados en el párrafo anterior. En el estudio de CD recientemente publicado por Marceau et al. (266), la proporción de enfermos que siguen precisando medicación supera en 15 puntos porcentuales nuestra cifra, mientras que 
los grupos de CB de nuestro entorno próximo (hospitales de Burgos y León) no aportan información sobre esta variable $(247,248)$.

Como ya se ha expuesto, a fin de emplear homogéneamente los criterios del consenso de SM de 2009 (96), no hemos realizado los cálculos para la proporción de enfermos que mejoran la hipercolesterolemia, puesto que el colesterol total no se incluye como criterio según el mencionado artículo. Desafortunadamente, no disponemos en este estudio de los datos preoperatorios de las fracciones del colesterol (bigh-density lipoprotein [HDL] y low-density lipoproteina [LDL]), lo cual supone una carencia notable de nuestro trabajo, ya que ello ha imposibilitado calcular la proporción de pacientes con criterio positivo de HDL para SM antes de la CB, siguiendo el consenso de Alberti et al. (96). La cifra media de HDL de la última revisión del postoperatorio es de $52,5 \mathrm{mg} / \mathrm{dl}$, lo que se corresponde con una proporción del 41\% de los pacientes con criterio positivo de HDL para SM, es decir con cifras bajas de esta fracción del colesterol. Este hallazgo no resulta discordante con lo publicado en la literatura científica, dado que la $\mathrm{CB}$ apenas ofrece ventajas en términos de incremento del HDL, tal y como aparece reflejado en el metaanálisis de Buchwald et al. (264). Estos autores presentaron unas cifras medias de ascenso de $\tan$ solo $2,7 \mathrm{mg} / \mathrm{dl}$ en los trabajos analizados sobre DBP, de forma exclusiva, y un descenso de $0,4 \mathrm{mg} / \mathrm{dl}$, aplicando medias ponderadas entre todos los individuos incluidos en la revisión, indiferentemente de la técnica quirúrgica (ambos resultados no significativos). En este sentido, los enfermos de la serie italiana de N. Scopinaro, partían de valores preoperatorios de $46 \mathrm{mg} / \mathrm{dl}$, ascendiendo a $51 \mathrm{mg} / \mathrm{dl}$ tras 10 años de la DBP (271). Se observa que nuestra cifra media de HDL en el seguimiento $(52,5 \mathrm{mg} / \mathrm{dl})$ es similar a la publicada por el autor que describió la técnica, y también a la de Ballesteros-Pomar et al. (247), 53,3 mg/dl al quinto año, aunque en el grupo del Hospital de León asciende a 58,1 
$\mathrm{mg} / \mathrm{dl}$ al décimo año postoperatorio. El valor de LDL postbariátrico obtenido en nuestra serie es de 72,3 mg/dl, aunque desafortunadamente, ni en los diversos artículos del grupo de N. Scopinaro $(237,238,241,271)$, ni en los trabajos de Marceau et al. (266) ni de Ballesteros-Pomar et al. (247), se notifica de forma concreta esta variable. Es comprensible, que la mejora de la hipercolesterolemia acontece por el descenso del LDL, dado que el HDL sufre pequeñas modificaciones tras la DBP, tal y como informan Scopinaro et al. (238). El meta-análisis de Buchwald et al. (264) notifica un descenso de 117,7 mg/ dl tras la intervención para el grupo de pacientes sometidos a DBP, pero no aporta la cifra concreta de esta fracción del colesterol en el seguimiento postbariátrico, por lo que no es posible compararlo con nuestro trabajo.

Por todo lo expuesto, y teniendo en cuenta las limitaciones y sesgos encontrados en relación a las variables discutidas en este epígrafe, así como el estricto criterio de mejora empleando el consenso de SM de 2009 (96), consideramos que los resultados de nuestro trabajo en relación con el metabolismo lipídico, son satisfactorios aunque discretamente inferiores a los esperables para la técnica de DBP.

\subsection{3.- MODIFICACIÓN DE LA PRESIÓN ARTERIAL}

Como ya se mencionó en la Introducción, la hipertensión arterial (HTA) es susceptible de resolverse o mejorar tras $\mathrm{CB}$, aunque las tasas son menores que para otras CAO como la DM2 o el síndrome de apnea obstructiva del sueño (SAOS), con cifras globales del 70,8-86,1\%, según el clásico meta-análisis de Buchwald et al. (264) publicado en 2004. Diez años más tarde, el meta-análisis de Chang et al. (166) muestra una tasa de remisión del 75\% para todas las técnicas revisadas conjuntamente y el meta-análisis de Ricci et al. (270), mencionado en el epígrafe anterior y publicado en 2015, muestra una reducción 
del riesgo del $18 \%$ para esta CAO por cada $5 \mathrm{Kg} / \mathrm{m}^{2}$ de pérdida de IMC, lo que la sitúa por detrás de la DM2 y la dislipemia en lo que respecta a la tasa de mejoría postbariátrica.

Nuestras cifras medias de PA sistólica y diastólica basales son 143,4 y 87,7 milímetros de mercurio $(\mathrm{mmHg})$, respectivamente. En la última revisión tras la DBP, se han registrado cifras medias de PA sistólica y diastólica de 127,2 y 75,2 mmHg, respectivamente. Estos datos son similares a los publicados por otros autores como Ballesteros-Pomar et al. (247) o Marceau et al. (266) [Véase tabla 46]. Así pues, hemos obtenido un descenso estadísticamente significativo de la PA sistólica y diastólica, y dicha significación se mantiene en el grupo de pacientes con criterio positivo de PA para SM según el consenso de Alberti et al. (96), mientras que se pierde en los no hipertensos. De ello se interpreta que las cifras de PA elevadas preoperatoriamente en el contexto de la HTA secundaria a OM son susceptibles de descender en nuestros pacientes tras la DBP, tal y como avala la literatura $(166,264)$, mientras que esta técnica no obtiene efectos sobre aquellos obesos sin criterio positivo de PA para SM antes de la CB. En relación a estos pacientes obesos mórbidos pero sanos desde el punto de vista cardiovascular y metabólico (concepto de obeso metabólicamente sano descrito en la Introducción), existe controversia en la literatura. Los trabajos publicados más recientemente son series cortas y restrospectivas, aunque apoyan un efecto beneficioso de la $\mathrm{CB}$ en este subgrupo de obesos (272-274), tal y como se ha objetivado en nuestro estudio para los pacientes intervenidos no diabéticos, a diferencia de los no dislipémicos y los no hipertensos. Sin embargo, estudios previos que analizaron la pérdida de peso mediante tratamiento médico-dietético, concluyeron que la mejora de las cifras ponderales no genera efectos entre los obesos metabólicamente sanos $(275,276)$. Es evidente, tal y como se ha expuesto en los epígrafes anteriores, que la DM es la CAO que más tasa de remisión alcanza tras la DBP en nuestra 
serie, con datos menos favorables para la HTA y la dislipemia. Éste puede ser el motivo por el cual, en una serie con un tamaño muestral pequeño, el beneficio de la CB entre los obesos mórbidos metabólicamente sanos sólo es ostensible, precisamente, para la CAO que mayor tasa de resolución obtiene.

La medicación antihipertensiva también se reduce significativamente en casi un fármaco tras la DBP. Nuestra tasa de descenso y suspensión de medicación es del 63,6\% (28 pacientes de 44 que precisaban estos fármacos antes de la CB). Según notificaron Gloy et al. (165) en su meta-análisis de 2013, la proporción de pacientes que logran reducir o suspender estos fármacos es del 59-70\%, aunque varía según los estudios revisados y según las técnicas barátricas empleadas. En relación a los trabajos ya conocidos de DBP y CD, cabe decir que el artículo del grupo del Hospital de León no aporta datos sobre fármacos antihipertensivos (247), mientras que Marceau et al. (266) sí notificaron que el 31\% de sus obesos sometidos a CD redujo la medicación antihipertensiva y que el 64\% la suspendió, aunque no notifica el criterio de HTA empleado. Se aprecia, por tanto, que nuestros resultados se ajustan a los publicados en el citado meta-análisis, aunque son notablemente inferiores a los presentados en series largas como la Marceau et al. (266). Sin embargo, es necesario tener en cuenta las características basales de nuestra muestra en relación a esta CAO, y que se especifican a continuación:

- Hemos registrado una elevada tasa de pacientes diagnosticados como hipertensos, empleando la definición del SM de Alberti et al. (96): el 90,7\% presentan criterio positivo de PA. Ello contrasta con la mayoría de las series, en las que la prevalencia de obesos intervenidos con diagnóstico preoperatorio de HTA es manifiestamente inferior a la nuestra $(35,4 \%)$ 
según el meta-análisis de Buchwald et al. (264) y 47\% según el de Chang et al. (166).

- Nuestras cifras medias de PA basal son muy similares a las presentadas por otros autores, sin embargo estos valores son así a expensas de una alta tasa de prescripción de fármacos antihipertensivos (de nuestros 113 obesos, $38,4 \%$ precisaban medicación en el momento preoperatorio), incluso con hasta 5 fármacos de distinto grupo en algunos enfermos.

Finalmente, observamos que el descenso de la proporción de pacientes con criterio positivo de PA es significativo y supone una tasa de resolución del $64,8 \%$, aunque se notifica un $2,1 \%$ de pacientes no hipertensos preoperatoriamente que positivizaron el criterio. Este resultado es inferior al esperado según la literatura para las técnicas bariátricas mixtas, como el meta-análisis de Chang et al. (166), que aporta una cifra del 78,13\% para este grupo de procedimientos en base a los estudios observacionales revisados. Ello se justifica en base al criterio empleado para considerar resolución de la HTA. En nuestro estudio hemos utilizado la definición del último consenso de SM (96), la cual es más estricta que otras disponibles como la de la SEEDO (170) en lo que respecta a las cifras de PA. De igual modo, no se ha considerado el concepto de mejoría, ya que no está incluido en la mencionada definición del SM publicada por Alberti et al. (96). Así pues, y teniendo en cuenta las características basales de nuestra muestra en relación a la HTA, con prevalencia muy alta y elevada proporción de pacientes con tratamiento antihipertensivo, consideramos que la mencionada tasa de resolución de HTA es satisfactoria, aplicando los estrictos criterios empleados en nuestro análisis. 
Tabla 46. Datos de modificación de PA para las variables PA sistólica y diastólica en el momento basal y en la última revisión tras $\mathrm{CB}$ así como la proporción de pacientes con criterio de HTA, comparando nuestros resultados con los publicados en la literatura [artículos de Ballesteros-Pomar et al. (247) y Marceau et al. (266)].

\begin{tabular}{|c|c|c|c|c|}
\hline \multicolumn{5}{|c|}{$\begin{array}{c}\text { COMPARACIÓN CON LA LITERATURA DE LAS VARIABLES DE } \\
\text { PRESIÓN ARTERIAL }\end{array}$} \\
\hline \multicolumn{2}{|c|}{ VARIABLE } & $\begin{array}{l}\text { Resultados } \\
\text { propios }\end{array}$ & $\begin{array}{l}\text { Ballesteros-Pomar } \\
\text { et al. (247) }\end{array}$ & $\begin{array}{l}\text { Marceau et al. } \\
\text { (266) }\end{array}$ \\
\hline \multirow{2}{*}{$\begin{array}{c}\text { PA } \\
\text { sistólica }\end{array}$} & Basal & $143,7 \mathrm{mmHg}$ & $143 \mathrm{mmHg}$ & $138,9 \mathrm{mmHg}$ \\
\hline & Tras DBP* & $127,2 \mathrm{mmHg}$ & $126,4 \mathrm{mmHg}$ & $130,7 \mathrm{mmHg}$ \\
\hline \multirow{2}{*}{$\begin{array}{c}\text { PA } \\
\text { diastólica }\end{array}$} & Basal & $87,7 \mathrm{mmHg}$ & $90,8 \mathrm{mmHg}$ & $84,7 \mathrm{mmHg}$ \\
\hline & Tras DBP* & 75,2 mmHg & $78,6 \mathrm{mmHg}$ & 77,1 mmHg \\
\hline \multirow{2}{*}{$\begin{array}{l}\text { Proporción } \\
\text { de HTA }\end{array}$} & Basal & $90,7 \%$ & $60,8 \%$ & $68 \%$ \\
\hline & Tras DBP* & $57,6 \%$ & n.n. & n.n. \\
\hline
\end{tabular}

*: Se muestran los resultados para una mediana de seguimiento de 5 años, salvo para los publicados por Marceau et al. que son a 10 años.

\subsection{4.- MODIFICACIÓN DE LOS PARÁMETROS DE DESNUTRICIÓN}

La técnica de Scopinaro, al igual que el $\mathrm{CD}$, son técnicas mixtas predominantemente malabsortivas y por este motivo, existe un riesgo mayor que con otros procedimientos de que los pacientes desarrollen alteraciones nutricionales durante el seguimiento postbariátrico $(165,177,222-226)$, lo que obliga a una suplementación oral de por vida, siguiendo las recomendaciones avaladas por distintas sociedades científicas $(172,175)$.

Para analizar el grado de complicaciones nutricionales en nuestro estudio, se han seleccionado como variables la hemoglobina y la albúmina. El primero de estos parámetros analíticos es representativo de la anemia y de la desnutrición proteica, puesto que la ferropenia es el estado carencial más frecuente tras la CB en general, según el meta-análisis 
de Gloy et al. (165), tal y como ya se expuso en la Introducción. La albúmina también es un marcador de desnutrición proteica aunque, según algunos artículos de revisión, no discrimina de forma fina el estado nutricional (223). Sin embargo, la cuantificación de esta proteína plasmática está ampliamente extendida y es empleada por numerosos grupos de CB con este fin. Así pues, Larrad et al. (257) notificaron un $0,29 \%$ de tasa de hipoproteinemia, definida como una albuminemia $<3,5$ gramos $(\mathrm{g}) / \mathrm{dl}$, y una tasa de anemia del 13\%, definida como una cifra de hemoglobina $<12 \mathrm{~g} / \mathrm{dl}$. Dado que estas definiciones pueden resultar arbitrarias dependiendo de los valores de corte de cada laboratorio, hemos preferido expresar nuestros resultados aportando el valor real de ambos parámetros analíticos, tal y como se ha definido en el capítulo de "Pacientes y Métodos".

Nuestros obesos parten de una cifra de hemoglobina de 13,9 $\mathrm{g} / \mathrm{dl}$, existiendo un descenso estadísticamente significativo, aunque el valor medio en el seguimiento postbariátrico es de $12,7 \mathrm{~g} / \mathrm{dl}$, cifra que supera el límite inferior propuesto por nuestro laboratorio. El artículo de Scopinaro et al. (238) no hace mención de las cifras de hemoglobina, aunque informa que su tasa de anemia es del 5\%, aplicando correctamente la suplementación con hierro. Marceau et al. (266), en su reciente trabajo sobre resultados a largo plazo del CD, sí aportan las cifras de hemoglobina, siendo ésta de 13,7 g/dl antes de la intervención, un valor similar al de nuestra serie. La cifra desciende mínimamente para una media de seguimiento de 7 años (13,2 g/dl), dato más favorable que el nuestro, aunque los autores del estudio no indican si existe significación estadística para esta diferencia. En nuestro entorno próximo, Sánchez et al. (248) no incluyeron datos de anemia postbariátrica en su análisis, a diferencia del artículo del grupo del Hospital de León, en donde sí consta este dato, con cifras pre y postoperatorias casi idénticas a las nuestras $(13,9$ y $12,1 \mathrm{~g} / \mathrm{dl}$, respectivamente). Estos autores definieron la anemia con cifras de hemoglobina $<10 \mathrm{~g} / \mathrm{dl}$, 
a diferencia de Larrad et al. (257), obteniendo una prevalencia preoperatoria de 1,1\% y de $8,9 \%$ a los 5 años de seguimiento. Por todo lo expuesto, consideramos que el riesgo de anemia tras DBP tiene una baja frecuencia globalmente, aunque el descenso de nuestra cifra de hemoglobina haya obtenido significación estadística [Véase tabla 47].

En relación a la desnutrición proteica, N. Scopinaro sostiene que es el estado carencial más frecuente tras DBP, dado que las necesidades de ingesta proteica diaria alcanzan los $90 \mathrm{~g}$, merced a las siguientes causas: inicialmente el componente restrictivo, seguido más adelante del efecto malabsortivo que minimiza la absorción total de aminoácidos, asociando, además, un requerimiento proteico incrementado y un exceso de pérdida de nitrógeno endógeno. Por este motivo se modificó la técnica, pasando a realizar la DBP "ad hoc stomach / ad hoc alimentary limb", lo cual supuso un descenso de este estado carencial desde el 30\% al 1\% (237). Aún con esta modificación del procedimiento, el requerimiento de 90 gr de proteínas al día sigue vigente y está avalado por la guías europeas de CB (175). A pesar de la exhaustiva explicación fisiopatológica, el autor de la técnica no indica valores de albúmina en ninguno de sus trabajos clásicos $(237,238,241,265)$. Nuestro resultados muestran un mínimo descenso $(0,1 \mathrm{~g} / \mathrm{dl})$ no significativo de la albuminemia, partiendo de una media preoperatoria de 4,1 g/dl. Siguiendo nuevamente a Marceau et al. (266), el descenso de la albuminemia tras CD también es mínimo a los 7 años de media de seguimiento, siendo las cifras del grupo canadiense idénticas a las nuestras. En relación a otros grupos de $\mathrm{CB}$ de la Comunidad Autónoma de Castilla y León, cabe decir que Ballesteros-Pomar et al. (247) mostraron también valores de albúmina muy similares a los de nuestra serie (4,3 y 4,2 g/dl, respectivamente, a los 5 años de seguimiento), mientras que el grupo de Burgos no presenta datos sobre el estado nutricional en su artículo, si bien notifica dos casos de desnutrición proteica severa que obligó a reintervenir y alargar el asa 
común (248). Así pues, observamos que esta complicación apenas reviste importancia en el seguimiento postbariátrico de la DBP, a condición de garantizar una adecuada ingesta y suplementación oral, de acuerdo a las guías vigentes (172,175) [Véase tabla 47].

Tabla 47. Datos de estado nutricional basales y postbariátricos para las variables hemoglobina y albúmina, comparando nuestros resultados con los publicados en la literatura [artículos de Ballesteros-Pomar et al. (247) y Marceau et al. (266)].

\begin{tabular}{|}
\hline \multicolumn{4}{|c|}{$\begin{array}{c}\text { COMPARACIÓN CON LA LITERATURA DE LAS MEDIAS DE } \\
\text { LOS PARÁMETROS DE EVALUACIÓN NUTRICIONAL }\end{array}$} \\
\hline \multicolumn{2}{|c|}{ VARIABLE } & $\begin{array}{c}\text { Resultados } \\
\text { propios }\end{array}$ & $\begin{array}{c}\text { Ballesteros-Pomar } \\
\text { et al. }(247)\end{array}$ & $\begin{array}{c}\text { Marceau et } \\
\text { al. }(266)\end{array}$ \\
\hline \multirow{2}{*}{ Hemoglobina } & Basal & $13,9 \mathrm{~g} / \mathrm{dl}$ & $13,9 \mathrm{~g} / \mathrm{dl}$ & $13,7 \mathrm{~g} / \mathrm{dl}$ \\
\cline { 2 - 5 } & Tras DBP* & $12,7 \mathrm{~g} / \mathrm{dl}$ & $12,1 \mathrm{~g} / \mathrm{dl}$ & $13,2 \mathrm{~g} / \mathrm{dl}$ \\
\hline \multirow{2}{*}{ Albúmina } & Basal & $4,1 \mathrm{~g} / \mathrm{dl}$ & $4,3 \mathrm{~g} / \mathrm{dl}$ & $4,1 \mathrm{~g} / \mathrm{dl}$ \\
\cline { 2 - 5 } & Tras DBP* & $4,0 \mathrm{~g} / \mathrm{dl}$ & $4,2 \mathrm{~g} / \mathrm{dl}$ & $4,0 \mathrm{~g} / \mathrm{dl}$ \\
\hline
\end{tabular}

*: Se muestran los resultados para una mediana de seguimiento de 5 años, salvo para los publicados por Marceau et al. que son a 7 años.

\subsection{5.- MODIFICACIÓN DEL METABOLISMO DEL CALCIO}

La alteración del metabolismo del calcio y la vitamina $\mathrm{D}$ es frecuente en los pacientes obesos y más aún en aquellos sometidos a $\mathrm{CB}$, como resultado de una pléyade de mecanismos etiopatogénicos, tal y como se expuso en la Introducción $(177,221-225)$. Es de esperar, por tanto, un estado de hipovitaminosis D asociado a cierto grado de hiperparatiroidismo secundario cuyo objetivo es mantener la calcemia en rangos aceptables. Las más recientes guías norteamericanas definen déficit de vitamina D $(25-\mathrm{OH}$ colecalciferol) para valores menores de 20 nanogramos (ng)/mililitro (ml) (225), aunque estas cifras pueden variar en función de los valores de referencia de cada laboratorio. Da fe de ello, una vez más, el estudio de Larrad et al. (257), quienes definen hipovitaminosis D con una cifra $<15 \mathrm{ng} / \mathrm{ml}$, no obstante en el artículo no se menciona el valor de corte 
empleado para la parathormona (PTH). En esta publicación, se muestra una prevalencia preoperatoria de hipovitaminosis D y de hiperparatiroidismo de 30 y $28 \%$, respectivamente, que asciende a 43 y 45\% en el seguimiento postbariátrico. En relación a la PTH, la cifra límite parece ser más homogénea, estando establecido el corte para clasificar el hiperparatiroidismo en 72 picogramos (pg)/ml (221,277). Por todo ello, y al igual que en el epígrafe anterior, hemos decidido presentar los valores analíticos de estos tres parámetros y no la proporción de pacientes con déficits empleando criterios que pudieran ser arbitrarios.

Tras comparar las cifras preoperatorias y del seguimiento postbariátrico para el calcio total, obtenemos un discreto descenso $(0,5 \mathrm{mg} / \mathrm{dl})$ con significación estadística, desde 9,4 a 8,9 mg/dl. Scopinaro et al. (278) analizaron la absorción instestinal de nutrientes tras DBP, obteniendo que el calcio absorbido corresponde al $28 \%$ de la cantidad ingerida pudiendo incrementar la ingesta y con ello aumentar la cifra real absorbida, a diferencia de los nutrientes de sustrato energético (incluidos los lípidos) que mostraban un techo de absorción. Por ello, con una adecuada suplementación según las guías vigentes (175) y en el contexto frecuente de hiperparatiroidismo secundario de los obesos tras CB, la aparición de hipocalcemia es rara tras DBP (238). Marceau et al. (266) encontraron un descenso mínimo aunque significativo $(0,06 \mathrm{~g} / \mathrm{l})$, sin repercusión clínica. En nuestro entorno próximo, cabe decir que el trabajo del grupo de Burgos no presenta ningún dato sobre el metabolismo del calcio (248), mientras que el trabajo con los resultados de DBP en el Hospital de León (247) presenta unas cifras casi idénticas a las nuestras [Véase tabla 48].

Tras el análisis de resultados de la vitamina $\mathrm{D}$, obtenemos una cifra media basal de 28,2 microgramos ( $\mu \mathrm{g}$ )/ litro (l) (unidad equivalente a $\mathrm{ng} / \mathrm{ml}$ ) y una mediana de 18,0 $\mu \mathrm{g} / \mathrm{l}$ 
en la última analítica de control del seguimiento postbariátrico. Sin embargo, el análisis inferencial de la diferencia de medias no alcanza la significación estadística, hecho que resulta llamativo y refleja la gran dispersión de los valores de $25-\mathrm{OH}$ vitamina $\mathrm{D}$ entre los 113 obesos de la serie con seguimiento en el HURH, a tenor de la desviación estándar y el rango intercuartílico (RIQ) obtenido para estas medidas de tendencia central. Es necesario tener en cuenta la alta frecuencia de hipovitaminosis D de la que parten nuestros obesos. Según los datos publicados por De Luis et al. (221), con obesas candidatas a CB evaluadas en nuestra Unidad de OM, un $71,3 \%$ presentaban deficiencia moderada de vitamina D $(<30 \mathrm{ng} / \mathrm{ml}$ ) y el 26,1\% deficiencia severa de vitamina D (<15 ng/ml). Revisando de nuevo los datos publicados, observamos en primer lugar que Marceau et al. (266) registraron cifras medias basales y a 7 años de media de seguimiento de 57 nanomoles $/ \mathrm{ml}$ (equivalente a 22,8 $\mu \mathrm{g} / \mathrm{l}$ ) y 81,2 nanomoles $/ \mathrm{ml}$ (equivalente a 32,5 $\mu \mathrm{g} / \mathrm{l}$ ), respectivamente. Este ascenso y mejoría de los valores de vitamina $\mathrm{D}$ tras la $\mathrm{CB}$ no es comparable con nuestro estudio debido a la diferencia de técnicas empleadas. Como ya se puntualizó en la Introducción, el CD parece obtener un mejor perfil para los déficits de micronutrientes que la DBP, teniendo en cuenta que la longitud de asa común es mayor tal y como describieron los autores de la técnica $(208,209)$. Citando de nuevo a Ballesteros-Pomar et al. (247), quienes presentaron recientemente resultados de DBP con seguimiento a 10 años, sus cifras de 25-OH vitamina $\mathrm{D}$ son similares a las nuestras inmediatamente antes de la intervención (30,1 $\mathrm{ng} / \mathrm{ml})$ pero más favorables en el seguimiento a 5 años $(28,7 \mathrm{ng} / \mathrm{ml})$, con una prevalencia de hipovitaminosis D del 52,4\%, definida con un valor $<20 \mathrm{ng} / \mathrm{ml}$. De este modo, se interpreta que en nuestra serie el déficit de esta vitamina liposoluble es notablemente mayor, a pesar de la adecuada suplementación que se indica en todos los obesos intervenidos, pudiendo estar justificado por las longitudes de asa común. El grupo de León tiene márgenes mucho más laxos para la longitud del mencionado asa, tramo 
intestinal en donde acontece la absorción de la vitamina D tras la DBP, que oscila entre 50 y 100 centímetros $(\mathrm{cm})$, a diferencia de nuestros obesos en quienes el asa común no supera los $70 \mathrm{~cm}$, según consta en los Protocolos de nuestra Unidad [Véase epígrafe 3.3.Protocolo clínico empleado].

Nuestros resultados muestran las siguientes cifras de PTH: media preoperatoria de $61,3 \mathrm{pg} / \mathrm{ml}$ y mediana postbariátrica de $82,8 \mathrm{pg} / \mathrm{ml}$. Se aprecia por tanto, un ascenso que es estadísticamente significativo. En los trabajos clásicos del grupo de N. Scopinaro no se muestra las cifras de PTH $(231,237,238,278)$. Por su parte, Marceau et al. (266) mostraron los siguientes valores en el preoperatorio y a los 7 años de media de seguimiento: 37,8 y $66,8 \mathrm{pg} / \mathrm{ml}$, respectivamente, aunque el $22 \%$ de los pacientes superaron un valor postbariátrico de $100 \mathrm{pg} / \mathrm{ml}$. Nuestras cifras medias son mucho menos favorables que las de los canadienses a tenor del RIQ obtenido (50,3-122,7 $\mathrm{pg} / \mathrm{ml})$, estando justificado porque ellos muestran resultados de $\mathrm{CD}$, técnica que obtiene mejor absorción de calcio que la DBP (231), tal y como se acaba de exponer. En nuestro entorno, encontramos el trabajo de Moreiro et al. (277), del equipo de OM y CB del Hospital Son Dureta de Mallorca, que analizó la situación de PTH y marcadores óseos antes y después de la DBP. Este artículo muestra valores de PTH preoperatoria de 55 y 62 pg/ml para mujeres y varones, respectivamente. Nuestro resultado queda incluido en este intervalo pero resulta discretamente elevado, teniendo en cuenta que el $73 \%$ de nuestros pacientes son mujeres, por lo que la cifra debería ser más próxima al valor de $55 \mathrm{pg} / \mathrm{ml}$ presentado por estos autores. La cifra de PTH a los 24 meses de la DBP según este mismo trabajo, se eleva a 119 y $86 \mathrm{pg} / \mathrm{ml}$ para mujeres y varones, respectivamente (277). Observamos, por tanto, una tendencia notablemente mayor que en nuestra serie a presentar hiperparatiroidismo, dada la mencionada distribución por sexo de la muestra en nuestro estudio. Similar hallazgo 
encontramos al comparar nuestras cifras con las del grupo del Hospital de León, quienes registraron una media de PTH basal de $63,7 \mathrm{pg} / \mathrm{ml}$ y de $111,0 \mathrm{pg} / \mathrm{ml}$, a los 5 años de seguimiento. Así pues, se aprecia que nuestro resultado muestra discretas diferencias para los valores de PTH preoperatorios respecto a las cifras publicadas por otros autores, mientras que nuestro resultado postoperatorio es más favorable, en términos de menor tasa de hiperparatiroidismo secundario [Véase tabla 48]. Se debe remarcar que todos los pacientes intervenidos en nuestra Unidad de CB, reciben suplementación oral con calcio y vitamina $\mathrm{D}$, una vez se restablece la tolerancia a la dieta tras la intervención, de acuerdo a las guías clínicas vigentes $(172,175)$.

Tabla 48. Datos del metabolismo del calcio basales y postbariátricos para las variables calcio, 25-OH vitamina D y PTH, comparando nuestros resultados con los publicados en la literatura [artículos de Ballesteros-Pomar et al. (247) y Marceau et al. (266)].

\begin{tabular}{l}
\hline \multicolumn{6}{|c|}{$\begin{array}{c}\text { COMPARACIÓN CON LA LITERATURA DE LAS MEDIAS DE } \\
\text { LOS PARÁMETROS DEL METABOLISMO DEL CALCIO }\end{array}$} \\
\begin{tabular}{|c|c|c|c|c|}
\hline \multicolumn{2}{|c|}{ VARIABLE } & $\begin{array}{c}\text { Resultados } \\
\text { propios }\end{array}$ & $\begin{array}{c}\text { Ballesteros-Pomar } \\
\text { et al. (247) }\end{array}$ & $\begin{array}{c}\text { Marceau et } \\
\text { al. }(266)\end{array}$ \\
\hline \multirow{2}{*}{ Calcio } & Basal & $9,4 \mathrm{mg} / \mathrm{dl}$ & $9,3 \mathrm{mg} / \mathrm{dl}$ & $2,29 \mathrm{~g} / 1$ \\
\cline { 2 - 5 } & Tras DBP* & $8,9 \mathrm{mg} / \mathrm{dl}$ & $8,8 \mathrm{mg} / \mathrm{dl}$ & $2,23 \mathrm{~g} / 1$ \\
\hline \multirow{2}{*}{$\begin{array}{c}25-O H \\
\text { vitamina D }\end{array}$} & Basal & $28,8 \mu \mathrm{g} / 1$ & $30,1 \mu \mathrm{g} / 1$ & $22,8 \mu \mathrm{g} / 1$ \\
\cline { 2 - 6 } & Tras DBP* & $18,0 \mu \mathrm{g} / \mathrm{l}$ & $28,7 \mu \mathrm{g} / 1$ & $32,5 \mu \mathrm{g} / 1$ \\
\hline \multirow{2}{*}{ PTH } & Basal & $61,3 \mathrm{pg} / \mathrm{ml}$ & $63,7 \mathrm{pg} / \mathrm{ml}$ & $37,8 \mathrm{pg} / \mathrm{ml}$ \\
\cline { 2 - 5 } & Tras DBP* & $82,8 \mathrm{pg} / \mathrm{ml}$ & $111,0 \mathrm{pg} / \mathrm{ml}$ & $66,8 \mathrm{pg} / \mathrm{ml}$ \\
\hline
\end{tabular}
\end{tabular}

*: Se muestran los resultados para una mediana de seguimiento de 5 años, salvo para los publicados por Marceau et al. que son a 7 años. 


\section{4.- RESULTADOS DE MORBIMORTALIDAD PRECOZ}

Los 274 pacientes estudiados en esta serie han sido sometidos a DBP, la cual, como se ha expuesto en la Introducción, es una técnica mixta que ha demostrado excelentes resultados ponderales y de mejora de las CAO, aunque está gravada con mayor morbimortalidad que otros procedimientos bariátricos. Ello aparece reflejado en multitud de estudios, entre ellos la revisión de la Cochrane Collaboration (269), aunque aporta resultados del CD y no, concretamente, de DBP; el meta-análisis de Chang et al. (166), teniendo en cuenta que este trabajo incluye la DBP junto con el CD y el BGYR y los denomina globalmente como gastric bypass, y el reciente artículo de revisión publicado en el British Journal of Surgery por P.E. O’Brien (216).

Un dato relevante en nuestro trabajo es la vía de abordaje para la intervención. Actualmente, sociedades científicas como la Society of American Gastrointestinal and Endoscopic Surgeons recomiendan el empleo de la cirugía laparoscópica (163), estando avalada por la literatura, puesto que presenta similares resultados ponderales y clínicos y se asocia a menor dolor, menor estancia hospitalaria y, especialmente, menor morbilidad postquirúrgica (concretamente de tipo leve, como infección de herida o eventración), sin encontrar diferencias significativas de morbilidad grave (reoperación, fuga) ni de mortalidad entre el abordaje abierto y el laparoscópico $(279,280)$. En esta misma línea y en relación a la técnica realizada en nuestro estudio, Ceriani et al. (281) analizaron una serie corta de 40 pacientes con DBP abierta frente a otros 40 por laparoscopia y obtuvieron resultados favorables al segundo grupo, incluso con un sorprendente menor tiempo operatorio por vía laparoscópica. Sin embargo, estos datos contrastan con los publicados en el clásico metaanálisis de Buchwald et al. (282) sobre mortalidad en CB publicado en 2007. Estos autores 
concluyeron que la cirugía abierta, para los procedimientos preferentemente malabsortivos, se asocia a menor mortalidad que la vía laparoscópica, con cifras del 0,76\% y 1,11\%, respectivamente. Por este motivo, en nuestra Unidad de OM y CB se realiza la DBP por vía abierta de forma preferente (97\%). En nuestro entorno cercano, el grupo del Hospital de Burgos publicó una proporción notablemente menor de cirugía abierta (23,6\%) sobre el total de enfermos del subgrupo de DBP así como ausencia de conversión (1,5\% en nuestra serie), encontrando diferencias significativas en los resultados postbariátricos favorables al grupo laparoscópico (incluyendo la serie completa, sin diferenciar por técnica), únicamente para la tasa de morbilidad y para la estancia hospitalaria (248). Sin embargo, y en relación a esta última variable, se observa una mediana de estancia postoperatoria en nuestro estudio de 9 frente a los 13,2 días que publican estos autores para la CB abierta (248). Otro trabajo español del grupo de S. Morales Conde en el Hospital Virgen del Rocío de Sevilla (283) refleja una estancia mediana idéntica a la nuestra para la técnica de DBP. Por último, y en relación con la adquisición de amplia experiencia por parte de los cirujanos bariátricos de nuestra Unidad, se observa que la mediana de estancia hospitalaria en nuestra serie desciende al comparar la época 1 frente a la época 2 (9 y 7 días, respectivamente), aunque la fecha para clasificarlas ha sido establecida de forma arbitraria (año del cambio de emplazamiento del HURH a su ubicación actual).

\subsection{1.- COMPLICACIONES MÉDICAS}

En nuestro estudio se ha realizado un análisis extremadamente exhaustivo de la complicaciones durante el ingreso tanto médicas como quirúrgicas, así como de la severidad de las mismas empleando la clasificación definida por Dindo et al. (246). En primer lugar, nuestra tasa de complicaciones médicas alcanza un valor de $12,5 \%$ sobre el total de 274 pacientes sometidos a DBP en nuestro centro. Revisando los artículos 
publicados sobre la técnica de DBP, observamos que nuestro dato es llamativamente superior a los presentados en la literatura, aunque en ellos se aprecia una recogida y exposición de datos menos selectiva que la realizada en nuestra serie. Scopinaro et al. (238) notificaron una tasa de 1,1\% para las complicaciones que ellos denominan generales y que solamente incluyen trombosis venosa profunda (TVP), TEP y neumonía. En un artículo más reciente de su grupo (241), que analiza resultados aplicando el sistema Bariatric Analysis and Reporting Outcome System (BAROS) (196), el análisis de complicaciones también se expone de forma muy restringida, aunque incluye complicaciones a lo largo de todo el seguimiento postbariátrico, a diferencia de nuestro trabajo. El artículo del grupo leonés de Ballesteros-Pomar et al. (247) no presenta las complicaciones de su serie, a excepción de la tasa de déficit nutricionales. Sánchez et al. (248) no mostraron la tasa de complicaciones médicas de forma aislada, ni tampoco un análisis de subgrupos de las mismas agrupando las distintas técnicas recogidas en su trabajo. Dentro de las complicaciones médicas expuestas en el artículo del grupo burgalés, registraron 4 pacientes con infección de tracto urinario sobre el total de 165 (2,4\%), cifra muy próxima a la nuestra (3,3\%); un caso de celulitis sacra y otro de parestesias en extremidades inferiores, frente a ninguno en nuestra serie. Sin embargo, en el estudio de Larrad et al. (257), la incidencia de infección urinaria es más baja que las anteriormente expuestas $(1,76 \%)$.

Centrando la atención sobre las complicaciones respiratorias, notificamos un único caso de TEP $(0,4 \%)$ y otro de TVP sin TEP $(0,4 \%)$ en nuestra serie. La cifra conjunta $(0,8 \%)$ dobla a la tasa publicada por Winegar et al. (217), quienes obtuvieron una prevalencia de $0,42 \%$ para eventos tromboembólicos venosos (TVP y TEP) tras revisar casi 74.000 enfermos de la Bariatric Outcomes Longitudinal Database. Este artículo notifica, igualmente, que hasta el $73 \%$ de los casos acontecieron tras el alta hospitalaria. Por el 
contrario, nuestro análisis sólo ha incluido, como ya se ha expuesto, las complicaciones durante el ingreso, motivo por el cual el valor de TVP y TEP obtenido estaría infraestimado. A pesar de ello, y teniendo en cuenta las cifras de TVP y TEP publicadas por este artículo para los subgrupos de cirugía abierta $(1,54 \%)$ y para la técnica de DBP $(5,56 \%)$, entendemos que nuestros resultados en relación a estas dos complicaciones médicas entran dentro lo esperable. Scopinaro et al. (238) notificaron, sobre un total de 1356 pacientes, 4 casos de TVP y 9 de TEP (de los cuales 4 fueron causa de exitus). Las cifras globales del autor que describió la DBP son más favorables que las nuestras, sin embargo se debe tener en cuenta la consecuencia y severidad de la complicación y no sólo el número, tal y como se presentará en el epígrafe 5.4.3.- Severidad de las complicaciones según la clasificación de Dindo-Clavien. Así pues, las complicaciones tromboembólicas no han sido causa de mortalidad postbariátrica inmediata, y el único exitus de nuestra serie por complicación respiratoria corresponde al obeso que sufrió una broncoaspiración masiva secundaria a transgresión dietética en el postoperatorio.

En relación a las complicaciones respiratorias distintas de TEP, obtenemos una incidencia del 3,3\% en nuestro estudio. De nuevo, al comparar con otra serie larga de la literatura, concretamente la publicada por Gupta et al. (218), que analiza complicaciones respiratorias empleando la base de datos del American College of Surgeons, se aprecia que nuestro resultado supera al de este trabajo (prevalencia de neumonía de 0,6\% e idéntica cifra para el fracaso respiratorio postoperatorio). No obstante, estos autores presentan una $\mathrm{OR}=8,06$ para sufrir neumonía, así como una $\mathrm{OR}=13,89$ para sufrir fracaso respiratorio postoperatorio en los pacientes sometidos a $\mathrm{DBP} / \mathrm{CD}$ respecto a los de $\mathrm{BGA}$. El trabajo de Weller et al. (279) comparando CB abierta frente a laparoscópica, presenta una tasa de complicaciones pulmonares diferentes de TEP idéntica a la nuestra. De este modo, nuestra 
cifra, supuestamente más elevada, de complicaciones respiratorias se fundamenta por un riesgo incrementado e inherente a la técnica bariátrica empleada en los obesos de este estudio, la DBP por vía abierta. Así pues, y tras revisar artículos exclusivamente sobre resultados en DBP, observamos que Larrad et al. (257) presentaron unas cifras de neumonía y atelectasia en el 0,88\% y 0,58\% de los casos, respectivamente. En un artículo de nuestro entorno con revisión de varias técnicas, como el de Sánchez et al. (248), sólo registraron 1 caso denominado insuficiencia respiratoria (sin especificar la etiología ni la severidad de la misma) sobre 165 pacientes sometidos a DBP. Asimismo, en el artículo del grupo de Sevilla (283), se presenta una descripción muy exhaustiva de las complicaciones respiratorias para la serie general: intubación prolongada $(10,5 \%)$, reintubación temprana (1\%) complicaciones pulmonares severas (2,36\%), broncoespasmo o laringoespasmo (1\%), neumonía confirmada por cultivo $(0.3 \%)$ y neumotórax (1\%). Comparando ambas publicaciones $(248,283)$, se observa claramente que cuanto más pormenorizada es la definición de las complicaciones respiratorias, mayor es la tasa registrada.

Por último, en nuestra serie no se ha detectado ningún caso de IAM en el postoperatorio inmediato ni tampoco de hipoglucemia hiperinsulinémicas, dato acorde a la escasa incidencia global publicada para estas entidades clínicas $(0,2 \%$ y $1 \%$, respectivamente) $(219,220)$. Los 3 pacientes que sufrieron hiperglucemia con necesidad de administración de insulina $(1,1 \%)$ estaban diagnosticados de DM2 con tratamiento insulínico antes de la indicación de $\mathrm{CB}$, por lo que no sorprende la aparición de esta eventualidad. 


\subsection{2.- COMPLICACIONES QUIRÚRGICAS}

La prevalencia de complicaciones quirúrgicas en nuestra serie alcanza una tasa del 26\%. Al igual que para las complicaciones de tipo médico, la recogida de datos ha sido extremadamente minuciosa, aunque presenta, de nuevo, la limitación de haberse realizado el registro exclusivamente durante periodo de ingreso hospitalario.

En primer lugar, la infección del sitio quirúrgico se ha definido siguiendo la clasificación del Center for Disease Control norteamericano y que es mundialmente utilizada (245). La infección superficial y/o profunda se localiza fuera de la cavidad abdominal en nuestro caso, afectando por tanto a la pared abdominal. La frecuencia de esta complicación es del 13,2\% entre nuestros obesos tratados mediante DBP. N. Scopinaro publicó 14 casos de infección de herida quirúrgica (equivalente a nuestra definición de infección de sitio quirúrgico superficial y/o profunda) sobre un total de 1356 pacientes, lo cual supone una tasa de $1,03 \%$, cifra notablemente inferior a la obtenida entre nuestros pacientes, aunque se debe tener presente que uno de esos 14 individuos falleció a consecuencia de la citada infección (238). El resultado en relación a la infección de herida publicado por Larrad et al. (257), en su serie de DBP, es similar al del grupo de N. Scopinaro $(1,47 \%)$, junto con un 0,88\% de pacientes con seroma no infectado. Evaluando de nuevo los datos de otros grupos de $\mathrm{CB}$ en nuestro entorno, encontramos una gran variabilidad: $16 \%$ en la serie del Hospital de Burgos (248) y 5,1\% en el Hospital Virgen del Rocío (283) [Véase tabla 48]. Es necesario recordar que estos trabajos analizan varias técnicas bariátricas, tanto por vía abierta como laparoscópica. En cuanto a la infección de órgano o espacio es necesario aclarar que se corresponde con la presencia de foco infeccioso (absceso o colección infectada) intraabdominal, obteniendo una tasa del 1,5\% entre nuestros pacientes. Ninguno 
de los autores citados en el párrafo anterior identifica esta complicación en sus respectivos artículos $(238,248,257,283)$.

La aparición de fuga y/o dehiscencia anastomótica en nuestro estudio es del 2,6\%. $\mathrm{Al}$ igual que para la complicación anteriormente expuesta, existe gran heterogeneidad en las cifras publicadas [Véase tabla 49], desde un sorprendente 0\% según A. Larrad (257) hasta un 2\% en el grupo sevillano de De la Matta et al. (283). El artículo de Weller et al. (279) que presenta las frecuencias de complicaciones entre CB abierta y laparoscópica, muestra una cifra de fuga similar a la nuestra $(1,97 \%)$, mientras que otras publicaciones aportan una cifra de hasta el 6,1\% para esta complicación (229).

El íleo paralítico postquirúrgico y el retraso de vaciamiento gástrico es una complicación difícil de definir. Una revisión sistemática de 2013 estableció un criterio mucho más laxo que el empleado en nuestro estudio, considerando como íleo prolongado a la ausencia de tolerancia o tránsito a heces pasadas 24 horas desde la intervención quirúrgica (284). El motivo es que los enfermos sometidos a DBP se mantenían 2 o 3 días en dieta absoluta de forma profiláctica durante los primeros años de actividad de nuestra Unidad de CB. Por ello, de haber utilizado en nuestro estudio dicho criterio se habría producido un sesgo por sobreestimación de esta complicación. En lo que respecta al íleo postquirúrgico y la gastroparesia tras $\mathrm{CB}$, cabe decir que son entidades insuficientemente notificadas en la literatura. De los artículos revisados, únicamente el de Larrad et al. (257) aporta el dato de dilatación aguda gástrica con una tasa de 0,29\% [Véase tabla 48].

La oclusión aguda en el postoperatorio inmediato de $\mathrm{CB}$, es una entidad infrecuente, más propia del seguimiento a largo plazo, siendo especialmente propensos los 
individuos sometidos a técnicas malabsortivas o mixtas dada la disposición anatómica del intestino en Y de Roux tras la intervención $(177,229)$. Sánchez et al. (248) notificaron un caso en su serie, secundario a hernia de intestino delgado por un puerto de laparoscopia, de modo que la tasa fue discretamente superior a nuestra serie $(0,6 \%$ y $0,4 \%$, respectivamente) [Véase tabla 49].

La hemorragia luminal en el periodo postquirúrgico inicial procede habitualmente de las líneas de grapado de los dispositivos empleados para la transección y las anastomosis intestinales, siendo menos frecuente esta complicación pasados los primeros 30 días (229). En nuestro estudio la frecuencia es del 2,6\%, cifra inferior a la de Sánchez et al. (4\%, aunque estos autores no discriminan entre hemorragia luminal o hemoperitoneo). Larrad et al. (257) informan de un único caso de hemorragia gástrica $(0,29 \%)$ a diferencia de Scopinaro et al. (238) quienes no aportan la cifra de esta complicación es sus trabajos, comunicando exclusivamente la hemorragia a cavidad abdominal. Por su parte, De la Matta et al. (283) no sufrieron complicaciones hemorrágicas de ningún tipo en sus enfermos [Véase tabla 49].

Finalmente, la hemorragia a la cavidad abdominal o hemoperitoneo, es una complicación grave que suele obligar a la reintervención, y en nuestro estudio se ha definido precisamente por este hallazgo intraoperatorio. En las series más desfavorables alcanza una incidencia del 4,4\% (177). Esta entidad supone el 0,7\% de la morbilidad de tipo quirúrgico en nuestro trabajo, dato discretamente más elevado que el publicado por otros autores como Scopinaro et al. (238) o Larrad et al. (257) [Véase tabla 49]. 
Tabla 49. Tasa de complicaciones quirúrgicas en el periodo postoperatorio precoz, comparando nuestros resultados con los publicados en la literatura [artículos de Scopinaro et al. (238), Larrad et al. (257), Sánchez et al. (248) y De la Matta et al. (283)].

\begin{tabular}{|c|c|c|c|c|c|}
\hline $\begin{array}{c}\text { COMPARACIÓN CON LA LITERATURA DE LAS COMPLICACIONES } \\
\text { QUIRÚRGICAS DURANTE EL INGRESO HOSPITALARIO }\end{array}$ \\
\hline $\begin{array}{c}\text { COMPLICACIÓN } \\
\text { QUIRÚRGICA }\end{array}$ & $\begin{array}{c}\text { Resultados } \\
\text { propios }\end{array}$ & $\begin{array}{c}\text { Scopinaro } \\
\text { et al. (238) }\end{array}$ & $\begin{array}{c}\text { Larrad et } \\
\text { al. }(257)\end{array}$ & $\begin{array}{c}\text { Sánchez et } \\
\text { al. }(248)\end{array}$ & $\begin{array}{c}\text { De la } \\
\text { Matta et } \\
\text { al. }(283)\end{array}$ \\
\cline { 1 - 4 } $\begin{array}{c}\text { Infección superficial } \\
\text { y/o profunda }\end{array}$ & $13,2 \%$ & $1,03 \%$ & $1,47 \%$ & $16 \%$ & $5,1 \%$ \\
\hline $\begin{array}{c}\text { Infección de órgano } \\
\text { o espacio }\end{array}$ & $1,5 \%$ & n.n. & n.n. & n.n. & n.n. \\
\hline Fuga & $2,6 \%$ & $0,2 \%$ & $0 \%$ & $1,2 \%$ & $2,0 \%$ \\
\hline Íleo paralítico & $5,1 \%$ & n.n. & $0,29 \%$ & n.n. & n.n. \\
\hline Oclusión & $0,4 \%$ & n.n. & n.n. & $0,6 \%$ & n.n. \\
\hline Hemorragia luminal & $2,6 \%$ & n.n. & $0,29 \%$ & \multirow{2}{*}{$4 \%$} & n.n. \\
\cline { 1 - 3 } Hemoperitoneo & $0,7 \%$ & $0,2 \%$ & $0,58 \%$ & & n.n. \\
\hline
\end{tabular}

\subsection{3.- SEVERIDAD DE LAS COMPLICACIONES SEGÚN LA} CLASIFICACIÓN DE DINDO-CLAVIEN

Como ya se ha expuesto anteriormente, Dindo et al. (246) propusieron, en su artículo de Annals of Surgery publicado en 2004, una nueva clasificación de las complicaciones postquirúrgicas basada en su severidad de acuerdo al tipo de tratamiento requerido. Así pues, la clasificación de Dindo-Clavien está completamente avalada en la literatura quirúrgica en general, aunque no tanto para la $\mathrm{CB}$ en particular, siendo escasas las publicaciones que emplean esta escala para evaluar las complicaciones postbariátricas. No obstante, es comprensible que se puede obtener el grado de Dindo-Clavien aunque no aparezca reflejado como tal, cuando los autores notifican adecuadamente el tipo de tratamiento requerido en los obesos con complicaciones postoperatorias. 
En nuestro estudio, la proporción de pacientes sin complicaciones incluidas en los grados de Dindo-Clavien es del 66,4\%. Según el meta-análisis de Chang et al. (166), en el subgrupo de pacientes sometidos a gastric bypass (término que incluye para estos autores la DBP), la aparición de complicaciones oscila entre el 12\% y el 33\%, de modo que nuestro dato de 33,6\% se encuentra en el límite alto de la incidencia. Un reciente artículo danés de Geubbels et al. (285), que empleó obesos sometidos a BGYR laparoscópico, obtuvo que el 80,4\% de ellos no presentaron complicaciones siguiendo la mencionada clasificación. La cifra es notablemente mejor que la nuestra, aunque es necesario tener presente las diferencias en cuanto a la técnica y a la vía de abordaje empleada por esos autores. Otro trabajo que presenta sus complicaciones según los grados de Dindo-Clavien es el de Lorente et al. (286), el cual también utiliza el OS-MRS para estratificar el riesgo preoperatorio de los obesos y, por este motivo, se comentará ampliamente en el siguiente epígrafe. Estos autores catalanes registraron un $87,4 \%$ de pacientes sin complicaciones, aunque de nuevo existen limitaciones para realizar esta comparación por el mismo motivo que el anterior trabajo. En la tabla 50 se resume la proporción de pacientes incluidos en cada uno de los grados de la clasificación de Dindo-Clavien, comparando los resultados propios con los de estos dos artículos. En relación a las complicaciones menores (grados I y II) de nuestro estudio, se observa mayor tasa que en las otras dos publicaciones. Asimismo, nuestra proporción de enfermos con complicaciones severas (grado IIIa en adelante) es del 7,6\%, cifra moderadamente más elevada que en la serie catalana de Lorente et al. (286) y en la serie holandesa de Geubbels et al. (285), aunque no llamativa dadas la limitaciones que se acaban de exponer para compararlas con nuestros resultados. El grado IIIb corresponde a pacientes que requieren una reoperación bajo anestesia general, siendo nuestra cifra menor a la presentada por Chang et al. (166) en su meta-análisis para el grupo de gastric bypass (1,1\% y 3\%, respectivamente). 
Tabla 50. Tasa de complicaciones postoperatorias clasificadas según los grados de DindoClavien precoz, comparando nuestros resultados con los publicados en la literatura [artículos de Lorente et al. (286) y de Geubbels et al. (285)].

\begin{tabular}{|c|c|c|c|}
\hline \multicolumn{4}{|c|}{ COMPARACIÓN DE TASA DE COMPLICACIONES } \\
SEGÚN LA CLASIFICACIÓN DE DINDO-CLAVIEN
\end{tabular}

Tratando de establecer comparaciones adecuadas de nuestro trabajo, en base al tipo de técnica bariátrica y la vía de abordaje, se confirma la aseveración inicial sobre la escasez de publicaciones que registran las complicaciones postquirúrgicas empleando la clasificación de Dindo-Clavien. La búsqueda en PubMed con el filtro "Clavien AND biliopancreatic" no arroja ningún resultado, de ahí la importancia de nuestro estudio. El ya mencionado artículo de Ceriani et al. (281) evaluó las diferencias entre obesos tratados con DBP abierta frente a laparoscópica, aunque desgraciadamente los autores no aportan información sobre complicaciones precoces, incluyendo únicamente en su análisis las siguientes variables: dolor postoperatorio, consumo de analgésicos, tiempo operatorio, estancia hospitalaria y hernia incisional. La reciente publicación en Obesity Surgery que analiza obesos sometidos a CD y seguimiento de hasta 20 años, publicado por Marceau et al. (266), notifica una tasa de complicaciones mayores superior a la nuestra (10,2\%). Las complicaciones menores de estos autores franceses alcanzaron, por el contrario, una frecuencia notablemente inferior a la nuestra $(8,8 \%$ frente a $25,9 \%)$. No obstante, es 
necesario puntualizar que Marceau et al. (266) no definieron claramente los conceptos de complicación mayor y menor, ni tampoco establecen los grados de Dindo-Clavien en su artículo, razón que explicaría las diferencias halladas, especialmente para la tasa de complicaciones menores.

Así pues, es necesario discutir el análisis de complicaciones graves (grados IIIa, IIIb, IV y V de Dindo-Clavien) respecto a lo publicado por otros trabajos, preferentemente aquellos que incluyan pacientes sometidos a DBP:

- De siete paciente con hemorragia luminal, tres precisaron tratamiento endoscópico (grado IIIa) y uno fue reintervenido (grado IIIb). Scopinaro et al. (209) no notificaron este tipo de complicación y Larrad et al. (257) registraron un caso que se resolvió con tratamiento conservador en palabras de los autores, interpretando por tanto un grado II, con lo que alcanzan una distribución por grados de Dindo-Clavien superior a nuestra serie. En los pacientes analizados por Sánchez et al. (248) hubo 6 casos de hemorragia sin especificar el tipo (luminal o intraabdominal), de los cuales 4 fueron reoperados (grado IIIb) y uno falleció (grado V).

- Nuestros dos pacientes con hemoperitoneo fueron reintervenidos y finalmente fallecieron por esta complicación. Larrad et al. (257) presentaron, igualmente, 2 casos de hemoperitoneo, ambos reintervenidos, de los cuales uno no sobrevivió. Scopinaro et al. (209) no indican el desenlace clínico de los enfermos complicados con hemoperitoneo, aunque entre las causas de exitus no aparece el hemoperitoneo. Los datos de hemorragia del artículo del grupo burgalés ya han sido expuestos en el guión anterior (248). 
- De 7 individuos con fuga, 3 requirieron tratamiento intervencionista bajo anestesia local (grado IIIa) y otro fue grado IV, por reingresar en unidad de cuidados críticos. En el trabajo de Scopinaro et al. (209) aparecen reflejados 2 casos de fuga, sin mencionar el tipo de tratamiento, aunque ninguno falleció por esta complicación. Larrad et al. (257), como ya se ha indicado anteriormente, no notifican ninguna fuga, a excepción de fístula biliar por colecistectomía simultanea en 2 pacientes, tratada con drenaje percutáneo (grado IIIa). El único caso con fuga en la serie de Sánchez et al. (248) culminó con el fallecimiento del enfermo (grado V), al tiempo que los autores presentaron un caso de reintervención (grado IIIb) debida a perforación intestinal de causa no filiada. En los pacientes del grupo del Hospital Virgen del Rocío, se registraron 6 casos de fuga y todos ellos fallecieron por esta complicación (grado V), correspondiendo además con pacientes sometidos a DBP (283).

- La infección del sitio quirúrgico superficial y/o profunda obligó a reintervenir a un paciente (grado IIIb) del total de 36 que presentaron esta complicación, mientras que los 4 enfermos con infección de órgano o espacio fueron tratados mediante intervencionismo sin anestesia general (grado IIIa). Larrad et al. (257) no informaron del tratamiento requerido en sus 5 pacientes con infección del sitio quirúrgico, y entre los 14 casos de infección de herida de Scopinaro et al. (209), hubo un fallecimiento por esta complicación. El grupo italiano añade también 9 casos definidos como dehiscencia de herida, sin especificar si dicha solución de continuidad interesaba a todos los planos de la pared abdominal (con la consiguiente evisceración) ni tampoco el tratamiento empleado para resolverla. En el 
trabajo de De la Matta et al. (283) no consta ningún caso de infección de herida, y en el de Sánchez et al. (248) no se indica el tratamiento empleado en sus 26 pacientes con esta complicación.

- El único enfermo de nuestra serie que sufrió una oclusión en el postoperatorio inmediato requirió reintervención, al igual que en el trabajo del Hospital de Burgos (grado IIIb) (248).

- El único enfermo de nuestra serie que sufrió TEP precisó ingreso en unidad de cuidados crítico por fallo respiratorio (grado IV). Es importante remarcar este dato, puesto que Sánchez et al. (248) notificaron un caso de insuficiencia respiratoria, sin aportar más información. Ningún paciente en los artículos de Larrad et al. (257) y de De la Matta et al. (283) sufrió esta complicación, mientras que en la serie italiana hubo 4 exitus (grado V) entre los 9 pacientes con diagnóstico de TEP (209).

- En nuestro estudio, como ya se ha expuso anteriormente, hemos tenido 9 pacientes con complicación respiratoria diferente de TEP y de ellos, 3 sufrieron fracaso respiratorio (grado IV) y otro falleció por broncoaspiración masiva tras cometer una transgresión dietética (grado V), con lo que este caso de exitus no es directamente atribuible a complicación postbariátrica. Scopinaro et al. (209) no dan información del tratamiento requerido por un enfermo con neumonía en su serie, ni tampoco lo hacen Larrad et al. (257) con los 5 enfermos de su serie que sufrieron neumonía y atelectasias. El grupo de Sevilla informa sobre la aparición de 3 pacientes que requirieron reintubación temprana (grado IV), 3 con bronco o laringoespasmos (sin datos sobre el tratamiento), otro caso de neumonía y otro de neumotórax, también sin información sobre su resolución. 


\section{5.- ANÁLISIS DE RESULTADOS EMPLEANDO EL OBESITY SURGERY-MORTALITY RISK SCORE}

El OS-MRS es una escala de aplicación rápida y sencilla, que clasifica preoperatoriamente a los obesos que se someterán a $\mathrm{CB}$ según su riesgo de mortalidad postquirúrgica en los primeros 90 días, tal y como describieron sus autores. DeMaria et al. emplearon una serie de pacientes tratados con BGYR, tanto en el estudio inicial (182), como en el estudio multicéntrico de validación liderado por este mismo autor (183). Como ya se expuso en la Introducción, según este score, ser varón, con edad igual o superior a 45 años, presentar un IMC $\geq 50 \mathrm{Kg} / \mathrm{m}^{2}$, estar diagnosticado de HTA o presentar riesgo de TEP, son datos que incrementan el riesgo de mortalidad tras $\mathrm{CB}$, tanto más cuanto mayor sea el número de criterios cumplidos.

A efectos de discusión de resultados, reviste gran interés la comparación de la distribución de las variables que componen esta escala de riesgo en nuestros obesos. Nuestra proporción de varones $(27 \%)$ es 8 puntos porcentuales mayor que la cifra del estudio inicial de DeMaria et al. (182). La diferencia es menos ostensible para la variable edad, con una proporción del 36,9\% de pacientes que pertenecen a la cohorte de edad $\geq 45$ años en nuestra serie y del 40,1\% en la publicación de estos autores. En el caso del grupo de IMC $\geq 50 \mathrm{Kg} / \mathrm{m}^{2}$, el 32,2\% de nuestros obesos sometidos a DBP cumplen este criterio, dato que es llamativamente inferior a la serie de DeMaria et al. (182), con un 50,1\%. Una situación inversa se da con los pacientes incluidos en la cohorte de riesgo de TEP, ya que la proporción en nuestra serie es de $23,4 \%$ frente $7,2 \%$. El criterio de positividad de este factor en nuestra serie ha sido el mismo que definió el trabajo inicial de DeMaria et al. (182). Para ello, se han empleado los datos registrados en el estudio de evaluación 
preanestésica (exploración física, ecocardiograma, estudio polisomnográfico), de modo que la descripción exhaustiva de los mismos por parte de los anestesiólogos ha contribuido, sin duda, a sobreestimar la proporción de casos positivos en esta variable. Finalmente, en relación a la presencia de HTA como criterio de riesgo en el OS-MRS, nuestra proporción de hipertensos según esta definición supera en algo más de 10 puntos porcentuales a la cifra de DeMaria et al. (182): 63,3\% y 52,1\%, respectivamente. Sin embargo, y tras comparar estos datos con los de otros artículos que se discutirán a continuación $(286,287)$, vemos que las proporciones son claramente heterogéneas [Véase tabla 51]. Además existen diferencias entre los mencionados trabajos a la hora de definir el criterio para HTA en el OS-MRS, y por tanto varía la clasificación de los pacientes como positivos para este factor del score es variable.

Tabla 51. Proporción de pacientes en cada variable de riesgo definida por el OS-MRS, comparando resultados propios con los publicados en la literatura [artículos de DeMaria et al. (182), Lorente et al. (286) y Sarela et al. (287)].

\begin{tabular}{|c|c|c|c|c|}
\hline \multicolumn{5}{|c|}{$\begin{array}{c}\text { COMPARACIÓN CON LA LITERATURA DE LA } \\
\text { PROPORCIÓN DE PACIENTES SEGÚN LOS } \\
\text { FACTORES DEL OS-MRS }\end{array}$} \\
\hline $\begin{array}{c}\text { VARIABLE DE } \\
\text { RIESGO }\end{array}$ & $\begin{array}{c}\text { Resultados } \\
\text { propios }\end{array}$ & $\begin{array}{c}\text { DeMaria } \\
\text { et al. (182) }\end{array}$ & $\begin{array}{c}\text { Lorente et } \\
\text { al. }(286)\end{array}$ & $\begin{array}{c}\text { Sarela et } \\
\text { al. }(287)\end{array}$ \\
\hline Sexo varón & $27 \%$ & $18,9 \%$ & $24,2 \%$ & $19 \%$ \\
\hline Edad $\geq 45$ años & $36,9 \%$ & $40,1 \%$ & $50,5 \%$ & $42 \%$ \\
\hline IMC $\geq 50 \mathrm{Kg} / \mathrm{m}^{2}$ & $32,2 \%$ & $50,1 \%$ & $9,6 \%$ & $37 \%$ \\
\hline HTA & $63,3 \%$ & $52,1 \%$ & $33.3 \%$ & $27 \%$ \\
\hline Riesgo de TEP & $23,4 \%$ & $7,2 \%$ & $6 \%$ & $3 \%$ \\
\hline
\end{tabular}

Por el contrario, los resultados que se observan al comparar la proporción de nuestros pacientes incluidos en cada una de las categorías basadas en la puntuación del OS- 
MRS se asemejan a la serie de DeMaria et al. (182), mientras que difieren notablemente de la serie de Lorente et al. (286) y Sarela et al. (287), ambas casi idénticas, con tendencia a presentar mayor porcentaje de pacientes en la categoría de riesgo bajo (clase A), como se puede observar en la tabla 52.

Tabla 52. Proporción de pacientes en cada categoría de riesgo definida por el OS-MRS, comparando resultados propios con los publicados en la literatura [artículos de DeMaria et al. (182), Lorente et al. (286) y Sarela et al. (287)].

\begin{tabular}{|c|c|c|c|c|}
\hline \multicolumn{6}{|c|}{$\begin{array}{c}\text { COMPARACIÓN CON LA LITERATURA DE LA } \\
\text { PROPORCIÓN DE PACIENTES SEGÚN LAS } \\
\text { CATEGORÍAS DEL OS-MRS }\end{array}$} \\
\hline $\begin{array}{c}\text { VARIABLE DE } \\
\text { RIESGO }\end{array}$ & $\begin{array}{c}\text { Resultados } \\
\text { propios }\end{array}$ & $\begin{array}{c}\text { DeMaria } \\
\text { et al. (182) }\end{array}$ & $\begin{array}{c}\text { Lorente et } \\
\text { al. (286) }\end{array}$ & $\begin{array}{c}\text { Sarela et } \\
\text { al. (287) }\end{array}$ \\
\hline Clase A & $40,5 \%$ & $46,1 \%$ & $62,6 \%$ & $60,1 \%$ \\
\hline Clase B & $51,7 \%$ & $48,2 \%$ & $35,4 \%$ & $35,9 \%$ \\
\hline Clase C & $7,8 \%$ & $5,7 \%$ & $2 \%$ & $4 \%$ \\
\hline
\end{tabular}

\subsection{1- MORBIMORTALIDAD SEGÚN EL OBESITY SURGERY-}

\section{MORTALITY RISK SCORE}

La revisión sistemática de Thomas et al. (184) confirmó la utilidad del OS-MRS y encontró un único artículo, publicado por Sarela et al. (287), que incluía 4 pacientes de 381 tratados mediante DBP o CD, ninguno de los cuales desarrolló complicaciones. No hemos encontrado ninguna otra publicación, tras revisar la literatura, que estudie la aplicación del OS-MRS como predictor de morbimortalidad en obesos intervenidos con la técnica de Scopinaro, de ahí la importancia de nuestro trabajo. 


\subsubsection{1.- Riesgo de morbimortalidad por variables}

Tras analizar nuestros resultados según los factores de riesgo de mortalidad que componen el OS-MRS, confirmamos un riesgo relativo $(\mathrm{RR})>1$ en tres de ellos (cohorte de varones, cohorte de edad $\geq 45$ años y cohorte con riesgo de TEP), sin alcanzar significación estadística. Al compararlos con el trabajo inicial de DeMaria et al. (182), observamos ciertas divergencias respecto a los valores de riesgo presentados por estos autores, ya que en nuestra muestra el máximo RR para mortalidad corresponde a la cohorte de TEP $(\mathrm{RR}=6,7)$, a diferencia del artículo en el que se describe el OS-MRS, en el cual es la cohorte de IMC $\geq 50 \mathrm{Kg} / \mathrm{m}^{2}$, con una odds ratio $(\mathrm{OR})=3,6$. Estas diferencias de riesgo, así como la ausencia de significación estadística, pueden explicarse por un tamaño muestral mucho menor en nuestra serie que en la presentada en el mencionado artículo, con 2075 obesos intervenidos. Igualmente, nuestra mortalidad durante el ingreso es de 3 individuos sobre un total de $274(1,1 \%)$, es decir 0,4 puntos porcentuales menor que la notificada por DeMaria et al. (182)(1,5\%), lo cual puede contribuir a que las diferencias entre las cohortes con y sin riesgo según el OS-MRS sean menos ostensibles en nuestra muestra. Es necesario mencionar nuevamente que las diferencias existentes en la proporción de pacientes incluidos en cada grupo de riesgo entre nuestro estudio y el de estos autores, difieren notablemente, lo cual hace poco comparables ambas series, contribuyendo a generar las diferencias observadas.

En las dos restantes variables del OS-MRS (cohorte de IMC $\geq 50 \mathrm{Kg} / \mathrm{m}^{2}$ y cohorte de HTA) ha sido imposible determinar el RR de mortalidad, puesto que existe pérdida de los datos de IMC y de PA sistólica y diastólica antes de la indicación de CB en los 3 pacientes que fallecieron en el postoperatorio temprano. Ello supone un claro sesgo de nuestro estudio a la hora de estimar el riesgo de mortalidad mediante este score, puesto que 
es precisamente el criterio de IMC $\geq 50 \mathrm{Kg} / \mathrm{m}^{2}$ el que genera más riesgo de mortalidad, según la revisión sistemática de Thomas et al. (184), con una $\mathrm{OR}=3,6$.

Aunque el OS-MRS fue inicialmente descrito para predecir la mortalidad, existen artículos que corroboran su empleo también para estimar el riesgo de morbilidad, tal es el caso del ya mencionado trabajo de Sarela et al. (287). Nuestro análisis de riesgo de morbilidad grave y mortalidad tras DBP empleando los mismos factores del OS-MRS es comparable al ya citado estudio publicado por Lorente et al. (286), del grupo de CB del Hospital del Mar en Barcelona. Como características diferenciales con nuestros individuos, este artículo incluye 198 pacientes intervenidos por vía laparoscópica empleando la GV y el BGYR. Lorente et al. (286) expusieron unos porcentajes de morbimortalidad cercanos a los aquí presentados para la cohorte de varones (16,7\% y 10,8\%, respectivamente), mientras que para el resto de cohortes de riesgo del OS-MRS, nuestros datos son más favorables que los expuestos en este artículo, con cifras aproximadamente un 50\% menor que las del grupo catalán [Véase tabla 53]. 
Tabla 53. Comparación de resultados de morbimortalidad por factores del OS-MRS entre nuestra serie y la de Lorente et al. (286).

\begin{tabular}{|c|c|c|c|}
\hline \multicolumn{4}{|c|}{$\begin{array}{l}\text { COMPARACIÓN DE MORBIMORTALIDAD SEGÚN LOS } \\
\text { FACTORES DEL OS-MRS }\end{array}$} \\
\hline \multicolumn{2}{|c|}{ VARIABLE } & $\begin{array}{l}\text { PORCENTAJE DE } \\
\text { MORBIMORTALIDAD }\end{array}$ & $\begin{array}{l}\text { SIGNIFICACIÓN } \\
\text { ESTADÍSTICA }\end{array}$ \\
\hline \multirow{2}{*}{$\begin{array}{l}\text { Cohorte de } \\
\text { sexo varón }\end{array}$} & $\begin{array}{l}\text { Resultados } \\
\text { propios }\end{array}$ & $10,8 \%$ & n.s. \\
\hline & $\begin{array}{l}\text { Lorente et } \\
\text { al. }\end{array}$ & $16,7 \%$ & n.s. \\
\hline \multirow{2}{*}{$\begin{array}{l}\text { Cohorte de } \\
\text { edad } \geq 45 \\
\text { años }\end{array}$} & $\begin{array}{l}\text { Resultados } \\
\text { propios }\end{array}$ & $6,9 \%$ & n.s. \\
\hline & $\begin{array}{l}\text { Lorente et } \\
\text { al. }\end{array}$ & $16,0 \%$ & n.s. \\
\hline \multirow{2}{*}{$\begin{array}{c}\text { Cohorte de } \\
\mathrm{IMC} \geq 50 \\
\mathrm{Kg} / \mathrm{m}^{2}\end{array}$} & $\begin{array}{l}\text { Resultados } \\
\text { propios }\end{array}$ & $11,4 \%$ & $p=0,028$ \\
\hline & $\begin{array}{l}\text { Lorente et } \\
\quad \text { al. }\end{array}$ & $21,1 \%$ & n.s. \\
\hline \multirow{2}{*}{$\begin{array}{l}\text { Cohorte con } \\
\text { HTA }\end{array}$} & $\begin{array}{c}\text { Resultados } \\
\text { propios }\end{array}$ & $8,2 \%$ & n.s. \\
\hline & $\begin{array}{l}\text { Lorente et } \\
\text { al. }\end{array}$ & $21,2 \%$ & $p=0,01$ \\
\hline \multirow{2}{*}{$\begin{array}{c}\text { Cohorte con } \\
\text { riesgo de } \\
\text { TEP }\end{array}$} & $\begin{array}{l}\text { Resultados } \\
\text { propios }\end{array}$ & $9,4 \%$ & n.s. \\
\hline & $\begin{array}{l}\text { Lorente et } \\
\quad \text { al. }\end{array}$ & $16,7 \%$ & n.s. \\
\hline
\end{tabular}

En cualquier caso, el análisis factor a factor del OS-MRS sólo ha resultado estadísticamente significativo en uno de ellos, tanto en nuestra muestra (cohorte de IMC $\geq 50 \mathrm{Kg} / \mathrm{m}^{2}$ ) como en la del Hospital del Mar (cohorte con HTA). No obstante, la discordancia de resultados se explica en base a que nuestro estudio ha comparado la aparición de morbilidad grave y mortalidad [grados IIIa, IIIb, IV y V de Dindo-Clavien (246)], mientras que la mencionada publicación ha incluido todos los grados que integran esta clasificación de severidad de las complicaciones postquirúrgicas. En caso de haber aplicado el mismo criterio en nuestra serie, es de esperar que los resultados hubieran sido similares, teniendo en cuenta la proporción de pacientes. De todo ello se interpreta que, 
tras realizar el ajuste por los factores de riesgo del OS-MRS, nuestra tasa de morbimortalidad es aceptable teniendo en cuenta que la inmensa mayoría de nuestros enfermos son intervenidos mediante cirugía abierta, a diferencia del trabajo de Lorente et al. (286), lo que genera un mayor riesgo de complicaciones menores, especialmente en relación con la herida quirúrgica, lo cual está sobradamente demostrado en la literatura $(277,278,286)$. Asimismo, es necesario tener en cuenta que la DBP es una técnica con excelentes resultados ponderales y metabólicos, pero que está gravada con mayor tasa de complicaciones que el BGYR y la GV, como ya se ha expuesto anteriormente.

\subsubsection{2.- Riesgo de morbimortalidad por categorías}

En segundo lugar, el análisis de riesgo de mortalidad empleando las categorías que integran el OS-MRS no ha resultado estadísticamente significativo en nuestra serie. Según el artículo de validación de DeMaria et al. (183), el riesgo de mortalidad en pacientes de clase B frente a clase A y en los de clase C frente a clase A es marcadamente superior a nuestros resultados $(\mathrm{RR}=5$ y 12 , respectivamente), al igual que ocurre con las cifras presentadas en la revisión sistemática de Thomas et al. (184), con RR $=5$ y 17, respectivamente. El trabajo de Lorente et al. (286) no aporta información exclusiva sobre el riesgo de mortalidad empleando el OS-MRS, ya que en palabras de sus autores "no puede extraerse información alguna para ratificar esta escala como predictiva de mortalidad, dado que en nuestra serie sólo fallece un paciente”. Es necesario, además, notificar la posible infraestadificación del score en el trabajo del grupo catalán, puesto que estos autores consideraron como criterio de HTA del OS-MRS la presencia exclusiva de PA sistólica $>160$ mmHg o la PA diastólica >95 mmHg. Sin embargo, en nuestro estudio también se ha incluido la pauta de tratamiento antihipertensivo en la variable "grupo de HTA", dado que así fue como se describió este factor de riesgo en el trabajo inicial de DeMaria et al. (182). 
A pesar de las discordancias en términos de RR de mortalidad aplicando los factores que componen el OS-MRS, el análisis de la proporción de pacientes que fallecen durante el ingreso, ajustando por categorías de esta escala, no difiere llamativamente de las cifras publicadas, a excepción de la clase C [Véase tabla 54]. Ello se interpreta, de nuevo, por el sesgo debido la pérdida de datos de IMC y PA sistólica y diastólica en los 3 individuos que fallecieron durante el ingreso. Ésto supone una infraestimación de la puntuación, y por tanto de la categoría del OS-MRS, para esos pacientes, ya que dos de ellos obtuvieron 2 puntos en la escala, de tal modo que, de haberse conocido los datos perdidos, podrían haber alcanzado una puntuación de hasta 4, pasando a ser clase $\mathrm{C}$ en el score. Ello ha contribuido, en gran medida, a que no se haya registrado ningún exitus entre los obesos de la categoría de máximo riesgo (clase C) tratados con DBP en nuestra serie. Por otro lado, en nuestro estudio se ha restringido el registro de mortalidad al período de ingreso hospitalario, de tal modo que los individuos no pertenecientes al Área sanitaria Oeste de Valladolid han podido fallecer sin existir constancia de ello en nuestra base de datos. En este sentido, los dos trabajos de DeMaria et al. (182,183), a diferencia de nuestra serie, notificaban los exitus acontecidos en los primeros 90 días de postoperatorio, motivo por el cual nuestra tasa de mortalidad puede haber sido infraestimada. Consideramos, igualmente, que el tamaño muestral bajo de nuestra serie ha influido en la ausencia de significación estadística. No obstante, otra posible interpretación es que nuestros resultados en términos de mortalidad no alcanzan diferencias ostensibles entre las 3 categorías del OSMRS, merced a una adecuada selección y manejo perioperatorio de nuestros obesos sometidos a DBP. 
Tabla 54. Proporción de exitus en el postoperatorio inicial según las categorías definidas por el OS-MRS y valor global, comparando resultados propios con los publicados en la literatura [ambos artículos de DeMaria et al. $(182,183)$ y revisión sistemática de Thomas et al. (184)].

\begin{tabular}{|c|c|c|c|c|}
\hline $\begin{array}{c}\text { COMPARACIÓN CON LA LITERATURA DE LA PROPORCIÓN } \\
\text { DE EXITUS SEGÚN LAS CATEGORÍAS DEL OS-MRS }\end{array}$ \\
\hline CATEGORÍA & $\begin{array}{c}\text { Resultados } \\
\text { propios }\end{array}$ & $\begin{array}{c}\text { DeMaria } \\
\text { et al. (182) }\end{array}$ & $\begin{array}{c}\text { DeMaria } \\
\text { et al. (183) }\end{array}$ & $\begin{array}{c}\text { Thomas } \\
\text { et al. (184) }\end{array}$ \\
\hline Clase A & $0,9 \%$ & $0,31 \%$ & $0,2 \%$ & $0,26 \%$ \\
\hline Clase B & $1,4 \%$ & $1,9 \%$ & $1,2 \%$ & $1,33 \%$ \\
\hline Clase C & $0 \%$ & $7,56 \%$ & $2,4 \%$ & $4,34 \%$ \\
\hline Global & $1,1 \%$ & $1,5 \%$ & $0,7 \%$ & $0,88 \%$ \\
\hline
\end{tabular}

Finalmente, el análisis de morbimortalidad grave (grados IIIa, IIIb, IV y V de la clasificación de Dindo-Clavien) en nuestra serie ajustada por las categorías del OS-MRS, pone de manifiesto un incremento de riesgo en la cohorte de pacientes de clase $\mathrm{B}$ frente a los de la clase $\mathrm{A}(\mathrm{RR}=2,5)$, con una fuerte asociación estadística aunque sin alcanzar el nivel de significación. No ocurre así en el caso de la cohorte de clase $C$ frente a la de clase A, ya que existe un riesgo de morbimortalidad mínimamente incrementado $(R R=1,1)$, lo cual supone un dato claramente discordante con los valores publicados y que se desarrollará a continuación. No obstante, este hallazgo resulta cuestionable dada la ausencia de significación al realizar los cálculos de inferencia estadística.

Los resultados de Lorente et al. (286) muestran, en el análisis univariante, una OR = 5,63 al comparar el riesgo de morbimortalidad en las clases B y C conjuntamente respecto a la clase A. El riesgo para este mismo dato en nuestra serie presenta una cifra notablemente menor $(\mathrm{RR}=2,3)$, lo cual se explica en base a la proporción de pacientes con morbimortalidad en cada categoría, ya que nuestras cifras son llamativamente inferiores a 
las del grupo catalán [Véase tabla 55]. De nuevo, la justificación de esta discordancia reside en la diferente definición de morbimortalidad: todos los grados de la clasificación de Dindo-Clavien en el estudio de Lorente et al. (286) frente a las complicaciones postquirúrgicas graves y mortalidad (grados IIIa, IIIb, IV y V) en nuestro estudio. A pesar de ello, se aprecia una tendencia común con el estudio catalán a que la cohorte de pacientes de clase B presente una tasa de complicaciones aproximadamente dos veces y media mayor que la clase $\mathrm{A}[\mathrm{RR}=2,7$, según los datos de Lorente et al. (286) y 2,4 en nuestra serie].

Como ya se ha mencionado anteriormente, el trabajo de Sarela et al. (287), llevado a cabo en el Reino Unido, también se asemeja metodológicamente al nuestro, puesto que analiza el OS-MRS como predictor de morbimortalidad e incluye, además, 4 pacientes con técnica de DBP y CD, a diferencia del estudio de Lorente et al. (286). Otro dato en común es la definición como evento de morbimortalidad para aquellas complicaciones graves únicamente (trasfusión, reintervención, reingreso, TEP y exitus), equivalentes en su mayoría a los grados III, IV y V de la clasificación de Dindo-Clavien, tal y como hemos planteado en el análisis de nuestra serie. Nuestros resultados de morbimortalidad grave para la serie completa y para la cohorte de clase A apenas difieren de los de Sarela et al. (287), en contraposición con las cifras para la clase B (morbimortalidad en nuestra serie dos veces superior) y para la clase $\mathrm{C}$ (tasa de complicaciones tres veces mayor en la del grupo inglés) [Véase tabla 55]. La explicación de estas diferencias radica, como ya se expuso previamente, en la infraestimación de la puntuación y en consecuencia de la clase, que presenta nuestro estudio debido a la pérdida de datos de IMC y PA en los 3 enfermos fallecidos en el postoperatorio inmediato. 
En referencia a nuestros resultados globales de mortalidad y morbilidad grave ajustados por categorías del OS-MRS, cabe decir que son satisfactorios, con un valor intermedio entre los publicados por Sarela et al. (287) y Lorente et al. (286) para las clases A y $\mathrm{B}$, teniendo en cuenta la diferencia de criterios para definir el concepto de morbimortalidad, como ya se ha explicado anteriormente, así como en la disparidad existente entre las series en lo que respecta a la proporción de enfermos incluidos en cada categoría de esta escala de riesgo y las limitaciones observadas en nuestro análisis.

Tabla 55. Proporción de pacientes con morbimortalidad en el postoperatorio inmediato según las categorías definidas por el OS-MRS y valor global, comparando resultados propios con los publicados en la literatura [artículos de Sarela et al. (287) y de Lorente et al. (286)].

\begin{tabular}{|c|c|c|c|}
\hline \multicolumn{4}{|c|}{ COMPARACIÓN CON LA LITERATURA DE LA } \\
PROPORCIÓN DE MORBIMORTALIDAD SEGÚN \\
LAS CATEGORÍAS DEL OS-MRS \\
\hline \multirow{2}{*}{ CATEGORÍA } & $\begin{array}{c}\text { Resultados } \\
\text { propios }\end{array}$ & $\begin{array}{c}\text { Sarela et al. } \\
(287)\end{array}$ & $\begin{array}{c}\text { Lorente et } \\
\text { al. }(286)\end{array}$ \\
\hline \multirow{2}{*}{ Clase A } & $\begin{array}{c}5 \text { de } 111 \\
(4,5 \%)\end{array}$ & $\begin{array}{c}8 \text { de } 229 \\
(3,5 \%)\end{array}$ & $\begin{array}{c}9 \text { de } 124 \\
(7,3 \%)\end{array}$ \\
\hline \multirow{2}{*}{ Clase B } & $\begin{array}{c}15 \text { de } 142 \\
(10,6 \%)\end{array}$ & $\begin{array}{c}8 \text { de } 137 \\
(5,8 \%)\end{array}$ & $\begin{array}{c}14 \text { de } 70 \\
(20,0 \%)\end{array}$ \\
\hline \multirow{2}{*}{ Clase C } & 1 de 21 & 3 de 15 & 2 de 4 \\
$(4,8 \%)$ & $(20,0 \%)$ & $(50 \%)$ \\
\hline \multirow{2}{*}{ Global } & $\begin{array}{c}21 \text { de } 274 \\
(7,7 \%)\end{array}$ & $\begin{array}{c}19 \text { de } 381 \\
(5 \%)\end{array}$ & $\begin{array}{c}8 \text { de } 189 \\
(12,6 \%)\end{array}$ \\
\hline
\end{tabular}

\subsection{2.- RESULTADOS PONDERALES Y CLÍNICOS SEGÚN EL}

\section{OBESITY SURGERY-MORTALITY RISK SCORE}

El OS-MRS, como ya se ha expuesto repetidamente, fue definido para estratificar el riesgo de mortalidad y, posteriormente, se ha hecho extensivo también para la morbilidad, tal y como demuestran las publicaciones mencionadas en el epígrafe anterior. Sin embargo, 
no existe referencia en ningún artículo al empleo de este score como predictor de resultados ponderales y clínicos en CB, y mucho menos de forma exclusiva para DBP. Algunos de los factores incluidos en esta puntuación (sexo, edad, IMC preoperatorio) constituyen variables predictoras de los resultados postbariátricos según diversas publicaciones, no así en nuestro estudio, como ya se ha expuesto anteriormente. Por estos motivos, reviste interés científico analizar si la inclusión de un paciente candidato a CB en una categoría concreta del OSMRS supone un dato relacionado con el efecto de la intervención sobre la pérdida de peso y la mejora del SM.

\subsubsection{1.- Resultados ponderales por categorías}

Los valores medios de peso e IMC preoperatorio y en la última revisión del seguimiento presentan diferencias significativas entre las 3 categorías del OS-MRS, observando que la adiposidad de los pacientes es mayor, cuánto más elevada es la categoría. Este hallazgo es comprensible dado que los enfermos de la clase $\mathrm{C}$ tienen más puntuación y por tanto, más probabilidad de que el factor IMC $\geq 50 \mathrm{Kg} / \mathrm{m}^{2}$ sea positivo. No obstante, en los trabajos de DeMaria et al. (182,183), en la revisión sistemática de Thomas et al. (184) y en los artículos de Lorente et al. (286) y Sarela et al. (287) no aparecen reflejados los datos medios de peso e IMC de sus pacientes incluidos en cada categoría.

$\mathrm{Al}$ estudiar la pérdida ponderal por categorías, se han encontrado diferencias significativas tanto para el descenso bruto de peso como de IMC dentro cada una de ellas, aunque al analizar el descenso medio de IMC entre las 3 categorías no se obtienen diferencias significativas, correspondiendo los valores más altos a la clase $\mathrm{B}\left(17,2 \mathrm{Kg} / \mathrm{m}^{2}\right)$. Según se ha explicado previamente, los datos brutos carecen de especial interés y, por ello, se ha incluido también el análisis inferencial de los parámetros de evaluación de pérdida de 
peso. Los resultados muestran una relación inversamente proporcional con fuerte asociación estadística, aunque sin alcanzar el nivel de significación. Así pues, se observa una tendencia a una menor cifra media de PEPP y PEIMCP cuanto mayor es la categoría del OS-MRS. Nuevamente, ninguno de los trabajos ya citados presentan una comparación análoga a nuestro estudio (182-184,286,287). A pesar de ello, este hallazgo no parece ser discordante con las publicaciones que estudian los factores relacionados con el descenso de peso.

Tal y como se ha expuesto al inicio del epígrafe, el incremento de edad, el sexo masculino y un IMC preoperatorio elevado son las variables del score que, según varias publicaciones, se asocian a peor resultado ponderal (258-262). Dado que estas variables, de forma aislada en el estudio univariante realizado, no se relacionan estadísticamente al fracaso ponderal, tampoco se ha alcanzado el nivel de significación al comparar el PEPP y el PEIMCP entre las tres clases del OS-MRS. Sin embargo, la tendencia observada parece sugerir que la concomitancia de estos factores y, por tanto, de una mayor puntuación en la escala de DeMaria sí podría asociarse con una pérdida de peso menos satisfactoria tras DBP, y quizá sea nuestro bajo tamaño muestral el responsable de no obtener resultados significativos tanto en el análisis de cada factor como en el de las categorías del OS-MRS.

\subsubsection{2.- Resultados metabólicos por categorías}

Los trabajos de E. DeMaria, en los que se definió y validó el OS-MRS $(182,183)$, no hacen mención alguna al estado metabólico de los pacientes en función de su categoría en este score. Tampoco aparece reflejado este dato en la revisión sistemática de Thomas et al. (184), ni hemos encontrado ningún otro artículo publicado que lo relacione tras revisar exhaustivamente la literatura. Con este fin, se han realizado cálculos inferenciales en los tres 
criterios de SM analizados en nuestro trabajo (glucemia, TAG y PA), evaluando el descenso en la proporción de pacientes con positividad para dichos criterios en cada una de las categorías A, B y C, respectivamente. Los resultados obtenidos ponen de manifiesto que las diferencias de descenso no son significativas entre las clases del OS-MRS para ninguno de los criterios de SM analizados. Se interpreta, por tanto, que el score de DeMaria no tiene utilidad, al menos en nuestra muestra, para predecir el grado de beneficio de la CB en relación a la mejora de las CAO, y concretamente a los tres componentes del SM incluidos en nuestro trabajo.

La justificación de esta ausencia de significación estadística puede estar relacionada con el escaso tamaño muestral existente en cada categoría al analizar separadamente los tres criterios de SM. En el caso del criterio de TAG, también es necesario tener en consideración que se obtuvo un descenso no significativo en el subgrupo de los 113 obesos con seguimiento como se ha notificado previamente [Véase epígrafe 5.3.2.- Modificación del metabolismo lipídico].

\subsubsection{3.- Resultados de estancia hospitalaria por categorías}

El OS-MRS no se definió como una puntuación predictora de la estancia hospitalaria de los pacientes en función de su categoría $(182,183)$. Tampoco aparece este dato en el ya citado artículo del grupo del Hospital del Mar que analiza la morbimortalidad empleando la clasificación de Dindo-Clavien en función del OS-MRS (286). Por este motivo, decidimos evaluar la posible asociación de ambas variables. Nuestro resultado no ha obtenido significación estadística al comparar las medias de estancia hospitalaria entre los 274 pacientes de la serie, estratificando por las tres categorías de la escala de DeMaria. No obstante, sí obtenemos una diferencia significativa entre la media de estancia conjunta 
para las categorías de mayor riesgo (B y C) frente a la categoría A. El resultado es plausible con el propio fundamento del score, dado que cuanto mayor es el riesgo de morbimortalidad tras $\mathrm{CB}$, es de esperar que mayor sea la duración del ingreso hospitalario. La ausencia de significación obtenida al comparar entre sí los tres valores medios, al contrario de lo que acontece con las medias entre la clase A y la clase B y C conjuntamente, puede sustentarse en base a la propia distribución de la proporción de enfermos incluidos en cada clase, y que se ha desarrollado al inicio de este epígrafe.

Tras revisar minuciosamente la literatura, encontramos artículos que incluyen en su análisis la clasificación de los obesos siguiendo el OS-MRS, así como la duración del ingreso hospitalario de los mismos, aunque no comparan de forma directa la relación entre ambas variables (289). Por ello, la asociación estadísticamente significativa encontrada en nuestro estudio sienta el fundamento para emplear este score como predictor de la estancia hospitalaria, aunque ello deberá ser corroborado en futuros estudios. 


\section{6.- LIMITACIONES DEL ESTUDIO}

El presente estudio presenta una serie de limitaciones generales, que se enumeran y explican a continuación, además de aquellas concretas que ya se han desarrollado en los epígrafes correspondientes de esta Discusión. Éstas son:

- El diseño del presente estudio es retrospectivo y por este motivo se restringe la aplicabilidad y extrapolación de resultados, así como, en última instancia, el nivel de evidencia científica derivado del mismo. Además, la recogida retrospectiva de datos ha supuesto pérdidas en algunas variables, como se expondrá seguidamente.

- El tamaño muestral de los pacientes que realizan seguimiento postbariátrico en nuestra Unidad de CB incluidos en este trabajo es bajo. Ello ha podido contribuir a que algunas de las diferencias analizadas no hayan alcanzado significación estadística.

- La ausencia de cifras preoperatorias de HDL ha obligado a desestimar dicha variable del estudio tras la revisión inicial de la base de datos. Ello ha impedido establecer la proporción de pacientes con criterio de HDL para SM antes de la $\mathrm{CB}$, resultando imposible realizar el análisis comparativo entre los valores basales y del seguimiento de las cifras brutas y también de la proporción de resolución del mencionado criterio. De igual modo, la pérdida masiva de datos sobre la circunferencia de cintura ha generado la misma situación que en el caso de HDL. Por todo ello, el hecho de no haber podido presentar un análisis completo de los 5 criterios que componen el SM, empleando el último consenso publicado en 2009 por Alberti et al. (96), supone una limitación de nuestro estudio. 
- La ausencia de datos de variables clínicas y analíticas preoperatorias de numerosos obesos procedentes de otros hospitales intervenidos en nuestra Unidad hace poco extrapolables los resultados a toda la población de obesos mórbidos tratados con $\mathrm{CB}$ en el HURH. En concreto, esta pérdida ha sido importante para los valores de las variables hemoglobina, albúmina, calcio total, 25-OH vitamina D y PTH.

- Se han registrado pérdidas en diversas variables clínicas y analíticas postbariátricas entre los 113 obesos que realizan su seguimiento en nuestro centro. Sin embargo, ninguna ha alcanzado un valor superior al $15 \%$, a excepción de la HbA1C, en la cual existe una ausencia de datos que alcanza el 69,8\%. La justificación reside en que en numerosos pacientes de la muestra, no se había solicitado este parámetro en la última analítica sanguínea del seguimiento postbariátrico. Asimismo, y en relación a esta misma variable, hacemos constar que no ha sido posible registrar las cifras preoperatorias por un porcentaje de pérdidas casi universal, obligándonos a desestimar esta variable tras la revisión inicial de la base de datos.

- El síndrome de apnea obstructiva del sueño es una CAO frecuente, pero cuya mejora no ha sido posible analizar en nuestro estudio, ante la disparidad de datos encontrados en su clasificación durante el análisis retrospectivo, así como la elevada tasa de pérdidas.

- La pérdida de información clínica relevante (IMC y PA sistólica y diastólica) en los 3 pacientes que fallecieron en el postoperatorio inmediato, supone un sesgo para la determinación del OS-MRS y, por consiguiente, para todos los análisis comparativos realizados en nuestro trabajo empleando esta escala. 



\section{6.- CONCLUSIONES}





\section{6.- CONCLUSIONES}

1. Los pacientes intervenidos para el tratamiento de obesidad mórbida en el Hospital Universitario Río Hortega de Valladolid, mediante la técnica de derivación biliopancreática, son adultos jóvenes, mayoritariamente mujeres y un tercio de ellos se incluyen en la categoría de obesidad extrema.

2. Para una mediana de seguimiento superior a 5 años, nuestros resultados ponderales se clasifican como excelentes o buenos en el $82 \%$ de los pacientes que realizan su revisión postbariátrica en nuestro hospital, con un porcentaje de exceso de peso perdido de $62,3 \%$ y un porcentaje de exceso de índice de masa corporal perdido de $68,9 \%$. No obstante, en nuestros obesos no se ha detectado un perfil concreto, basado en las variables preoperatorias estudiadas, capaz de predecir el fracaso ponderal de la técnica a $\operatorname{los} 5$ años.

3. Empleando los criterios del consenso de Alberti para síndrome metabólico, obtenemos que la derivación biliopancreática es efectiva para la mejora de la diabetes mellitus tipo 2 , la dislipemia y la hipertensión arterial, como se expone a continuación:

- Alteración del metabolismo de la glucosa. Nuestra tasa de resolución o mejora de diabetes mellitus tipo 2 es del 95\%, con una suspensión o reducción de los antidiabéticos orales y/o la insulina en el 100\% de los individuos.

- Alteración del metabolismo lipídico. Tras la derivación biliopancreática, existe un descenso de las cifras de colesterol total y de triglicéridos, 
especialmente evidente entre aquellos obesos con hipertrigliceridemia antes de la cirugía.

- Alteración de la presión arterial. Las cifras de presión arterial sistólica y diastólica descienden tras la intervención, y en el 63\% de los pacientes se reduce o suspende la medicación antihipertensiva.

Las cifras de hemoglobina y albúmina descienden discretamente tras la derivación biliopancreática, toda vez que los pacientes reciben suplementos sistemáticamente, de acuerdo a las guías clínicas vigentes. El metabolismo del calcio también se altera tras la intervención, especialmente en forma de marcada hipovitaminosis D. No obstante, la calcemia desciende mínimamente merced al hiperparatiroidismo secundario que se establece.

4. En la serie completa de pacientes intervenidos, un tercio de ellos sufrieron algún tipo de complicación médica y/o quirúrgica, predominantemente leves según la clasificación de Dindo-Clavien. Asimismo, éste es el primer estudio en el que se registra y notifica la morbimortalidad tras la derivación biliopancreática empleando la citada clasificación.

5. En la cohorte completa de obesos estudiados, el Obesity Surgery-Mortality Risk Score no logra establecer diferencias ostensibles de morbilidad grave y mortalidad para las tres categorías de este índice.

6. No se han hallado diferencias en cuanto a resultados ponderales y metabólicos entre los obesos incluidos en cada una de las tres categorías del Obesity Surgery-Mortality Risk Score. Por el contrario, sí hemos obtenido que los pacientes de la categoría A presentan una estancia hospitalaria más corta que los incluidos en las categorías B y C conjuntamente. 


\section{7.- BIBLIOGRAFÍA}





\section{7.- BIBLIOGRAFÍA}

1. World Health Organization. Obesity and overweight. Acceso a través de la página web: http://www.who.int/mediacentre/factsheets/fs311/en/

2. Serra-Majem L, Bautista-Castaño I. Etiology of obesity: two "key issues" and other emerging factors. Nutr Hosp. 2013; 28 Suppl 5: 32-43.

3. Van Itallie TB. "Morbid" obesity: a hazardous disorder that resists conservative treatment. Am J Clin Nutr. 1980; 33(2 Suppl): 358-63.

4. Rubio MA, Salas-Salvadó J, Barbany M, Aranceta J, Bellido D, Blay V, et al. Consenso SEEDO 2007 para la evaluación del sobrepeso y la obesidad y el establecimiento de criterios de intervención terapéutica. Med Clin (Barc). 2007; 128(5): 184-96.

5. Wang ZM, Pierson RN, Heymsfield SB. The five-level model: a new approach to organizing body-composition research. Am J Clin Nutr. 1992; 56(1): 19-28.

6. Kraybill HF, Hankins OG, Bitter HL. Body composition of cattle. I. Estimation of body fat from measurement in vivo of body water by use of antipyrine. J Appl Physiol. 1951; 3(11): 681-9.

7. Kraybill HF, Bitter HL, Hankins OG. Body composition of cattle. II. Determination of fat and water content from measurement of body specific gravity. J Appl Physiol. 1952; 4(7): 575-83.

8. Kyle UG, Piccoli A, Pichard C. Body composition measurements: interpretation finally made easy for clinical use. Curr Opin Clin Nutr Metab Care. 2003; 6(4): 387-93.

9. Thibault R, Pichard C. The evaluation of body composition: a useful tool for clinical practice. Ann Nutr Metab. 2012; 60(1): 6-16.

10. Elia M. Body composition analysis: an evaluation of 2 component models, multicomponent models and bedside techniques. Clin Nutr. 1992; 11(3): 114-27.

11. Mazess RB, Peppler WW, Gibbons M. Total body composition by dual-photon (153Gd) absorptiometry. Am J Clin Nutr. 1984; 40(4): 834-9.

12. Heymsfield SB, Wang J, Kehayias J, Heshka S, Lichtman S, Pierson RN. Chemical determination of human body density in vivo: relevance to hydrodensitometry. Am J Clin Nutr. 1989; 50(6): 1282-9.

13. Heyward VH. Evaluation of body composition. Current issues. Sports Med. 1996; 22(3): 146-56. 
14. Fuller NJ, Jebb SA, Laskey MA, Coward WA, Elia M. Four-component model for the assessment of body composition in humans: comparison with alternative methods, and evaluation of the density and hydration of fat-free mass. Clin Sci (Lond). 1992; 82(6): 687-93.

15. Zaragozano JF. Exploración del estado nutricional y composición corporal. An Esp Pedriatr. 1998; 48: 111-5.

16. Heymsfield SB, Waki M. Body composition in humans: advances in the development of multicompartment chemical models. Nutr Rev. 1991; 49(4): 97-108.

17. World Health Organization. Physical status: the use and interpretation of anthropometry. Acceso a través de la página web: http://www.who.int/childgrowth/publications/physical_status/en/

18. Carmienke S, Freitag MH, Pischon T, Schlattmann P, Fankhaenel T, Goebel H, et al. General and abdominal obesity parameters and their combination in relation to mortality: a systematic review and meta-regression analysis. Eur J Clin Nutr. 2013; 67(6): 573-85.

19. Jensen MD, Ryan DH, Apovian CM, Ard JD, Comuzzie AG, Donato K, et al. 2013 AHA/ACC/TOS guideline for the management of overweight and obesity in adults: a report of the American College of Cardiology/American Heart Association Task Force on Practice Guidelines and The Obesity Society. Circulation. 2014; 129(25 Suppl 2): S102-38.

20. Eknoyan G. Adolphe Quetelet (1796-1874) -- the average man and indices of obesity. Nephrol Dial Transplant. 2008; 23(1): 47-51.

21. Keys A, Fidanza F, Karvonen MJ, Kimura N, Taylor HL. Indices of relative weight and obesity. J Chronic Dis. 1972; 25(6): 329-43.

22. World Health Organization. Obesity: preventing and managing the global epidemic. Acceso a través de la página web: http://www.who.int/nutrition/publications/obesity/WHO_TRS_894/en/

23. World Health Organization. BMI classification. Acceso a través de la página web: http:/ /apps.who.int/bmi/index.jsp?introPage=intro_3.html

24. Deurenberg P, Deurenberg-Yap M, Wang J, Lin FP, Schmidt G. The impact of body build on the relationship between body mass index and percent body fat. Int J Obes Relat Metab Disord. 1999; 23(5): 537-42.

25. Oliveros E, Somers VK, Sochor O, Goel K, Lopez-Jimenez F. The concept of normal weight obesity. Prog Cardiovasc Dis. 2014; 56(4): 426-33.

26. Deurenberg P, Deurenberg-Yap M, Guricci S. Asians are different from Caucasians and from each other in their body mass index/body fat per cent relationship. Obes Rev. 2002; 3(3): 141-6. 
27. World Health Organization. The Asia Pacific perspective: Redefining obesity and its treatment. Acceso a través de la página web: http://www.wpro.who.int/nutrition/documents/Redefining_obesity/en/

28. Deurenberg-Yap M, Chew SK, Deurenberg P. Elevated body fat percentage and cardiovascular risks at low body mass index levels among Singaporean Chinese, Malays and Indians. Obes Rev. 2002; 3(3): 209-15.

29. Vikram NK, Pandey RM, Misra A, Sharma R, Devi JR, Khanna N. Non-obese (body mass index $<25 \mathrm{~kg} / \mathrm{m} 2$ ) Asian Indians with normal waist circumference have high cardiovascular risk. Nutrition. 2003; 19(6): 503-9.

30. Misra A, Khurana L. The metabolic syndrome in South Asians: epidemiology, determinants, and prevention. Metab Syndr Relat Disord. 2009; 7(6): 497-514.

31. Misra A, Vikram NK. Insulin resistance syndrome (metabolic syndrome) and obesity in Asian Indians: evidence and implications. Nutrition. 2004; 20(5): 482-91.

32. Misra A, Shrivastava U. Obesity and dyslipidemia in South Asians. Nutrients. 2013; 5(7): 2708-33.

33. Misra A, Khurana L. Obesity-related non-communicable diseases: South Asians vs White Caucasians. Int J Obes (Lond). 2011; 35(2): 167-87.

34. Huxley R, Mendis S, Zheleznyakov E, Reddy S, Chan J. Body mass index, waist circumference and waist:hip ratio as predictors of cardiovascular risk--a review of the literature. Eur J Clin Nutr. 2010; 64(1): 16-22.

35. Zheng W, McLerran DF, Rolland B, Zhang X, Inoue $M$, Matsuo $K$, et al. Association between body-mass index and risk of death in more than 1 million Asians. N Engl J Med. 2011; 364(8): 719-29.

36. Chen Y, Copeland WK, Vedanthan R, Grant E, Lee JE, Gu D, et al. Association between body mass index and cardiovascular disease mortality in east Asians and south Asians: pooled analysis of prospective data from the Asia Cohort Consortium. BMJ. 2013; 347: f5446.

37. Deurenberg P, Yap M, van Staveren WA. Body mass index and percent body fat: a meta analysis among different ethnic groups. Int J Obes Relat Metab Disord. 1998; 22(12): 1164-71.

38. Razak F, Anand SS, Shannon H, Vuksan V, Davis B, Jacobs R, et al. Defining obesity cut points in a multiethnic population. Circulation. 2007; 115(16): 2111-8.

39. Flegal KM, Graubard BI, Williamson DF, Gail MH. Excess deaths associated with underweight, overweight, and obesity. JAMA. 2005; 293(15): 1861-7.

40. Troiano RP, Frongillo EA, Sobal J, Levitsky DA. The relationship between body weight and mortality: a quantitative analysis of combined information from existing studies. Int J Obes Relat Metab Disord. 1996; 20(1): 63-75. 
41. Manson JE, Stampfer MJ, Hennekens CH, Willett WC. Body weight and longevity. A reassessment. JAMA. 1987; 257(3): 353-8.

42. Flegal KM, Kit BK, Orpana H, Graubard BI. Association of all-cause mortality with overweight and obesity using standard body mass index categories: a systematic review and meta-analysis. JAMA. 2013; 309(1): 71-82.

43. Berrington de Gonzalez A, Hartge P, Cerhan JR, Flint AJ, Hannan L, MacInnis RJ, et al. Body-mass index and mortality among 1.46 million white adults. N Engl J Med. 2010; 363(23): 2211-9.

44. Whitlock G, Lewington S, Sherliker P, Clarke R, Emberson J, Halsey J, et al. Bodymass index and cause-specific mortality in 900000 adults: collaborative analyses of 57 prospective studies. Lancet. 2009; 373(9669): 1083-96.

45. Niedziela J, Hudzik B, Niedziela N, Gąsior M, Gierlotka M, Wasilewski J, et al. The obesity paradox in acute coronary syndrome: a meta-analysis. Eur J Epidemiol. 2014; 29(11): 801-12.

46. Kramer CK, Zinman B, Retnakaran R. Are metabolically healthy overweight and obesity benign conditions?: A systematic review and meta-analysis. Ann Intern Med. 2013; 159(11): 758-69.

47. American Society for Metabolic and Bariatric Surgery. Disease of Obesity. Acceso a través de la página web: https://asmbs.org/patients/disease-of-obesity

48. National Institutes of Health, National Heart, Lung, and Blood Institute Obesity Education Initiative Expert Panel Obesity Education Initiative, North American Association for the Study of Obesity. "The practical Guide. Identification, Evaluation, and Treatment of Overweight and Obesity in Adults". Ed. National Institutes of Health. Bethesda (Maryland). 2000.

49. Janssen I, Katzmarzyk PT, Ross R. Waist circumference and not body mass index explains obesity-related health risk. Am J Clin Nutr. 2004; 79(3): 379-84.

50. Pouliot MC, Després JP, Lemieux S, Moorjani S, Bouchard C, Tremblay A, et al. Waist circumference and abdominal sagittal diameter: best simple anthropometric indexes of abdominal visceral adipose tissue accumulation and related cardiovascular risk in men and women. Am J Cardiol. 1994; 73(7): 460-8.

51. Tchernof A, Després JP. Pathophysiology of human visceral obesity: an update. Physiol Rev. 2013; 93(1): 359-404.

52. Grundy SM, Cleeman JI, Daniels SR, Donato KA, Eckel RH, Franklin BA, et al. Diagnosis and management of the metabolic syndrome: an American Heart Association/National Heart, Lung, and Blood Institute Scientific Statement. Circulation. 2005; 112(17): 2735-52. 
53. Florath I, Brandt S, Weck MN, Moss A, Gottmann P, Rothenbacher D, et al. Evidence of inappropriate cardiovascular risk assessment in middle-age women based on recommended cut-points for waist circumference. Nutr Metab Cardiovasc Dis. 2014; 24(10): 1112-9.

54. Nazare JA, Smith JD, Borel AL, Haffner SM, Balkau B, Ross R, et al. Ethnic influences on the relations between abdominal subcutaneous and visceral adiposity, liver fat, and cardiometabolic risk profile: the International Study of Prediction of Intra-Abdominal Adiposity and Its Relationship With Cardiometabolic Risk/IntraAbdominal Adiposity. Am J Clin Nutr. 2012; 96(4): 714-26.

55. World Health Organization. Waist Circumference and Waist-Hip Ratio. Acceso a través de la página web: http://www.who.int/nutrition/publications/obesity/WHO_report_waistcircumfere nce_and_waisthip_ratio/en/

56. Siren R, Eriksson JG, Vanhanen H. Waist circumference a good indicator of future risk for type 2 diabetes and cardiovascular disease. BMC Public Health. 2012; 12: 631.

57. Bombelli M, Facchetti R, Fodri D, Brambilla G, Sega R, Grassi G, et al. Impact of body mass index and waist circumference on the cardiovascular risk and all-cause death in a general population: data from the PAMELA study. Nutr Metab Cardiovasc Dis. 2013; 23(7): 650-6.

58. Jacobs EJ, Newton CC, Wang Y, Patel A V, McCullough ML, Campbell PT, et al. Waist circumference and all-cause mortality in a large US cohort. Arch Intern Med. 2010; 170(15): 1293-301.

59. Koster A, Leitzmann MF, Schatzkin A, Mouw T, Adams KF, van Eijk JTM, et al. Waist circumference and mortality. Am J Epidemiol. 2008; 167(12): 1465-75.

60. Molarius A, Seidell JC. Selection of anthropometric indicators for classification of abdominal fatness -- $\quad$ a critical review. Int J Obes Relat Metab Disord. 1998; 22(8): 719-27.

61. Ashwell M, Gunn P, Gibson S. Waist-to-height ratio is a better screening tool than waist circumference and BMI for adult cardiometabolic risk factors: systematic review and meta-analysis. Obes Rev. 2012; 13(3): 275-86.

62. Lanthier N, Leclercq IA. Adipose tissues as endocrine target organs. Best Pract Res Clin Gastroenterol. 2014; 28(4): 545-58.

63. Moreno MJ, Martínez JA. Adipose tissue: a storage and secretory organ. An Sist Sanit Navar. 2002; 25(Suppl 1): 29-39.

64. Perez Miguelsanz MJ, Cabrera Parra W, Varela Moreiras G, Garaulet M. Distribución regional de la grasa corporal. Uso de técnicas de imagen como herramienta de diagnóstico nutricional. Nutr Hosp. 2010; 25(2): 207-23. 
65. Cannon B, Nedergaard J. Brown adipose tissue: function and physiological significance. Physiol Rev. 2004; 84(1): 277-359.

66. Van Marken Lichtenbelt WD, Vanhommerig JW, Smulders NM, Drossaerts JMAFL, Kemerink GJ, Bouvy ND, et al. Cold-activated brown adipose tissue in healthy men. N Engl J Med. 2009; 360(15): 1500-8.

67. Shen W, Wang Z, Punyanita M, Lei J, Sinav A, Kral JG, et al. Adipose tissue quantification by imaging methods: a proposed classification. Obes Res. 2003; 11(1): 5-16.

68. Frayn KN, Karpe F, Fielding BA, Macdonald IA, Coppack SW. Integrative physiology of human adipose tissue. Int J Obes Relat Metab Disord. 2003; 27(8): 875-88.

69. Wang QA, Tao C, Gupta RK, Scherer PE. Tracking adipogenesis during white adipose tissue development, expansion and regeneration. Nat Med. 2013; 19(10): 1338-44.

70. Waki H, Tontonoz P. Endocrine functions of adipose tissue. Annu Rev Pathol. 2007; 2: 31-56.

71. Cao H. Adipocytokines in obesity and metabolic disease. J Endocrinol. 2014; 220(2): T47-59.

72. Fundación Española de la Nutrición, Gregorio Varela Moreiras (coordinador). "Libro blanco de la nutrición en España". Ed. Fundación Española de la Nutrición. Madrid. 2013.

73. Dhurandhar EJ, Keith SW. The aetiology of obesity beyond eating more and exercising less. Best Pract Res Clin Gastroenterol. 2014; 28(4): 533-44.

74. Allen G, Safranek S. FPIN's clinical inquiries. Secondary causes of obesity. Am Fam Physician. 2011; 83(8): 972-3.

75. González Jiménez E. Obesity: etiologic and pathophysiological analysis. Endocrinol Nutr. 2013; 60(1): 17-24.

76. Aranceta-Bartrina J, Serra-Majem L, Foz-Sala M, Moreno-Esteban B, Grupo colaborativo SEEDO. Prevalencia de obesidad en España. Med Clin (Barc). 2005; 125(12): 460-6.

77. Waalen J. The genetics of human obesity. Transl Res. 2014; 164(4): 293-301.

78. Herring MP, Sailors MH, Bray MS. Genetic factors in exercise adoption, adherence and obesity. Obes Rev. 2014; 15(1): 29-39.

79. Zhang Y, Liu J, Yao J, Ji G, Qian L, Wang J, et al. Obesity: pathophysiology and intervention. Nutrients. 2014; 6(11): 5153-83. 
80. Gremese E, Tolusso B, Gigante MR, Ferraccioli G. Obesity as a risk and severity factor in rheumatic diseases (autoimmune chronic inflammatory diseases). Front Immunol. 2014; 5: 576.

81. Drager LF, Togeiro SM, Polotsky VY, Lorenzi-Filho G. Obstructive sleep apnea: a cardiometabolic risk in obesity and the metabolic syndrome. J Am Coll Cardiol. 2013; 62(7): 569-76.

82. Mostad IL, Langaas M, Grill V. Central obesity is associated with lower intake of whole-grain bread and less frequent breakfast and lunch: results from the HUNT study, an adult all-population survey. Appl Physiol Nutr Metab. 2014; 39(7): 819-28.

83. Allison KC, Grilo CM, Masheb RM, Stunkard AJ. Binge eating disorder and night eating syndrome: a comparative study of disordered eating. J Consult Clin Psychol. 2005; 73(6): 1107-15.

84. Instituto Nacional de Estadística. Encuesta Nacional de Salud 2011-2012. Acceso a través de la página web: http://www.ine.es $/$ jaxi/menu.do?type $=$ pcaxis\&path $=/$ t15/p419\&file=inebase

85. Finkelstein EA, Brown DS, Wrage LA, Allaire BT, Hoerger TJ. Individual and aggregate years-of-life-lost associated with overweight and obesity. Obesity. 2010; 18(2): 333-9.

86. Instituto Nacional de Estadistica. Salud. Defunciones según la causa de muerte. Acceso a través de la página web: http:/ $/$ www.ine.es $/$ jaxi $/$ menu.do?type $=$ pcaxis $\&$ path $=/ \mathrm{t} 15 / \mathrm{p} 417 \&$ file $=$ inebase $\& \mathrm{~L}=$ 0

87. Oliva J, Gonzalez L, Labeaga JM, ALvarez C. Salud pública, economía y obesidad: el bueno, el feo y el malo. Gac Sanit. 2008; 22(6): 507-10.

88. Gabinete de estudios Bernard Krief. "Costes sociales y económicos de la obesidad y sus patologías asociadas (hipertensión, hiperlipidemias y diabetes): los tratamientos de futuro y el coste-beneficio generado por su aplicación en el horizonte del año 2005 en España. Estudio prospectivo Delphi: libro blanco". Ed. Bernard Krief. Madrid. 1999.

89. Guh DP, Zhang W, Bansback N, Amarsi Z, Birmingham CL, Anis AH. The incidence of co-morbidities related to obesity and overweight: a systematic review and meta-analysis. BMC Public Health. 2009; 9: 88.

90. Álvarez-Castro P, Sangiao-Alvarellos S, Brandón-Sandá I, Cordido F. Endocrine function in obesity. Endocrinol Nutr. 2011; 58(8): 422-32.

91. Forga L, Petrina E, Barbería JJ. Complications of obesity. An Sist Sanit Navar. 2002; 25(Suppl 1): 117-26.

92. Kaur J. A comprehensive review on metabolic syndrome. Cardiol Res Pract. 2014; 2014: 943162. 
93. Reaven GM. Banting lecture 1988: Role of insulin resistance in human disease. Diabetes. 1988; 37(12): 1595-607.

94. Expert Panel on Detection, Evaluation, and Treatment of High Blood Cholesterol in Adults. Executive Summary of The Third Report of The National Cholesterol Education Program (NCEP) Expert Panel on Detection, Evaluation, And Treatment of High Blood Cholesterol In Adults (Adult Treatment Panel III). JAMA. 2001; 285(19): 2486-97.

95. Alberti KG, Zimmet P, Shaw J, IDF Epidemiology Task Force Consensus Group. The metabolic syndrome -- a new worldwide definition. Lancet. 2005; 366(9491): 1059-62.

96. Alberti KG, Eckel RH, Grundy SM, Zimmet PZ, Cleeman JI, Donato KA, et al. Harmonizing the metabolic syndrome: a joint interim statement of the International Diabetes Federation Task Force on Epidemiology and Prevention; National Heart, Lung, and Blood Institute; American Heart Association; World Heart Federation; International Atherosclerosis Society; and International Association for the Study of Obesity. Circulation. 2009; 120(16): 1640-5.

97. American Diabetes Association. Diagnosis and classification of diabetes mellitus. Diabetes Care. 2010; 33(Suppl 1): S62-9.

98. Danaei G, Finucane MM, Lu Y, Singh GM, Cowan MJ, Paciorek CJ, et al. National, regional, and global trends in fasting plasma glucose and diabetes prevalence since 1980: systematic analysis of health examination surveys and epidemiological studies with 370 country-years and $2 \cdot 7$ million participants. Lancet. 2011; 378(9785): 31-40.

99. Nolan CJ, Damm P, Prentki M. Type 2 diabetes across generations: from pathophysiology to prevention and management. Lancet. 2011; 378(9786): 169-81.

100. Gomis R, Artola S, Conthe P, Vidal J, Casamor R, Font B. Prevalence of type 2 diabetes mellitus in overweight or obese outpatients in Spain. OBEDIA Study. Med Clin (Barc). 2014; 142(11): 485-92.

101. Liu XM, Liu YJ, Zhan J, He QQ. Overweight, obesity and risk of all-cause and cardiovascular mortality in patients with type 2 diabetes mellitus: a dose-response meta-analysis of prospective cohort studies. Eur J Epidemiol. 2014; 30(1): 35-45.

102. Tobias DK, Pan A, Jackson CL, O'Reilly EJ, Ding EL, Willett WC, et al. Body-mass index and mortality among adults with incident type 2 diabetes. N Engl J Med. 2014; 370(3): 233-44.

103. Nikolic D, Katsiki N, Montalto G, Isenovic ER, Mikhailidis DP, Rizzo M. Lipoprotein subfractions in metabolic syndrome and obesity: clinical significance and therapeutic approaches. Nutrients. 2013; 5(3): 928-48.

104. Franssen R, Monajemi H, Stroes ESG, Kastelein JJP. Obesity and dyslipidemia. Med Clin North Am. 2011; 95(5): 893-902. 
105. Al-Goblan AS, Al-Alfi MA, Khan MZ. Mechanism linking diabetes mellitus and obesity. Diabetes Metab Syndr Obes. 2014; 7: 587-91.

106. Álvarez-Lario B, Alonso-Valdivielso JL. Hyperuricemia and gout; the role of diet. Nutr Hosp. 2014; 29(4): 760-70.

107. Johnson RJ, Nakagawa T, Sanchez-Lozada LG, Shafiu M, Sundaram S, Le M, et al. Sugar, uric acid, and the etiology of diabetes and obesity. Diabetes. 2013; 62(10): 3307-15.

108. Grassi D, Ferri L, Desideri G, Di Giosia P, Cheli P, Del Pinto R, et al. Chronic hyperuricemia, uric acid deposit and cardiovascular risk. Curr Pharm Des. 2013; 19(13): 2432-8.

109. Cea Soriano L, Rothenbacher D, Choi HK, García Rodríguez LA. Contemporary epidemiology of gout in the UK general population. Arthritis Res Ther. 2011; 13(2): R39.

110. López-Jiménez F, Cortés-Bergoderi M. Update: systemic diseases and the cardiovascular system (i): obesity and the heart. Rev Esp Cardiol. 2011; 64(2): 140-9.

111. Bastien M, Poirier P, Lemieux I, Després JP. Overview of epidemiology and contribution of obesity to cardiovascular disease. Prog Cardiovasc Dis. 2014; 56(4): 369-81.

112. Nakamura K, Fuster JJ, Walsh K. Adipokines: a link between obesity and cardiovascular disease. J Cardiol. 2014; 63(4): 250-9.

113. Morange PE, Alessi MC. Thrombosis in central obesity and metabolic syndrome: mechanisms and epidemiology. Thromb Haemost. 2013; 110(4): 669-80.

114. Wilson PWF, D'Agostino RB, Sullivan L, Parise H, Kannel WB. Overweight and Obesity as Determinants of Cardiovascular Risk. Arch Intern Med. 2002; 162(16): 1867.

115. Yusuf S, Hawken S, Ounpuu S, Dans T, Avezum A, Lanas F, et al. Effect of potentially modifiable risk factors associated with myocardial infarction in 52 countries (the INTERHEART study): case-control study. Lancet. 2004; 364(9438): 937-52.

116. Lu Y, Hajifathalian K, Ezzati M, Woodward M, Rimm EB, Danaei G. Metabolic mediators of the effects of body-mass index, overweight, and obesity on coronary heart disease and stroke: a pooled analysis of 97 prospective cohorts with 1.8 million participants. Lancet. 2014; 383(9921): 970-83.

117. Kenchaiah S, Evans JC, Levy D, Wilson PWF, Benjamin EJ, Larson MG, et al. Obesity and the risk of heart failure. N Engl J Med. 2002; 347(5): 305-13. 
118. Clark AL, Fonarow GC, Horwich TB. Obesity and the obesity paradox in heart failure. Prog Cardiovasc Dis. 2014; 56(4): 409-14.

119. Abed HS, Wittert GA. Obesity and atrial fibrillation. Obes Rev. 2013; 14(11): 929-38.

120. Wang TJ, Parise H, Levy D, D’Agostino RB, Wolf PA, Vasan RS, et al. Obesity and the risk of new-onset atrial fibrillation. JAMA. 2004; 292(20): 2471-7.

121. Dehlendorff C, Andersen KK, Olsen TS. Body mass index and death by stroke: no obesity paradox. JAMA Neurol. 2014; 71(8): 978-84.

122. Abete I, Arriola L, Etxezarreta N, Mozo I, Moreno-Iribas C, Amiano P, et al. Association between different obesity measures and the risk of stroke in the EPIC Spanish cohort. Eur J Nutr. 2015; 54(3): 365-75.

123. Klovaite J, Benn M, Nordestgaard BG. Obesity as a causal risk factor for deep venous thrombosis: a Mendelian randomization study. J Intern Med. 2015; 277(5): 573-84.

124. Littleton SW. Impact of obesity on respiratory function. Respirology. 2012; 17(1): 43-9.

125. Santamaria F, Montella S, Pietrobelli A. Obesity and pulmonary disease: unanswered questions. Obes Rev. 2012; 13(9): 822-33.

126. Leiria LOS, Martins MA, Saad MJA. Obesity and asthma: beyond TH2 inflammation. Metabolism. 2014; 64(2): 172-81.

127. Chau EHL, Lam D, Wong J, Mokhlesi B, Chung F. Obesity hypoventilation syndrome: a review of epidemiology, pathophysiology, and perioperative considerations. Anesthesiology. 2012; 117(1): 188-205.

128. Isono S. Obesity and obstructive sleep apnoea: mechanisms for increased collapsibility of the passive pharyngeal airway. Respirology. 2012; 17(1): 32-42.

129. Leong WB, Arora T, Jenkinson D, Thomas A, Punamiya V, Banerjee D, et al. The prevalence and severity of obstructive sleep apnea in severe obesity: the impact of ethnicity. J Clin Sleep Med. 2013; 9(9): 853-8.

130. Bonsignore MR, McNicholas W'T, Montserrat JM, Eckel J. Adipose tissue in obesity and obstructive sleep apnoea. Eur Respir J. 2012; 39(3): 746-67.

131. Grotle M, Hagen KB, Natvig B, Dahl FA, Kvien TK. Obesity and osteoarthritis in knee, hip and/or hand: an epidemiological study in the general population with 10 years follow-up. BMC Musculoskelet Disord. 2008; 9: 132.

132. Sabharwal S, Root MZ. Impact of obesity on orthopaedics. J Bone Joint Surg Am. 2012; 94(11): 1045-52. 
133. Gower BA, Casazza K. Divergent effects of obesity on bone health. J Clin Densitom. 2013; 16(4): 450-4.

134. Franceschi F, Papalia R, Paciotti M, Franceschetti E, Di Martino A, Maffulli N, et al. Obesity as a risk factor for tendinopathy: a systematic review. Int J Endocrinol. 2014; 2014: 670262.

135. Berger NA. Obesity and cancer pathogenesis. Ann N Y Acad Sci. 2014; 1311: 57-76.

136. De Pergola G, Silvestris F. Obesity as a major risk factor for cancer. J Obes. 2013; 2013: 291546.

137. Renehan AG, Tyson M, Egger M, Heller RF, Zwahlen M. Body-mass index and incidence of cancer: a systematic review and meta-analysis of prospective observational studies. Lancet. 2008; 371(9612): 569-78.

138. Lashinger LM, Rossi EL, Hursting SD. Obesity and resistance to cancer chemotherapy: interacting roles of inflammation and metabolic dysregulation. Clin Pharmacol Ther. 2014; 96(4): 458-63.

139. American Psychiatric Association. DSM-5 Manual Diagnóstico y Estadístico de los Trastornos Mentales (Spanish Edition). 5ª ed. Ed. Panamericana. 2014.

140. Nousen EK, Franco JG, Sullivan EL. Unraveling the mechanisms responsible for the comorbidity between metabolic syndrome and mental health disorders. Neuroendocrinology. 2013; 98(4): 254-66.

141. Yen YC, Huang CK, Tai CM Psychiatric aspects of bariatric surgery. Curr Opin Psychiatry. 2014;27(5):374-9.

142. Acosta A, Camilleri M. Gastrointestinal morbidity in obesity. Ann N Y Acad Sci. 2014; 1311: 42-56.

143. Locke GR, Talley NJ, Fett SL, Zinsmeister AR, Melton LJ. Risk factors associated with symptoms of gastroesophageal reflux. Am J Med. 1999; 106(6): 642-9.

144. Mion F, Dargent J. Gastro-oesophageal reflux disease and obesity: pathogenesis and response to treatment. Best Pract Res Clin Gastroenterol. 2014; 28(4): 611-22.

145. Dietrich P, Hellerbrand C. Non-alcoholic fatty liver disease, obesity and the metabolic syndrome. Best Pract Res Clin Gastroenterol. 2014; 28(4): 637-53.

146. Bonfrate L, Wang DQ, Garruti G, Portincasa P. Obesity and the risk and prognosis of gallstone disease and pancreatitis. Best Pract Res Clin Gastroenterol. 2014; 28(4): 623-35.

147. Uy MC, Talingdan-Te MC, Espinosa WZ, Daez MLO, Ong JP. Ursodeoxycholic acid in the prevention of gallstone formation after bariatric surgery: a meta-analysis. Obes Surg. 2008; 18(12): 1532-8. 
148. Falagas ME, Kompoti M. Obesity and infection. Lancet Infect Dis. 2006; 6(7): 438-46.

149. Franz MJ, VanWormer JJ, Crain AL, Boucher JL, Histon T, Caplan W, et al. Weight-loss outcomes: a systematic review and meta-analysis of weight-loss clinical trials with a minimum 1-year follow-up. J Am Diet Assoc. 2007; 107(10): 1755-67.

150. Gargallo Fernández M, Marset JB, Lesmes IB, Izquierdo JQ, Sala XF, Salas-Salvadó J; Grupo de Consenso FESNAD-SEEDO. FESNAD-SEEDO consensus summary: evidence-based nutritional recommendations for the prevention and treatment of overweight and obesity in adults. Endocrinol Nutr. 2012; 59(7): 429-37.

151. Fock KM, Khoo J. Diet and exercise in management of obesity and overweight. J Gastroenterol Hepatol. 2013; 28 Suppl 4: 59-63.

152. Sacks FM, Bray GA, Carey VJ, Smith SR, Ryan DH, Anton SD, et al. Comparison of weight-loss diets with different compositions of fat, protein, and carbohydrates. N Engl J Med. 2009; 360(9): 859-73.

153. Washburn RA, Szabo AN, Lambourne K, Willis EA, Ptomey LT, Honas JJ, et al. Does the method of weight loss effect long-term changes in weight, body composition or chronic disease risk factors in overweight or obese adults? A systematic review. PLoS One. 2014; 9(10): e109849.

154. Bray GA. Medical treatment of obesity: the past, the present and the future. Best Pract Res Clin Gastroenterol. 2014; 28(4): 665-84.

155. Food and Drug Administration. Acceso a través de la página web: http://www.fda.gov/

156. European Medicines Agency. Acceso a través de la página web: http://www.ema.europa.eu/ema/

157. Klein S, Fontana L, Young VL, Coggan AR, Kilo C, Patterson BW, et al. Absence of an effect of liposuction on insulin action and risk factors for coronary heart disease. N Engl J Med. 2004; 350(25): 2549-57.

158. Larrañaga A, García-Mayor R. Psychological treatment for obesity. Med Clin (Barc). 2007; 129(10): 387-91.

159. Johns DJ, Hartmann-Boyce J, Jebb SA, Aveyard P. Diet or exercise interventions vs combined behavioral weight management programs: a systematic review and metaanalysis of direct comparisons. J Acad Nutr Diet. 2014; 114(10): 1557-68.

160. Smits LP, Bouter KEC, de Vos WM, Borody TJ, Nieuwdorp M. Therapeutic potential of fecal microbiota transplantation. Gastroenterology. 2013; 145(5): 946-53. 
161. Koehestanie P, de Jonge C, Berends FJ, Janssen IM, Bouvy ND, Greve JWM. The effect of the endoscopic duodenal-jejunal bypass liner on obesity and type 2 diabetes mellitus, a multicenter randomized controlled trial. Ann Surg. 2014; 260(6): 984-92.

162. Verlaan T, Paulus GF, Mathus-Vliegen EMH, Veldhuyzen EAML, Conchillo JM, Bouvy ND, et al. Endoscopic gastric volume reduction with a novel articulating plication device is safe and effective in the treatment of obesity (with video). Gastrointest Endosc. 2015; 81(2): 312-20.

163. SAGES Guidelines Committee. SAGES guideline for clinical application of laparoscopic bariatric surgery. Surg Endosc. 2008; 22(10): 2281-300.

164. Dumon K, Savulionyte G. Bariatric surgery produces greater weight loss and improvements in medical conditions than non-surgical treatment of obesity. Evid Based Med. 2014; 19(4): 138.

165. Gloy VL, Briel M, Bhatt DL, Kashyap SR, Schauer PR, Mingrone G, et al. Bariatric surgery versus non-surgical treatment for obesity: a systematic review and metaanalysis of randomised controlled trials. BMJ. 2013; 347: f5934.

166. Chang SH, Stoll CR, Song J, Varela JE, Eagon CJ, Colditz GA. The effectiveness and risks of bariatric surgery: an updated systematic review and meta-analysis, 20032012. JAMA Surg. 2014; 149(3): 275-87.

167. Ribaric G, Buchwald JN, McGlennon TW. Diabetes and weight in comparative studies of bariatric surgery vs conventional medical therapy: a systematic review and meta-analysis. Obes Surg. 2014; 24(3): 437-55.

168. Colquitt JL, Pickett K, Loveman E, Frampton GK. Surgery for weight loss in adults. Cochrane Database Syst Rev. 2014; 8: CD003641.

169. Angrisani L, Santonicola A, Iovino P, Formisano G, Buchwald H, Scopinaro N. Bariatric Surgery Worldwide 2013. Obes Surg. 2015; 25(10): 1822-32.

170. Rubio MA, Monereo S, Lecube A, Resa J, Masdevall C, de la Cruz Vigo F, et al. Joint Position Statement of the SEEN-SECO-SEEDO-SED Societies on metabolic surgery for type 2 diabetes mellitus. Endocrinol Nutr. 2013; 60(10): 547-8.

171. Pories WJ, Swanson MS, MacDonald KG, Long SB, Morris PG, Brown BM, et al. Who would have thought it? An operation proves to be the most effective therapy for adult-onset diabetes mellitus. Ann Surg. 1995; 222(3): 332-9.

172. Mechanick JI, Youdim A, Jones DB, Garvey WT, Hurley DL, McMahon MM, et al. Clinical practice guidelines for the perioperative nutritional, metabolic, and nonsurgical support of the bariatric surgery patient--2013 update: cosponsored by American Association of Clinical Endocrinologists, The Obesity Society, and American Society for Metabolic \& Bariatric Surgery. Obesity. 2013; 21(Suppl 1): S1-27. 
173. Picot J, Jones J, Colquitt JL, Gospodarevskaya E, Loveman E, Baxter L, et al. The clinical effectiveness and cost-effectiveness of bariatric (weight loss) surgery for obesity: a systematic review and economic evaluation. Health Technol Assess. 2009; 13(41): 1-190.

174. Richards NG, Beekley AC, Tichansky DS. The economic costs of obesity and the impact of bariatric surgery. Surg Clin North Am. 2011; 91(6): 1173-80.

175. Fried M, Yumuk V, Oppert JM, Scopinaro N, Torres A, Weiner R, et al. Interdisciplinary European guidelines on metabolic and bariatric surgery. Obes Surg. 2014; 24(1): 42-55.

176. Lakdawala M, Bhasker A. Report: Asian Consensus Meeting on Metabolic Surgery. Recommendations for the use of Bariatric and Gastrointestinal Metabolic Surgery for Treatment of Obesity and Type II Diabetes Mellitus in the Asian Population: August 9th and 10th, 2008, Trivandrum, India. Obes Surg. 2010; 20(7): 929-36.

177. Juan Carlos Ruiz de Adana, Raquel Sánchez Santos (editores). "Cirugía de la obesidad mórbida. Guías clínicas de la Asociación Española de Cirujanos". $2^{a}$ ed. Ed. Aran. Madrid. 2012.

178. Flum DR, Belle SH, King WC, Wahed AS, Berk P, Chapman W, et al. Perioperative safety in the longitudinal assessment of bariatric surgery. N Engl J Med. 2009; 361(5): 445-54.

179. Buchwald H. A bariatric surgery algorithm. Obes Surg. 2002; 12(6): 733-50.

180. ASMBS Clinical Issues Committee. Updated position statement on sleeve gastrectomy as a bariatric procedure. Surg Obes Relat Dis. 2012; 8(3): e21-6.

181. Martínez-Ramos D, Salvador-Sanchis JL, Escrig-Sos J. Preoperative weight loss in bariatric surgery candidate patients. Evidence-based recommendations. Cir Esp. 2012; 90(3): 147-55.

182. DeMaria EJ, Portenier D, Wolfe L. Obesity surgery mortality risk score: proposal for a clinically useful score to predict mortality risk in patients undergoing gastric bypass. Surg Obes Relat Dis. 2007; 3(2): 134-40.

183. DeMaria EJ, Murr M, Byrne TK, Blackstone R, Grant JP, Budak A, et al. Validation of the obesity surgery mortality risk score in a multicenter study proves it stratifies mortality risk in patients undergoing gastric bypass for morbid obesity. Ann Surg. 2007; 246(4): 574-8.

184. Thomas H, Agrawal S. Systematic review of obesity surgery mortality risk score -preoperative risk stratification in bariatric surgery. Obes Surg. 2012; 22(7): 1135-40.

185. Tariq N, Moore LW, Sherman V. Bariatric surgery and end-stage organ failure. Surg Clin North Am. 2013; 93(6): 1359-71. 
186. Lazzati A, Iannelli A, Schneck A-S, Nelson AC, Katsahian S, Gugenheim J, et al. Bariatric surgery and liver transplantation: a systematic review a new frontier for bariatric surgery. Obes Surg. 2015; 25(1): 134-42.

187. Larrad Á, Sánchez-Cabezudo C. Indicadores de calidad en cirugía bariátrica y criterios de éxito a largo plazo. Cir Esp. 2004; 75(3): 301-4.

188. Van de Laar A. Bariatric Outcomes Longitudinal Database (BOLD) suggests excess weight loss and excess BMI loss to be inappropriate outcome measures, demonstrating better alternatives. Obes Surg. 2012; 22(12): 1843-7.

189. Van de Laar AW, Acherman YI. Weight loss percentile charts of large representative series: a benchmark defining sufficient weight loss challenging current criteria for success of bariatric surgery. Obes Surg. 2014; 24(5): 727-34.

190. Buse JB, Caprio S, Cefalu WT, Ceriello A, Del Prato S, Inzucchi SE, et al. How do we define cure of diabetes?. Diabetes Care. 2009; 32(11): 2133-5.

191. Dixon JB, Zimmet P, Alberti KG, Rubino F, International Diabetes Federation Taskforce on Epidemiology and Prevention. Bariatric surgery: an IDF statement for obese type 2 diabetes. Surg Obes Relat Dis. 2011; 7(4): 433-47.

192. Epstein LJ, Kristo D, Strollo PJ, Friedman N, Malhotra A, Patil SP, et al. Clinical guideline for the evaluation, management and long-term care of obstructive sleep apnea in adults. J Clin Sleep Med. 2009; 5(3): 263-76.

193. Sjöström L. Review of the key results from the Swedish Obese Subjects (SOS) trial a prospective controlled intervention study of bariatric surgery. J Intern Med. 2013; 273(3): 219-34.

194. Bower G, Toma T, Harling L, Jiao LR, Efthimiou E, Darzi A, et al. Bariatric Surgery and Non-Alcoholic Fatty Liver Disease: a Systematic Review of Liver Biochemistry and Histology. Obes Surg. 2015; 25(12): 2280-9.

195. Altieri MS, Pryor AD. Gastroesophageal Reflux Disease After Bariatric Procedures. Surg Clin North Am. 2015; 95(3): 579-91.

196. Oria HE, Moorehead MK. Bariatric analysis and reporting outcome system (BAROS). Obes Surg. 1998; 8(5): 487-99.

197. Anderson B, Switzer NJ, Almamar A, Shi X, Birch DW, Karmali S. The impact of laparoscopic sleeve gastrectomy on plasma ghrelin levels: a systematic review. Obes Surg. 2013; 23(9): 1476-80.

198. Mason EE. Vertical banded gastroplasty for obesity. Arch Surg. 1982; 117(5): 701-6.

199. Miller K, Pump A, Hell E. Vertical banded gastroplasty versus adjustable gastric banding: prospective long-term follow-up study. Surg Obes Relat Dis. 2007; 3(1): 84-90. 
200. Kuzmak LI, Yap IS, McGuire L, Dixon JS, Young MP. Surgery for morbid obesity. Using an inflatable gastric band. AORN J. 1990; 51(5): 1307-24.

201. Gumbs AA, Gagner M, Dakin G, Pomp A. Sleeve gastrectomy for morbid obesity. Obes Surg. 2007; 17(7): 962-9.

202. Cigaina V. Gastric pacing as therapy for morbid obesity: preliminary results. Obes Surg. 2002; 12(Suppl 1): 12S-16S.

203. Cha R, Marescaux J, Diana M. Updates on gastric electrical stimulation to treat obesity: Systematic review and future perspectives. World J Gastrointest Endosc. 2014; 6(9): 419-31.

204. Talebpour M, Amoli BS. Laparoscopic total gastric vertical plication in morbid obesity. J Laparoendosc Adv Surg Tech A. 2007; 17(6): 793-8.

205. DeWind LT, Payne JH. Intestinal bypass surgery for morbid obesity. Long-term results. JAMA. 1976; 236(20): 2298-301.

206. Scopinaro N, Gianetta E, Civalleri D, Bonalumi U, Bachi V. Bilio-pancreatic bypass for obesity: 1. An experimental study in dogs. Br J Surg. 1979; 66(9): 613-7.

207. Scopinaro N, Gianetta E, Civalleri D, Bonalumi U, Bachi V. Bilio-pancreatic bypass for obesity: II. Initial experience in man. Br J Surg. 1979; 66(9): 618-20.

208. Hess DS, Hess DW. Biliopancreatic diversion with a duodenal switch. Obes Surg. 1998; 8(3): 267-82.

209. Marceau P, Hould FS, Simard S, Lebel S, Bourque RA, Potvin M, et al. Biliopancreatic diversion with duodenal switch. World J Surg. 1998; 22(9): 947-54.

210. Mason EE, Ito C. Gastric bypass in obesity. Surg Clin North Am. 1967; 47(6): 1345-51.

211. Capella RF, Capella JF, Mandec H, Nath P. Vertical Banded Gastroplasty-Gastric Bypass: preliminary report. Obes Surg. 1991; 1(4): 389-95.

212. Fobi MA, Lee H. The surgical technique of the Fobi-Pouch operation for obesity (the transected silastic vertical gastric bypass). Obes Surg. 1998; 8(3): 283-8.

213. Wittgrove A, Clark G, Tremblay L. Laparoscopic Gastric Bypass, Roux-en-Y: Preliminary Report of Five Cases. Obes Surg. 1994; 4(4): 353-7.

214. Sánchez-Pernaute A, Rubio Herrera MA, Pérez-Aguirre E, García Pérez JC, Cabrerizo L, Díez Valladares L, et al. Proximal duodenal-ileal end-to-side bypass with sleeve gastrectomy: proposed technique. Obes Surg. 2007; 17(12): 1614-8.

215. Rutledge R. The mini-gastric bypass: experience with the first 1,274 cases. Obes Surg. 2001; 11(3): 276-80. 
216. O’Brien PE. Controversies in bariatric surgery. Br J Surg. 2015; 102(6): 611-8.

217. Winegar DA, Sherif B, Pate V, DeMaria EJ. Venous thromboembolism after bariatric surgery performed by Bariatric Surgery Center of Excellence Participants: analysis of the Bariatric Outcomes Longitudinal Database. Surg Obes Relat Dis. 2011; 7(2): 181-8.

218. Gupta PK, Gupta H, Kaushik M, Fang X, Miller WJ, Morrow LE, et al. Predictors of pulmonary complications after bariatric surgery. Surg Obes Relat Dis. 2012; 8(5): 574-81.

219. Lancaster RT, Hutter MM. Bands and bypasses: 30-day morbidity and mortality of bariatric surgical procedures as assessed by prospective, multi-center, risk-adjusted ACS-NSQIP data. Surg Endosc. 2008; 22(12): 2554-63.

220. Cui Y, Elahi D, Andersen DK. Advances in the etiology and management of hyperinsulinemic hypoglycemia after Roux-en-Y gastric bypass. J Gastrointest Surg. 2011; 15(10): 1879-88.

221. De Luis DA, Pacheco D, Izaola O, Terroba MC, Cuellar L, Cabezas G. Micronutrient status in morbidly obese women before bariatric surgery. Surg Obes Relat Dis. 2013; 9(2): 323-7.

222. Muñoz M, Botella-Romero F, Gómez-Ramírez S, Campos A, García-Erce JA. Iron deficiency and anaemia in bariatric surgical patients: causes, diagnosis and proper management. Nutr Hosp. 2009; 24(6): 640-54.

223. Koch TR, Finelli FC. Postoperative metabolic and nutritional complications of bariatric surgery. Gastroenterol Clin North Am. 2010; 39(1): 109-24.

224. Thibault R, Huber O, Azagury DE, Pichard C. Twelve key nutritional issues in bariatric surgery. Clin Nutr. 2015; Mar 3. pii: S0261-5614 [publicado online pendiente de impresión].

225. Cole AJ, Beckman LM, Earthman CP. Vitamin D Status Following Bariatric Surgery: Implications and Recommendations. Nutr Clin Pract. 2014; 29(6): 751-8.

226. Chaudhry UI, Kanji A, Sai-Sudhakar CB, Higgins RS, Needleman BJ. Laparoscopic sleeve gastrectomy in morbidly obese patients with end-stage heart failure and left ventricular assist device: medium-term results. Surg Obes Relat Dis. 2015; 11(1): 88-93.

227. Rodríguez López M, López JA, Díaz B, Velasco R, Pinto P, Pacheco D. Gastrectomía vertical laparoscópica: grapado de la sonda de calibración. Una complicación poco descrita en la literatura. Bariátrica \& Metabólica IberoAmericana. 2015; 5(1): 667-670. 
228. Rosenthal RJ, Diaz AA, Arvidsson D, Baker RS, Basso N, Bellanger D, et al. International Sleeve Gastrectomy Expert Panel Consensus Statement: best practice guidelines based on experience of $>12,000$ cases. Surg Obes Relat Dis. 2012; 8(1): 8-19.

229. Campanile FC, Boru CE, Rizzello M, Puzziello A, Copaescu C, Cavallaro G, et al. Acute complications after laparoscopic bariatric procedures: update for the general surgeon. Langenbecks Arch Surg. 2013; 398(5): 669-86.

230. Acquafresca PA, Palermo M, Rogula T, Duza GE, Serra E. Early surgical complications after gastric by-pass: a literature review. Arq Bras Cir Dig. 2015; 28(1): 74-80.

231. Elía Guedea M, Gracia Solanas JA, Royo Dachary P, Ramírez Rodríguez JM, Aguilella Diago V, Martínez Díez M. Prevalence of anal diseases after Scopinaro's biliopancreatic bypass for super-obese patients. Cir Esp. 2008; 84(3): 132-7.

232. Matlaga BR, Shore AD, Magnuson T, Clark JM, Johns R, Makary MA. Effect of gastric bypass surgery on kidney stone disease. J Urol. 2009; 181(6): 2573-7.

233. Rao RS, Gentileschi P, Kini SU. Management of ventral hernias in bariatric surgery. Surg Obes Relat Dis. 2011; 7(1): 110-6.

234. Mann JP, Jakes AD, Hayden JD, Barth JH. Systematic review of definitions of failure in revisional bariatric surgery. Obes Surg. 2015; 25(3): 571-4.

235. Kellogg TA. Revisional bariatric surgery. Surg Clin North Am. 2011;91(6):1353-71.

236. Scopinaro N, Gianetta E, Pandolfo N, Anfossi A, Berretti B, Bachi V. Biliopancreatic bypass. Proposal and preliminary experimental study of a new type of operation for the functional surgical treatment of obesity. Minerva Chir. 1976; 31(10): 560-6.

237. Scopinaro N. Biliopancreatic diversion: mechanisms of action and long-term results. Obes Surg. 2006; 16(6): 683-9.

238. Scopinaro N, Adami GF, Marinari GM, Gianetta E, Traverso E, Friedman D, et al. Biliopancreatic diversion. World J Surg. 1998; 22(9): 936-46.

239. Scopinaro N, Marinari GM, Camerini G. Laparoscopic standard biliopancreatic diversion: technique and preliminary results. Obes Surg. 2002; 12(2): 241-4.

240. Stock-Damgé C, Aprahamian M, Raul F, Marescaux J, Scopinaro N. Small-intestinal and colonic changes after biliopancreatic bypass for morbid obesity. Scand J Gastroenterol. 1986; 21(9): 1115-23.

241. Marinari GM, Murelli F, Camerini G, Papadia F, Carlini F, Stabilini C, et al. A 15year evaluation of biliopancreatic diversion according to the Bariatric Analysis Reporting Outcome System (BAROS). Obes Surg. 2004; 14(3): 325-8. 
242. Astiarraga B, Gastaldelli A, Muscelli E, Baldi S, Camastra S, Mari A, et al. Biliopancreatic diversion in nonobese patients with type 2 diabetes: impact and mechanisms. J Clin Endocrinol Metab. 2013; 98(7): 2765-73.

243. De Luis DA, Pacheco D, Izaola O, Romero A, Marcos JL, Pelaz J, et al. Early clinical and surgical results of biliopancreatic diversion. Obes Surg. 2005; 15(6): 799-802.

244. De Luis DA, Pacheco D, Izaola O, Terroba MC, Cuellar L, Martin T. Clinical results and nutritional consequences of biliopancreatic diversion: three years of follow-up. Ann Nutr Metab. 2008; 53(3-4): 234-9.

245. Centers for Disease Control and Prevention. Healthcare-associated Infections (HAIs). Surgical Site Infections (SSI). Acceso a través de la página web: http://www.cdc.gov/HAI/ssi/ssi.html

246. Dindo D, Demartines N, Clavien P-A. Classification of surgical complications: a new proposal with evaluation in a cohort of 6336 patients and results of a survey. Ann Surg. 2004; 240(2): 205-13.

247. Ballesteros-Pomar MD, González de Francisco T, Urioste-Fondo A, González-Herraez L, Calleja-Fernández A, Vidal-Casariego A, et al. Biliopancreatic Diversion for Severe Obesity: Long-Term Effectiveness and Nutritional Complications. Obes Surg. 2015; May 17 [publicado online pendiente de impresión].

248. Sánchez Manuel FJ, Rodríguez Serrano S, de la Plaza Galindo M, Palomo Luquero A, Seco Gil JL. Advances in bariatric surgery: from the open approach to the biliopancreatic bypass with laparoscopic gastric preservation. Twelve years of experience. Cir Esp. 2012; 90(9): 576-81.

249. Alastrué Vidal A, Sitges Serra A, Jaurrieta Más E, Sitges Creus A. Anthropometric parameters for a Spanish population. Med Clin (Barc). 1982; 78(10): 407-15.

250. De Witt Hamer PC, Tuinebreijer WE. Preoperative weight gain in bariatric surgery. Obes Surg. 1998; 8(3): 300-1.

251. Eisenberg D, Duffy AJ, Bell RL. Does Preoperative Weight Change Predict Postoperative Weight Loss after Laparoscopic Roux-en-Y Gastric Bypass in the Short Term?. J Obes. 2010; 2010: pii: 907097.

252. Taylor E, Chiasson P, Perey B. Predicting Bariatric Surgical Outcomes: Does Preoperative Weight Gain Correlate with Lesser Postoperative Weight Loss?. Obes Surg. 1995; 5(4): 375-7.

253. Gerber P, Anderin C, Thorell A. Weight loss prior to bariatric surgery: an updated review of the literature. Scand J Surg. 2015; 104(1): 33-9. 
254. Harnisch MC, Portenier DD, Pryor AD, Prince-Petersen R, Grant JP, DeMaria EJ. Preoperative weight gain does not predict failure of weight loss or co-morbidity resolution of laparoscopic Roux-en-Y gastric bypass for morbid obesity. Surg Obes Relat Dis. 2008; 4(3): 445-50.

255. Sherman WE, Lane AE, Mangieri CW, Choi YU, Faler BJ. Does Preoperative Weight Change Predict Postoperative Weight Loss After Laparoscopic Sleeve Gastrectomy?. Bariatr Surg Pract Patient Care. 2015; 10(3): 126-9.

256. Dorman RB, Rasmus NF, al-Haddad BJS, Serrot FJ, Slusarek BM, Sampson BK, et al. Benefits and complications of the duodenal switch/biliopancreatic diversion compared to the Roux-en-Y gastric bypass. Surgery. 2012; 152(4): 758-65.

257. Larrad-Jiménez A, Díaz-Guerra CS-C, de Cuadros Borrajo P, Lesmes IB, Esteban BM. Short-, mid- and long-term results of Larrad biliopancreatic diversion. Obes Surg. 2007; 17(2): 202-10.

258. Livhits M, Mercado C, Yermilov I, Parikh JA, Dutson E, Mehran A, et al. Preoperative predictors of weight loss following bariatric surgery: systematic review. Obes Surg. 2012; 22(1): 70-89.

259. Courcoulas AP, Christian NJ, O'Rourke RW, Dakin G, Patchen Dellinger E, Flum DR, et al. Preoperative factors and 3-year weight change in the Longitudinal Assessment of Bariatric Surgery (LABS) consortium. Surg Obes Relat Dis. 2015; Jan 23. pii: S1550-7289 [publicado online pendiente de impresión].

260. Still CD, Wood GC, Chu X, Manney C, Strodel W, Petrick A, et al. Clinical factors associated with weight loss outcomes after Roux-en-Y gastric bypass surgery. Obesity. 2014; 22(3): 888-94.

261. Parri A, Benaiges D, Schröder H, Izquierdo-Pulido M, Ramón J, Villatoro M, et al. Preoperative predictors of weight loss at 4 years following bariatric surgery. Nutr Clin Pract. 2015; 30(3): 420-4.

262. Benoit SC, Hunter TD, Francis DM, De La Cruz-Munoz N. Use of Bariatric Outcomes Longitudinal Database (BOLD) to Study Variability in Patient Success After Bariatric Surgery. Obes Surg. 2014; 24(6): 936-43.

263. Dallal RM, Quebbemann BB, Hunt LH, Braitman LE. Analysis of weight loss after bariatric surgery using mixed-effects linear modeling. Obes Surg. 2009; 19(6): 732-7.

264. Buchwald H, Avidor Y, Braunwald E, Jensen MD, Pories W, Fahrbach K, et al. Bariatric surgery: a systematic review and meta-analysis. JAMA. 2004; 292(14): 1724-37.

265. Marinari GM, Papadia FS, Briatore L, Adami G, Scopinaro N. Type 2 diabetes and weight loss following biliopancreatic diversion for obesity. Obes Surg. 2006; 16(11): 1440-4. 
266. Marceau P, Biron S, Marceau S, Hould F-S, Lebel S, Lescelleur O, et al. Long-Term Metabolic Outcomes 5 to 20 Years After Biliopancreatic Diversion. Obes Surg. 2015; 25(9): 1584-93.

267. Yu J, Zhou X, Li L, Li S, Tan J, Li Y, et al. The long-term effects of bariatric surgery for type 2 diabetes: systematic review and meta-analysis of randomized and nonrandomized evidence. Obes Surg. 2015; 25(1): 143-58.

268. Miras AD, Risstad H, Baqai N, Law S, Søvik TT, Mala T, et al. Application of the International Diabetes Federation and American Diabetes Association criteria in the assessment of metabolic control after bariatric surgery. Diabetes Obes Metab. 2014; 16(1): 86-9.

269. Colquitt JL, Pickett K, Loveman E, Frampton GK. Surgery for weight loss in adults. Cochrane database Syst Rev. 2014; 8: CD003641.

270. Ricci C, Gaeta M, Rausa E, Asti E, Bandera F, Bonavina L. Long-term effects of bariatric surgery on type II diabetes, hypertension and hyperlipidemia: a metaanalysis and meta-regression study with 5-year follow-up. Obes Surg. 2015; 25(3): 397-405.

271. Scopinaro N. Thirty-five years of biliopancreatic diversion: notes on gastrointestinal physiology to complete the published information useful for a better understanding and clinical use of the operation. Obes Surg. 2012; 22(3): 427-32.

272. Pelascini E, Disse E, Pasquer A, Poncet G, Gouillat C, Robert M. Should we wait for metabolic complications before operating on obese patients? Gastric bypass outcomes in metabolically healthy obese individuals. Surg Obes Relat Dis. 2015; May 8 pii: S1550-7289 [publicado online pendiente de impresión].

273. Goday A, Benaiges D, Parri A, Ramón JM, Flores-Le Roux JA, Pedro Botet J. Can bariatric surgery improve cardiovascular risk factors in the metabolically healthy but morbidly obese patient?. Surg Obes Relat Dis. 2014; 10(5): 871-6.

274. Jiménez A, Perea V, Corcelles R, Moizé V, Lacy A, Vidal J. Metabolic effects of bariatric surgery in insulin-sensitive morbidly obese subjects. Obes Surg. 2013; 23(4): 494-500.

275. Shin M-J, Hyun YJ, Kim OY, Kim JY, Jang Y, Lee JH. Weight loss effect on inflammation and LDL oxidation in metabolically healthy but obese (MHO) individuals: low inflammation and LDL oxidation in MHO women. Int J Obes (Lond). 2006; 30(10): 1529-34.

276. Karelis AD, Messier V, Brochu M, Rabasa-Lhoret R. Metabolically healthy but obese women: effect of an energy-restricted diet. Diabetologia. 2008; 51(9): 1752-4.

277. Moreiro J, Ruiz O, Perez G, Salinas R, Urgeles JR, Riesco M, et al. Parathyroid hormone and bone marker levels in patients with morbid obesity before and after biliopancreatic diversion. Obes Surg. 2007; 17(3): 348-54. 
278. Scopinaro N, Marinari GM, Pretolesi F, Papadia F, Murelli F, Marini P, et al. Energy and nitrogen absorption after biliopancreatic diversion. Obes Surg. 2000; 10(5): 436-41.

279. Weller WE, Rosati C. Comparing outcomes of laparoscopic versus open bariatric surgery. Ann Surg. 2008; 248(1): 10-5.

280. Reoch J, Mottillo S, Shimony A, Filion KB, Christou N V, Joseph L, et al. Safety of laparoscopic vs open bariatric surgery: a systematic review and meta-analysis. Arch Surg. 2011; 146(11): 1314-22.

281. Ceriani V, Lodi T, Porta A, Gaffuri P, Faleschini E, Roncaglia O, et al. Laparoscopic versus open biliopancreatic diversion: a prospective comparative study. Obes Surg. 2010; 20(10): 1348-53.

282. Buchwald H, Estok R, Fahrbach K, Banel D, Sledge I. Trends in mortality in bariatric surgery: a systematic review and meta-analysis. Surgery. 2007; 142(4): 621-32.

283. De la Matta-Martín M, Acosta-Martínez J, Morales-Conde S, Herrera-González A. Perioperative morbi-mortality associated with bariatric surgery: from systematic biliopancreatic diversion to a tailored laparoscopic gastric bypass or sleeve gastrectomy approach. Obes Surg. 2012; 22(7): 1001-7.

284. Vather R, Trivedi S, Bissett I. Defining postoperative ileus: results of a systematic review and global survey. J Gastrointest Surg. 2013; 17(5): 962-72.

285. Geubbels N, de Brauw LM, Acherman YIZ, van de Laar AWJM, Bruin SC. Risk Stratification Models: How Well do They Predict Adverse Outcomes in a Large Dutch Bariatric Cohort?. Obes Surg. 2015; 25(12): 2290-301.

286. Lorente L, Ramón JM, Vidal P, Goday A, Parri A, Lanzarini E, et al. Obesity surgery mortality risk score for the prediction of complications after laparoscopic bariatric surgery. Cir Esp. 2014; 92(5): 316-23.

287. Sarela AI, Dexter SPL, McMahon MJ. Use of the obesity surgery mortality risk score to predict complications of laparoscopic bariatric surgery. Obes Surg. 2011; 21(11): 1698-703.

288. Shabanzadeh DM, Sørensen LT. Laparoscopic surgery compared with open surgery decreases surgical site infection in obese patients: a systematic review and metaanalysis. Ann Surg. 2012; 256(6): 934-45.

289. Agrawal S. Impact of bariatric fellowship training on perioperative outcomes for laparoscopic Roux-en-Y gastric bypass in the first year as consultant surgeon. Obes Surg. 2011; 21(12): 1817-21. 
Esta Tesis Doctoral comenzó a escribirse en octubre de 2014 en la Ciudad libre y hanseática de Hamburgo y se concluyó en diciembre de 2015 en la muy noble, leal, heroica y laureada Ciudad de Valladolid. 